On Insurgency: The Social Origins of Rebel Military Strategy: 1983-2010

Zuri R. Linetsky

M.A., University of Chicago 2007

B.A., University of Florida, 2004

A Dissertation presented to the Graduate Faculty of the University of Virginia in Candidacy for the Degree of Doctor of Philosophy

Woodrow Wilson Department of Politics

University of Virginia

May, 2014 


\section{On Insurgency: \\ The Social Origins of Rebel Military Strategy: 1983-2010}

Introduction:

The Changing Nature of Violence in the Modern World

1. On Insurgency: A Theory of Insurgent Military Strategy

2. A Statistical Analysis of the Causes of Rebel Military Strategy

4. The Communist Party of Nepal-Maoist and Traditional Guerrilla Warfare 143 
(C) Copyright by

Zuri Linetsky

All rights reserved

March 2014 
For my mom, Elina Linetsky,

for never doubting me-even when I gave her cause. 


\section{Introduction: The Changing Nature of Violence in the Modern World}

\section{Violence and the State}

Throughout human history war has been constant concern for states. As a result, states have built up large and complex military forces to protect themselves from external threats. While effective deterrents against external military threats, state militaries have been ineffective at deterring, or winning, intrastate wars. Indeed, state militaries have preformed quite poorly in small and irregularly fought civil wars, with states loosing as estimated $75 \%$ of the insurgencies and civil wars they have fought since 1976 (Mack 1975; Lyall and Wilson 2009).

In excess of 150 intrastate conflicts have occurred since World War II (Kalyvas and Balcells 2010; Lyall and Wilson 2009). During this period civil wars have outpaced interstate wars by nearly four to one, 150:38 (Sarkees and Wayman 2010). As of February 2014 there are 31 ongoing civil conflicts throughout the globe, of these, six reach the requisite 1,000 battlerelated death per year threshold to be coded as civil "wars": Syria, Afghanistan, Somalia, Pakistan, Yemen, and Sudan (Themnér and Wallensteen 2013).

The Syrian Civil war is by far the most costly ongoing intrastate conflict. In 2012 there were over 15,000 battle-related fatalities in Syria (Themnér and Wallensteen 2013). This violence is also affecting neighboring states. Two of the largest cities in Lebanon and Jordan are now refugee camps, putting an increasingly large economic and political strain on these states (McClelland NYT, 02.13.14). Furthermore, the violence itself is spreading. Lebanon's 
Hezbollah has been drawn into the Syrian conflict, on the regime's side, to support its economic and political benefactor; this has caused increased levels of violence inside Lebanon as Syrian rebels have attacked Hezbollah strongholds in Beirut.

Additionally, Iraq's Al Qaeda affiliate has been reinvigorated as a result of the Syrian war. The Islamic State of Iraq has merged "with similarly named elements of the opposition in neighboring Syria, the group currently operates in Iraq under the name of the Islamic States in Iraq and the Levant (or alternately, the Syria, ISIL, (ISIS))... U.S. officials estimated in November 2011 that there might be 800-1000 AQ-I/ISIL members” (CRS 2014, 11). ISIL, led by Abu Bakr Al Baghdadi, in conjunction with various other groups, has seized and held major parts of both Ramadi and Fallujah in Iraq's restive Anbar province. Moreover, ISIL had seized control of oil fields in eastern Syria's Deir al-Zour province and was selling oil back to the Assad Regime (CRS 2014, 17; Hubbard et al. NYT 01.28.14).

The threat of civil war is not isolated to the Middle East, Asia, and Africa. Violence associated with the ongoing narco-war in Mexico claimed between 47,000 and 70,000 lives between 2006 and 2012. ${ }^{1}$ In fact, the Peña-Nieto administration reported that over 1,000 people died per month in December 2012 and January 2013. And while the head of the Sinaloa Drug Cartel was captured on February 22, 2014, there is no indication that this will lower drug-related violence; on average, leadership decapitation of drug trafficking organizations is correlated with increases in the overall level of drug-related violence (Archibold and Thompson NYT, 02.22.14; Dickenson 2013). It is worth noting that the foregoing does not account for cartel-related violence in the United States, or American military and intelligence activity in Mexico.

\footnotetext{
${ }^{1}$ It is possible to dispute that the narco-wars in Mexico actually constitute a civil war or insurgency, as the drug cartels do not have the publicly stated goal of taking political power (Sambanis 2004). However, the violence is internal to the state, and the drug cartels have access to, and make demands on, politicians. These demands might indicate that taking political power may be a downstream goal or that a patron-client relationships are effective tools through which political power can be wielded (Archibold and Thompson 2014; Dickenson 2013).
} 
This discussion highlights a critical feature of intrastate violence: it often spreads beyond it area of origin. Put differently, civil wars often expand to include foreign actors, both state and non-state. Of the 31 ongoing intrastate conflicts, twenty-five percent (8) "were internationalized, meaning that they saw international involvement with troop support from an external state to one or both warring parties in the conflict" (Themnér and Wallensteen 2013, 510).

Therefore, intrastate wars are an ongoing and incredibly costly concern for states. Numerous states are currently involved in, or affected by, ongoing civil wars and insurgencies. These facts make the study of intrastate war a continued necessity for political science, in terms accumulating more information on the causes, consequences and conduct of these conflicts. Increasing our understanding of these so-called small wars also has practical implications for policy makers in that a more nuanced understanding of these conflicts may help end them faster, minimize their costs, and possibly prevent their reoccurrence. This dissertation takes up these issues.

\section{Common Themes: Theory and Practice in Civil Wars and Insurgencies}

The prevalence of civil wars and insurgencies has yielded increasing numbers of practical and theoretical analyses. Two key themes run through this literature: first, the role of popular support as a source of succor, resources, and information for both insurgent movements, and states. Second, the importance of terrain for determining how/where insurgents and incumbents base, organize and fight.

The first complete American writing on this subject is found in the United States Navy's Small War's Manual (1940). ${ }^{2}$ A “small war" is defined as an operation wherein military force is used in combination with political pressure inside another state that is unstable or acting against

\footnotetext{
${ }^{2}$ The document was an updated version of various reports and manuals analyzing American military adventures in Latin America and the Philippines between 1898 and 1934.
} 
American principles as defined by the Monroe Doctrine. Furthermore, in small wars the opposition employs "guerrilla warfare" in an asymmetric conflict to attain its goals (Navy 1940, $1-2 ; 1-1 ; 1-9)$

Two major themes of the Manual are the role of the population and the impact of terrain. "Opposition forces become more formidable when the terrain is difficult, and the resistance increases as the [state's] Force [sic] moves inland from its bases. Every native is a potential clever opponent who knows the country, its trails, resources, and obstacles, and who has friends and sympathizers on every hand" (Navy 1940, 1-9). Thus, knowledge of both the human and geographic terrain of an area of operations is key in small wars. Moreover, assuming that rebel supporters are "honeycombed" throughout the population, which undermines the collection of intelligence, every effort must be made to avoid placing needless hardship on the population, and instead to develop their support, friendship and respect (Navy 1940,1-15).

Two of the most prominent revolutionary texts, Mao Tse-Tung's On Guerrilla Warfare (1937) and Che Guevara's Guerrilla Warfare (1961) form the core of the rebel's perspective on insurgencies; both maintain the focus on popular support and terrain. The guerrilla is a "social reformer" fighting against the reigning social institutions (Guevara 1961, 10). The people for whom the guerrilla fights therefore become the locus of the insurgent's military formations, making it possible for guerrillas to fight in the "enemy's rear areas"(Tse-Tung 1961). Moreover, rough and mountainous terrain is key for base areas and creating a formal organizational structure/building the guerrilla's capacity for warfare (Guevara 1961, 78).

Similarly, as the European colonial empires retreated, their officers recorded the military lessons learned from anti-colonial insurgencies. Sir Robert Grainger Ker Thompson's Defeating Communist Insurgency: Experiences from Malaya and Vietnam (1966), and David Galula's 
Counterinsurgency Warfare: Theory and Practice (1964), both discuss the themes of popular support and challenging terrain. In these cases explicit attention is paid to separating out the insurgent from the population in an effort to provide safety for, and build trust amongst, the population (Galula 1964). This was especially vital in rough and hard to access terrain like that in Vietnam and Malaya. A real-world expression of these lessons is the American Strategic Hamlet Program (Kalyvas and Kocher 2009).

As the Cold War ended and the great powers withdrew support from their client states, political scientists began tracking an alarming trend: many former client states were devolving into civil war. Ethnic, sectarian, and resource-based conflicts that had been suppressed with outside support boiled over. Scholarly analyses therefore focused on the roles of ethnic and religious identity as well as the availability of lootable resources as the driving forces of intrastate warfare (Posen 1993; Kauffman 1996). The early wave of scholarship on the subject of civil wars was artificially divided between greed or grievance -based accounts of civil war (Collier and Hoeffler 2004).

Other scholarship identified a new set of variables that better accounted for the trends and variations in civil violence. It argued that civil wars in the post-Cold War period are not a product of "ethnic or religious differences or broadly held grievances but, rather, conditions that favor insurgency $[s i c]$. Insurgency is a technology of military conflict characterized by small, lightly armed bands practicing guerrilla warfare from rural bases" (Fearon and Laitin 2003, 75). The conditions that favored insurgency were, as with previous scholarship, rough terrain, popular support, and the size of a state's population (Fearon and Laitin 2003; Kalyvas and Balcells 2010). 


\section{The Modern Face of Old Wars}

The intrastate war literature has failed to grapple with one critical demographic trend of the post World War Two world. Since 1945 the majority of the world's population, has migrated out of the countryside towards urban areas. In fact, as of 2009, for the first time in human history, urban dwellers outnumbered their rural counterparts (United Nations 2010). The most significant urban growth has occurred in the least developed parts of the globe, Africa and Asia. From 1950-2009 the annual average rates of change in urban population (as percentage) have been $4.31 \%$ in Africa, and 3.45\% in Asia (United Nations 2010). Since 1945, sixty-four percent of all insurgencies and civil wars have occurred in these two regions (Lyall and Wilson 2009). If population and terrain are key determinants of how rebel fight in civil wars, then the global urbanization trend must have some discernable impact on how intrastate wars are conducted in areas where rural populations are shrinking; as populations change and migrate rebels and rebellions must migrate and change as well.

This dissertation therefore seeks to identify the ways in which the global demographic trend of urbanization is affecting the conduct of civil wars and insurgencies. If rebel organizations depend on popular support then they must be forced to work within the available population. Thus, if a state is highly urbanized, a rebellion must organize itself in and around an urban population. Syria provides anecdotal evidence. The majority of Syrians $(60 \%)$ live in cities. It is unsurprising then that violence in the ongoing Syrian Civil War has been concentrated in and around major cities like Hama, Homes and Damascus. The various rebel groups that make up the Free Syrian Army (FSA) seek out supportive populations, and therefore willing recruits, amongst the populations of these cities. The question remains though how does operating in a 
city affect the ways in which these groups fight? More specifically, how does urbanization affect the growth and maintenance of a rebel organization and its associated military strategy?

\section{My Argument}

I argue that urbanization has driven rebels to change the types of military strategies they employ in war. I hypothesize that varying levels of urban population growth (henceforth urbanization) have a direct effect on where rebellions occur. Additionally, urbanization affects the availability of higher education. Both of these factors shape the quality and numbers of available rebel recruits. The type and number of people recruited into an insurgent organization are the dually necessary but individually insufficient factors that affect insurgent's military and organizational capabilities. These capabilities determine the military strategy rebels adopt.

The process of urbanization has two critical effects. First, it increases the number of individuals within a state that have higher levels of education and formal technical training; cities have a larger number of schools and technical training centers than rural areas (World Bank 2008; Majumdar et al. 2004). Second, urbanization fundamentally alters where insurgent movements coalesce. ${ }^{3}$ I theorize that three types of rebel movements result from varying levels of urbanization: (a) urban; (b) rural; (c) mixed, or those that occur in states where the population is distributed between rural and urban areas. The locations in which insurgent movements occur dictate the availability of variously skilled and educated individuals, as well as the total number of potential recruits (Diani and McAdam 2003).

\footnotetext{
${ }^{3}$ Urbanization, while ubiquitous, is uneven. That is, while most countries have experienced a steady flow of people into urban areas - and away from rural ones - since World War II, the rate of change varies significantly by region and by country. Thus, while some states have urbanized rapidly and have a greater percentage of their population in urban rather than rural areas, this trend is not occurring at the same pace across countries. Nor is it the case that all states will inevitably be highly urbanized at some point in the future. Thus, not all countries have, nor are they likely to have, the same levels of urban population growth.
} 
Insurgents must marshal supporters; the areas in which rebellions occur affect the likelihood of collective action differently. Popular participation is highly constrained in the case of urban and rural rebellions. In the former case, communities of people are small and tightly knit. Urban communities organize at the neighborhood level, thereby limiting the number and diversity of people that are linked to rebellion organizers and recruiters. The small number of people visibly linked to urban rebel organizations (regardless of their abilities) lead to a popular perception that additional new recruits will not help a nascent rebellion achieve its goals. Put differently, people do not want to waste their contributions to social movements. Moreover, people do not want to be associated with small and ineffective rebellions due to the danger of being caught and sanctioned by the state. Consequently, urban rebellions often remain small and lack significant military and organization capabilities. (Gould 1993). ${ }^{4}$ Similarly, in rural areas, communities of people small and tightly knit, and even though many rural residents may have cause to take up arms they are too loosely connected to one another to effectively organize largescale, cohesive and capable rebel movements.

In contrast, insurgents fighting in states with mixed populations - those that encompass both urban and rural spaces - have access, and are in a position, to recruit greater numbers of both highly skilled and unskilled individuals. This is because the urban and rural elements of this population are linked to one another through a variety of social connections. The ties that bind these communities are used to create a sense of popular and diverse participation, limit the state's ability to sanction any one individual, and ultimately create a bandwagon of support for rebellion (discussed below). Large-scale recruitment is therefore the first necessary but individually insufficient determinant of rebel military capacity.

\footnotetext{
${ }^{4}$ For the initial discussion of individuals taking advantage of the public goods resulting from the work of the collective action, see Mancur Olson (1965). More recent discussions available in: Finkel et al. 1989, Lichbach 1995, as well as Kalyvas and Kocher 2007.
} 
The recruitment of variously skilled and educated individuals is the second necessary factor for increasing insurgent organizational and military capacity. The more skilled and educated individuals that rebels can conscript the more likely they will be to develop a sophisticated organizational structure. This is due to several factors. First, using and maintaining modern weaponry necessitates technological sophistication, which is a byproduct of higher levels of educational attainment. Moreover, higher levels of education push rebels to be more discriminating in terms of whom they attack (Wood 2010).

Second, the average individual is more likely to contribute to a rebellion when (s)he believes their contribution will not be wasted. Contributions to larger organizations with large numbers of skilled and educated (or politically efficacious) members are more likely to be thought of as good investments (Gould 1993; Petersen 2001; Wood 2010). Third, large numbers of educated and skilled individuals joining a rebellion suggests that more poorly skilled individuals will join as well due to the decreasing likelihood of being caught; as more people join an insurgency the state's ability to sanction any one individual decreases, there is safety in numbers (Mason 1996). Fourth, as a rebellion grows there is an increased likelihood that any one member will have connections with foreign sources of support—financial and/or material— which allows insurgent groups to acquire more sophisticated weaponry, higher levels of military training, and bases of support outside of a war zone (Byman et al. 2001). Therefore, recruiting both large numbers and high quality participants are jointly necessary but individually insufficient conditions for raising the military and organizational capacity of an insurgent group.

When insurgent capacity increases, rebels are more likely to adopt a military strategy focused on targeting state military forces with heavy weaponry as opposed to any other unconventional military strategy. When combined, education, increased group size (Wood 2010), 
and outside support allow rebels to be more discriminating in their target selection due to the higher quality and caliber of their weaponry, as well as the higher levels of technical ability of the average fighter. In short, the global urbanization trend has increased the set of potential military strategies that rebels can adopt. This choice however is contingent on network structure, the availability of skilled recruits, as well as overall organizational capacity.

\section{The Plan of the Dissertation}

The rest of the chapters in the dissertation are concerned with laying out the core causal logic of my theory on rebel strategic adoption and providing evidence for my theoretical claims. Chapter 1 therefore focuses on explicating the component parts of my argument. It also provides sematic and operational definitions all the relevant variables.

In Chapter 2 I test my argument quantitatively. Using a new data set I test the effect of urbanization as well as other key theoretical variables on my dependent variable of interest, insurgent military strategy.

Chapters three through five are qualitative case studies on the social origins of insurgent military strategy. In these chapters I use process tracing to show how urbanization has affected the ways in which insurgents chose to fight in war.

In Chapter 6 I conclude. I discuss the policy implications of my theory and offer some thoughts on productive avenues for future research. 


\section{Chapter 1: On Insurgency: A Theory of Insurgent Military Strategy}

\section{The Puzzle}

Since the publication of Carl Von Clausewitz's On War (1832; 1989) most scholarly analyses of insurgent conflicts have stipulated that rebel groups employ the same military strategy. Traditional scholarship posits that insurgents emanate from the rural hinterlands of a state and locate their bases in the most difficult terrain. Lightly armed rebels harass a state's military forces with hit-and-run attacks, with the goal of sapping their enemy's political will for continued conflict (Laqueur 1976). Based on his observations of the 1916-1918 Arab Revolt against the Ottoman Empire T.E. Lawrence claimed that insurgents had three main attributes: they never attacked prepared positions; they never attempted to defend a point or line — they never held ground; their critical virtue lay in their ability to disperse in depth (T.E. Lawrence 1929). Furthermore, densely populated urban areas were considered the "graveyard of revolutionaries and [their] resources" (Moss 1971). In short, insurgencies have been generally conceived of as rural phenomena, conducted in more or less the same manner over time (Laqueur 1976).

However, since the end of World War II several global trends have challenged this view of insurgent military strategy. First, since 1945 at least seventeen insurgencies have taken place 
exclusively in cities with many more being fought in both urban and rural settings. ${ }^{5}$ Second, insurgents fighting since 1945 have exhibited a range of military strategies. Some organizations have targeted civilians with improvised explosive devices and suicide bombers; some have used artillery and rockets randomly against civilians; others have followed a traditional hit-and-run guerrilla warfare strategy; and others have employed rockets, artillery, and anti-tank missiles, while fighting pitched battles against state militaries.

Given these variations in urbanization and insurgent military strategies, this study focuses on one critical issue: why insurgents adopt certain unconventional military strategies as opposed to others?

Every organization requires a strategy to accomplish its goals — be they political, military or otherwise. In developing and articulating a military strategy, insurgent groups undertake a systematic analysis of the weaknesses of their opponent, devise a plan for attacking these limitations, and at the same time, attempt to anticipate how their opponent will respond. Rebels devise a war plan based on what targets they believe should be attacked and the weapons necessary for these attacks (Galula 1964; Posen 2001; Dixon 2012). In short, the study of insurgent military strategy matters because insurgent strategic choices dictate how quickly and effectively rebels are able to impose costs on incumbents in pursuit of their ultimate goals (Stam 1996).

This dissertation offers a unique taxonomy of the strategies employed by insurgents in war. I argue that strategy is best conceived of as a combination of the targets of rebel violence (civilian vs. military) and the weapons employed (heavy vs. light). Examining these two

\footnotetext{
${ }^{5}$ The list of urban insurgencies includes: Palestine 1945-47; Cyprus 1954-59; Algeria 1954-62; Venezuela 1963-64; Aden 1963-67; Argentina 1973-77; Lebanon 1975-90; Turkey 1976-1980; Ireland 1968-98; Palestinian Intifada 1987-1994, 2000-06; Algeria 1992-02; Pakistan 1993-99; Iraq 2003-10; Somalia 1991-ongoing; Chechnya 1994-96; Côte-d'Ivoire 2002-2007 (Beckett 2001).
} 
components of strategy, derived from the literature on both conventional and unconventional military strategy (Pape 1996; Mearsheimer 1983; Stam 1996) yields a set of four distinct rebel military strategies, which have been used in conflicts around the world.

\section{Research Design}

Urbanization creates discrete spatially delimited communities within states. These communities are the key to explaining insurgent military strategies in war. In order to analyze the influence of urbanization on insurgent military strategies in war, I employ a mixed methods approach. For quantitative analysis I compile a new data set of 33 separate insurgencies that occurred and concluded between 1984 and 2010. The quantitative tests I conduct in chapter 2 are designed to test whether or not the links in the causal theory articulated below have a statistically identifiable causal effect (across cases) on the military strategies of rebel groups; I generate six hypothesis, which I test using this new data set. Thus, the quantitative tests I conduct provide external validity for my theory on the origins of insurgent military strategy.

While quantitative data analysis reveals the average causal effect of a particular independent variable on the outcome variable, thereby explaining trends in the population of cases, it does not describe how a variable works in practice. That is, quantitative analysis sheds light on causal effects not on the causal mechanisms by which independent variables affect the outcome under study. In order to flesh out causal mechanisms I employ qualitative analysis (Gerring 2007; George and Bennett 2005).

Chapters three through five are in-depth case studies of three insurgencies. The cases are selected by employing Mill's "method of difference," also known as the most similar case method (Gerring 2007; George and Bennett 2005; Waldner 1999; Mill 1872). This case selection method is predicated upon selecting cases that vary on the dependent variable, but "are similar 
on various factors that might have contributed to that outcome" (Gerring 2007, 131). In all three cases rebels endeavored to expand their capacity for violence by recruiting large numbers of variously skilled and educated fighters. However, not all of these organizations succeeded in building up high levels of organizational and military capacity. The nature of urbanization in a state is the key determinant of insurgent capacity.

I use process tracing to demonstrate how every step of my theory operates in each case. Using process tracing I can show how various levels of urbanization affect the quantity and quality of potential rebel recruits, which in turn determines insurgent organizational capabilities and, ultimately, the military strategies that insurgent organizations adopt. At the same time, process tracing allows me to eliminate other potential independent variables as the main causal factors for my theory. Each case study therefore (Hezbollah, the CPN-Maoist, and Hamas) traces the development process that insurgents go through as they work to adopt the military strategies I identify below. Finally, by employing process tracing I am able to demonstrate how and why Hezbollah and Hamas were able to change their martial strategies over time. Process tracing provides internal validity for my theory.

This chapter proceeds as follows. In section three I offer a detailed discussion of unconventional military strategy and of the set of strategies available to insurgent groups. In section four I discuss both the existing literature on insurgent strategic choices as well as existing accounts on the impact of urbanization on violence in civil wars and insurgencies. In section five I articulate my theory of rebel strategic adoption in several steps. I begin by demonstrating the relationship between urbanization and education. Second, I explain how urbanization determines where rebellions occur. I then address the relationship between the location of a nascent rebel movement and its recruitment of educated individuals, as well as on organizational capacity. 
Finally, I explain how capabilities determine insurgent military strategy. Section six summarizes the theory outlined in this chapter and discusses the statistical tests conducted in chapter two, as well as the qualitative case studies in chapters three though five.

\section{Definitions and Scope of Research}

\subsection{Unconventional Military Strategy}

The dependent variable of this dissertation is rebel military strategy. I argue that insurgent methods of violence can be conceptualized in a typology of unconventional military strategies with four ideal types: terrorism, indiscriminate violence, guerrilla warfare, and hybrid warfare (see Table 1 below). These are unconventional strategies by virtue of the fact that none of the strategies discussed find any utility in large set-piece battles of annihilation. The hallmark of irregular (or unconventional) warfare is an absence of identifiable frontlines (Duyvesteyn 2005). The strategies discussed here do not require large forces or the movement of troops en mass, and can be employed by groups lacking a traditional hierarchical organizational structure.

Formally, strategy is defined as the way in which an actor plans to use its military forces in a theatre of war (Mearsheimer 1983; Stam 1996; Arreguín-Toft 2005; Kalyvas and Balcells 2010). Thus, every combatant in war must decide what forces to use, and how to use them [weapons $\mathrm{X}$ targets]. Each of the ideal types of unconventional strategies is therefore a distinct way in which an insurgent organization can choose to employ its available weaponry against a given set of targets in combat.

\subsection{Insurgency}

This unconventional strategic typology is applied exclusively to cases of insurgency, which, for the purposes of this work, is considered to be a distinct category of warfare (Lyall and Wilson 2009; Kalyvas and Balcells 2010). In developing a data set of 286 insurgencies, Lyall 
and Wilson (2009) posit two defining characteristics of insurgency. First, an insurgency is considered to be a prolonged violent conflict between a nonstate actor fighting to gain a political end - independence, increased autonomy, or delegitimizing the prevailing political authorityand a larger political power, the incumbent.

These conflicts are further defined by the use of guerilla warfare by a nonstate actor. Guerrilla warfare is defined as "a strategy of armed resistance that (1) uses small, mobile groups to inflict punishment on the incumbent through hit-and-run strikes while avoiding direct battle when possible and (2) seeks to win the allegiance of at least some portion of the noncombatant population" (Lyall and Wilson 2009; CIA 2009). ${ }^{6}$ Thus, an insurgency is defined by warfare between the state and at least one nonstate actor, in which the latter employs an unconventional military strategy. In addition, for the purposes of this work, to be considered an insurgency, a conflict must have had a minimum of 25 battle-related deaths per year, per dyad.

Importantly, a focus on group strategy in insurgencies allows this study to demonstrate variation on the defining component of rebellion, which has largely been considered a homogenous concept - guerrilla warfare. This is accomplished in two ways. First, I demonstrate that there is variation in the types of military strategy employed by insurgents between cases. Second, I show that over the course of a conflict rebels may change strategies but remain unconventional in their orientation.

\footnotetext{
${ }^{6}$ The CIA defines an insurgency as a "protracted political-military activity directed toward completely or partially controlling the resources of a country though the use of irregular military forces and illegal political organizations. Insurgent activity —including guerilla warfare, terrorism, and political mobilization... propaganda, recruitment, front and cover party organization, and international activity - is designed to weaken government control and legitimacy while increasing insurgent control and legitimacy. The common denominator of most insurgent groups is their desire to control a particular territory. This objective differentiates insurgent groups from purely terrorist organizations" (2009).
} 


\subsection{Defining the Typology}

The ideal types of insurgent strategy developed here are distinguished from one another by two key features (1) the targets of insurgent attacks (civilian versus military); (2) the types weapons used—small arms or heavy weapons such as large caliber artillery, or unguided missiles (Berman et al. 2011; Kalyvas and Balcells 2010; Lyall and Wilson 2009; Arreguín-Toft 2005).

There are two sources of information on rebel targets. Primarily, I gather the total number of targeted civilian deaths $(c)$, and the total number of battle-related deaths for every year of a conflict (d) (Lacina and Gleditsch 2005; UCDP 2011). I then divide the aggregate number of civilians killed by the total number of battle-related deaths $(c / d)$. If civilian casualties account for over $50 \%$ of total battle deaths in a year of conflict, the insurgent organization is coded as targeting civilians. Statistics on civilian targeting are based on the Uppsala Conflict Data Program's definition, which "encompasses only those [civilian] fatalities that are caused by the intentional and direct use of violence. Intentional killings [sic] refer to any action that is taken to deliberately kill civilians... [and] Direct killings [sic] encompasses all deaths caused directly by an actor, such as bombing or shooting" (Eck and Hultman 2007).

If casualty figures are unavailable, an alternative source of information is the number of insurgent attacks. Where the number of insurgent attacks against civilians constitute over $50 \%$ of total rebel attacks, the insurgent organization is coded as attacking civilians. Two separate and discrete measures for targets are useful (and necessary) because in large conflicts lasting several years, compiling a list of all insurgent attacks is impractical. In cases of short conflicts, or ones where bombings are the dominant insurgent weapon, the number of attacks may be usefully employed (Pape 2003). Targets are measured at the conclusion of a conflict (Gleditsch et al. 2007). 
Adopting a specific percentage as the criterion for civilian targeting can be viewed as arbitrary. However, the fifty percent of battle-death threshold allows for greater confidence in the fact that an insurgent organization is systematically targeting civilians (that civilian victimization is in fact intentional). This work assumes that killing large numbers of civilians is difficult and requires forethought. This fifty percent threshold eliminates random coincidence as the potential explanation of civilian deaths. Most importantly, the 50\% threshold works as a control on the relative size of a conflict. In cases with relatively few battle-related deaths this threshold allows for a clear estimation of insurgent targeting (Valentino et la. 2004; Valentino 2004).

For the purposes of this work civilian targets are defined as individuals who are members of neither a rebel organization nor the incumbent's military apparatus: neutral noncombatants. Furthermore, a civilian target may include infrastructure such as roads, bridges, and communication networks, in addition to other non-military structures. In contrast, military targets include barracks, bases, military forces (men and material), civilian leadership, police forces, and other paramilitary organizations.

I include police forces and paramilitary organizations in the military target category. This decision may be viewed with some skepticism, as police forces are not generally thought of as tools for war fighting, and paramilitary forces may simply be poorly armed civilians. However, in cases where a state has a limited capacity to deploy its military, the police may be the only (relatively) organized fighting force available to the incumbent for combating insurgents. This was the case in the early years of the Nepalese civil war where the " 46,500 -man police force, [was] the first line of armed defense - for Nepal possessed no local forces of any kind" (Marks 2003). Therefore, by including police in the military target category a more fine-grained analysis of the relationship between targets and insurgent military strategy can be achieved. 
The second component of the typology is the weapons used by insurgents. Heavy weaponry is defined as any crew-served weapons; any weapons requiring three or more combatants to operate, which is derived from the UN Register of Conventional Arms (1991; 2009) and the UN International Instrument to Enable States to Identify and Trace, in a Timely and Reliable Manner, Illicit Small Arms and Light Weapons (2006). According to the Register heavy arms include: tanks; armored personnel carries (APC's) and vehicle mounted guns; large caliber artillery such as Howitzers, mortars, and multiple launch rocket systems; aircraft and helicopters; warships; missiles and missile launchers. In short weapons that require any type of vehicle, or a crew of three or more men to operate. If any of these weapons are employed more than once in a conflict year, a group is coded as employing heavy weapons.

In contrast, light arms are any weapons up to .50 caliber and mortars under 100 millimeters. This can be further defined as anything that a single soldier can carry. Thus, in addition to pistols and revolvers small arms can include some machine guns, fuel-air explosives, and homemade bombs (Sislin and Pearson 2001).

\subsection{The Typology}

This section lays out the typology of unconventional military strategies. Creating this typology is useful for two purposes. First, the typology identifies how the relevant measures of insurgent strategy can vary, thereby demonstrating the heterogeneous nature of guerilla warfare. Second, the typology allows for the comparison of heretofore analytically distinct types of unconventional warfare because all the strategies outlined are based on comparable units (Brady and Collier 2004; King et al. 1994). This latter benefit of using a typology falls in line with recent research on insurgency and terrorism being a choice of insurgent organizations based on the constraints they face (Keefer and Loayaza 2008; Berman and Laitin 2005). 
Table 1 presents the strategies that insurgent groups employ based on their weapons systems and who they target. Below, I define the critical elements of each type of strategy. According to the CIA, operational environment and the training of rebel leaders generally determine an organization's strategy. However, a group's operational environment including the culture of the population, economic, political, and geographic factors of the combat environment, in addition to "the insurgents' initial strength; the role of outside parties; and government capabilities... frequently override training and ideology as a determinant of strategy in successful insurgencies" (2009). The discussion that follows is an attempt to - contra extant definitionssystematize, and deductively analyze, the types and determinants of, insurgent strategy.

\begin{tabular}{|c|c|c|c|}
\hline Table 1. & \multicolumn{3}{|c|}{ Target } \\
\hline \multirow{3}{*}{ Weapons } & \multirow[b]{2}{*}{$\begin{array}{l}\text { Light } \\
\text {-Suicide bombs } \\
\text {-RPG's } \\
\text {-Machine Guns }\end{array}$} & Civilian & Military \\
\hline & & Terrorism & Guerilla Warfare \\
\hline & $\begin{array}{l}\text { Heavy } \\
\text {-Tanks/APC } \\
\text {-Artillery } \\
\text {-Missiles }\end{array}$ & $\begin{array}{c}\text { Indiscriminate } \\
\text { Violence }\end{array}$ & Hybrid Warfare \\
\hline
\end{tabular}

\subsubsection{Hybrid Warfare}

At one end of the spectrum is hybrid warfare, which can be employed by insurgents to repel an incoming military incursion, where "rebels tend to "hover just below the military horizon,'... yet, they are frequently able to establish territorial control" (Kalyvas and Balcells 2010). Hybrid threats therefore incorporate the full spectrum of unconventional military tactics including suicide bombings, hit-and-run attacks, the launching of missiles and rockets (either guided or unguided) and conventional defensive tactics (Hoffman 2007; Saab and Blanford 2011). 
There are several indicators of a hybrid military strategy. First, this strategy emphasizes the destruction of enemy military forces and the denial of opposing military objectives. This strategy often takes the form of defense in depth (Mearsheimer 1983; Biddle 2004). Therefore, organization employing this type of strategy will avoid indiscriminately killing civilians. Second, only the most capable organizations will adopt this strategy. That is, only the largest, and therefore the most capable, organizations will adopt this type of warfare (Wood 2010). Third, heavy weaponry will be employed by hybrid organizations; groups adopting this strategy are able to use guided missiles, mortars, and anti-tank weapons as artillery (in addition to conventional artillery and tanks in some cases) in support of force movements, or to deter enemy air and ground force movements. Fourth, organizations adopting this strategy willingly cede ground to advancing incumbent forces in order to attrite them as they move past prepared positions, a strategy that closely mimics defense-in-depth (Mearsheimer 1983). Fifth, complex command, control, communication, and intelligence networks $-\mathrm{C}_{3} \mathrm{I}-$ characterize organizations adopting this strategy. It should be pointed out that this type of warfare has been "observed in recent decades in conflicts such as Chechnya, Slovenia, Bosnia, Croatia, Rwanda, and in actions such as Bai Beche or the Shah-i-Kot valley in Afghanistan in 2001-02” and in the ongoing Syrian civil war (Biddle and Freidman 2008; Higgins 2012).

An example of this military strategy is Hezbollah's war against Israel in 2006. In the case of Hezbollah, small groups of fighters (5-60) held ground with anti-tank guided missiles (ATGMs) and small arms at prepared positions, supported by stand-off mortar fire, for extended periods of time against advancing Israeli infantry and tank units (Blanford 2010). In addition, Hezbollah assaulted Israeli-held positions and buildings, with cover fire from mortar teams. Moreover, Hezbollah was adept at using mines, with minefields south of the Litani river 
organized to canalize IDF vehicles into open ground within range and in view of Hezbollah antitank weapons (Biddle and Freidman 2008). Hezbollah did launch large numbers of rockets indiscriminately into Israel during the campaign — from hardened supply bunkers—but its focus was on denying Israeli military objectives, and halting the Israeli advance north of the Litani River. Finally, they eschewed the use of civilians as shields; intelligence reports indicated that urban areas had been emptied of civilians (Biddle and Freidman 2008).

Thus, the key elements of this strategy are heavy weapons, which are used to repel or destroy advancing armor and air units, and for targeting incumbent military forces by insurgents. It is also important to note that hybrid forces can, and do, successfully hold territory. Organizations employing this type of strategy have significant logistic networks for supporting complex operations. Therefore, following the above criteria, in addition to Hezbollah, the Afghan Northern Alliance forces fighting the Taliban, the FRUD in Djibouti and the Liberation Tigers of Tamil Eelam are major cases of hybrid groups over the last twenty-five years. Insurgent organizations in this category fit into the bottom-right quadrant of table 1.

\subsubsection{Guerrilla Warfare}

Guerrilla warfare is considered to be the insurgent's traditional military strategy. It was the strategy of the Viet Cong in Vietnam and the Spanish partisans in the Peninsular War against France, for whom the term guerrilla warfare was initially coined (Schmitt 1963; 2004). In this case, fighters — generally untrained — using predominantly small arms (possibly even using axes and machetes), mines, bombs, and snipers conduct hit-and-run attacks. Groups using the strategy attack military, police, and infrastructural targets with the goal of breaking the will of the local population and state military forces for continued combat. Groups employing guerrilla warfare lack the organizational capability, in terms of men and material, for larger-scale attacks, and thus 
focus on hit-and-run attacks, which maximize military casualties. The key goal here is to outlast the incumbent. Groups in this category fight their battle in the headlines of incumbent media outlets - this may be aptly called information-age asymmetric warfare (Biddle and Freidman 2008). Organizations here are attempting to extend the timeframe of a conflict in order to maximize costs for the incumbent, push for a negotiated settlement, or possibly bring another actor into the conflict to support them (DeRouen and Sobek 2004). ${ }^{7}$ This strategy is not useful for organizations attempting to hold ground, or for denying incumbent military objectives.

An apposite example of a traditional guerrilla warfare organization is the CPN-M in Nepal. This Maoist rebel organization began its military operations in the rural hinterlands of Nepal. They depended on support from the large, poor, and rural community of the Mid-Western District of Nepal. At the outset of the conflict the rebels were equipped with World War II era .303 Lee Enfield bolt action rifles, which they captured from the Nepalese police force- the Royal Nepalese Army did not enter into the conflict until five years into the war, 2001. The main targets of CPN-M attacks from 1996-2001 were consequently the 46, 500 man Nepalese police force (Marks 2003). Due to the location and relative poverty of its main group of supporters, the CPN-M had little access to domestic or foreign monetary support.

Restated, guerrilla organizations will generally attack incumbent military and police forces, state-sponsored paramilitary forces, and infrastructure in order to depress an incumbent's willingness to fight. Civilians may be killed due to insurgent use of crude weaponry, but are not

\footnotetext{
${ }^{7}$ These authors demonstrate that extending the duration of a civil war helps the rebels obtain some of their goals via a negotiated settlement. This finding provides the logic for why an organization would fight an insurgency even when the best strategy it can hope for is guerrilla warfare or terrorism. The act of fighting lengthens the time horizon of the conflict, and therefore increases the likelihood that an organization will obtain some of its political goals through a negotiated settlement. This is especially true when the incumbent believes that it will gain a quick and decisive victory, but rebels are able to prevent this.
} 
generally explicitly targeted. ${ }^{8}$ In addition, this strategy is most likely to be adopted by organizations with limited military capacity due to the nature of their support base. The Islamic Army in Iraq fighting during the Iraqi insurgency (2003-10) is an additional case of this strategic type. Guerilla warfare is located in the top-right quadrant of table 1.

\subsubsection{Terrorism}

Operations in densely populated settings, or in states with sparsely populated hinterlands erode two critical determinants of insurgent strategy, organizational capacity and defensive depth. In cases where these factors are truncated, insurgents will prefer a strategy that attrites an incumbent's will for continued violence over time. In highly urbanized areas insurgents' preferred strategy is terrorism or "urban insurgency" (Beckett 2001). This is because dispersion, cover, concealment, and suppression are harder to accomplish in densely populated areas. In such cases, insurgents will rely on killing civilians and instilling fear by imposing psychological damage in place of direct military confrontations.

In this instance, rebels are small and therefore lack organizational capacity. As a result, groups employing terror generally are incapable of holding territory or even fighting extended battles with incumbent military forces. Here, organizations lack significant organizational structure and generally attack targets quickly and covertly, with an emphasis on imposing high psychological costs on the civilian population. These attacks are geared towards sapping incumbent resolve by imposing high political costs through indirect confrontations. The dominant weapons of this strategy include suicide bombings, kidnappings, assassinations, forced internal displacement of civilians, and political unrest. Indiscriminate attacks on the most readily available targets, as well as on targets whose destruction will attract a maximum amount of

\footnotetext{
${ }^{8}$ This is a departure from Kalyvas (2006). Kalyvas posits that civilians will be targeted in insurgencies and civil wars when little information is available to actors regarding their allegiances.
} 
attention, and create the most amount of havoc possible, are favored (Pape 2005). As a result, organizations employing this strategy will not rely on militarily trained fighters and lack anything resembling a cohesive armed force. Instead, civilians are used for attacks (Benmelech and Berrebi 2007).

Hamas (Harakat al-Muqāwamah al-Islāmiyyah) is a pertinent example of this strategy. In 1991, four years after its formation, Hamas established its military wing the Izz al-Din alQassam brigade, with the initial mission of eliminating Palestinians collaborating with Israeli authorities (Abu-Amr 1993; Hoffman and McCormick 2004). In 1993, after Hamas leaders were allowed to return to the West bank and Gaza Strip from exile in southern Lebanon, the Islamic Resistance began a major bombing campaign against Israeli civilians, with the goal of stifling the ongoing peace process. The organization conducted its first wave of suicide attacks in April of 1994, killing Israeli civilians almost exclusively, in an effort to end the progress that was being made between Israel and the PLO on the implementation of the Oslo accords. In fact, according to leading Israeli experts on suicide terrorism, this wave of attacks "were decisive in 'erod[ing] [sic $]$ Israel's collective confidence in the peace process.' This in turn, 'played right into the hand of extremist Hamas clerics who opposed negotiations with Israel'” (Hoffman and McCormick 2004).

In sum, insurgents employing this strategy generally attack civilians, with the ultimate aim of wreaking a maximum amount of psychological damage. The dominant tools of much recent terrorism have been the suicide bomber and the IED_-improvised explosive device. Organizations adopting this type of strategy may also rely on homemade bombs, and targeted assassinations. Other organizations that have adopted this type of strategy include Palestinian Islamic Jihad, Fatah, and several Iraqi insurgent groups including Al-Qaeda in Iraq (Rosen 
2010). In addition, the AFDL in the Democratic Republic of Congo, as well as the GIA in Algeria, and the CNDD in Burundi are examples of organizations employing this strategy. Terrorism occupies the top-left quadrant of table 1.

\subsubsection{Indiscriminate Violence}

Indiscriminate violence is defined here as the use of heavy weapons against civilians. This strategy emphasizes imposing costs on an incumbent by killing civilians at random, and causing a maximum amount of damage. Groups adopting this strategy may be attempting, or made an abortive attempt, to move towards a hybrid strategy. Such groups are able to recruit the skilled/educated fighters, and likely have a foreign source of economic and military support, but lack either the organizational size or the strategic depth to effectively employ heavy weapons for hybrid warfare.

Based on qualitative analyses of the twenty-two observations of this strategy it is evident that groups adopting this strategy are in fact making an effort to transition towards hybrid warfare. In 9 of the 22 indiscriminate violence observations, rebel groups employed hybrid warfare after employing indiscriminate violence. In the remaining 13 observations (two of which are dropped from the dataset due to a lack of data), 11 observations are of groups that attempted to adopt a hybrid warfare strategy but failed. These 11 observations are drawn from the Abkhaz Secessionist war and the Second Intifada; in each case rebels attempted to adopt a hybrid warfare strategy but failed - chapter five offers an in-depth discussion of such an abortive strategic adoption by Hamas. Therefore, a campaign of targeted civilian victimization with heavy weapons (labeled here indiscriminate violence) is likely to be an intermediate strategy employed when rebels are attempting to transition away from one strategy towards hybrid warfare. This strategy is located in the bottom-left quadrant of table 1. 
A pertinent example of this strategy is the indiscriminate use of heavy weapons against the civilian population by the Abkhaz Secessionist Movement (1992-1993). The use of heavy weapons was part of an ethnic cleansing campaign conducted by the Abkhaz separatists, the goal of which was to drive ethnic Georgians out of Abkhazia (UCDP 2011).

A large part of the Abkhaz fighting force were some 1,500 non-native armed volunteers from Russia's Northern Caucuses, mainly Circassians and Chechens - otherwise known as the Confederation of Caucasian Mountains Peoples (Collier and Sambanis 2005, 269; Aybak 2001, 189). One of the main rebel leaders was Shamil Basayev, a noted Chechen terrorist (Murphy 2004, 14). Evidence suggests that these largely non-native rebels received significant Russian support in their fight against the Georgian state. Thus, when the conflict broke out in August 1992, invading Georgian forces beat back a poorly-trained/armed Abkhaz militia (Collier and Sambanis 2005, 272). However, by October, "the Abkhaz troops were armed with T-72 tanks, Grad rocket launchers, and other heavy equipment that they had not previously possessed" and were able to achieve a series of military victories against Georgian forces (Aybak 2001, 190). In this instance, the massive outside support is suggestive of a rebel organization at least attempting to adopt hybrid warfare. However, due to a lack of organizational capacity the rebels used their heavy weapons in a large-scale ethnic cleansing program in an effort to undermine the will of the Georgian military forces.

Due to the fact that indiscriminate violence is likely to be a transitional strategy between terrorism and hybrid warfare, and because the dataset includes only 22 observations of indiscriminate violence, I do not offer a distinct theoretical explanation of this strategy. More, due to my hypothesis that this strategy is a means to a hybrid warfare end, in the statistical 
analysis I include observations of indiscriminate violence into the hybrid warfare category. This coding decision is discussed in chapter 2.

In sum, I argue that four types of insurgent military strategy exist, but to this point, all four have been considered guerrilla warfare. By examining the key components of insurgent strategy, namely the targets of violence and the weapons used, I am able to identify discrete types of rebel military strategies, which allows for greater specificity when discussing how insurgents fight in war. More, this typology allows for the analysis of how rebel groups might change their strategies during a conflict, and why all insurgencies are not fought in the same ways. I now turn to a discussion of the ways in which the existing literature on insurgency and civil war has grappled with rebel military strategy and its origins.

\section{Literature Survey}

There are four existing explanations for why insurgents adopt their strategies. The first, argues that strategy is a function of the enemy. That is, both states and insurgents react to one another's strategies in war; those insurgents able to select a strategy opposite to that of the incumbent will win their conflict. The key point here being: the interaction of certain strategies may lead to protracted wars, thus dramatically reducing the role relative power plays in the process of a given conflict. Protracted conflicts raise costs for stronger, generally democratic state actors, thereby sapping public support for continued combat operations, leading ultimately to state capitulation. Thus, in cases where rebels employ a military strategy opposite to that of the state, combat operations are long lasting, which increases the likelihood that the weaker actor will win the conflict (Arreguín-Toft 2005).

A second vein of scholarship focuses on external funding for insurgents. Several scholars in this body of work have posited that where insurgents are funded by outside benefactors their 
military strategy will be more complex. "Insurgencies that seek more than survival in the face of a government counterinsurgency campaign... must make a qualitative leap in their organizational, political, and military efforts. Outsiders can help groups through this transition" (Byman et al. 2001).

Others have argued that until the end of the Cold War, insurgency had been a function of three main factors. First, Marxist theories of peoples' revolution expounded by Mao, Che, and others, were widely disseminated and consequently, provided a model of military organization. In effect communist revolutionary thinkers created a universally applicable organizational doctrine for insurgent groups. Second, were revolutionary beliefs, which "mobilized transnational revolutionary networks often composed of educated and cosmopolitan individuals; these would link up with traditional rural networks but assume leadership" (Kalyvas and Balcells 2010). Finally, great power funding provided arms, trainers, and economic support for insurgent groups. With the end of the Cold War however, funding from the Soviet Union and transnational revolutionary networks withered. Due to the closing of these supply lines combat between insurgents and weak states became, by necessity, more symmetrical; weak states became militarily weaker and rebels lost the ability to learn guerilla warfare. Thus, since 1990, symmetrical nonconventional warfare and conventional civil wars have increased as a percentage of intrastate wars, while the occurrence of insurgencies has decreased significantly (Kalyvas and Balcells 2010).

Fourth, it has been argued that insurgents adopt certain tactics, suicide bombing in particular, as a result of their relative age. That is, younger organizations (and especially young organizations that have religious motivations) will be more likely to adopt innovative military strategies because they lack ridged organizational structures and overall organizational capacity. 
Younger groups, it is claimed, lack focus, and attack experience "making them more flexible and therefore more likely to adopt new innovative tactics" (Horowitz 2010). Adoption of a particular set of tactics in this line of argumentation is also heavily influenced by whom rebels are connected to, and how their organizations are configured.

\subsection{Urbanization}

The final claim of the traditional literature is that a state's terrain affects both the likelihood and type of insurgent conflicts. Traditionally, terrain has been conceived of as the proportion of a state's area that is mountainous and/or rural (Fearon and Laitin 2003); areas considered to be outside of a weak state's infrastructural power (Majumdar et. al. 2004). In large rural or mountainous areas, weak states are unlikely to maintain the capacity to interdict rebel logistical networks, or impact the security of rebel planning and training activities. Therefore, in mountainous and extremely rural states, guerilla warfare will be the dominant form of insurgent military activity. A pertinent example of this is the Maoist insurgents located in the most rural and underdeveloped regions of Nepal between 1996 and 2006 (Marks 2003). In short, rural and mountainous areas provide insurgents with widely dispersed sources of food, munitions, recruits and shelter - an ideal area for hit-and-run operations by lightly armed forces (Taw and Hoffman 1994).

These claims have been substantiated by Fearon and Laitin's (2003) finding that the onset of a guerrilla war in a state that is roughly half mountainous is $13.2 \%$ higher than in a state with no mountainous at all. This finding has been extended in other works, which posit that poor, mountainous states are more likely to suffer guerilla wars than suicide attacks (Berman and Laitin 2005). 
Interestingly, this body of work offers two countervailing analyses on the effects of increasing urbanization on the process of insurgencies. Some works argue that the urban environment is an anathema to traditional guerrilla warfare, and that urban insurgencies are generally an anomalous form of intrastate warfare (Staniland 2010). The substance of this position being that insurgencies are at their core efforts at state building, and it is effectively impossible to build parallel political hierarchies in cities, as the state's material advantages can overwhelm rebels (Staniland 2010). Therefore, in cases where insurgents do operate in cities they are forced into smaller groups, as aggregating in cities risks detection. More, large logistical supply lines are difficult to maintain in urban areas, where state armed forces are more likely to detect the movement of arms, men, and supplies, making large organizations impossible to supply (Taw and Hoffman 1994). After all, insurgents cannot simply rent an apartment to stockpile weapons and train recruits (Chaliand 1982). Therefore, cases in which rebels successfully initiate and sustain military operations in urban spaces are outliers to the trend of rural-based insurgencies.

As outlined by Carlos Marighella (1985), the urban insurgent is effectively a terrorist, operating in small independent cells in order to avoid detection, focusing on terrorizing the population with systematic violence focused on civilians in order to create a popular sense of havoc and disorder, thereby undermining confidence in the state (O’Neill et al. 1980).

Other works argue that the guerrillas are adept at exploiting both the dense human and structural environment of urban areas; urban terrain in this view is the "great equalizer" for less skilled, less equipped forces. Urban forces equipped with light, often-homemade arms can use the cover offered by modern buildings and densely populated areas to defend against armorheavy forces for a significant period of time, even when the latter has total air-superiority and 
overwhelming fire support (Taw and Hoffman 1994). In this view, insurgents can fight across terrain types (Chaliand 1982).

It is critical to note several gaps with this literature. First, the debate on the impact of terrain on the likelihood and type of insurgent warfare remains unsettled. In fact, the existing literature, to this point, offers contradictory predictions about the effects of terrain, with some authors arguing that guerrilla warfare can be employed in any region of a state (Moss 1971), while others argue that urban environs are the domains of terrorists exclusively (Laqueur 1976; Marighella 1985)

Second, none of the analyses in the existing literature has attempted to examine the relationship between varying levels of urbanization and insurgent military strategy. If rural areas provide the necessary strategic depth for insurgents to disperse their forces (Biddle 2004), operating in urban areas should logically affect several additional aspects of insurgent operations, namely: the ways in which insurgents choose to deploy their forces, the targets they choose, and the weapons they can obtain and use. In short, varying levels of urbanization and its concomitant consequences, such as the shirking of rural populations, and the increasing population density of urban centers, should have observable effects on how insurgents choose to fight.

Based on these issues and lacunae with the existing works on rebel strategic adoption, below I offer a new theory to explain how and why rebel military strategies vary between cases and across time. More specifically, I argue that the critical determinate of insurgent military strategy is the extent of urbanization within a state. Urbanization affects levels of educational attainment, and the size of communities within states. The ability of insurgents to recruit educated and skilled individuals into a rebellion is dictated by the nature of local communities. 
The number and quality of rebel recruits are the dually necessary but individually insufficient determinants of rebel organizational capacity. As capacity increases so does the probability that rebels will adopt a discriminating military strategy that explicitly avoids civilian victimization, and instead targets state military forces with heavy weaponry (hybrid warfare). Where capacity is low, due to either few educated recruits or limited organizational size, rebels will adopt guerrilla warfare, terrorism, or indiscriminate violence.

\section{Urbanization and Insurgent Military Strategy}

\subsection{Urbanization and Education}

I argue that an identifiable causal relationship exists between urbanization and insurgent military strategy. Urbanization drives changes in educational attainment and community structures within states. These dually necessary but individually insufficient changes determine insurgent organizational and military capabilities. These capabilities then affect rebel strategic choice.

This section lays out the first step in the causal argument outlined above: here I discuss the relationship between rising levels of urbanization and educational attainment. Urbanization affects the type and quality of potential rebel recruits due to rising levels of educational investment in urban versus rural areas of developing states. A phenomenon that is particularly acute in Middle Eastern and North Africa countries, where on average, both urban poor and nonpoor have higher enrollment rates in educational institutions than their rural counterparts (World Bank 2008; Majumdar et al. 2004).

Thus, as urbanization increases there is a higher likelihood that any given community will include individuals with higher levels of education and technical skills (Lipset 1960; Fair 2004; World Bank 2008; Majumdar et al. 2004; Byman et al. 2001). Communities/populations in states 
with low levels of urbanization have fewer members with even a secondary level of education, technical or military training, and monetary resources. The relationship between urbanization and educational attainment is illustrated graphically (with a lowess line added) in figure 1.

Figure 1 demonstrates that there is a positive and statistically significant $(0.001)$ relationship between urbanization and educational attainment. It is reasonable to suggest that the relationship demonstrated in Figure 1 is endogenous, as urbanization may drive increased educational attainment, or educated individuals may be drawn to cities in urbanized states. I offer no causal claim on whether urbanization is driving this process or not. Instead, I claim only that in urbanizing states, a larger proportion of the population has access to secondary school education, thereby increasing the likelihood that any individual member of a community from which a rebel group seeks support, will have a range of skills and technical abilities.

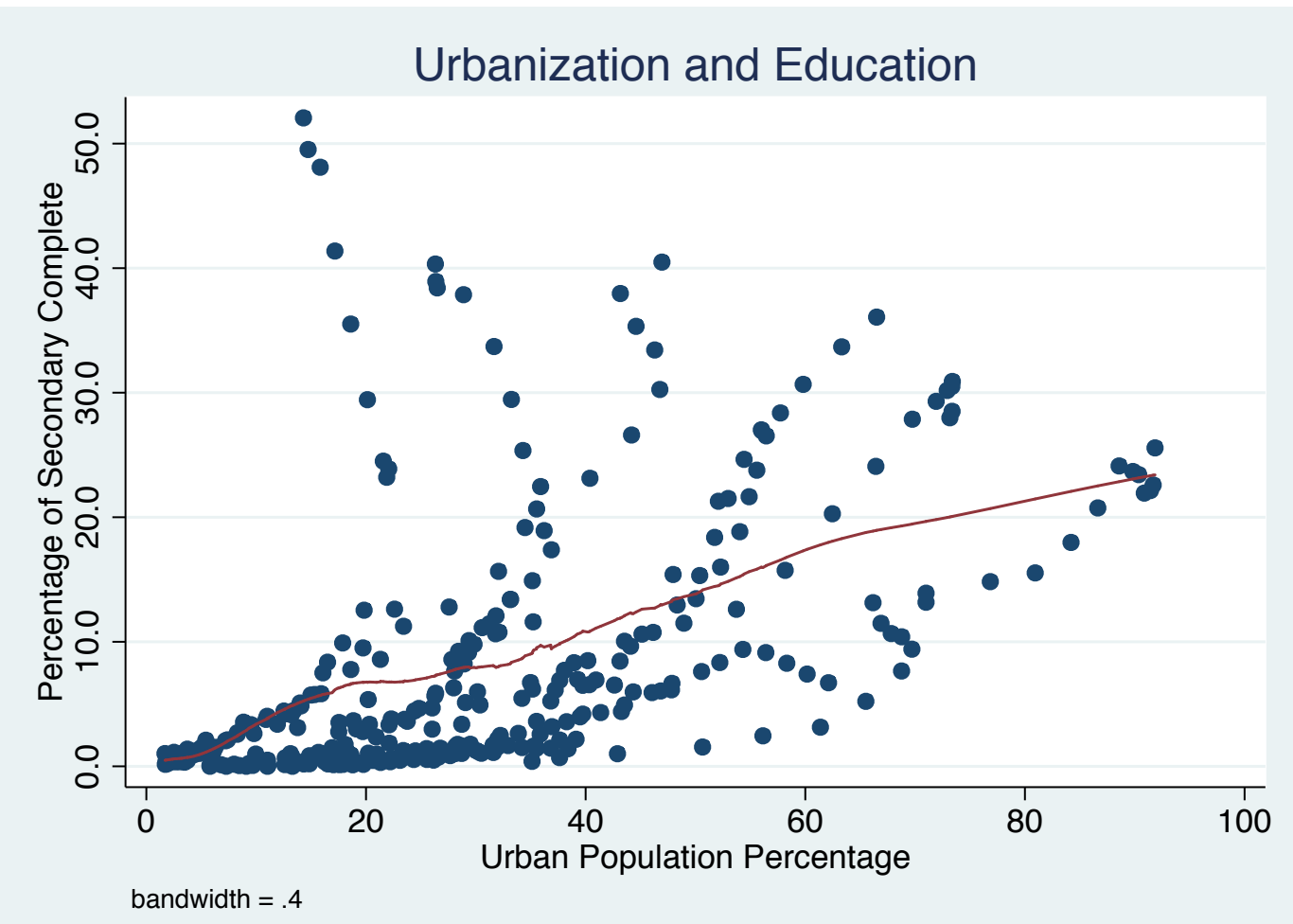

FIGURE 1. Educational attainment and urbanization 1950-2010. 
Recruiting educated urban individuals is vital to the survival of rebel organizations for several reasons. First, existing evidence suggests that education increases the likelihood of an individual supporting and participating in resistance, in addition to more general political participation (Booth and Seligson 2006; Krueger 2007). More, higher levels of educational attainment have been found to increase an individual's sense of political efficacy - the belief that one's participation will make a difference. Thus, people with a strong sense of political efficacy may be more likely to believe that their participation in rebellion or protest will make a difference due to their educational resources and political expertise (Finkel et al. 1989). According to Huntington, "Urbanization, increases in literacy, education, and media exposure all give enhanced aspirations and expectations which, if unsatisfied, galvanize individuals and groups into politics" $(1968,47)$.

Second, education has been found to increases the probability that individuals will consider the impact of a particular military strategy on the achievement of a group's political goals (Krueger and Maleckovà 2003; Krueger 2007; Shafiq and Sinno 2010). Third, higher levels of educational attainment increase the probability that a new rebel recruit will have some degree of technical skill, which boosts an organization's capacity to develop and employ a range of weapons (Fair 2004; Wood 2010). For example, "suicide attacks are complex tasks that require a considerable level of task specific and general human capital. Suicide bombers must reach their targets [covertly]... [and after] reaching the target, suicide bombers must decide on the timing and the exact location of their attack" (Benmelech and Berrebi 2007). The high costs of failure in such operations (both to the bomber and the organization) suggest therefore, that bombers will be well educated and mentally stable individuals. In addition, organizations will be 
more likely to assign better able fighters to higher value targets (Benmelech and Berrebi 2007; Kavanagh 2011).

Relatedly, attaining a secondary level of education allows any new recruit to be trained in the use of modern armaments, which require high levels of technical sophistication for proper use (Blanford 2011). Moreover, committed and educated individuals are better able to articulate a cohesive political narrative based on an organization's military success to recruit new members (Majumdar et al. 2004; O’Bagy 2012).

The Tamil Tigers (LTTE) fighting the Sri Lankan state are an apt example of an insurgent organization focused on recruiting educated and variously skilled individuals. The Tigers made extensive use of universities (generally located in urban areas of the state) to "acquire technical talent and recruit militant manpower as well as ideologues" (Fair 2004). The LTTE (fighting in both rural and urban areas) explicitly targeted Tamil engineering students in Jaffna City, their expertise was likely useful in designing the first suicide belt (Fair 2004). Moreover, universities provided a venue for rebel leaders to interact with nongovernmental organizations to manage the public discourse surrounding the conflict. Finally, universities served as a way for diaspora communities to affect the dissemination of the political message of the rebels they support (Fair 2004).

Based on the foregoing, it is clear that insurgents require urban and educated recruits to conduct a rebellion; educated urban recruits are a necessary component of insurgent capacity. However, education is itself insufficient. I now turn to analyzing how and why the locations in which groups operate influence their preferred military strategy. I argue that the second necessary but individually insufficient component for differentiating insurgent military strategies is the nature of the community that rebels recruit from. Supportive communities shape the 
number and quality of recruits available to insurgent groups, thereby determining rebel military and organizational capacity.

\subsection{Spatially Delimited Rebel Organizations and Strategy}

From the above discussion, it is reasonable to infer that groups coalescing and operating in urban areas are most likely to adopt the hybrid strategy mentioned above. Urban groups recruit in an environment rich with educated and technically skilled individuals and therefore should be able to rapidly build up their military and organizational capabilities. Increasing levels of organizational wherewithal should allow urban rebels to adopt the most discriminating unconventional military strategy possible-hybrid warfare. However, in addition to affecting the average levels of educational attainment, urbanization also determines the number of individuals willing to participate in rebellion. In other words, increasing educational attainment, while necessary, is itself insufficient to raise rebel capabilities. The second necessary but insufficient factor is the number of people that insurgents recruit and draw on for support. The number of people that insurgents can recruit into their organization is a function of the location in which they operate-insurgent size is spatially determined. The combination of educational attainment and number of recruits is necessary and sufficient for increasing rebel military capacity.

\subsubsection{Spatially Defined Insurgent Organizations}

I argue that urbanization has fundamentally altered the areas in which rebels operate as well as the populations from whom they seek support. Thus, in highly urbanized states, rebel groups coalesce in cities, as cities are the best sources of potential supporters for nascent rebellions (Gould 1995). Sparsely urbanized states - where most people live and work in the countryside - facilitate the proliferation of traditional, rural insurgencies because rebels must draw on village support (Fearon and Laitin 2003). States in which rapidly rising levels of 
urbanization produces a population that is mixed between urban and rural spaces facilitate the proliferation of insurgent groups that operate in both urban and rural areas. In this last case, rebels draw on populations that are at once rural and urban.

This work's focus on spatially defined insurgent organizations assumes that people identify, and organize in accordance with the relationships they develop in their daily lives. Individuals are most likely to associate with their neighbors/neighborhoods or people that reside/work in close proximity to them. If most of their neighbors do the same then, "friends' friends are necessarily (at least) my neighbors. This simple fact means that... [relationships] founded on spatial proximity provide fertile ground for the emergence of plausible collective identities: individuals with ties to neighbors can readily observe numerous others whose patterns of social interactions match their own" (Gould 1995). In other words, the mobilization of people for participation in insurgency can be accomplished through spatially defined, local, relationships. Larger groups of people lead to larger rebel groups with a more diverse membership.

\subsubsection{Urbanization and Support for Rebellion}

The location of the people that support insurgent organizations is a critical component in determining who joins an insurgent organization (Siegel 2009). Urbanization determines the locations in which rebel groups coalesce. However, while urbanization is the ubiquitous demographic trend of the post-World War Two world, it occurs differently in every country (United Nations 2010). Varying rates of urban population growth force insurgents to organize in three discrete parts of the state: rural areas, urban areas and mixed regions - what have been dubbed "peri-urban" regions, or areas that are a mix of both urban and rural spaces, or in which urban and rural dwellers comingle (Kilcullen 2012). 
Insurgencies break out in urban areas in countries (or in parts of states) where a clear majority of the population resides in urban spaces, or in countries where one or two cities account for the majority of the state's population growth (United Nations 2010). Although cities are traditionally thought of as stronghold of state power, rebellions will coalesce in urban areas for several reasons. First, insurgents are, in general, reliant on a portion of a state's population for support, in terms of men and material. In highly urbanized areas, populations willing to bear the costs of violent collective action are located in cities. Secondly, in urbanized or urbanizing states, the city is an environment rich with targets for insurgent attacks. Attention-grabbing attacks in urban areas provide publicity for insurgent groups. Third, cities connect nascent rebels with educated people, and other activists (Fair 2004; Taw and Hoffman 1994). Finally, within cities communities of people are tightly knit, which facilitates recruitment and teamwork on a small scale.

The case of the (1984) Sikh insurgency in Amritsar, the capital city of India's Punjab state is a prime example. Jarnail Singh Bhindranwale founded the initial insurgent group in 1982. It was built upon Sikh religious identity and its political demands as a distinct nation within India. Many of the people recruited into the organization were educated in both religious schools and in Indian universities (Fair 2004). Bhindranwale and his followers operated in and around the Sikh holy city of Amritsar, due to its cultural and religious importance for India's Sikh population; Amritsar afforded Bhindranwale with an increasingly politically aware and educated support base. In fact, Bhindranwale and his followers ultimately drew recruits to, operated out of, and died in, the Golden Temple inside of Amritsar (Fair 2004; Brar 1993).

The urban area allowed Bhindranwale and his followers to raise money from supporters, as well as through more illicit means, as the Punjab was steadily urbanizing during this period. 
"As families (both Sikh and Hindu) that could afford to live in cities chose to move, there was a number of opportunities to cultivate sympathetic families to provide shelter to the militants. This also meant that targets were moving to the cities - that is, the Punjab's Hindus" (Fair 2004, 82). This organization was however small, and killed many civilians because of the narrow group of people they appealed to/drew on for support. They were decisively beaten by the Indian military in Operation Bluestar (1984). In their wake several other small Sikh groups proliferated based around the All Indian Sikh Student Federation (Fair 2004).

Thus, urban rebellions are generally small in size, encompass tightly related individuals, and have a high number of educated and skilled members. Individuals in urban areas know one another directly, and have few (if any) ties to individuals outside of their immediate vicinity/immediate set of relationships (Granovetter 1973). In this type of rebellion members generally live in the same neighborhood/area of a given city, and come from the same crosssection of people. The Mahdi army in Baghdad's Sadr city is a pertinent example. It grew out of a group of Shi'a seminary students and young men recruited near mosques in 2003/4 (Howard 2007; BBC 2008). Therefore, in urban rebellions, participants and supporters are bound together by strong social ties because of the limited physical distance separating individuals from one another. As a result, members of urban insurgent groups are perceived to be similar (homogenous), which limits the ability of urban insurgencies to expand past their initial membership (Granovetter 1973).

Homogenous groups of people generally have similar cost-benefit calculations in terms of participation in violent collective action. Within an urban community, information on the actions of others and pressing issues within the community is widely available for members. However, limited information is available "in terms of knowledge of the world beyond... [one's] 
own friendship circle" (Granovetter 1973, 1371; Kalyvas 2006). Therefore, when presented the same information regarding participation in costly collective action urban dwellers are likely to make the same decision, but will be unable to appeal to people with a different cost-benefit calculation.

Restated, the homogeneity within an urban community that supports a rebellion undermines the ability of a nascent insurgency to grow; urban communities are small and tightly knit, and the people that make up these communities are very similar. The similarities amongst people in small communities suggest that rebel recruits will generally be motivated to fight for similar reasons/benefits, and be willing to bear similar costs of violence. These benefits and costs will not motivate people outside of the initial group to join - these factors are discussed below (Gates 2002).

Thus, when urban rebellions occur, insurgent military and organizational capacity is low due to a finite pool of potential recruits. Narrow military and organizational capacity limits the range of viable military strategies that rebels can adopt. Additionally, since urban communities are small and tightly bound, where a rebellion does occur, competing rebel groups are likely to coalesce. Competition between spatially delimited organizations (representing other subsets of the populace) will preclude coordination amongst groups thereby undermining every organization's capabilities, as demonstrated in the ongoing conflict in Syria (August 2011ongoing). The rebel groups that developed in Hama city are in and of themselves separate organizations, and they are distinct from those groups that coalesced in the northern Hama countryside. "The networks that conduct rebel operations in northern Hama sit astride the border with Idlib province, stretching to the town of Khan Sheykhun. However, these networks do not extend south to Hama city" (Holliday 2012, 23). 
By comparison, rural insurgencies occur in states with low levels of urbanization. On average, rural insurgencies are made up of small groups of people from the same rural community (village) or of people from the same (ethnic) group residing in a particular rural region of a state. There are several consequences of this type of membership. First, rural insurgents generally lack any formal education or technical training. Second, while villagers and members of the same spatially delimited group of people know one another and can work together, rural insurgencies are hard-pressed to expand beyond their initial base of support. A pertinent example of this type of rebellion is the Nepalese Maoist insurgency. This insurgency was based in part of the support of the rural Kham Magar ethnic group in the Mid-Western region of Nepal. The Kham Magar lived in an area with so little infrastructure, and with communities separated by large enough physical distances that organizational "expansion proved... difficult, and the level of popular involvement was commensurately [low]" (Marks 2003).

In rural areas small groups of people are tightly connected to one another through close social ties within their area of residence, but are generally unconnected to people outside their immediate locality, due to issues of physical distance. Great distances or physical barriers (mountains, jungles, deserts etc.) make interaction and coordination between distant communities difficult or impossible. As a result, rural community members will rarely interact with people who are not from their immediate locality. This lack of social ties between scattered rural communities distorts the spread of information, thereby limiting the likelihood of largescale collective action (Granovetter 1973).

Rural insurgents face issues with building military and organizational capacity similar to those working in urban areas. In this case, small groups of tightly connected and similar people 
can be motivated to participate in rebellion, but expanding a rural organization's support base is difficult. Due to the physical distance between groups of people, rural rebel movements are not highly visible to the average person. Thus, it is hard for core rebel members to develop interpersonal relationships with scattered groups of people, which limit recruitment opportunities (Diani and McAdams 2003). Additionally, there are few prominent military targets in rural areas. This lack of targets hurts rural insurgents' ability to spread their message of resistance via military operations. As a result, insurgent organizations rooted in rural areas have limited military and organizational capabilities.

Finally, mixed insurgencies occur in states where urbanization is ongoing and occurring rapidly. These types of insurgent groups find support in populations that span both urban and rural spaces, as well as in populations in "peri-urban" areas - suburban slums and townships that develop on the outskirts of rapidly expanding cities that account for a significant share of urban population growth (Kilcullen 2012). In this instance, membership in a rebellion is large and diverse - the organization is heterogeneous in terms of membership - encompassing variously educated and skilled individuals living across a state. This type of population exists in states where urbanization is rapidly changing the demographic makeup of a state, to wit, shifting a state's population away from its rural roots. A mixed population can be spread across a state, and thus not localized to any one part of a country; this type of community is both urban and rural. Mixed communities of people include family members dispersed due to new urban job opportunities, university students studying away from home, marriages that create an incentive to move, or formerly rural people searching for better opportunities in cities (Caruso 2011; Walton 1984; Norton 1983). 
The diversity of rapidly urbanizing states, and of the individuals from these states that participate in violent collective action stems from the demands of the city on urban migrants. That is, individuals that move towards cities often work in menial or manual capacities inside the city (that urban-dwellers may refuse to take on) whilst living on its outskirt. In point of fact, cities are functionally reliant of urban migrants/peri-urban dwellers (chapter five discusses this phenomena in the Palestinian context). These new urban migrants provide core areas of the city with a range of services - public transit, cleaning/maintenance services, shopkeepers, food service, police, firefighters, and medical staff — even though they do not, or cannot afford live there. These urban migrants also function as connecting points between urban and rural parts of rapidly urbanizing states, and between the rural hinterland and the international community, much like the port of Colombo connected Sri Lanka's Tamil Tigers with its supportive diaspora community. Areas to which rural migrants flow in effect "sit astride key communication nodes that connect that city to the external world as well as to its food, energy, [labor] and water supplies"(Kilcullen 2012, 25).

Mixed insurgencies, arising in both urban and rural areas, therefore encompass people that are at once tightly connected to their immediate locality and indirectly connected to others that are not in their immediate vicinity, but to whom they are nonetheless related (Granovetter 1973; Kilcullen 2012). These indirect connections, serve as routes along which information and influence can flow between pockets of tightly bound network members (Granovetter 1973). Mixed communities are thus heterogeneous groups of people. These members have less in common than members of purely urban (rural) communities because they have different, spatially dictated needs, and are likely to have varied cost-benefit calculations with regards to participation in collective violence. 
Thus, in mixed insurgencies although people are physically separate from one another, all potential joiners have access to at least some information about others in the potentially supportive population. In sum, the indirect connections that link pockets of people in mixed populations, function as mechanisms of identity and informational diffusion, which can "reach a larger number of people, and traverse greater social distance" than strong/direct ties alone (Granovetter 1973, 1366). A greater number of indirect ties suggest greater access to information about the world beyond one's immediate social ties, and higher levels of participation in violent collective action (Granovetter 1973).

Insurgents with access to this type of population use available information to motivate local participation in insurgency (Neill 2005). In these cases first mover insurgents emphasize the lower costs of joining an insurgency late due to safety in numbers, as well as the positive/negative incentives available, to motivate participation in rebellion (discussed below). In practice, first mover insurgents in mixed communities create a spatial bandwagoning effect that drives up aggregate participation in rebellion (Lichbach 1995; Oliver and Marwell 1988). This leads to high levels of recruitment among both skilled and unskilled fighters.

In sum, the location of a community of rebel supporters affects popular participation differently. That is, due to the level of urbanization of given state, rebels will be in a position to recruit educated individuals, as well as large numbers of other network members; only be able to recruit small numbers of educated and skilled individuals; only recruit unskilled people. Who insurgents can motivate to participate in rebellion is directly related to where a supportive population is located. As discussed below, the types and number of people that insurgents can recruit establishes insurgent organizational and military capacity, which in turn determines the 
military strategy that rebels will be able to adopt. I now turn to explaining why some areas of a state facilitate higher levels participation in rebellion than others.

\subsubsection{The Free Rider Problem and Participation in Rebellion}

"The problem for actors involved in mobilization is to convince potential participants that, given their social situation, they are both likely to benefit from and, as a result, obligated to contribute to collective effort" (Gould 1995). In short, to launch an insurrection rebels must motivate some number of individuals to participate; insurgents must address the collective action problem. Based on the where rebel groups coalesce, collective action will either be widespread or very limited due to the problems associated with motivating free riders to participate in collective action.

Several interactive factors affect participation in insurgency. First, gaining tangible benefits from participation such as social or economic services. Second, the "desire to avoid making contributions that will be wasted" (Gould 1993; Petersen 2001). Third, individuals are more likely to join insurgent movements as larger numbers and increasingly diverse types of other people do because there is safety in numbers (Mason 1996). The provision of social services is a positive incentive program that serves to reinforce/incentivize popular participation in rebellion-positive feedback (Blanford 2011; Flanigan 2008). Safety in numbers and the desire to avoid wasting a contribution are the mechanisms that motivate popular participationtacit, passive, or active-in an insurgency.

Individuals are more likely to participate in, or contribute to, organizations when their donations will help make a movement successful. However, when rebel groups are small, or are predicated upon the support of a very small subsection of the population, individuals are likely to view potential contributions to the rebellion as being a waste of valuable resources (Popkin 
1979). At the core of this argument is the fact that people have concerns outside of participating in rebellion (Lichbach 1995). Some individuals must harvest crops, build bridges, and teach in schools; people must generate income to survive, and they do not want to waste this income on a small rebellion that may be crushed, or on a donation that may lead to a state sanction.

Therefore, when/where rebellions are small most individuals prefer to remain outside of a rebellion; on average risk-averse individuals estimate that if few people participate in violence, one person's contribution will make little difference to the maintenance or success of a movement (Finkel et al. 1989). Low levels of participation (due to community-based organization) in urban areas at the outset of a violent rebellion therefore negatively impacts the likelihood of large numbers of late joiners. This effect of locally based rebel organization is similar is rural areas. However, when people from both urban and rural areas are visibly participating in rebellion, potential recruits are less likely to think their contributions will be wasted on a small an ineffectual organization.

Secondly, there is safety in numbers (Kuran 1991; Lichbach 1995). That is, the probability of being caught and sanctioned by an incumbent (let $\mathrm{m}=$ the coercive capacity of the state, and $\mathrm{S}_{\mathrm{g}}=$ incumbent ability to punish with sanctions) for supporting rebels decreases as the aggregate number of individuals supporting a rebel organization $(\mathrm{r})$ increases. Thus, $\mathrm{P}\left(\mathrm{S}_{\mathrm{g}} \mid \mathrm{m}\right)=$ $\mathrm{m} / \mathrm{r}$ ). Therefore, as more people support insurgents, the harder it is for the state to identify and sanction any one individual — the state's capacity to sanction is constant while rebel support can vary. Thus, given that decisions regarding participation in collective action are often sequential, a large and diverse core group of first mover rebels can affect higher levels of popular support, because non-participators will realize that the costs of participation — in terms of being sanctioned by the state_-decline over time as a rebellion grows (Lichbach 1995; Oliver et al. 
1985; Oliver and Marwell 1988; Marwell et al 1988; Neil 2005). For “any level of support for the rebels, $r$, [citizen] $a_{j}$ 's expected value of sanctions $S_{g}$, consists of the value (s)he attaches to the sanctions multiplied by the probability of receiving the sanction" (Mason 1996). In cases where many non-joiners exist early on in a rebellion, participation will likely be low later, as the danger of any one individual being sanctioned by the state remains high.

Safety in numbers is critical for driving costly collective action. Decreasing the costs of participation for late joiners creates a bandwagon of support for a growing rebellion. Due to the high potential costs associated with rebellion many people take a wait-and-see approach to participating in dissent. Outside of first mover rebels, most people willing to participate make their contributions to rebellion contingent on what previous (non)contributors have done. Thus, there is a sequential component to decision-making with regards to participation in rebellion. "Those who arrive early to collective dissent influence latecomers... the most committed join at time $t$; this both raises the probability of success (benefits) and lowers the probability of repression (costs) at time $t+1$; this, in turn, encourages those even less committed to join at $t+2$, and so on" (Lichbach 1995, 115). Every receipt of information on others organizing raises an individual's probability of participating in rebellion, as well as the probability of the same individual recruiting others (Diani and McAdam 2003). If too few people participate in the early stages of an insurgency then the costs of participating later will not be significantly reduced. Also, if a population of potential participants is too narrow/small or too unconnected due to location, the costs of participation will not drop. As a consequence, no selective positive/negative incentives will increase popular participation — contributions will be seen as a waste.

Community heterogeneity is vital for bandwagoning in rebellion. More risk accepting members of a network spur more risk-averse people to participate. Seeing that individuals not 
directly connected to a nascent insurgency, with different cost/benefit analyses, are participating in rebellion influences individual decision-making. Put differently, student protest might influence workers to join, which in turn may drive rural individuals to protest, creating a large bandwagon of participation, thereby decreasing the number of visible nonparticipations. The logic being that when groups of unlike people participate in rebellion there are assurances to others that a collective bandwagon may ensue, making individual participation less costly (Petersen 2001, 247). Information diffuses throughout an indirectly related population and is used by local rebel entrepreneurs to facilitate recruitment into a rebellion. "Chains of direct ties can indirectly link actors with others who are quite distant from them and lead to the widespread diffusion of information" (Diani and McAdam 185). This drives up aggregate contributions to a rebellion, which in turn affects the perception that individual contributions to an insurgency are not wasted.

In effect, the above factors adversely affect participation in urban-based insurgencies. Where people are tightly connected to one another there will be few willing late-joiners to an insurgency. Here, the pool of potential recruits is homogenous and mobilized rapidly, but they have few, if any, connections to individuals outside of their community, leading to a small rebel organization (Petersen 2001). People outside of the community have no connection or interest in the rebellion, and given its relatively small size, view potential contributions to violent collective action as a waste. Moreover, in urban areas, the state is better able to sanction any one individual, which further decreases the likelihood of individual participation in rebellion; no bandwagon of support can form. Therefore, urban insurgents have limited organizational capacity due to a small number of willing participants - and the large number of people outside of the organization. However, given an urban location, those that do participate in rebellion are 
likely to be well educated or technically skilled. This increases the probability that the group will adopt terrorism as its military strategy (Benmelech and Berrebi 2007).

A similar logic applies for rural insurgencies. Where first actor rebels do develop, they are too unconnected to other communities of people to motivate participation in insurgency (Siegel 2009; Petersen 2001). Consequently, rebels in the countryside will generally have severely truncated organizational and military capabilities, in terms of their abilities to recruit educated and skilled people or large numbers of untrained supporters. Given that the state can identify small numbers of rebels, the probability of being sanctioned by the state rises for those individuals who do take part in rebellion, further depressing the number of willing participants. Therefore, rebels operating in rural areas will have few options in terms of military strategy, and will be most likely to adopt traditional guerrilla warfare.

Contrastingly, in states where the population straddles urban and rural spaces the heterogeneity of the populace increases the likelihood of high levels of popular participation. In this case, there is greater variance in the types of people that are linked to one another. First mover insurgents motivate people to participate in a rebellion locally, and this local organization serves as an assurance to other, distant and (non)contributing individuals that there are others willing to bear the costs of insurgency. Due to incomplete information, first mover rebels can use their informational advantages to represent high levels of participation in distant communities, thereby assuring more risk-averse late joiners of the safety and benefits of joining a rebellion.

As a result of these factors, more people participate, and there is an increased belief that individual contributions will make an observable difference in a rebellion - and thus not be wasted (Finkel 1989; Gould 1993). These factors create a bandwagon effect leading to larger scale - relative to purely urban or rural rebellions - violent collective action. Heterogeneous 
participation makes the average risk-averse individual believe that (s)he is less likely to receive a "sucker's" payoff for participating in an insurgency. This fact increases the total number of participants, which concomitantly increases insurgent organizational capabilities, thereby allowing for the adoption of hybrid warfare.

Practically, in very urban areas, like the Gaza Strip, it is very difficult to obtain high levels of participation in rebellion due to the tightly knit nature of urban communities, and a higher likelihood of being sanctioned for participation. Consequently, regardless of the selective incentives offered by groups like Hamas, and the high levels of education of their recruits, few individuals will take an active role in fighting the Israeli occupation (Krueger and Maleckovà 2003; Krueger 2007). From a military-strategic point of view, this lack of active participants means that Hamas will have very limited organizational and military capacity, as only highly risk accepting individuals will participate in rebellion, and their contribution will be high - to wit, suicide bombers. For Hamas, the combination of few highly motivated contributors, and the organization's consequent low organizational capacity, drives the group's preference for terrorism and indiscriminate violence (Rocket Threat 2007).

The Maoist rebels fighting in Nepal (CPN-M) are an apposite case of rebels operating in a rural area. The CPN-M was based in the rural mid-western regions of Nepal and sought support from poor rural castes. This body of people offered the organization few educated or trained recruits, and its membership had no relationship to the urban areas of Nepal (Marks 2004). Being rooted in this community significantly limited the CPN-M's appeal, as well as their military and organizational capacity. As a result, the Maoists adopted traditional guerrilla warfare.

Finally, Hezbollah is rooted in a mixed population; the Shi'a community of Lebanon is dispersed across the southern Suburbs of Beirut, the coastal cities of Tyre and Sidon, the Beqaa 
Valley, and across Lebanon south of the Litani River (Blanford 2011). This organization has access to a wide range, and large numbers of individuals available for recruitment, as fewer people in the network are visibly connected to nonparticipants. Hezbollah has therefore been able to adopt a hybrid military strategy.

In sum, the location in which insurgents coalesce has a critical impact on how an organization develops due to the collective action problem. In order to maintain itself once created, and possibly expand, rebel groups must also offer some positive inducements for participation. I now turn to a discussion of these positive inducements. ${ }^{9}$

\subsubsection{Positive Incentives for Participation}

Insurgent organizations exchange social services and political representation for support from both urban intellectuals and rural constituents (Flanigan 2008). Social services and political representation operate as positive feedback mechanisms for recruits, in that they reward recruits' commitment to participate in rebellion despite its costs. Organizations that can provide the best benefits to the largest number of network members will therefore have the greatest amount of popular support, thereby increasing their capacity, which allows them to adopt the most demanding military strategy.

Mason (1996) points out that the value of supporting a rebel organization for an average citizen is based on the goods they receive, minus the taxes they pay rebels in return, in terms of money, violence, resources, and time.

$$
\mathrm{V}_{\mathrm{r}}=\mathrm{U}\left(\mathrm{X}_{\mathrm{r}}\right)+\mathrm{U}\left(\mathrm{Y}_{\mathrm{r}}\right)+\mathrm{U}\left(\mathrm{Y}_{\mathrm{g}}\right)-\mathrm{T}_{\mathrm{r}}
$$

\footnotetext{
${ }^{9}$ It should be pointed out that some insurgent organizations have used forced recruitment to expand their ranks (Kalyvas and Kocher 2007; Humpheys and Weinstein 2008). Interestingly though, even in these cases positive inducements are given to forced recruits to motivate their continued active participation in the organization-in addition to the threat of death and reprisals against family members (Humpheys and Weinstein 2008). Carrots (selective incentives) and sticks (violence) can be used at the same time. I focus on the nature of the carrots used by insurgents. Furthermore, forced recruits are often children and unskilled rural people, which from the perspective of this work would undermine organizational capacity.
} 
In this equation, the value of supporting rebels $\left(\mathrm{V}_{\mathrm{r}}\right)$ is a function of the goods provided by rebels, both excludable and nonexcludable $\left[\mathrm{U}\left(\mathrm{X}_{\mathrm{r}}\right)+\mathrm{U}\left(\mathrm{Y}_{\mathrm{r}}\right)\right]$, in addition to the nonexcludable goods provided by the state $\left[\mathrm{U}\left(\mathrm{Y}_{\mathrm{g}}\right)\right]$, minus the taxes required by rebels $\left(\mathrm{T}_{\mathrm{r}}\right)$.

In cases where an insurgency begins in an urban area, the costs associated with mobilizing rural support raises the tax rate associated with the provision of goods. In other words, it costs insurgents more to provide goods to out of area individuals. The distance between rural and urban areas increases the costs of the provision of goods, and therefore the taxes rebels must demand (Gates 2002). The consequence of an increased tax rate is that citizens gain little from the potential benefits offered by out-of-area insurgents. The lack of potential benefits, and the fact that no safety in numbers exists for out-of-area individuals fundamentally undermines rebel ability to expand their base of support, and therefore limits their areas of operation. In some cases this may drive forced recruiting which has little impact on organizational capacity (see footnote 7).

It should be noted that this same logic applies to those insurgents rooted in rural areas, working to recruit in cities. The costs of provisioning services for urban populations, where the state is a competing provider, increases the taxes necessary to outcompete the state, which in turn drives down rebel support. In fact, when taxes required by insurgents are too high it may lead to popular defection to the state, which can provide limited excludable and nonexcludable goods at a better price (Gates 2002). This may also lead to forcible recruiting by insurgents. As a result, expanding outside of the initially supportive population for many groups may be impossible due to the high costs.

In contrast, organizing in a mixed population allows insurgents to incentivize support from diversely educated and skilled individuals in different areas of a state. In this case, 
insurgents are not forced to provide benefits for out-of-area individuals, as their areas of operation encompasses both urban and rural constituents. More, providing benefits to a large population reinforces the notion that many people are participating, which decreases the perception that any one individual will be sanctioned for participating in rebellion. ${ }^{10}$

The CPN-Maoist in Nepal could offer no social services to potential recruits or their families, and did little in the way of social or infrastructural improvements in areas in which it maintained a presence (or outside of it). Thus, the CPN-M was unable to significantly expand its support structure. Due to these organizational limitations the Maoists relied on traditional guerrilla warfare operations in the hinterlands of Nepal.

Based on the foregoing discussion of rebel recruitment, this chapter now turns to an explication of the relationship between recruitment and rebel capability. That is, the number and quality of recruits available to an insurgent organization are the dually necessary but individually insufficient determinants of group capabilities. Insurgent capabilities drive the selection of rebel military strategy.

\section{Capacity and Insurgent Military Strategy}

The locations in which insurgents recruit affect their military and organizational capacity. Capacity refers to material and informational resources that an organization deploys to engage in military combat (Asal Rethemeyer 2008). Due to significant information problem associated with the study of intra-state violence, in this work insurgent capacity is understood as both the size of an insurgent organization (Wood 2010; Asal Rethemeyer 2008; Gates 2002) and the skills

\footnotetext{
${ }^{10}$ It should be noted that this is logic of incentivizing support with goods runs counter to that of Weinstein (2007). I posit that all rebel groups will try to give out goodies to supporters, but will be limited in how many people they can reach by the social network they work through. Weinstein contends that benefits are only useful for certain types of movements, with a certain type of constituents, those he calls "consumers." Here I avoid discussing the "type" of participants, because human intent is unknowable. In addition, I assume that all people are at once "consumers" and "investors."
} 
that individual recruits bring to an insurgent group, education (Krueger and Maleckovà 2003; Krueger 2007).

Based on the forgoing, rebel capabilities are a direct result of the number and quality (level of educational attainment) of the people an organization can attract, and this is driven by the level urbanization in a given state. Only groups that are both large and include educated people will have the necessary capacity to adopt a hybrid warfare strategy. In other words, only groups rooted recruiting in mixed populations will have sufficient organizational capacity to adopt hybrid warfare. In contrast, small groups with many educated people-rooted in urban areas - will most likely adopt terrorism (Pape 2005; Krueger and Maleckovà 2003; Krueger 2007). Groups with few educated individuals — those emanating from rural regions—will prefer on traditional guerilla warfare.

As discussed above, recruiting a wide range of individuals with diverse skill sets, or human capital, is essential to a rebel movement. The larger a rebel group's constituency the greater the probability that "its membership includes individuals (a) skilled at methods of death and destruction, (b) capable of raising and managing money, and (c) possessed of access to restricted information, places, and materials. In short bigger organizations should be more capable" (Asal and Rethemeyer 2008). Furthermore, as rebel size increases and better-educated individuals come into leadership positions, groups become more discriminating in terms of their targeting. Insurgents with high levels of military capabilities are in a position to employ sophisticated weaponry discriminately, whereas leaders of organizations with limited capabilities will be unable to conduct discriminating attacks due lack of precise weaponry, and a limited number of fighters who can deploy available weapons against more technically adept incumbent forces (Berman and Laitin 2005). Thus, larger groups are more likely to eschew civilian 
victimization favoring instead the use of heavy weaponry versus state military forces (Wood 2010).

Relatedly, foreign funding, in the form of money and weaponry is available for highly capable groups for two reasons: first due the increasing likelihood that any individual rebel will have connections to foreign sources of support as a rebellion grows; diasporas donate to rebellions for "communal reasons" (Byman et al. 2001). That is, as organization's ranks grow it is more likely that any one of these individuals has access to sympathetic diaspora communities through family, kinship, or friendship ties, with access to wealth and other necessary materials. More, as educational levels increase within an organization, there is a higher probability that any one member will be trained in asset management, which ensures that foreign donations will not be wasted.

Foreign supporters will also be more likely to invest in a rebellion as it demonstrates the ability to survive and grow (Lichbach 1995); "endogeny begets exogeny, rather than vice-versa. The willingness of external sources to contribute to a rebellion depends on the rebellion's internal strength" (Leites and Wolf Jr. 1970). Put differently, external support is epiphenomenal of organizational success and sophistication, as groups that can obtain external support must first demonstrate an ability to successfully collect, move, and mobilize arms or monetary support. "Insurgent efforts to raise money from diasporas often enjoy a bandwagon effect. Military victories tend to capture greater support from abroad, which in turn provides more money for continued success in the domestic theater" (Byman et al. 2001). Thus, only groups able to demonstrate sustained military effectiveness will gain access to funding and sophisticated weaponry. Groups perceived as most likely to sustain themselves are those with well-educated 
leaders and cadres. Education allows leaders to articulate their political and military goals to potential donors, regardless of their actions in combat.

Stated explicitly, insurgent capacity is a function of two necessary but individually insufficient factors: size and skill. When few skilled fighters are available, terrorism will be an organization's preferred military strategy. This is due to several factors. Educated rebel recruits are concentrated in cities. Groups from urban areas face significant collective action problems due to the tightly knit nature of urban communities. Smaller groups may have foreign donors willing to provide money, but they will not have the manpower necessary to operate and maintain heavy and sophisticated weapons. Each fighter in a small organization therefore must maximize the physical and psychological damage (s)he can impart on the opposing state. Explicitly targeting large civilian populations accomplishes this goal.

"[E]xisting models and analysis of terrorist group activities suggest that individuals with high levels of education are more productive workers in the market economy and more efficient terrorist” (Kavanagh 2011). Thus, groups with only a few highly skilled individuals can wage a massive terror campaign against an overwhelmingly powerful state's civilian population. Terrorism, is an extremely demanding military strategy requiring high levels of planning, secrecy, and technical skill, but not a large organizational structure (Benmelech and Berrebi 2007; Berman and Laitin 2005; Fair 2004). Groups with leaders/members that preformed well in the market economy also receive outside support due to their perceived military wherewithal/capabilities, which allows them to bear the costs of terrorism (Levitt 2006). Thus, terrorism is the preferred strategy for urban groups.

Guerrilla warfare then is preferred when an organization has no access to the skills necessary for terrorism or the size/network dispersal required for hybrid warfare. Here an 
unskilled rural population can band together with the weaponry available to them and work to attrite an incumbent's will to fight over time through hit-and-run attacks. No foreign support is generally available due to a lack of foreign connections, and a general dearth of technically or militarily skilled individuals that can lead complex military operations. Most cases of guerrilla warfare occur in the rural hinterlands of a state where insurgents develop out of a small tightly knit rural community, with little or no violence occurring in the main urban centers (Fearon and Laitin 2003; Marks 2003). This military strategy is therefore neither organizationally taxing in terms of the allocation of men and material, nor does is require a high level of technical sophistication to avoid detection in cities. Guerrillas will prefer to kill opposition military forces because they cannot afford to alienate members of their already sparse support network.

Finally, hybrid warfare is the military strategy that groups with both technical and military skills, the organizational size to mirror conventional military strategies, the physical space in which to operate, and a source for money and material, prefer to adopt. Organizations adopting this strategy are led and supported by well-trained and educated individuals. Hybrid organizations are also most likely to have a diverse group of supporters provides that provide connections to foreign sources of support. Here, selecting into warfare against a state's military forces may actually lead to the accomplishment of the organization's goals faster - relative to any other strategy - by rapidly escalating the cost and consequences of combat operations for an opposing state. This strategy is focused on attriting the will of an opponent as well as the denial of enemy military objectives; targeting civilians does not allow for the denial of enemy military objectives (Pape 1996). 
The two Liberian Civil Wars (1989-1996; 1999-2003) are instructive examples here. ${ }^{11}$ In the First Liberian Civil War (1989-1996) a number of competing insurgent organizations fought the Liberian state and one another-NPFL, INPFL, ULIMO, ULIMO-K, and ULIMO-J. Both the initiating insurgent organization, Charles Taylor's NPFL, and a splinter group, the Prince Johnson-led INPFL, depended on support from Gio and Mano ethnic groups that resided in the sparsely populated rural north-west of Liberia. While the NPFL began its operations in the north of the state and fought south, the INPFL conducted its military operations largely in the capital city of Monrovia. Despite the fact that the INPFL was credited with capturing and killing then president Samuel Doe, it was unable to grow past its initial size because it competed for support with the NPFL, from sparse rural social networks with no connections to Monrovia. As a result, by 1992 the INPFL was disbanded due to a lack of support (UCDP 2011). The groups in the First Liberian Civil War employed guerrilla warfare and terrorism.

By contrast, in the Second Liberian Civil War 1999-2003 LURD (Liberians United for Reconciliation and Democracy) was made up of many different ethnic groups from across the rural areas of Liberia, as well as Monrovia. It included former members of the rural NPFL, the urban INPFL, the various ULIMO factions, the Armed Forces of Liberia, and foreign fighters. This nexus of supporters (what can in-toto be considered a mixed group of supporters; with foreign military support) increased the organizational capacity of LURD, allowing it to deploy a hybrid military strategy, in which it used heavy weapons against the Charles Taylor-led armed forces of Liberia. This hybrid strategy was evident in LURD's use large-caliber anti-aircraft

\footnotetext{
${ }^{11}$ These are especially good examples as they offer a controlled comparison of insurgent groups all of which received both safe heaven and support in terms of men, money and material.
} 
guns and truck mounted heavy machine guns during the conflict, as well as during its siege of Monrovia (Barbazon 2003; IRIN 2012). ${ }^{12}$

In sum, this work argues that insurgent military strategy is driven by urbanization. In states with a population that spans both rural and urban areas insurgents are able to recruit more educated individuals from urban centers, and are in a position to recruit more participants in general. Recruiting a range of individuals raises insurgent military and organizational capacity. Increases in insurgent capacity allows rebels to move away from civilian victimization or traditional guerrilla warfare in favor of a more sophisticated military strategy centered on denying incumbent military and political objectives by targeting state military forces with the most advanced weapons possible, hybrid warfare. Where military and organizational capacity is limited, and depending on the areas in which rebels coalesce, groups are most likely to adopt traditional guerrilla warfare or terrorism.

\section{Conclusions}

This chapter set out to articulate a theory of rebel strategic adoption predicated upon the global trend of urbanization. I have argued that urbanization is uneven around the globe and therefore has varying affects on insurgent military strategies in war. Urbanization has changed the locations in which rebels operate, and has increased statewide levels of educational attainment. Insurgents in particular areas of a state work to recruit the most educated and largest number of supporters - the dually necessary but individually insufficient determinants of rebel capacity. However, due to their location (rural, urban, or peri-urban), rebels may face serious challenges in terms of motivating popular participation and expanding their base of support.

\footnotetext{
${ }^{12}$ It should be pointed out that between the two conflicts, while rates of educational attainment remained effectively constant (roughly 6 percent of the population), urbanization had increased by roughly three percent between the two conflicts, providing some support to my theory that increasing urbanization is affecting insurgent military strategies.
} 
Only in cases of mixed populations will insurgents be able to alleviate the collective action problem and recruit the largest and most diverse group of supporters.

Where insurgents can motivate the largest number of urban and rural supporters, and thus the largest possible number of educated and skilled individuals, to join a rebellion, a group will have high levels of organizational and military capabilities. This is because as overall levels of group education rise there is a concomitant increase in: group military skill, the knowledge to employ sophisticated weaponry, and the ability to spread political messages. In addition, with increasing organizational size there is a higher likelihood that members of a rebel organization will have links to foreign sources of support, in terms of money and material. Higher levels of military and organizational capacity should therefore lead to the most sophisticated and discriminating military strategy, hybrid warfare, instead of traditional guerrilla warfare, terrorism, or indiscriminate violence. Where capacity is limited due small community size, or a limited number of well educated and diversely skilled recruits (which are predicated upon the level of urbanization within a state) insurgents will be most likely to adopt terrorism or guerrilla warfare, respectively.

In sum, urbanization simultaneously alters where insurgents originate/fight and the average level of education within a state. Insurgent groups work in different parts of a state, and based on the level of urbanization, recruit diversely educated and skilled people in the largest possible numbers. Where urbanization allows for large scale and diverse recruiting, rebels gain the most amount of military and organizational capacity, allowing them to adopt a sophisticated and discriminating military strategy. Where urbanization very high or very low diverse recruiting is limited, which truncates rebel capabilities, leading to either less demanding and less discriminating military strategies such as terrorism, guerrilla warfare, or indiscriminate violence. 


\section{Chapter 2: A Statistical Analysis of the Causes of Rebel Military Strategy}

\section{The Theory}

To recapitulate, in the previous chapter I offered a theory of insurgent strategic adoption. I posit that different levels of urbanization have changed where and how rebel military organizations have fought in insurgencies. I argued that urbanization has concomitantly changed where rebels recruit and fight, as well as the availability of higher education. These changes have affected in the number and quality of individuals willing to participate in rebellion. The increasing numbers of well-educated and better-trained individuals that can take part in an insurgency account for changes in the military and organizational capacity of insurgent groups. These capabilities then determine the strategies that rebels adopt in war.

The statistical tests conducted below demonstrate that urbanization, education, and rebel organizational capacity all have positive and statistically significant effects on the probability that insurgents will adopt hybrid warfare instead of guerrilla warfare. Other factors such as foreign support and the number of groups fighting an incumbent in a given year are also found to affect insurgent strategic decisions. There is also a regional dynamic to how insurgents are fighting. I find little evidence to support the claims that incumbent regime type or military strategies influence which martial strategy insurgent groups adopt. 


\section{Hypotheses on Insurgent Strategy}

Based on the foregoing I develop and test several hypotheses on the effects of urbanization on insurgent strategic adoption. As discussed above, existing works on insurgency offer conflicting analyses with regards to the effect of urbanization on rebel military strategies. Some works suggest that if urbanization influences insurgent strategy, it will increase the likelihood of terrorism, due to the concentration of state power in urban areas. Moreover, there is an increased likelihood of detection if insurgents aggregate in cities, therefore, groups operating in urban environments should be small and prefer terrorism as a strategy (Marighella 1985). Other works claim that urbanization should have no discernable impact on how insurgents fight. Thus, guerrilla warfare should remain the sine qua non of rebel military activity in urban spaces and in fact across all types of terrain (Taw and Hoffman 1994; Chaliand 1982).

As discussed above urbanization is linked to changing insurgent military strategies through a series of causal linkages. The effects of urbanization are twofold. First, there is a relationship between expanding urban populations and higher levels of statewide education. Thus, I argue it is reasonable to expect that in more urbanized states insurgents will have greater access to widely skilled and educated individuals. Secondly, urbanization fundamentally changes the locations in which rebel groups coalesce, which affect collective action. These of factors are dually necessary, but individually insufficient to increase rebel organization and military capacity. However, higher levels of education alone should also increase the likelihood of terrorism as a strategy.

Hypothesis 1: Higher levels of urbanization increase the likelihood of both terrorism and hybrid warfare.

Hypothesis 2: Higher levels of educational attainment increase the probability that insurgents will adopt hybrid warfare and terrorism. 
The foregoing discussion has highlighted the fact that insurgent capacity influences how insurgents fight. A traditional proxy for insurgent capacity is overall organizational size. Smaller organizations will likely be forced to adopt terror due to limits on their organizational capacity, while larger organizations have more organizational capacity, more access to support—in terms of money, men, and material—and therefore should adopt a more complex military strategy, namely hybrid warfare (Gates 2002; Wood 2010).

Additionally, the number of rebel organizations competing in a given polity, should affect strategic adoption (Cunningham 2006; Cunningham et al. 2009; Shellman et al. 2010). In states where various organizations compete for control, the competition between organizations for recruits dictates how each will fight later (Weinstein 2007). Put in terms of the foregoing theory, where many small urban rebel organizations compete, each will have very limited capacity. As a result, where many rebel groups exit none will be capable of adopting hybrid warfare.

Contrastingly, where one group recruits from a mixed and heterogeneous population, it will have high levels of organization and military capacity, as it will be most likely to affected popular participation in collective action. In this instance, hybrid warfare will be the preferred military strategy.

Hypothesis 3: Where larger insurgent groups exist, rebels will be more likely to adopt hybrid warfare.

Another variable that may impact strategic choice is Rough Terrain, coded as percentage of area in a state that is mountainous. The relationship between terrain and onset or outcome of insurgency has been widely discussed in the literature on civil and insurgency (Fearon and Laitin 2003). As a result, terrain should have an independent effect on the strategy insurgents adopt.

Hypothesis 4: Groups fighting in rough or mountainous terrain will favor a guerrilla warfare strategy. 


\subsection{International Variables}

Incumbent regime type may also influence insurgent choice of strategy. That is, it has been hypothesized that democracies are vulnerable to the costs of war, and are particularly sensitive to the costs of asymmetric conflicts (Lyall 2010). Thus, strategies geared to raising costs and extending the length of a war may be used more often against democratic incumbents (Reiter and Stam 2002).

Hypothesis 5: Insurgents fighting more democratic states will be more likely to adopt terrorism.

Foreign support is also seemingly important to understanding how an insurgency is able to fund its operations and train its forces. In fact, works studying the outcomes of insurgency and civil war generally cite external support as key to insurgent victory (Byman et al. 2001). It is unclear however if foreign support is necessary or sufficient for an insurgent organization to adopt a particular strategic doctrine. Therefore, it is necessary to explore what role foreign support may play in determining which military strategy insurgents adopt. This analysis examines the effect of the combination of economic and military support as well as the availability of a safe haven in a neighboring state (Lyall and Wilson 2009).

Hypothesis 6: Foreign aid-in terms of financial and military support, and the provision of a safe haven-will be most likely in cases where rebels adopt hybrid warfare.

\subsection{Strategic Variables}

The way an incumbent fights has a determinant effect on how insurgents choose to fight. Following Arreguín-Toft (2005) insurgents should always prefer a strategy opposite to that of the incumbent they face. Thus, if the incumbent intentionally victimizes the civilian population insurgents should prefer guerrilla warfare as a strategy. 
Hypothesis 7: When incumbents intentionally victimize civilians, insurgents should prefer a traditional guerrilla warfare strategy.

\section{Empirics and Data Analysis}

\subsection{The Dependent Variable}

The empirical task of this chapter is to demonstrate that urbanization has played an instrumental role in affecting the types of military strategies that insurgents adopt in war. Following the typology I develop in Chapter 1, the dependent variable for this study (Strategy) is operationalized by examining both the weaponry and targets of a rebel organization in every year of insurgencies that began after 1984. A conflict is coded as hybrid where the insurgent employs heavy weapons against military targets; guerilla war is coded as a case in which insurgents use light weapons against military targets; cases of terrorism are coded when rebels use light weapons against civilian targets; and cases of indiscriminate violence are war years in which insurgents target civilians with heavy weapons. It should be noted that if an insurgent uses a heavy weapon once in any year of a conflict it is coded using heavy weapons for that year. I consider conflict years in which insurgent violence against civilians accounts for greater than 50 percent of total battle-related deaths, a year in which rebels are targeting civilians instead of the incumbent's military. In the dataset I compile, terrorism accounts for 61 observations, indiscriminate violence for 22, guerrilla warfare for 100, and hybrid warfare for 93 (as illustrated in Figure 1).

It is also worth noting that there is some regional variation in the occurrence of these military strategies. Thirty-three percent of the observations in this study (91/276) occur in subSaharan Africa. Of those, 46 percent are coded as guerrilla warfare, 24 percent hybrid warfare, 26 percent terrorism, with indiscriminate violence accounting for only 3 percent of African observations. Asia accounts for 31 percent of the total observations of this study, with 52 percent 
of Asian observations falling into the hybrid warfare category. In Asia only 33 percent of observations followed a traditional guerrilla strategy, with 9 and 6 percent of cases in the terrorism and indiscriminate violence categories, respectively. Seventy-four percent of observations in the former Soviet Union - a total of 27 observations occur in this region-are hybrid in nature. No cases of terrorism occur, there are 5 cases of indiscriminate violence (19\%), and two cases of guerrilla warfare (7\%). Finally, the Middle East and North Africa (MENA countries) accounted for seventy-three out of 276 observations (26\%). Of those, 40 percent were coded as terrorism, thirty-eight percent as guerrilla warfare, $12 \%$ as indiscriminate violence, and ten percent were coded as hybrid. In short, there is a significant amount of regional heterogeneity in the dataset.

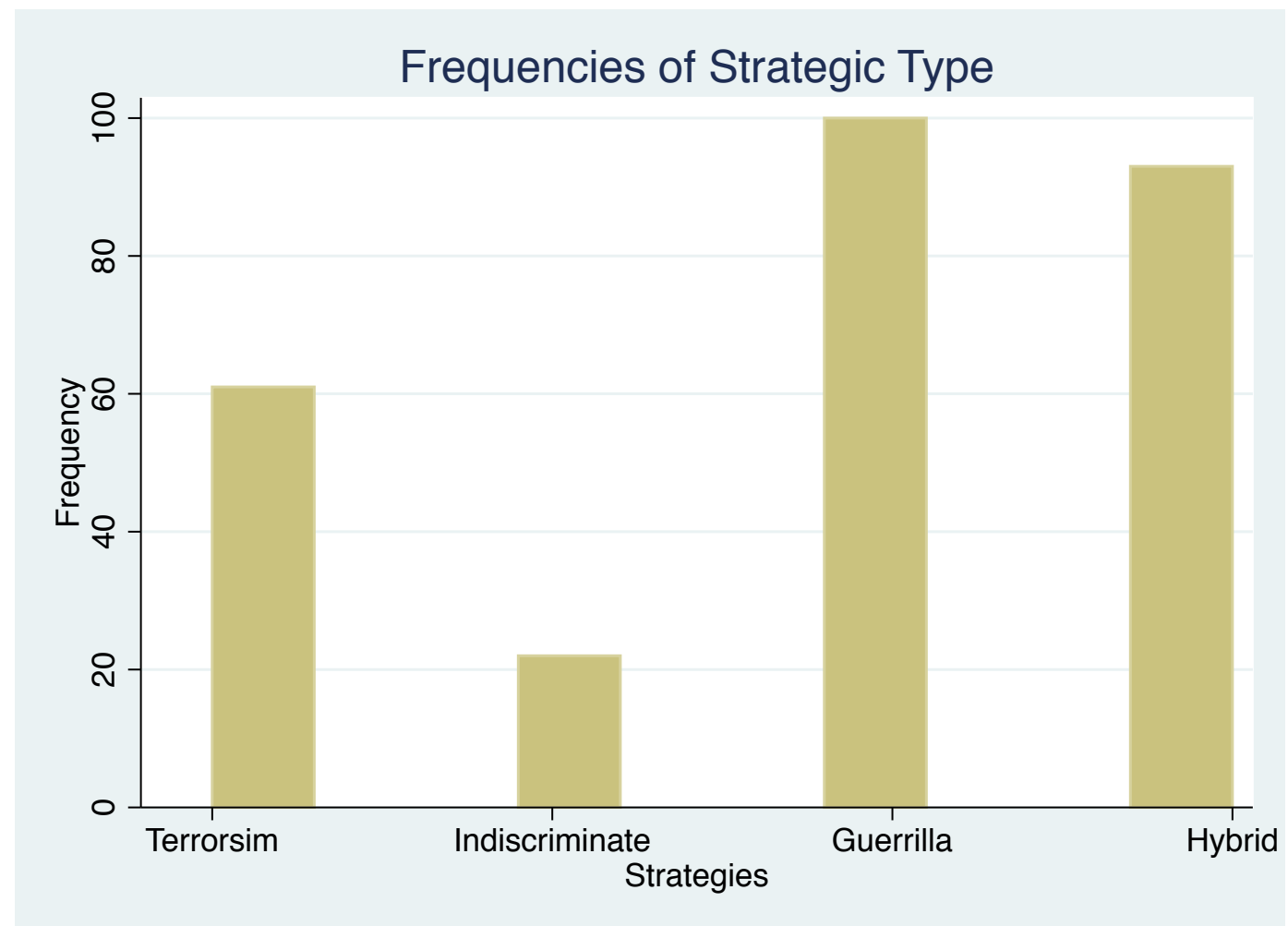

FIGURE 1. Frequency for each value of the dependent variable

The unit of observation for the dependent variable of this study is insurgency year. The dataset includes conflicts between 1984-2010. These data are used to analyze how insurgent 
organizations at war fought in every year of a conflict - after the conflict reached the 25 battlerelated death threshold. The criteria for identifying cases of insurgency are those used by Jason Lyall and Isaiah Wilson III (as discussed above). These insurgencies were cross-referenced with cases of civil war discussed by Kalyvas and Balcells (2010), Nicholas Sambanis (2004), Fearon and Laitin (2003), as well as the Uppsala Conflict Data Program (UCDP 2011) in order to determine the start date of armed conflict at the 25 battle-death threshold. In addition to establishing the initial year of conflict, the comparison assisted in ascertaining the end points of each conflict. Following Sambanis (2004) and UCDP (2011), a conflict is considered terminated when one of three conditions is met: when battle-deaths fall below 25 in a year; when a change of regime/transfer of power takes place; when an armistice is announced/signed.

The UCDP (2011) data is critical for this work as it identifies incidents of violence involving states and rebel groups that have caused a minimum of 25 battle-related fatalities in a given calendar year of a conflict. Moreover, the UCDP includes information on each rebel group active in every intrastate conflict since 1984. This information was used to generate the set of state-insurgent conflicts in every year of each conflict in the dataset. ${ }^{13}$ In sum, the dataset covers 42 conflicts with 77 rebel groups, yielding a total of 276 observations.

The size of the dataset for this work is constrained by data availability. That is, available data on one-sided violence against civilians begins in 1984. This limits the cases of insurgency that can be included, as it remains very difficult to accurately establish which groups in a given conflict were intentionally targeting civilians prior to 1984 . Moreover, the UCDP data on the size

\footnotetext{
${ }^{13}$ For example, the UCDP identifies the First Intifada in the Occupied Territories as containing, in various years, the Palestinian Liberation Organization (PLO), the Rejectionist Front, the Popular Front for the Liberation of Palestine (PFLP), Palestinian Islamic Jihad (PIJ), and HAMAS. In the dataset developed here, this conflict includes available information on civilian victimization and battle-related deaths, as well as weaponry for each group per conflict year; each group forms a unique dyad with the state for every year of the conflict. This allows for the analysis of how insurgent strategies within the conflict changed over time (Hultman 2007; Cunningham 2006 Cunningham et al. 2009).
} 
of insurgent groups is sparse prior to 1984 , limiting my ability to estimate the impact of insurgent capacity on the strategy dependent variable. These limitations however allow for more in-depth analysis of cases beginning after 1984, as every conflict year of each insurgency is included in the dataset. This facilitates a more nuanced understanding of variation within each conflict.

\subsection{Model and Variables}

\section{Table 1. Summary Statistics}

\begin{tabular}{lrrrrr}
\hline Variable & Mean & Standard deviation & Min & Max & \multicolumn{1}{c}{ Obs. } \\
\hline Strategy & 2.19 & 0.78 & 1 & 3 & 276 \\
Explanatory variables & & & & & \\
Educational Attainment & 15.23 & 13.15 & 0 & 51.58 & 267 \\
Urbanization Rate & 39.54 & 25.45 & 6.46 & 91.71 & 287 \\
Rough Terrain & 2.41 & 1.38 & 0 & 4.41 & 287 \\
Number of Groups & 4.04 & 3.44 & 2 & 20 & 287 \\
Insurgent Size & 15.42 & 30.19 & 0.075 & 300 & 275 \\
Support & 0.66 & 0.47 & 0 & 1 & 287 \\
Government vs. Civilians & 0.29 & 0.46 & 0 & 1 & 276 \\
Democracy & 0.87 & 5.34 & -9 & 10 & 267 \\
Control Variables & & & & & \\
Middle East & 0.25 & 0.44 & 0 & 1 & 287 \\
Eurasia & 0.39 & 0.48 & 0 & 1 & 287 \\
\hline
\end{tabular}

The statistical model employed to test the determinants of the four types of insurgent strategy is a multinomial logit analysis. This type of model allows for the comparison of several separate logit analysis against a common reference category (Gelman and Hill 2007; DeRouen Jr. and Sobek 2004). The dependent variable, strategy, is categorical, taking on a value of 1 for terrorism, 2 for guerilla warfare, and 3 for hybrid warfare. In the analysis conducted below guerilla warfare serves as the base category, against which all other strategies are compared.

It should be noted that indiscriminate violence is included in the hybrid category. ${ }^{14}$ This coding decision is made for two reasons. First, as discussed in chapter 1, I hypothesize that

\footnotetext{
${ }^{14}$ A similar decision was made in Kalyvas and Balcells (2010).
} 
indiscriminate violence is a transitory strategy, which groups adopt as they attempt to move towards the hybrid warfare strategy. Of the 22 observations of indiscriminate violence, all but 4 occur in the course of a conflict in which a rebel group employed hybrid warfare after employing indiscriminate violence. Of these 4 cases, two are observations from the Abkhaz Secessionist war, in which—as I argued in chapter 1 - the rebels made an abortive attempt at implementing hybrid warfare, but simply could not execute it.

Second, due to the limited number of observations of indiscriminate violence, there is little analytical value to keeping it as a discrete value of the strategy dependent variable. That is, no substantive information can be gleaned from such a limited number of cases. Thus, this category is folded into hybrid warfare. In order to test the affect of this coding decision indiscriminate violence is included in other values of the dependent variable and dropped entirely from the regression in the course of the robustness checks.

In each of the multinomial logit analyses below, observations are clustered by dyad identification. That is, it is likely that the observations in the dataset are independent across cases but are not necessarily independent within case. Put differently, the strategy employed by one insurgent group fighting a state in year two of an insurgency may not be completely unrelated to the strategy it employed in year one. Therefore, these yearly observations violate the assumption of independent observations. To adjust for this I cluster the data by dyad identification. The data are clustered by individual conflicts between states and insurgents per conflict year. Thus, in the case of the Iraqi insurgency (2003-2010) the conflict between the Iraqi state and the Mahdi Army is one cluster of observations, while the conflict between the state and Al Qaeda in Iraq is a separate cluster of observations (Long and Freese 2006). 


\subsection{Explanatory Variables}

Three novel explanatory variables are included in this analysis in order to better analyze the direct and indirect effects of urbanization on insurgent strategic choice: Educational Attainment, Urbanization Rate, and Insurgent Size. Urbanization Rate is measured using the United Nations World Urbanization Prospects Data (2009 revision). The measure includes estimates and projections of the total urban populations for every country over the period 19502050. Estimates of the percentage of a state's population living is urban centers occur in five year increments. Given that shifts occur slowly and vary little from year to year, I assume a constant rate of change from one observation to the next. Therefore, to obtain yearly estimates of the percentage of a state's population that is urban I use the following formula: $\left(\mathrm{t}_{2}-\mathrm{t}_{1}\right) / 5=\Delta \mathrm{t} ; \Delta \mathrm{t}$ is the percent of a state's population that is urban for every year of a conflict in the dataset. ${ }^{15}$

The measure of Educational Attainment is taken from the Barro-Lee Educational Attainment Dataset (2010). This dataset is based on census and survey information complied by UNESCO, Eurostat, and other sources. The data reports levels of educational attainment by members a state's population over the age of 15; the data is reported in five-year intervals (Barro-Lee 2010). I use only that data reporting the percentage of a state's population above the age of 15 that has completed secondary school. To obtain yearly estimates of educational attainment I use the formula above, $\left(t_{2}-t_{1}\right) / 5=\Delta t$, to measure the yearly change in a state's level of educational attainment. Higher levels of educational attainment are expected to be positively associated with hybrid warfare and terrorism.

Insurgent Size is the third variable of interest in this study. The size of an insurgent group is thought to be an effective proxy for a rebel group's military capacity (Wood 2010; Asal and

\footnotetext{
${ }^{15}$ A note should be made here regarding the definition of urban area. The UN does not have its own definition of "urban" population, instead the UN follows the definition used in each country included in the data. The definitions are generally those of national statistical offices carrying out the latest available census (UN 2009).
} 
Rethermeyer 2008). Thus, the larger an organization, the more likely it will be to maintain extensive logistical lines, have well-trained, well-educated fighters, and the expertise to employ the most modern weaponry, including heavy weapons. Insurgent Size is a categorical variable, where the total size of an insurgent group for every year of a conflict is divided by 1000 to help with interpretation. As a result, the variable ranges from 0.075 at its minimum to 300 at its maximum value (UCDP 2011; The Military Balance). Increasing rebel size should be positively related to a hybrid warfare strategy.

As mentioned above, I code and include variable for the number of groups fighting every year of a war. Number of Groups is a categorical variable with a minimum of 2 and a maximum of 20. This variable may change from year to year in a given conflict as groups merge, disband, are defeated, or splinter. The number of groups is expected to be positively associated with strategies targeting civilians, as the total number of rebel groups is inversely proportional to their individual size, thereby degrading each organization's military capacity.

A critical dummy variable (Government vs. Civilians) is included in the analysis to account for yearly state-sponsored civilian targeting. An incumbent intentionally massacring civilians is expected to be positively associated with guerilla warfare. This variable is measured by dividing targeted civilian deaths by battle-deaths - in this case, only deaths attributed to the incumbent (Valentino et al. 2004).

To test the effect of incumbent regime type I include the aggregate Polity IV (Marshall and Jeggers 2000) score of each state in the dataset (Democracy). The democracy variable should be positively correlated with terrorism as it is used to extend a war's timeframe and impose high costs on an incumbent — two factor thought to impact democracies most (Lyall 2010). 
Following Lyall and Wilson (2009), to test the effect of external support from a third party on strategic choice, a dummy variable (Support) is included as a measure of whether an insurgent received economic and military aid, as well as the use of sanctuary inside a neighboring state. Supports takes on a value of 1 if rebels received any type of external support, and 0 is no support was made available. Support is expected to be positively associated with hybrid warfare.

I include Rough Terrain in a separate model as a measure of the percentage of mountainous terrain in a given country. The natural logarithm of this variable is included in the regression. Following the existing literature, a large proportion of mountainous terrain should have a positive effect on guerrilla warfare compared to any other type of rebel strategy; rough terrain is traditionally thought to favor traditional guerrilla groups like the July 26 Movement in Cuba (Fearon and Laitin 2003). Rough Terrain is included in a separate regression because it is highly correlated with Urbanization Rate (-0.59), and should have the inverse effect of both Education and Urbanization Rate. That is, states with larges percentages of mountainous terrain should lack urban spaces, and as a result should have lower levels of educational attainment.

A set of control variables (Africa, Eurasia, as well as Middle East and North Africa) is included. Eurasia is employed to control for factors specific to both former Soviet states and Asian countries. I employ a combined dummy variable because Russia straddles the divide between Asia and Europe, with Asia beginning east of the Ural Mountains. More importantly, few observations occur west of Urals. Eurasia should be positively correlated with hybrid warfare. The Middle East and North Africa variable encompasses countries in the Middle East 


\begin{tabular}{|c|c|c|c|}
\hline & Model 1 & Model 2 & Model 3 \\
\hline \multicolumn{4}{|l|}{ 1. Terrorism } \\
\hline Educational Attainment & $\begin{array}{l}-0.041 \\
(0.036)\end{array}$ & & \\
\hline Urbanization Rate & & $\begin{array}{l}0.013 \\
(0.01)\end{array}$ & \\
\hline Rough Terrain & & & $\begin{array}{l}-0.114 \\
(0.17)\end{array}$ \\
\hline Number of Groups & $\begin{array}{l}-0.036 \\
(0.06)\end{array}$ & $\begin{array}{l}-0.021 \\
(0.05)\end{array}$ & $\begin{array}{l}-0.023 \\
(0.05)\end{array}$ \\
\hline Insurgent Size & $\begin{array}{l}0.040 \\
(0.03)\end{array}$ & $\begin{array}{l}0.036 \\
(0.03)\end{array}$ & $\begin{array}{c}0.036 \\
(0.03)\end{array}$ \\
\hline Support & $\begin{array}{l}-0.037 \\
(0.44)\end{array}$ & $\begin{array}{l}0.035 \\
(0.51)\end{array}$ & $\begin{array}{l}-0.115 \\
(0.44)\end{array}$ \\
\hline Government vs. Civilians & $\begin{array}{c}1.021^{* *} \\
(0.46)\end{array}$ & $\begin{array}{c}1.033^{* *} \\
(0.49)\end{array}$ & $\begin{array}{c}1.053 * * \\
(0.48)\end{array}$ \\
\hline Democracy & $\begin{array}{c}0.169 * * * \\
(0.06)\end{array}$ & $\begin{array}{c}0.182 * * * \\
(0.06)\end{array}$ & $\begin{array}{l}0.149 * * \\
(0.06)\end{array}$ \\
\hline Middle East \& North Africa & $\begin{array}{l}0.940 \\
(0.78)\end{array}$ & $\begin{array}{l}-0.041 \\
(0.78)\end{array}$ & $\begin{array}{l}0.253 \\
(0.54)\end{array}$ \\
\hline Eurasia & $\begin{array}{l}-1.329 \\
(0.95)\end{array}$ & $\begin{array}{c}-1.438^{*} \\
(0.87)\end{array}$ & $\begin{array}{l}-1.243 \\
(0.85)\end{array}$ \\
\hline Constant & $\begin{array}{l}-0.672 \\
(0.65) \\
\end{array}$ & $\begin{array}{c}-1.347^{*} \\
(0.69) \\
\end{array}$ & $\begin{array}{r}-0.667 \\
(0.58) \\
\end{array}$ \\
\hline 3. Hybrid Warfare & & & \\
\hline Educational Attainment & $\begin{array}{c}0.068^{* *} \\
(0.03)\end{array}$ & & \\
\hline Urbanization Rate & & $\begin{array}{c}0.069 * * * \\
(0.02)\end{array}$ & \\
\hline Rough Terrain & & & $\begin{array}{c}-0.817 * * * \\
(0.25)\end{array}$ \\
\hline Number of Groups & $\begin{array}{l}-0.113 \\
(0.08)\end{array}$ & $\begin{array}{c}-0.211 * * * \\
(0.07)\end{array}$ & $\begin{array}{c}-0.19^{* * *} \\
(0.06)\end{array}$ \\
\hline Insurgent Size & $\begin{array}{c}0.089 * * * \\
(0.02)\end{array}$ & $\begin{array}{c}0.079 * * * \\
(0.02)\end{array}$ & $\begin{array}{c}0.079 * * * \\
(0.02)\end{array}$ \\
\hline Support & $\begin{array}{c}1.386^{* *} \\
(0.56)\end{array}$ & $\begin{array}{c}1.565^{* * *} \\
(0.52)\end{array}$ & $\begin{array}{c}1.197 * * \\
(0.56)\end{array}$ \\
\hline Government vs. Civilians & $\begin{array}{c}1.330^{* *} \\
(0.65)\end{array}$ & $\begin{array}{l}0.318 \\
(0.65)\end{array}$ & $\begin{array}{c}0.544 \\
(0.64)\end{array}$ \\
\hline Democracy & $\begin{array}{l}0.085 \\
(0.06)\end{array}$ & $\begin{array}{l}0.089 \\
(0.06)\end{array}$ & $\begin{array}{l}0.026 \\
(0.07)\end{array}$ \\
\hline Middle East \& North Africa & $\begin{array}{l}0.072 \\
(0.98)\end{array}$ & $\begin{array}{c}-2.104^{*} \\
(1.16)\end{array}$ & $\begin{array}{r}1.077 \\
(0.73)\end{array}$ \\
\hline Eurasia & $\begin{array}{l}0.732 \\
(1.00)\end{array}$ & $\begin{array}{l}1.658^{*} \\
(0.95)\end{array}$ & $\begin{array}{c}2.442 * * * \\
(0.86)\end{array}$ \\
\hline Constant & $\begin{array}{c}-3.388^{* * * *} \\
(0.98) \\
\end{array}$ & $\begin{array}{c}-3.981 * * * \\
(1.09) \\
\end{array}$ & $\begin{array}{l}-0.265 \\
(0.85) \\
\end{array}$ \\
\hline Observations $(N)$ & 239 & 247 & 247 \\
\hline Wald $\operatorname{chi}^{2}(16)$ & 87.24 & 61.53 & 86.96 \\
\hline Pseudo $R^{2}$ & 0.328 & 0.302 & 0.289 \\
\hline
\end{tabular}


and North Africa, and should have a positive relationship with terrorism; Africa, here states in sub-Saharan Africa, is the reference category. ${ }^{16}$

The results of the multinomial regressions are presented in Tables 2-6, which display the estimated coefficients for terrorism, and hybrid war (with the exception of table 4 which presents the results of a bivariate logistical analysis). The coefficients in the multinomial logit tables must be interpreted with reference to the base category, guerrilla warfare. Guerrilla warfare is selected as the base category because it is thought to be the most prevalent form of insurgent strategy over time. Thus, all other strategies should be considered in reference to it. In table 2 I use the three novel variables discussed above to provide evidence for my theory of rebel strategic adoption. ${ }^{17}$

\subsection{Hybrid Warfare}

Most critically for this study Urbanization Rate, Educational Attainment, and Insurgent Size all provide support for the theoretical relationships posited above. The results of model 1 reveal a strong, significant, and robust effect of Educational Attainment on the probability that a rebel group will adopt hybrid warfare as opposed to a traditional guerrilla strategy. Holding all other variables at their sample mean, increasing educational attainment by one unit (one percent) increases the probability that insurgents will adopt hybrid warfare as opposed to guerrilla warfare by 1.8 percent. More, moving from the $50^{\text {th }}$ percentile (sample mean) to the $75^{\text {th }}$ percentile of educational attainment—one standard deviation—increases the likelihood of rebels adopting hybrid warfare as oppose to guerrilla warfare by 30 percent. These findings provide partial support for hypothesis 2 .

\footnotetext{
${ }^{16}$ Latin American and Europe are excluded as regional dummies because no observations in the dataset occur in these regions.

${ }^{17}$ It should be noted that the results presented in the table are robust to the inclusion of 29 country fixed effects.
} 
Pertinent examples of the effect of higher levels of educational attainment of rebel strategic adoption are evident in the cases of Sierra Leon and Sri Lanka. In the former case, the percentage of the population finishing secondary school was between 9 and 13 percent during the civil war (1991-2000), and insurgents employed either terrorism or guerrilla warfare. In Sri Lanka however, over the course of the twenty-five year civil war education rates increased from 25 percent in 1984 to 52 percent by the end of the conflict in 2009 . This increase in educational attainment occurred concurrently to a shift away from guerrilla, towards hybrid warfare by the Tamil Tigers.

Using Clarify, it is possible to generate a graph of the predicted probability of hybrid warfare being adopted as a military strategy as Educational Attainment ranges from its minimum to its maximum value ( 1 to 51 percent of the population finishing secondary school). In figure 2 Number of Groups, Insurgent Size, and Democracy (aggregate Polity IV score) are held at their means, rebels do receiving state support, and the state is killing civilians indiscriminately. The graph demonstrates (as expected) that as levels of education increase so does the likelihood that a rebel group will adopt hybrid warfare.

Using the same set of control variables, figure 3 demonstrates the affect of rising levels of Educational Attainment on the probability of rebels adopting a guerrilla warfare strategy. Interestingly, this graph demonstrates that the small likelihood of rebel adoption on guerrilla warfare decreases to a near zero probability as the levels of education within a state increase. 
Figure 2. Graph of Predicted Probabilities

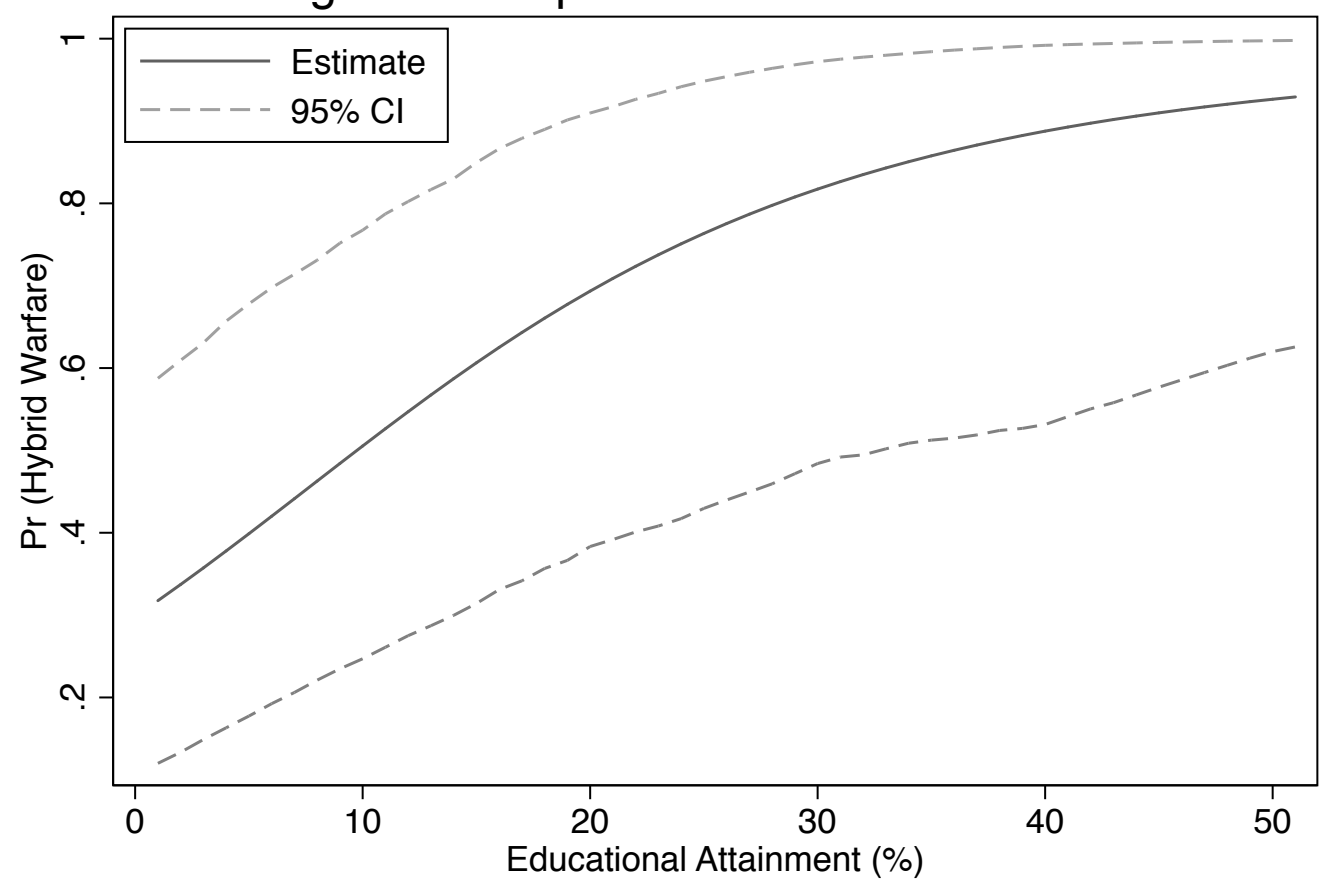

Figure 3. Graph of Predicted Probabilities

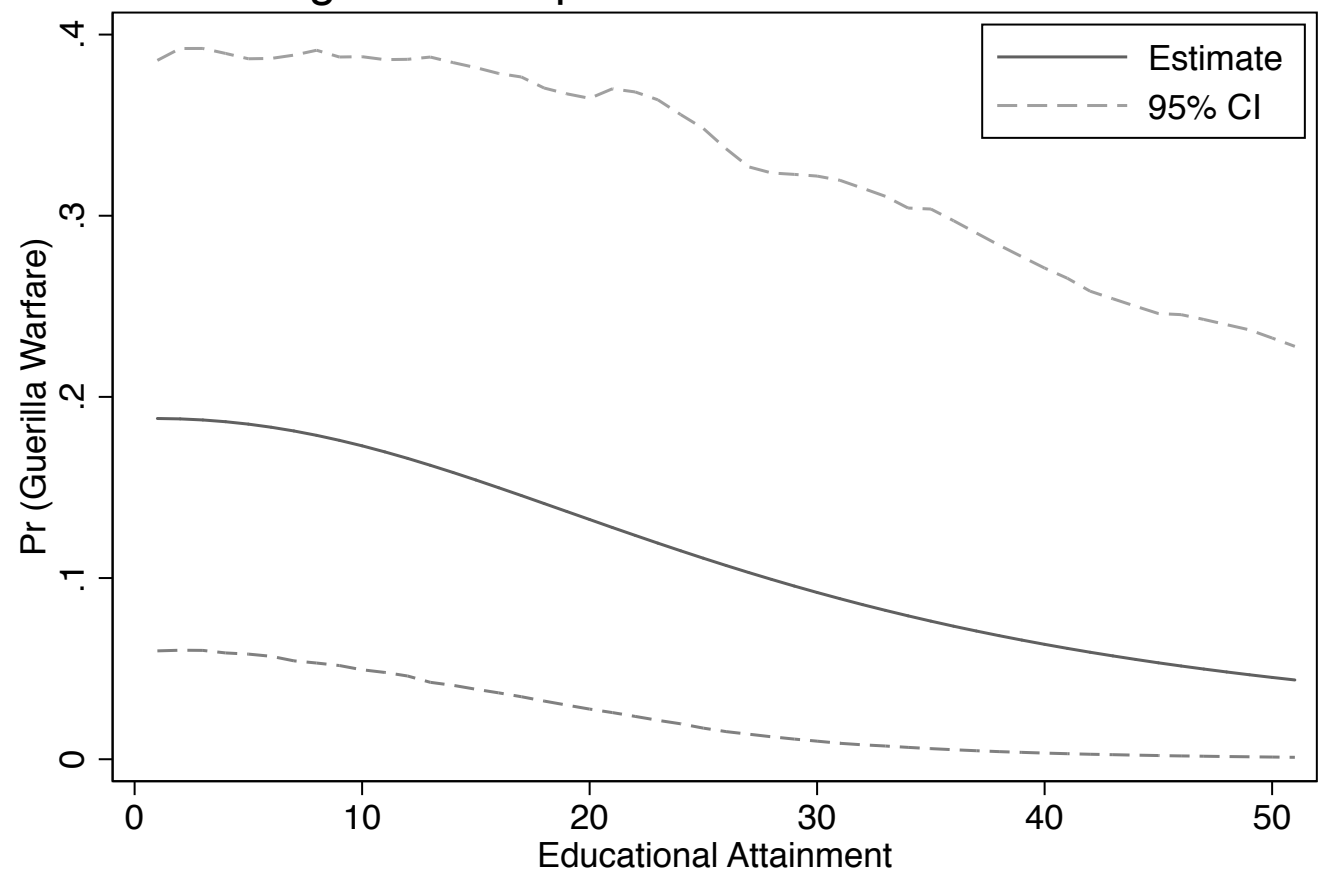

In model 2, and consistent with my expectations, Urbanization Rate has a positive, significant, and robust effect on insurgent adoption of hybrid warfare vis-à-vis guerrilla warfare. 
This constitutes a partial substantiation of hypothesis 1 . Turning to the marginal effect of Urbanization Rate, holding all other variables constant, a one percent increase in a state's urban population yields a 1 percent increase in the likelihood that insurgents will adopt hybrid warfare as compared to guerrilla warfare. Further examination of this relationship reveals that moving from the $50^{\text {th }}$ percentile of urbanization (sample mean) to the $75^{\text {th }}$ yields a 17 percent increase in the likelihood of hybrid warfare being adopted as compared to guerrilla warfare. Lebanese Hezbollah, where 86 percent of the population resides in urban spaces, employed hybrid warfare against Israel in their 2006 war. By contrast, Liberian insurgents (1989-1996) fighting at different times, and in different parts of the state — which is 40 percent urban — preferred traditional guerrilla warfare and terrorism. Both the effects of education and urbanization provide substantive support to hypothesis 1 .

Figures 4 and 5 are graphical representations of the predicted probabilities of rebels adopting hybrid warfare and guerrilla warfare, respectively, as Urbanization Rate ranges from its minimum to its maximum (1 to 99 percent of a state's population residing in urban areas). In these graphs, as in figures 2 and 3, Number of Groups, Insurgent Size, and Democracy (aggregate Polity IV score) are held at their means, rebels are receiving foreign support, and the state is killing civilians indiscriminately. 
Figure 4. Graph of Predicted Probabilities

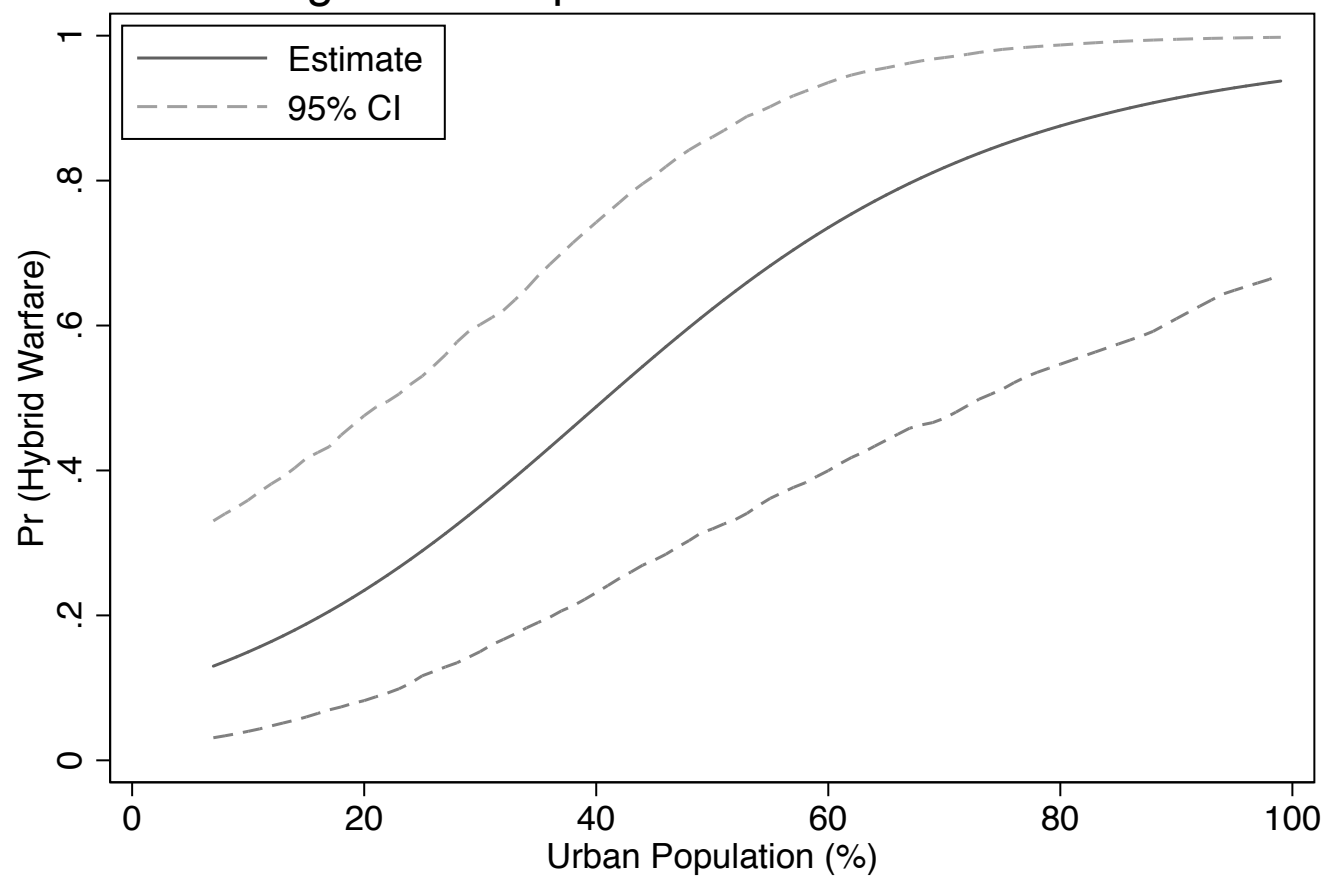

Figure 5. Graph of Predicted Probabilities

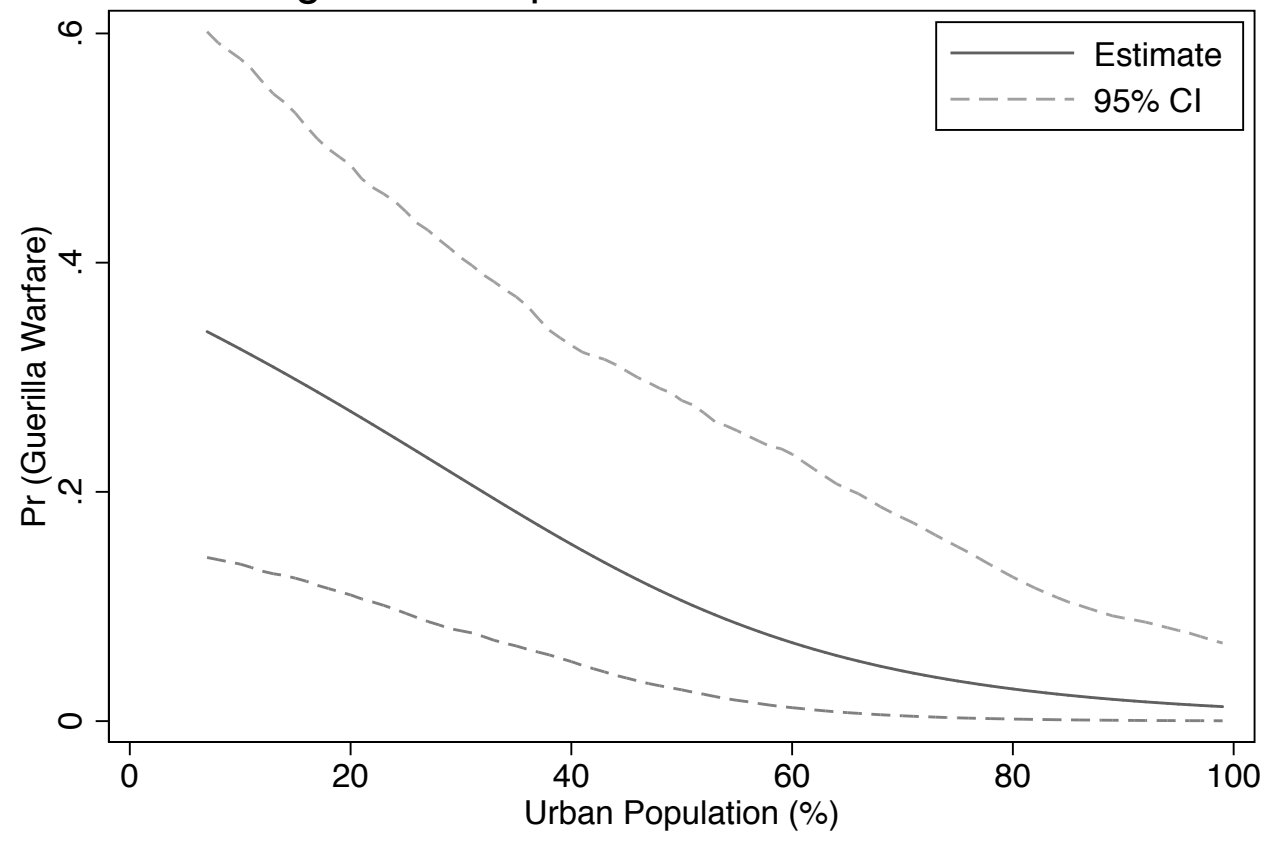


In an effort to further substantiate the findings of models 1 and 2, model 3 tests the effect of Rough Terrain on insurgent strategic adoption. Rough Terrain is the inverse measure of urbanization and education. Model 3 demonstrates, as expected, that rough terrain has a negative, significant, and robust effect on the probability of rebels adopting hybrid as opposed to guerrilla warfare. In fact Rough Terrain decreases the likelihood that rebels will adopt hybrid warfare as oppose to guerrilla warfare by 19 percent (holding all other variables at their sample means).

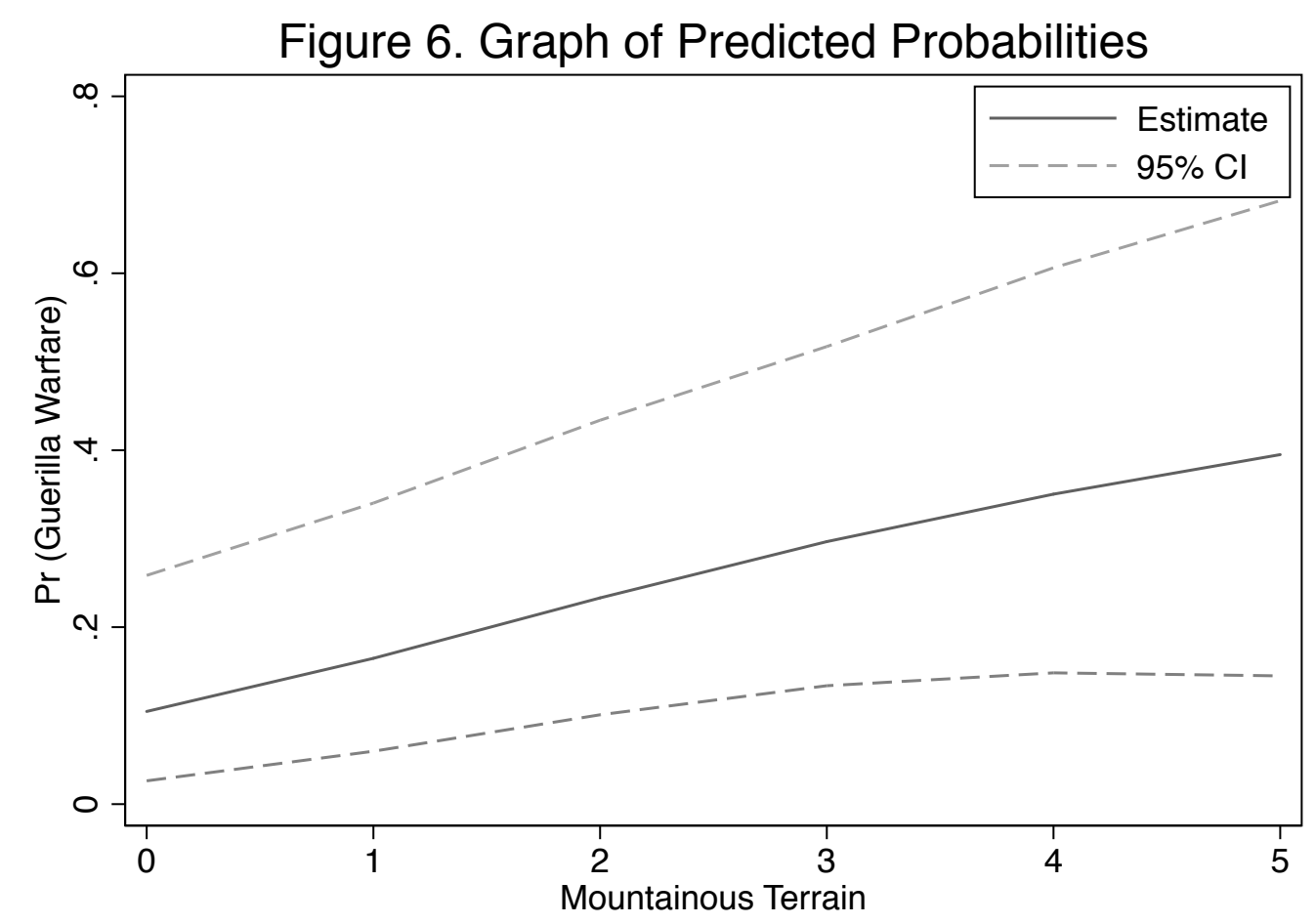


Figure 7. Graph of Predicted Probabilities

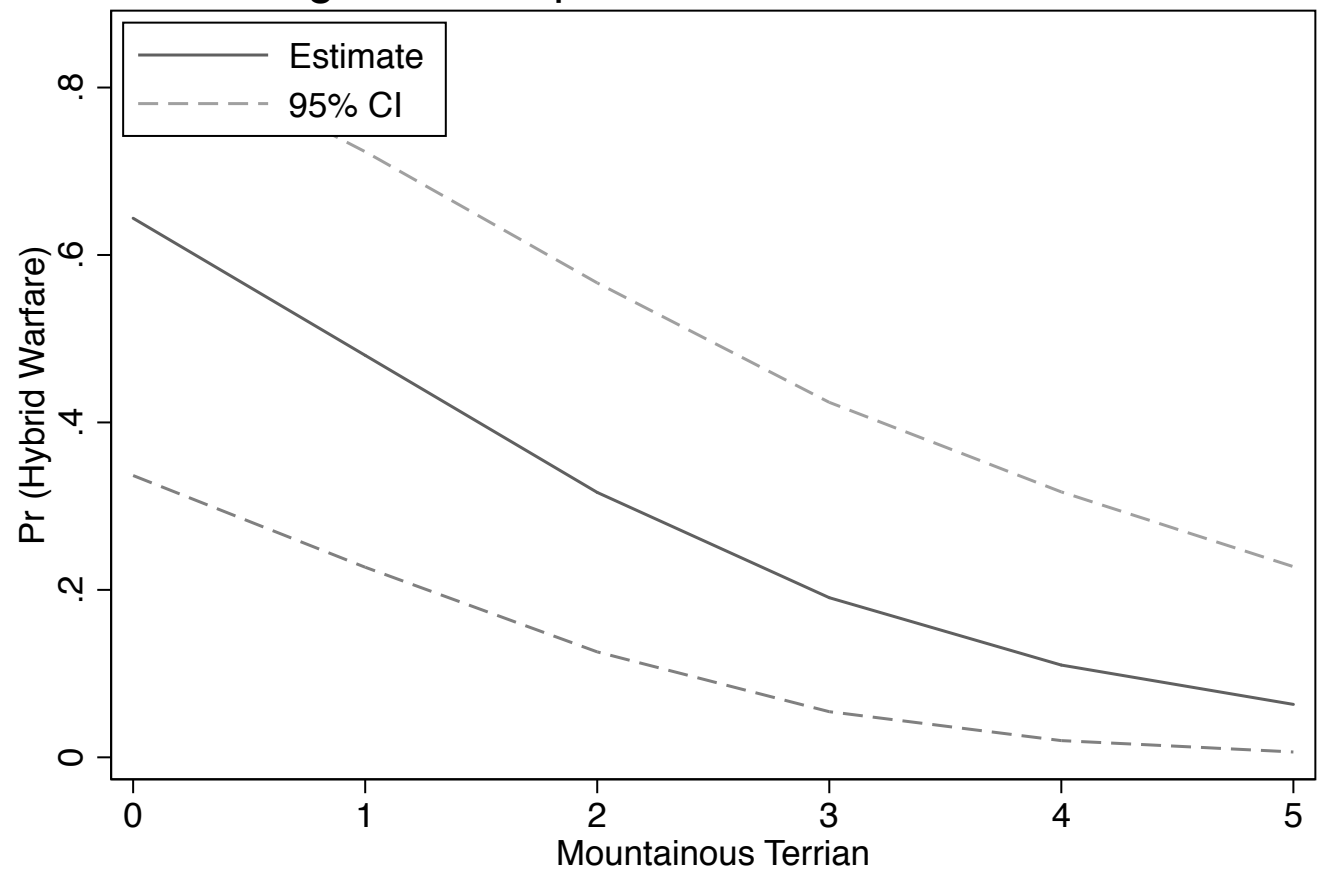

Figures 6 and 7 demonstrate the stark affect of Rough Terrain on the predicated probabilities of rebel adoption of guerrilla and hybrid warfare respectively. As expected, mountainous terrain has a positive and significant affect on the probability of rebels adopting guerrilla warfare when Number of Groups, Insurgent Size, and Democracy (aggregate Polity IV score) are held at their means, rebels receiving foreign support, and the state is killing civilians indiscriminately. Using the same set of controls, it is evident that Rough Terrain has a significantly negative affect on the predicted probability of rebels adopting hybrid warfare.

A pertinent example of this effect is Nepal, where over the course of the civil war (19962006) secondary school completion ranged from 4 to 6 percent and urbanization did not exceed 17 percent, both of which were nearly a standard deviation below the respective sample averages. Nepalese Maoists fought almost exclusively in the rural hinterlands of the state and followed a guerrilla warfare strategy. This finding is a substantiation of hypothesis 4 . 
All three models above also demonstrate that rebels are more likely to adopt the hybrid warfare strategy, as opposed to guerrilla warfare, as they increase in organizational and military capacity. Recalling that Insurgent Size is a proxy for military capacity, as the number of rebels increases, holding all else constant, insurgents are 1.4 percent more likely to adopt the hybrid military strategy as opposed to traditional guerrilla warfare in model 1; larger rebel groups are 1.1 percent more likely to adopt hybrid warfare is model 2 , and 0.7 percent more likely to adopt hybrid warfare in model 3. This finding supports hypothesis 3.

This finding is further supported by the fact that in models 2 and 3 increasing the number of groups decreases the probability that any insurgent organization in a given intrastate conflict will adopt hybrid warfare as compared to guerrilla warfare. Turning to the marginal effects of Number of Groups, as the number of rebel groups in a conflict increases (in model 2) the likelihood of any of them adopting hybrid warfare, as opposed to guerrilla warfare, decreases by $4.5 \%$. In model 3 , increasing the number of groups in a conflict decreases the likelihood of hybrid warfare vis-à-vis guerrilla warfare by $3.5 \%$. This negative effect of Number of Groups may substantiate the claim that as the number of groups in a conflict increases, all groups have decreased organizational and military capacity, thereby making them more likely to adopt guerrilla warfare as opposed to hybrid warfare. In model 1, Number of Groups has the correct negative sign, which supports the lack of capacity hypothesis, however the variable is insignificant, raising a question about its sensitivity.

In support of hypothesis 6, external support for insurgent groups, in terms of military and economic aid as well as the provision of safe haven, has a substantive, significant, and robust impact on rebel strategic choice. External support has a positive and significant impact on the likelihood that rebel groups will chose the hybrid strategy as opposed to guerrilla warfare. In 
fact, the choice for the hybrid strategy is 32 percent more likely than the guerilla strategyholding all other variables constant — when insurgents are receiving military and economic aid, as well as being afforded access to safe haven (model 1). In model 2 the affect is similar, with foreign support increasing the likelihood of hybrid warfare adoption, as opposed to guerrilla warfare by 33 percent. In model 3 the affect of foreign support is somewhat muted, as it increases the likelihood of hybrid warfare vis-à-vis guerrilla warfare by 20 percent.

\subsection{Terrorism}

In examining the factors that affect the probability of rebels adopting a terrorism strategy, several findings are apparent. First and foremost, few of the variables of interest for this study are significant in any of the regressions. Therefore, I cannot offer a conclusive discussion of how Educational Attainment, Urbanization Rate, or Rough Terrain affect the likelihood that insurgents will adopt terrorism. The lack of a finding for these variables may be due to several issues. A small number of terrorism observations may impact the results. This explanation seems reasonable given both the growing literature and data on the relationship between education and individual propensities for taking part in terrorist activities (Krueger and Malečková 2003; Krueger 2007; Berman et al. 2011; Kavanagh 2011). Alternatively, it is possible that terrorist strategy is not affected by terrain, or social network location/type, and is therefore not a comparable military strategy.

Second, an incumbent's regime type has a consistently significant, robust, and positive effect on insurgent preference for terrorism, lending support to hypothesis 5. A one-unit increase in an incumbent's Polity IV score (in model 1) increases the probability of rebels employing terrorism in place of guerrilla warfare by 1.7 percent. As democratic norms and practices increase, the likelihood of terrorism being the preferred rebel military strategy instead of 
guerrilla warfare also rises by $2.5 \%$ and $3 \%$ in models 2 and 3 respectively. This finding suggests that there may be an interaction between regime type and terrorism as a military strategy. That is, given my contention in chapter 1 that terrorism is geared towards sapping incumbent resolve for conflict by imposing high political costs through indirect confrontations, democratic states may be viewed as more susceptible to indirect attacks. Democracies may be viewed by insurgents as more willing to make concessions to groups employing terrorism as opposed to guerrilla warfare. Alternatively, given Downes's (2008) finding that democracies are will target civilians in war, terrorism may be the insurgent's proportional response.

Third, the foregoing analysis provides supporting evidence for hypothesis 6 . In all three models I find that the intentional victimization of civilians by incumbents increases the likelihood that rebels will adopt terrorism as opposed to guerrilla warfare. In model 1, insurgents are $7.7 \%$ more likely to adopt terrorism versus guerrilla warfare when the state intentionally victimizes civilians. Intentional civilian victimization by incumbents increases the probability of terrorism versus guerrilla warfare by $15 \%$ in model 2 and $18.7 \%$ in model 3 . It should be noted however that this finding is endogenous, in that it is unclear if intentional civilian victimization by states is causing this rebel strategic preference or vice-versa. However, it is nonetheless clear that state and rebel military strategies interact in some fashion.

The above findings regarding the influence of democracy and intentional civilian victimization by incumbents suggest that insurgents prefer a tit-for-tat military strategy in some cases, contra Arreguín-Toft (2001, 2005). Moreover, these findings offer an interesting implication for Downes's (2008) work on democratic civilian victimization. That is, when democracies do intentionally target civilians in war it is likely that this strategy will lead, at least in the short term, to a higher loss of life for both rebel and regime supporters. 
The above analyses were re-estimated with a variable measuring yearly GDP per capita (Gleditsch 2002). This variable was included to test the effect of wealth on rebel strategic choice. The logic here being: potential rebels must forego income-earning employment to participate in a rebellion (Collier and Hoeffler 2004; Berman et al. 2011). In states where individual incomes are higher, individuals should be less willing to participate in rebellion which shrinks the pool of rebel fighters, thereby truncating insurgent military capacity, and as a consequence limiting how rebels can chose to fight. Thus, as GDP per capita rises rebels should have less organizational and military capacity, which should drive them to pursue terrorism as their military strategy.

Relatedly, higher GDP per capita suggests that the state will be able to collect greater tax revenues, which would increase its ability to develop financial, police, administrative, and military institutions that would be useful in suppressing a rebellion. Therefore, in states with higher GDP per capita insurgents would be constrained in the type of military strategies they could adopt; in this case higher GDP per capita would most likely result in rebel adopting terrorism, to avoid state detection. When the models above are re-estimated including the measure of GDP per capita, the variable has neither a statistically, nor substantively, significant impact on the results.

Additionally the regressions were re-estimated with Lyall and Wilson's (2009) scaled mechanization variable, to test for an interaction between incumbent military orientation and that of insurgents. That is, in many cases insurgents employ the weapons that they are able to capture from their opposing incumbent, and as such, as states increase the technological sophistication of their militaries there could be a concomitant rise in insurgent use of technologically sophisticated weaponry. For the purposes of this work, many newer hi-tech weapons fall into the heavy weapon category. Consequently, as incumbents mechanize, there should be an associated 
increase in the likelihood of insurgents adopting hybrid warfare. Contrary to this theoretical expectation, I find that state mechanization has neither a substantive nor a significant impact on rebel strategic adoption.

\section{Robustness Checks I}

Table 3 presents several robustness checks for the findings in Table 2. Models three through five replicate the regressions in models one through three without regional controls, while still clustering observations by dyad identification. The findings in Table 3 are generally consistent with those in Table 2. Most importantly for the purposes of this work, the sign and significance of Education, Urbanization Rate, Rough Terrain, and Insurgent Size remain largely unchanged; Rough Terrain decreases is significance from the 0.01 level in model 3 to the 0.5 level in model 6.

The most notable difference between the two tables is in model 4. In this case, it is evident that without controlling for regional variation, increasing the percent of the population residing in urban areas increases the likelihood that insurgents will adopt either terrorism or hybrid warfare instead of guerrilla warfare. The odds of this occurring, when not taking regional variations into account are quite small however, with the probability of hybrid warfare increasing by only 0.3 percent, and that of terrorism by 0.01 percent. This decrease in substantive significance may be attributed to the fact that Africa as a region, which represent both the largest number of observations in the dataset, and has the lowest levels of urbanization, is suppressing this variable's effect. 


\begin{tabular}{|c|c|c|c|}
\hline & Model 4 & Model 5 & Model 6 \\
\hline \multicolumn{4}{|l|}{ 1. Terrorism } \\
\hline Educational Attainment & $\begin{array}{l}-0.007 \\
(0.03)\end{array}$ & & \\
\hline Urbanization Rate & & $\begin{array}{c}0.026^{* *} \\
(0.01)\end{array}$ & \\
\hline Rough Terrain & & & $\begin{array}{l}-0.309 \\
(0.21)\end{array}$ \\
\hline Number of Groups & $\begin{array}{l}-0.080 \\
(0.05)\end{array}$ & $\begin{array}{c}-0.062 * * \\
(0.03)\end{array}$ & $\begin{array}{c}-0.067^{* *} \\
(0.03)\end{array}$ \\
\hline Insurgent Size & $\begin{array}{l}0.040 \\
(0.03)\end{array}$ & $\begin{array}{l}0.041 \\
(0.03)\end{array}$ & $\begin{array}{c}0.038 \\
(0.03)\end{array}$ \\
\hline Support & $\begin{array}{l}0.109 \\
(0.43)\end{array}$ & $\begin{array}{l}0.223 \\
(0.45)\end{array}$ & $\begin{array}{l}0.041 \\
(0.42)\end{array}$ \\
\hline Government vs. Civilians & $\begin{array}{c}1.486^{* * *} \\
(0.44)\end{array}$ & $\begin{array}{c}1.181^{* *} \\
(0.49)\end{array}$ & $\begin{array}{c}1.285^{* * *} \\
(0.47)\end{array}$ \\
\hline Democracy & $\begin{array}{c}0.163^{* *} \\
(0.06)\end{array}$ & $\begin{array}{c}0.144^{* * *} \\
(0.05)\end{array}$ & $\begin{array}{l}0.129^{* *} \\
(0.06)\end{array}$ \\
\hline Constant & $\begin{array}{l}-1.23 * \\
(0.69) \\
\end{array}$ & $\begin{array}{c}-2.252^{* * *} \\
(0.82) \\
\end{array}$ & $\begin{array}{l}-0.446 \\
(0.56) \\
\end{array}$ \\
\hline \multicolumn{4}{|l|}{ 3. Hybrid Warfare } \\
\hline Educational Attainment & $\begin{array}{c}0.082 * * * \\
(0.03)\end{array}$ & & \\
\hline Urbanization Rate & & $\begin{array}{c}0.031^{* *} \\
(0.01)\end{array}$ & \\
\hline Rough Terrain & & & $\begin{array}{c}-0.413^{*} \\
(0.22)\end{array}$ \\
\hline Number of Groups & $\begin{array}{l}-0.097 \\
(0.08)\end{array}$ & $\begin{array}{c}-0.231 * * * \\
(0.08)\end{array}$ & $\begin{array}{c}-0.240 * * * \\
(0.07)\end{array}$ \\
\hline Insurgent Size & $\begin{array}{c}0.098^{* * *} \\
(0.02)\end{array}$ & $\begin{array}{c}0.083^{* * * *} \\
(0.02)\end{array}$ & $\begin{array}{c}0.082^{* * * *} \\
(0.02)\end{array}$ \\
\hline Support & $\begin{array}{c}1.407 * * * \\
(0.52)\end{array}$ & $\begin{array}{c}1.428^{* * * *} \\
(0.51)\end{array}$ & $\begin{array}{c}1.244^{* *} \\
(0.55)\end{array}$ \\
\hline Government vs. Civilians & $\begin{array}{l}1.040^{*} \\
(0.56)\end{array}$ & $\begin{array}{l}0.060 \\
(0.52)\end{array}$ & $\begin{array}{c}0.184 \\
(0.54)\end{array}$ \\
\hline Democracy & $\begin{array}{l}0.075 \\
(0.05)\end{array}$ & $\begin{array}{l}0.116^{*} \\
(0.06)\end{array}$ & $\begin{array}{l}0.097 \\
(0.06)\end{array}$ \\
\hline Constant & $\begin{array}{c}-3.340^{* * *} \\
(0.93) \\
\end{array}$ & $\begin{array}{c}-1.992 * * \\
(0.79) \\
\end{array}$ & $\begin{array}{r}0.203 \\
(0.79) \\
\end{array}$ \\
\hline Observations (N) & 239 & 247 & 247 \\
\hline Wald $\operatorname{chi}^{2}(16)$ & 72.25 & 66.54 & 47.03 \\
\hline Pseudo $R^{2}$ & 0.289 & 0.221 & 0.214 \\
\hline
\end{tabular}

The change in sign of the urbanization variable in the terrorism category is also a critical difference from the initial set of regressions. This change can also be attributed to regional bias; 
the Middle East is one of the most urbanized regions in the dataset, and it accounts for over 48 percent of the cases of terrorism in the analysis. Moreover, African state are the most rapidly urbanizing states in the world, and also account for 39 percent of terrorism observations in the data. Therefore, model 4 demonstrates that the omission of regional dummy variables, which control for the urban terrorism bias in both Africa and the Middle East, has had an important effect on the terrorism value of the dependent variable.

When omitting regional controls from the analysis, the nature of the incumbent state maintains its affect on the probability of insurgents adopting terrorism as a strategy. That is, if the government systematically targets civilians there is an 11 percent increase in the likelihood that rebels will adopt terrorism versus guerrilla warfare in model 4, holding all other variables constant. The probability of terrorism being adopted in place of guerrilla warfare increases to $17 \%$ in models 5 and 6 when the state targets civilians intentionally. If an incumbent government is a democracy rebels will be $1.8 \%$ more likely to adopt terrorism as opposed to guerrilla warfare in model 4 , and $1.2 \%$ more likely in models 5 and 6 .

It should also be noted that the Number of Groups variable has statistical significance in both the terrorism and hybrid warfare categories of models 5 and 6 . Thus, when discounting the effect of regional variation, and holding all other variables constant increasing the number of groups in an insurgency by three (a standard deviation) there is a 2.4 percent decrease in the likelihood that insurgents will adopt terrorism as opposed to guerrilla warfare (model 5). This effect is more pronounced when for hybrid warfare, in that increasing the number of groups in a rebellion decrease the probability of hybrid warfare being adopted in place of guerrilla warfare by $4.4 \%$. In model six the decrease in the likelihood of terror and hybrid warfare versus guerrilla warfare is $2.3 \%$ and $4.6 \%$ respectively. 


\section{Robustness Checks II}

Table 4 presents a series of regressions with a dichotomous dependent variable, where a zero (a negative outcome) is obtained when hybrid warfare is not employed, and a 1 occurs in cases where insurgents do adopt hybrid warfare. In effect, this set of regressions compares hybrid warfare against all other types of unconventional warfare. In these models hybrid warfare is obtained in 115 cases while other forms of unconventional military strategy constitute the remaining 161 observations. Most critically for this work, the key variables of Education, Urbanization Rate, and Rough Terrain remain statistically and substantively significant with the correct signs. As do the variables Insurgent Size and Support.

\begin{tabular}{|c|c|c|c|}
\hline & Model 7 & Model 8 & Model 9 \\
\hline Educational Attainment & $\begin{array}{c}0.074 * * * \\
(0.03)\end{array}$ & & \\
\hline Urbanization Rate & & $\begin{array}{c}0.058^{* * * *} \\
(0.02)\end{array}$ & \\
\hline Rough Terrain & & & $\begin{array}{c}-0.771 * * * \\
(0.24)\end{array}$ \\
\hline Number of Groups & $\begin{array}{l}-0.084 \\
(0.08)\end{array}$ & $\begin{array}{c}-0.185^{* *} \\
(0.08)\end{array}$ & $\begin{array}{c}-0.178 \\
(0.07)^{* * *}\end{array}$ \\
\hline Insurgent Size & $\begin{array}{c}0.069 * * * \\
(0.02)\end{array}$ & $\begin{array}{c}0.060 * * * \\
(0.02)\end{array}$ & $\begin{array}{c}0.061 * * * \\
(0.02)\end{array}$ \\
\hline Support & $\begin{array}{c}1.308^{* * *} \\
(0.52)\end{array}$ & $\begin{array}{c}1.453 * * * \\
(0.53)\end{array}$ & $\begin{array}{c}1.194 * * \\
(0.53)\end{array}$ \\
\hline Government vs. Civilians & $\begin{array}{l}0.786 \\
(0.62)\end{array}$ & $\begin{array}{l}-0.207 \\
(0.55)\end{array}$ & $\begin{array}{l}0.001 \\
(0.56)\end{array}$ \\
\hline Democracy & $\begin{array}{l}0.007 \\
(0.05)\end{array}$ & $\begin{array}{l}0.007 \\
(0.07)\end{array}$ & $\begin{array}{l}-0.039 \\
(0.06)\end{array}$ \\
\hline Middle East and North Africa & $\begin{array}{l}-0.466 \\
(0.91)\end{array}$ & $\begin{array}{c}-2.343^{*} \\
(1.25)\end{array}$ & $\begin{array}{l}0.707 \\
(0.69)\end{array}$ \\
\hline Eurasia & $\begin{array}{l}1.118 \\
(0.88)\end{array}$ & $\begin{array}{c}2.038^{* *} \\
(0.89)\end{array}$ & $\begin{array}{c}2.827 * * * \\
(0.78)\end{array}$ \\
\hline Constant & $\begin{array}{l}-3.690 \\
(0.97)\end{array}$ & $\begin{array}{l}-3.882 \\
(1.03)\end{array}$ & $\begin{array}{l}-0.702 \\
(0.85)\end{array}$ \\
\hline $\begin{array}{l}\text { Observations (N) } \\
\text { Wald chi }{ }^{2}\end{array}$ & $\begin{array}{c}239 \\
46.77\end{array}$ & $\begin{array}{c}247 \\
28.68\end{array}$ & $\begin{array}{c}247 \\
34.96\end{array}$ \\
\hline Pseudo R ${ }^{2}$ & 0.386 & 0.335 & 0.329 \\
\hline
\end{tabular}

${ }^{*} p<.1 ; * * p .05 ; * * * p<.01$ (robust standard errors clustered on dyad in parentheses) 
Similar to the results in Table 2, and as evidenced by the findings in Table 3, there is a regional component to the findings. That is, Eurasia is positively and significantly correlated to the occurrence of hybrid warfare, as opposed to all other forms of warfare.

\section{Robustness Checks III}

Table 5 presents another lens through which the data can be examined. In this case the dependent variable, Strategy, is recoded as a categorical variable taking on three values, as in Tables 2 and 3. However, in these models, instead of incorporating the indiscriminate violence value of the dependent variable into the hybrid warfare category, it is included in the terrorism measure. As a result, in this set of regressions there are 83 cases of terrorism, 100 cases of guerrilla warfare, and 93 observations of hybrid warfare instead of 61, 100, and 115 respectively - a 22 observation change.

The sign and significance of all the key variables in these regressions reflect the findings of the previous tests, with some marginal changes. In models 10-12 as in models 1-3 Educational Attainment, Urbanization Rate, and Rough Terrain all remain substantively and statistically significant. In practical terms, Education Attainment and Urbanization Rate both still increase the likelihood that insurgents will adopt hybrid warfare instead of guerrilla warfare by 0.8 and 0.4 percent respectively (when holding Number of Groups, Insurgent Size, and Democracy at their means, and assuming that rebels have foreign support and the state is intentionally victimizing civilians). Rough Terrain decreases the likelihood that rebels will adopt hybrid warfare in place of guerrilla warfare by $7 \%$.

As with previous models, Insurgent Size remains substantively and statistically significant. In model 10 increasing group size leads to an increase in the probability that rebels 
will adopt hybrid warfare in place of guerrilla warfare by $0.6 \%$. In model 11 the likelihood of hybrid warfare being adopted increases by $0.5 \%$, and in model 12 there is a $0.2 \%$ increase.

The most glaring difference between these models and those in table 2 is that Support is no longer substantively or statistically significant. Foregoing research has consistently demonstrated that foreign support has a critical impact on insurgencies (Lyall and Wilson 2009; Kalyvas and Balcells 2010; Byman et al. 2001), yet these models do not reflect this finding. Due to this change in the statistical and substantive significance of the Support variable, it can be argued that indiscriminate violence should be included in the hybrid warfare category of the dependent variable. That is, in all previous models Support is both substantively and statistically significant in increasing the probability that insurgents will adopt hybrid warfare instead of guerrilla warfare. Given that this is not the case in models $10-12$, it is reasonable to suspect that these models are incorrectly specified. Since the only difference between models 10-12 and the base models above (1-3) is the recoded dependent variable, I argue that indiscriminate violence is correctly placed in the hybrid warfare value of the dependent variable. However, in table 6 I examine the effect of dropping indiscriminate violence as a value of the dependent variable completely.

Additionally, as in the base models, Government vs. Civilians and Democracy and both associated with an increase in the likelihood that rebels will adopt terrorism as opposed to guerrilla warfare. While this finding is endogenous, the relationship is robust to several different model specifications. 


\begin{tabular}{|c|c|c|c|}
\hline & Model 10 & Model 11 & Model 12 \\
\hline \multicolumn{4}{|l|}{ Terrorism } \\
\hline Educational Attainment & $\begin{array}{l}0.024 \\
(0.03)\end{array}$ & & \\
\hline Urbanization Rate & & $\begin{array}{c}0.031 * \\
(0.02)\end{array}$ & \\
\hline Rough Terrain & & & $\begin{array}{c}-0.198 \\
(0.17)\end{array}$ \\
\hline Number of Groups & $\begin{array}{r}-0.072 \\
(0.06)\end{array}$ & $\begin{array}{c}-0.098 * * * \\
(0.03)\end{array}$ & $\begin{array}{c}-0.093 * * * \\
(0.03)\end{array}$ \\
\hline Insurgent Size & $\begin{array}{l}0.048 \\
(0.03)\end{array}$ & $\begin{array}{l}0.045 \\
(0.03)\end{array}$ & $\begin{array}{c}0.041 \\
(0.03)\end{array}$ \\
\hline Support & $\begin{array}{l}0.697 \\
(0.50)\end{array}$ & $\begin{array}{c}0.934^{*} \\
(0.52)\end{array}$ & $\begin{array}{c}0.744 * \\
(0.45)\end{array}$ \\
\hline Government vs. Civilians & $\begin{array}{c}1.306^{* * *} \\
(0.44)\end{array}$ & $\begin{array}{c}1.056 \\
(0.46)^{* *}\end{array}$ & $\begin{array}{c}1.101 * * \\
(0.44)\end{array}$ \\
\hline Democracy & $\begin{array}{c}0.204 * * * \\
(0.06)\end{array}$ & $\begin{array}{c}0.185 \\
(0.06)^{* * *}\end{array}$ & $\begin{array}{c}0.169 * * * \\
(0.06)\end{array}$ \\
\hline Middle East and North Africa & $\begin{array}{l}0.159 \\
(0.74)\end{array}$ & $\begin{array}{r}-0.612 \\
(0.79)\end{array}$ & $\begin{array}{l}0.571 \\
(0.54)\end{array}$ \\
\hline Eurasia & $\begin{array}{c}-0.884 \\
(0.96)\end{array}$ & $\begin{array}{l}-0.427 \\
(0.72)\end{array}$ & $\begin{array}{l}-0.324 \\
(0.71)\end{array}$ \\
\hline Constant & $\begin{array}{c}-1.587 * * \\
(0.74) \\
\end{array}$ & $\begin{array}{c}-2.259 * * * \\
(0.83)\end{array}$ & $\begin{array}{r}-0.805 \\
(0.61) \\
\end{array}$ \\
\hline \multicolumn{4}{|l|}{ Hybrid Warfare } \\
\hline Educational Attainment & $\begin{array}{c}0.073 * * \\
(0.03)\end{array}$ & & \\
\hline Urbanization Rate & & $\begin{array}{c}0.055^{* * *} * \\
(0.02)\end{array}$ & \\
\hline Rough Terrain & & & $\begin{array}{c}-1.035 * * * \\
(0.28)\end{array}$ \\
\hline Number of Groups & $\begin{array}{r}-0.051 \\
(0.08)\end{array}$ & $\begin{array}{c}-0.192 * * \\
(0.09)\end{array}$ & $\begin{array}{c}-0.172 * * \\
(0.07)\end{array}$ \\
\hline Insurgent Size & $\begin{array}{c}0.085^{* * *} * \\
(0.02)\end{array}$ & $\begin{array}{c}0.076^{* * *} \\
(0.02)\end{array}$ & $\begin{array}{c}0.082 * * * \\
(0.02)\end{array}$ \\
\hline Support & $\begin{array}{c}0.359 \\
(0.58)\end{array}$ & $\begin{array}{l}0.852 \\
(0.55)\end{array}$ & $\begin{array}{l}0.464 \\
(0.56)\end{array}$ \\
\hline Government vs. Civilians & $\begin{array}{l}0.574 \\
(0.68)\end{array}$ & $\begin{array}{l}-0.095 \\
(0.69)\end{array}$ & $\begin{array}{l}-0.221 \\
(0.81)\end{array}$ \\
\hline Democracy & $\begin{array}{l}-0.025 \\
(0.06)\end{array}$ & $\begin{array}{l}0.036 \\
(0.07)\end{array}$ & $\begin{array}{c}-0.072 \\
(0.07)\end{array}$ \\
\hline Middle East and North Africa & $\begin{array}{l}-1.157 \\
(1.09)\end{array}$ & $\begin{array}{c}-1.925 * \\
(1.08)\end{array}$ & $\begin{array}{c}0.785 \\
(0.86)\end{array}$ \\
\hline Eurasia & $\begin{array}{l}0.548 \\
(0.93)\end{array}$ & $\begin{array}{l}1.409^{*} \\
(0.84)\end{array}$ & $\begin{array}{c}3.023 * * * \\
(0.89)\end{array}$ \\
\hline Constant & $\begin{array}{c}-2.661 * * * \\
(0.82)\end{array}$ & $\begin{array}{c}-3.022 * * * \\
(0.93)\end{array}$ & $\begin{array}{l}0.219 \\
(0.78) \\
\end{array}$ \\
\hline Observations (N) & 239 & 247 & 247 \\
\hline Wald chi $i^{2}$ & 82.20 & 74.57 & 90.31 \\
\hline Pseudo $R^{2}$ & 0.334 & 0.306 & 0.326 \\
\hline
\end{tabular}


Furthermore, the change in the Support variable in this set of models lends further credence to the hypothesis that indiscriminate violence and hybrid warfare are related. That is, my reasoning for including indiscriminate violence in the hybrid warfare category was that the former can be seen as a unsuccessful attempt to adopt the latter as a strategy (Blanford 2011). The substantive changes in the regression results provide some circumstantial evidence for this theoretical intuition.

\section{Robustness Checks IV}

In table 6 Strategy is recoded to exclude the indiscriminate violence value of the dependent variable entirely, as a separate way to test the robustness of the findings in table 2 . Therefore, in this set of models the dependent variable takes on only three values, terrorism, guerrilla warfare, and hybrid warfare. Due to the exclusion of the indiscriminate violence category the sample size shrinks by 22 observations, with 61 observations of terrorism, 100 cases of guerrilla warfare, and 93 instances of hybrid warfare. The results in table 6 , further substantiate the findings in table 2. Educational Attainment, Urbanization Rate, and Rough Terrain maintain their correct signs and their statistical significance, as does Insurgent Size.

More, the substantive impact of Educational Attainment and Urbanization Rate is consistent with previous models. A one percent increase in secondary school completion leads to a 1.7 percent increase in the likelihood that insurgents will adopt hybrid warfare as opposed to guerrilla warfare. Similarly, a standard deviation increase in a state's urban population leads to a 0.8 percent increase in the probability that an insurgent group will adopt hybrid as opposed to guerrilla warfare. 


\begin{tabular}{|c|c|c|c|}
\hline & Model 13 & Model 14 & Model 15 \\
\hline \multicolumn{4}{|l|}{ Terrorism } \\
\hline Educational Attainment & $\begin{array}{c}-0.0367 \\
(0.03)\end{array}$ & & \\
\hline Urbanization Rate & & $\begin{array}{l}0.013 \\
(0.02)\end{array}$ & \\
\hline Rough Terrain & & & $\begin{array}{l}-0.112 \\
(0.17)\end{array}$ \\
\hline Number of Groups & $\begin{array}{c}-0.041 \\
(0.06)\end{array}$ & $\begin{array}{l}-0.034 \\
(0.05)\end{array}$ & $\begin{array}{l}-0.025 \\
(0.05)\end{array}$ \\
\hline Insurgent Size & $\begin{array}{l}0.034 \\
(0.03)\end{array}$ & $\begin{array}{l}0.033 \\
(0.03)\end{array}$ & $\begin{array}{c}0.032 \\
(0.03)\end{array}$ \\
\hline Support & $\begin{array}{l}0.177 \\
(0.48)\end{array}$ & $\begin{array}{l}0.226 \\
(0.51)\end{array}$ & $\begin{array}{l}0.057 \\
(0.47)\end{array}$ \\
\hline Government vs. Civilians & $\begin{array}{c}1.109^{* *} \\
(0.45)\end{array}$ & $\begin{array}{c}1.178^{* *} \\
(0.47)\end{array}$ & $\begin{array}{c}1.178 * * * \\
(0.45)\end{array}$ \\
\hline Democracy & $\begin{array}{c}0.187 * * * \\
(0.06)\end{array}$ & $\begin{array}{c}0.197 * * * \\
(0.06)\end{array}$ & $\begin{array}{c}0.165^{* * * *} \\
(0.06)\end{array}$ \\
\hline Middle East and North Africa & $\begin{array}{l}0.994 \\
(0.74)\end{array}$ & $\begin{array}{l}0.079 \\
(0.79)\end{array}$ & $\begin{array}{l}0.419 \\
(0.53)\end{array}$ \\
\hline Eurasia & $\begin{array}{l}-1.406 \\
(1.02)\end{array}$ & $\begin{array}{l}-1.497 \\
(0.92)\end{array}$ & $\begin{array}{l}-1.326 \\
(0.90)\end{array}$ \\
\hline Constant & $\begin{array}{l}-0.819 \\
(0.72)\end{array}$ & $\begin{array}{c}-1.514 * * \\
(0.77) \\
\end{array}$ & $\begin{array}{l}-0.811 \\
(0.66)\end{array}$ \\
\hline \multicolumn{4}{|l|}{ Hybrid Warfare } \\
\hline Educational Attainment & $\begin{array}{c}0.074 * * \\
(0.03)\end{array}$ & & \\
\hline Urbanization Rate & & $\begin{array}{c}0.068 * * * \\
(0.02)\end{array}$ & \\
\hline Rough Terrain & & & $\begin{array}{c}-1.027 * * * \\
(0.29)\end{array}$ \\
\hline Number of Groups & $\begin{array}{l}-0.051 \\
(0.08)\end{array}$ & $\begin{array}{c}-0.202 * * \\
(0.08)\end{array}$ & $\begin{array}{c}-0.171^{* *} \\
(0.07)\end{array}$ \\
\hline Insurgent Size & $\begin{array}{c}0.089 * * * \\
(0.02)\end{array}$ & $\begin{array}{c}0.085 * * * \\
(0.03)\end{array}$ & $\begin{array}{c}0.091 * * * \\
(0.02)\end{array}$ \\
\hline Support & $\begin{array}{l}0.507 \\
(0.60)\end{array}$ & $\begin{array}{l}1.052^{*} \\
(0.57)\end{array}$ & $\begin{array}{l}0.494 \\
(0.59)\end{array}$ \\
\hline Government vs. Civilians & $\begin{array}{l}0.648 \\
(0.70)\end{array}$ & $\begin{array}{l}-0.208 \\
(0.73)\end{array}$ & $\begin{array}{l}-0.209 \\
(0.78)\end{array}$ \\
\hline Democracy & $\begin{array}{l}-0.021 \\
(0.06)\end{array}$ & $\begin{array}{l}0.047 \\
(0.07)\end{array}$ & $\begin{array}{l}-0.066 \\
(0.07)\end{array}$ \\
\hline Middle East and North Africa & $\begin{array}{l}-1.079 \\
(1.08)\end{array}$ & $\begin{array}{c}-2.325^{*} \\
(1.21)\end{array}$ & $\begin{array}{c}0.757 \\
(0.86)\end{array}$ \\
\hline Eurasia & $\begin{array}{l}0.581 \\
(0.92)\end{array}$ & $\begin{array}{l}1.711^{*} \\
(0.94)\end{array}$ & $\begin{array}{c}3.055^{* * *} * \\
(0.91)\end{array}$ \\
\hline Constant & $\begin{array}{c}-2.888^{* * *} * \\
(0.93) \\
\end{array}$ & $\begin{array}{c}-3.703 * * * \\
(1.12)\end{array}$ & $\begin{array}{l}0.103 \\
(0.80) \\
\end{array}$ \\
\hline Observations (N) & 219 & 226 & 226 \\
\hline Wald $c h i^{2}$ & 80.16 & 58.04 & 78.16 \\
\hline Pseudo $R^{2}$ & 0.364 & 0.335 & 0.345 \\
\hline
\end{tabular}


In terms of Rough Terrain, as a state's terrain gets more mountainous there is a 9.5\% decrease in the probability that rebels will adopt hybrid warfare instead of guerrilla warfare. As always, Insurgent Size has both a statistically and substantively significant impact on the probability that insurgents will chose hybrid warfare over guerrilla warfare. In model I this variable increases the probability of hybrid warfare adoption by $1.1 \%$; in model 2 by $0.8 \%$; in model 3 by $0.4 \%$.

Interestingly however, Support once again looses all statistical significance in this set of regressions. This may suggest several things. First, the measure of support being used in this study is very sensitive to model specification, which may mean it is a poor measure of support. Alternatively, this may suggest that foreign support is not a determining factor in insurgent strategic choice. Finally, the changes in the foreign support variable may mean that this set of models is incorrectly specified, which artificially suppresses the statistical impact of Support on insurgent strategic choice.

In total, the empirical analysis supports my theoretical expectations. Urbanization and education are contributing to the rebel strategic decision to eschew civilian victimization while increasing their ability to wield sophisticated weaponry against opposing state militaries. Consequently, rebels are adopting hybrid as opposed to guerrilla warfare where conditions permit.

This analysis demonstrates that rebels are fighting incumbents in urban settings with heavy weaponry, whilst eschewing civilian victimization. Urban areas are traditionally thought to be the graveyards of insurgencies; it has been argued historically that rebels will disperse and rely on terrorism when fighting in urban states. The above analysis undermines this traditional 
thinking. Simply put, rebels have begun to adapt their military strategies to the global trend of urbanization.

Additionally, the sensitivity tests conducted here suggest that the findings in, and specification of, models 1-3 are robust and replicable. Based on the foregoing, I also find that incorporating the indiscriminate violence value of the dependent variable into the hybrid warfare category in models 1-3 does not bias my results. In fact, this coding may be a more accurate representation of the macro-level factors affecting insurgent strategic decisions.

\section{Conclusions}

Given that recent research has demonstrated that insurgents are winning a greater percentage of their conflicts with more powerful states over time (Lyall and Wilson 2009; Arreguín-Toft 2001, 2005), it is critical to understand why insurgents are choosing to fight in areas thought to provide incumbents with decisive strategic advantage — cities. To analyze this phenomenon I have offered a novel set of statistical tests to determine if the causes of rebel strategic choice are rooted in urbanization, educational attainment, rough terrain, and organizational capacity. Far from destroying insurgent military capacity, rebels are taking advantage of the positive externalities of the political economy of urbanization, and are developing new military methods for achieving their political objectives.

The above findings fit with new research on the process of insurgencies. Berman et al. (2011) have shown that there is a negative correlation between unemployment and violence directed at government forces. Their findings are consistent with one of two potential theoretical explanations, but the authors cannot distinguish between the alternatives. For Berman et al., unemployment and violence against government forces are uncorrelated because either, as local economic conditions worsen, information on rebels is cheaper and so incumbents can buy more 
information, thereby undermining insurgent operations. Or, techniques to enhance securitybuilding barriers and security check points—-work to inhibit economic activity and targeted insurgent violence, pushing insurgents to kill civilians.

I show that highly educated, and thus, individuals more likely to be employed, are increasingly likely to use targeted violence against the state, as opposed to guerrilla warfare or violence against civilians. This finding is due to the fact that urbanization is driving constitutive changes in insurgent military capacity. Urbanization is affecting insurgent levels of education and technical abilities, which is increasing rebel military capacity, which in turn has allowed insurgents to adopt a more sophisticated military strategy, hybrid warfare. In other words, I offer a clear theory of why unemployment would not be correlated with violence against state military forces.

The foregoing analysis has also demonstrated why there is variation in the types of military strategies adopted by insurgents in war. This variation can be attributed to the effects of urbanization on the nature of social networks within a given state. I show that rebels have begun to take advantage of the statewide benefits of urbanization. These findings run counter to the conventional wisdom on insurgency and civil war.

In analyzing insurgent strategy I also contribute to the growing literature on the process of intrastate conflicts, that is, how insurgencies and civil wars are fought, a subject matter generally ignored in the work on the onset, outcome, and duration of civil wars and insurgencies. Most importantly, I demonstrate that urbanization, the major demographic trend in the developing regions of the globe will have a determinative effect on how future intrastate conflicts are fought. 


\section{Chapter 3: Hezbollah and Hybrid Warfare}

\section{Introduction}

I argue that the process of urbanization is fundamentally changing how insurgencies are conducted. The location in which a rebellion develops impacts the quality of recruits as well as the number of people willing to take part in costly and violent collective action. The quality and quantity of recruits are the jointly necessary but individually insufficient components of rebel capabilities. High organizational and military capabilities facilitate the adoption of hybrid warfare (the most sophisticated unconventional military strategy), low capabilities lead to rebel adoption of guerrilla warfare in rural areas, and terrorism in urban spaces.

The purpose of this chapter to explain how a hybrid organization develops. I demonstrate that Lebanese Hezbollah's (literally "The Party of Allah" of "Party of God") hybrid warfare strategy is a direct result of increasing urbanization and rising levels of educational attainment amongst Lebanon's Shi'a population. To this end I trace the process through which The Party of God developed its hybrid warfare capability from 1982 onwards. The chapter culminates in a detailed discussion of Hezbollah's 2006 war with Israel in which the latter effectively mobilized its hybrid warfare strategy. This case study of Hezbollah demonstrates that the key to Hezbollah's ascendance as the preeminent hybrid warfare organization is its diverse recruitment base, which is a product of significant demographic changes that have occurred in Lebanon since 
the early 1970's. This diversely skilled and educated support base has increased Hezbollah's organizational and military capabilities over time, and has facilitated The Party of God's adoption of the most sophisticated unconventional military strategy, hybrid warfare.

My argument will be falsified if urbanization and education do not rise as Hezbollah's military strategy evolves. Additionally, if Hezbollah does not expand, in terms of its size and the diversity of its membership over time, my argument will have been proved false. That is, in order to substantiate my theoretical claims Hezbollah must (a) grow larger over time; (b) increasingly recruit individuals with higher levels of educational attainment; (c) fight in both cities and rural areas.

\section{Hezbollah and Hybrid Warfare}

On July 12, 2006, after a six year lull in major military engagements between Israel and Hezbollah (following the unilateral withdrawal of Israeli troops from Southern Lebanon in 2000) the secretary-general of Hezbollah, Sheik Sayed Hassan Nasrallah, "launched the most daring assault of his tenure as Hezbollah's leader: the capture of two Israeli soldiers in a raid that left eight other Israeli soldiers dead. He called the attack 'Operation Truthful Promise'” (Shatz 2006). This attack precipitated a thirty-four day war between Israel and Hezbollah ( July 12August 14,2006 ) in which Israel failed to win the decisive victory that its military doctrine dictates (Ben-Horin and Posen 1981).

There are several interesting facts that have come to light in the wake of this war. First, the war demonstrated that Hezbollah is capable of fielding a highly trained and well-organized military force with an intricate understanding of combined arms warfare (Biddle 2004; Biddle and Friedman 2008). Second, Hezbollah operates freely Lebanon's Shi'a areas: southern Lebanon, the southern suburbs of Beirut (known as the "al-Dahiya al-Janubiya"), Tyre, and the 
Beqaa valley. Third, due to its organizational infrastructure Hezbollah is at once capable of surviving heavy bombardment by the Israeli Air Force (IAF), and fighting to deny the Israeli Defense Forces (IDF) its strategic goals in combat. In fact, Hezbollah demonstrates the ability to inflict a high number of casualties the IDF's top infantry forces; Hezbollah ambushed and inflict heavy casualties on Israel's "elite Golani Infantry Brigade" in a battle for control of Bint Jbial (Smith 2006).

Fourth, Hezbollah has fundamentally altered its military strategy over time. At outset of the Israeli military occupation of southern Lebanon Hezbollah employed suicide bombings against military targets in a guerrilla warfare strategy, but over time The Party of God has shifted to a hybrid warfare military strategy. By the 2006 war, Hezbollah had entirely abandoned its guerilla warfare strategy and the use of suicide bombers. Instead, it adapted to using heavy weaponry in positional defense of key areas in Southern Lebanon—closely mirroring the conventional military strategy of defense in depth—in order to attrite mobile Israeli tank forces. Moreover, Hezbollah consciously worked to limit Israeli ability to use helicopters in close air support (Byman 2003; Friedman and Biddle 2008).

Hezbollah is thus the paradigmatic example of an insurgent organization successfully adopting a hybrid military strategy. This chapter therefore reviews the evolution of Hezbollah's strategy through its 2006 war with Israel. I analyze how the dispersion of the Lebanon's Shi'a community across the state, in both urban and rural spaces, has driven Hezbollah's strategic evolution. More, the chapter demonstrates that the changes in Hezbollah's strategic doctrine have occurred concomitantly with increasing urbanization and rising levels of educational attainment.

\section{Lebanon and Hezbollah}

Hezbollah is a Shi'a political and military organization that began to coalesce in 1982. 
Four factors drove the creation of Hezbollah: the changing socioeconomic position of the Lebanese Shi'a population in the latter third of the twentieth century; Imam Musa al-Sadr and his 1978 disappearance; the Israeli-Palestinian conflict and the former's invasion of Southern Lebanon in 1982; and the 1979 Iranian Revolution (Norton 1987; Ranstorp 1997).

\subsection{Demographics and the Origins of Social Mobilization}

Hezbollah coalesced as a direct result of the political mobilization of Lebanon's Shi'a population. This political mobilization was due to the changing social, demographic, and political conditions of Lebanon's Shi'a community. The Lebanese political system was founded in 1943 on confessional politics. Lebanon is a religiously heterogeneous state encompassing Sunni and Shi'a Muslims, Druze, Maronites, as well as other Christian traditions. At its founding, the Lebanese political system was designed to represent the political interests of these various confessional groups. To that end, and based on a 1932 census, political and administrative posts were allocated among the various religious communities according to their numbers within the population. Consequently, the most populous (in 1932) Maronites hold the office of the President, Sunnis the office of Prime Minister, and Shi'a the Speaker of Parliament (Harik 1996; Norton 1987).

As Lebanon's population has grown since independence, the proportions of the confessional groups have changed. In 1932, the major confessional groups were broken down as follows: Maronite Christians accounted for 30 percent of the Lebanese population, Sunni Muslims 20\%, Shi'a 18\%, and Greek Orthodox 11\% (Maktabi 1999). By 1986 these proportions had shifted dramatically with the Shi'a accounting for nearly thirty percent of the total population of the state (Norton 1987). This figure is buttressed by more recent, but unofficial, statistical data which indicates that "27 percent of the population is Sunni Muslim, 27 percent 
Shi'a Muslim, 21 percent Maronite Christian, eight percent Greek Orthodox" with the final 17 percent of the population being made up of Druze and other Christina denominations (Department of State 2010). Other figures estimate that the Shi'a population went from $26.2 \%$ in 1975 to $30.8 \%$ in 1984 (a year following Hezbollah's founding), to at least $40 \%$ of the total Lebanese population in 2005 (Mazran 2009).

These marked demographic shifts are the result of two factors. First, the Lebanese Muslim population has higher-than-average birth rates, while few from these (two) confessional groups settle outside of the state. Second, Maronite Christians have emigrated in large numbers over the last sixty years (Norton 1987, Department of State 2010). Consequently, since World War II, the Shi'a population in Lebanon has grown faster than any other confessional group. This population growth, with a lack of concomitant growth in political representation (until the 1989 Ta'if agreement) created a population willing to participate in political protest for better political representation and greater access to governmental services (Shanahan 2005, 107; Hazran 2009). The Shi'a resent the fact that, although the size of their confessional group has surpassed that of the Maronite and Sunni populations, they have received no comparable increase in political influence, as was required by the state's confessional formula (Harik 1999, 44). This created an opportunity for the Shi's to be mobilized as a group.

\subsection{2 (Un)Employment and Urbanization as the Basis for Mobilization}

Internal migration of the Shi'a due to economic pressures accompanied the population shifts discussed above. Traditionally, Lebanon's Shi'a population has live in the rural areas of southern Lebanon and the Beka'a Valley in the northeast. However, between 1959 and 1974 the percentage of the total labor force employed in agriculture within Lebanon declined from $48.9 \%$ percent to 18.9 percent. This drop was due to stagnating prices and caps on production for local, 
labor intensive, cash crops (tobacco and sugar beets) and an increase in capital intensive citrus farming (Salim 1978). Due to this transformation in agricultural production, large numbers of rural Shi'a began migrating to Beirut and its suburbs, taking jobs in the services sector, "which increased its share of the [urban] labor force from $39 \%$ to $63 \%$ over the same period" (Norton 1987, 22; Shanahan 2005, 33).

Additionally, violence associated with the Palestinian-Israeli conflict in the south pushed more Shi'a towards Beirut and out of their traditional villages. From 1978 forward the Israeli military began periodic military operations in southern Lebanon in their ongoing conflict with the Palestinian Liberation Organization; this culminated in the Israeli occupation of Southern Lebanon from 1982-2000. Israeli military activity in the south drove the migration of poorly educated rural Shia into cities (mainly southern Beirut and Tyre). This influx of southern Shia to urban areas created a large community of people who were both outside of the traditional patronclient power relationships in Beirut, and looking for political representation and leadership (Shanahan 2005, 34; Ajami 1986, 123).

According to UN estimates, between 1975 and 2010 the urban population of Lebanon increased-from 66.98 to 87.24 percent - by 20.3 percent, and average annual change of 0.58 percent. In real terms, the Lebanon's urban population increased by an estimated 1,935,091people between 1975 and 2010 (United Nations 2013) ${ }^{18}$ Before the onset of the civil war in 1975 Beirut itself accounted for roughly seventy-five percent of Lebanon's urban population, and it drew some $75 \%$ of rural émigrés. "By the early 1970 s, Beirut's annual rate of growth was estimated at 4.0 percent" (Khalaf 1987; Salim 1978). Shiites have accounted for more than half of the inhabitants of Beirut and its suburbs since 1975 (Hazran 2009).

\footnotetext{
${ }^{18}$ This estimate is based on the United Nations population estimates of 2,765,000 for 1975 and 4,341,000 for 2010 (2013).
} 
These population shifts created a large and dispersed, but intimately connected Shi'a population. That is, the links between the newly urbanized and their former villages were not broken by urban migration, "the intensity and increasing scale of 'urbanization' as a physical phenomena... [was not] accompanied by a proportional degree of 'urbanism' as a way of life" (Khalaf 1987). Rural émigrés lived in cities but were not of cities, as they did not establish new exclusively urban lives, in fact they preferred to hold on to their traditional rural social networks (Khalaf and Kongstad 1973).

The Shi'a population held onto their traditional rural relationships for several reasons. First, Shi'a were excluded from the patron-client relationships in the city, which served the Sunni population almost exclusively. Removed from these urban clientelist relationships, the Shi'a were forced to rely on ties to their home villages and the political patrons (zu'ama) that serviced them (Norton 1987, 27; Shanahan 2005). The practical implication of this reliance on old rural patronage networks for the provision of services was: while urban populations grew in terms of population, older kinship ties, communal loyalties, and confessional identities remained. "In many respects Beirut...[another major cities became] more a 'mosaic' of distinct urban communities [distinguished by confessional identity] than a 'melting pot' of amorphous urban masses" (Khalaf 1987).

Some came fleeing the poverty of the traditional Shiite areas around Baalbek, in east Lebanon. Others had escaped from the intense Israeli-Palestinian fighting in Jebel Amel, a traditionally Shiite area of south Lebanon. Still others were twice or more displaced - first from east or south Lebanon, and then again, from one of the large suburbs of east Beirut that were forcibly "cleansed" of Muslims by Christian Falangist militias in 1975 and 1976. (Cobban 2005).

Ultimately though, the tradition rural patrons proved unable to provide services and security for the growing urban populations that turned to them during the civil war. Thus, the prevailing system of political power derived from land holding was being annulled (Ajami 1986, 72). The failure of the zu'ama to provide for their traditional clients opened the door for new 
specifically Shi'a organizations, like The Movement of the Deprived, its military wing Harakat Amal, and ultimately for Hezbollah, to provision urbanizing Shi'a population with the social services they required/demanded. Given the overwhelming mass of Shi'a that were congregating in cities, yet maintaining their rural social linkages, these new Shi'a organizations had access to a population that was at once urban and rural.

The second reason for the maintenance of urban-rural ties was Lebanon's electoral laws. In Lebanon, shifting one's voting rights from one area to another is a difficult legal process, which limits the number of people willing to go through it. As a result, most urban Shi'a have been forced to return to their birth villages to vote (Harik 1999, 47). "Like chickens being brought home to roost, urban dwellers were transported to their villages so that they could cast their vote for their patron, sometime in anticipation of favors to be received and sometimes for cash payment" (Norton 1987, 28). In fact, the Shi'a residents of the south Beirut suburbs did not believe in registering to vote in the city/shantytowns in which they lived, they viewed a vote in Beirut as a waste given the overwhelming political power of the Sunni population (Ajami 1986, 70).

In addition to internal Shi' a migration, the better-educated and wealthier members of the Shi'a community migrated (from 1960 on) to western and North African countries. The key consequence of this was that these educated, and relatively prosperous, Shi'a formed a powerful diaspora community in Lebanon's Shi'a social network. This diaspora community became a source of money, as well as new technology, and ideas for villages. In fact, the monetary remittances from expatriate Shi'a in the United States and West Africa "made possible schooling for a younger generation. This was the first generation to know anything beyond grinding poverty and toil of the land" (Ajami 1986, 73). These links between home villages and the 
outside world decreased the differences between rural and urban Shi'a (Norton 1987). Thus, the Shi'a constituted a large, dispersed, and heterogeneous group of people, looking for better opportunities within Lebanon (and abroad), and were consequently, amenable for political mobilization.

In sum, a fundamental economic shift drove demographic changes in Lebanon. These demographic changes did two things. First, they dispersed the Shi'a community in Lebanon, changing it from a predominantly rural population to one that crossed between rural and urban areas. Second, it undermined existing power structures, and created a situation in which the Shi'a were looking for better political representation.

\subsection{Imam Musa al-Sadr and a Mixed (Urban and Rural) Population}

Given these socio-economic and demographic factors the initial driving force behind the Shi'a political mobilization was Sayyid Musa al-Sadr. Sadr was an Iranian-born, Najaf-educated, Shi'a cleric. Sadr's Movement of the Deprived was the first nongovernmental Shi'a organization, and was the impetus for the political mobilization of Lebanon's Shi's. Without this foundational organization Hezbollah could not have formed.

Sadr came to Lebanon at the invitation of the Mufti of Tyre, the predominantly Shi'a coastal city in 1956. Immediately Sadr began working for greater Shi'a representation in the Lebanese government with the ultimate goal of improving the living conditions of, and uniting, Lebanon's fractious Shi'a population. To this end he participated in the formation of the Shiite Higher Council—located in Beirut—in 1967, and then the Movement of the Deprived as well as its associated militia, Amal, in 1974 (Byman 2005; Qassem 2005; Ajami 1986). Both organizations articulated demands "in the military, social, economic, and political realms, including improved measures for defense of the South, the provision of development funds, 
construction and improvement of schools and hospitals, and an increase in the number of Shi' is appointed to senior government positions" (Norton 1987, 44).

However, Imam Musa al-Sadr was faced a unique problem in Lebanon: the rapidly expanding and urbanizing Shi'a population was divided along regional lines. The Shi'a of southern Lebanon viewed themselves as distinct from those in the northeastern Bekaa Valley. The south relied on the cultivation of legal tobacco, while in the Bekaa farmers cultivated sugar beets and illegal hashish. "The people of the south were patient, subdued peasants, their villages within the reach of the authority. The Shia of the Bekaa Valley were wild and assertive clansmen who resisted the encroachment of outside power" (Ajami 1986, 127). Exacerbating the separation between these communities was that each viewed the other with disdain; the south was more settled and learned, which the men of the Bekka saw as a timid and squeamish existence. In contrast, the men of the south viewed the former as rough wild men whose behavior deviated from accepted practices, both socially and religiously. (Ajami 1986).

Imam Sadr actively worked to bridge the differences between these two Shi'a populations. He accomplished this through his involvement with the cause of rural sharecroppers in these two regions. Agricultural workers wanted higher prices for their products and the right to unionize. Small growers of tobacco in the south and sugar beets in the Beka'a Valley had very little of their own land (the average small farmer's plot of land was less that two dumans, or under $1 / 2$ an acre), and as a result generated little income above subsistence. This inability to generate income regularly put many small farmers into debt. Politicians and traditional rural patrons largely ignored these issues because they had an interest in low wages for planters given their ownership of the land. (Ajami 1986).

The largest agribusiness owners in both the South and the Beka'a kept the prices of 
tobacco and sugar beets down in order to buoy their respective monopolies on the importation of American cigarettes and foreign sugar (Salim 1978). The import-focus of these monopoly concerns fundamentally undermined small-scale agriculture in both areas and forced rural populations off their land. Sadr advocated on behalf of these populations, who while regionally disparate, were faced with similar economic and social pressures (Ajami 1986).

To appeal to these populations (including the rural workers who were loosing their agricultural jobs, southern Shi'a facing violence due to Israeli-Palestinian violence, the otherwise reticent Beka'a communities, and the ever expanding population of urban slum-dwellers in southern Beirut) Sadr introduced new language and themes into his sermons, speeches and press interviews. He turned to using themes of "disinheritance" and "deprivation." This language introduced issues of fairness and equality for the Shi'a, which bridged perceived regional divisions (Ajami 1986, 136). From Sadr's perspective, these populations while once very different had developed common causes: a lack of employment opportunities for both urban and rural Shia, a dearth of social services across regions, and an unrepresentative political system (Salim 1978; Ajami 1986).

Employing these themes, Imam Musa, at a rally in the Bekaa Valley city of Ba'albak in March 1974, launched his "popular mass movement, Harakat al-Mahrumin (Movement of the Deprived). With this movement he vowed to struggle relentlessly until the security needs and the social grievances of the deprived — in practice the Shi'a — we satisfactorily addressed by the government" (Norton 1987, 48). It must be noted here that although a religious leader founded Harakat al-Mahrumin, it was a secular organization, whose expressed purpose was bringing Lebanon's Shi'a together along communal rather than ideological lines (Byman 2005). Imam Sadr selected the themes of dispossession and deprivation because they had greater appeal than 
religious language or the themes of extant leftist organizations (Ajami 1986).

Of particular interest to the theory of motivating large-scale collective action in a mixed population are Sadr's use of media, and incomplete information to motivate support for Harakat al- Mahrumin. Sadr used the influential and politically centrist Lebanese news daily Al Nahar to spread his themes amongst the Shi'a and non-Shi'a alike. In fact, the media was key for affecting social mobilization: at the founding of Harakat al-Mahrumin, Lebanon has some 400 political publications, which Sadr used to spread his message (Salim 1978). Further, when delivering speeches in the Bekaa Valley or in Tyre men from the other region attended, information about these speeches (in one area or the other) could therefore filter through every Shi'a community, creating the opportunity for a cascade of participation in collective action (Ajami 1986, 148).

In fact, in pursuit of greater popular appeal and external support, Sadr composed a fatwa which stated that the Alawis of Syria were a part of the Shi'a Islam: “"the regime of Hafiz al Asad needed quick religious legitimacy; the Shi'is of Lebanon, Musa al Sadr had decided, needed a powerful patron. Interests busily converged from every direction"” (Ajami, 1986, 174).

Within a year of the founding of Harakat al-Mahrumin, the Lebanese civil war broke out, and by July 1975, a militia associated with Sadr's Movement of the Deprived was formed. The militia, Afwaj al-Muquwama al-Lubnaniya (known by the acronym AMAL, literally "hope") was a necessary facet of Sadr's mobilization strategy, as in the context of the expanding civil war neither the state, nor the Shiite Higher Council could/would protect the Shi'a from violence (Norton 1987). Over time, Amal subsumed The Movement of the Deprived as both a political and military organization.

In the last three years of Sadr's life Amal drew support from a small but diverse crosssection of Lebanon - its size was limited due to the large number of competing militant 
organizations, and internal conflicts (Norton 1987). This group of people included educated lawyers that were part of the left-leaning parties that formed in the 1950's and 60's like the Ba'athists and communists, the sons of peasants from the south and the Beka'a Valley, as well as petty urban traders. In short, Amal appealed to both rural and urban youth, with varied (but nonethe-less rising) levels of education (Ajami 1986, 169-72).

Thus, Sayyid Musa al-Sadr can be considered the necessary spark for the political mobilization of Lebanon's Shi'a population. He formed the first explicitly Shi'a political movement, as well as the founding Shi'a militia. He used the rapidly changing demographic and economic realities of the poor Shi'a community in Lebanon to organize the foundational social support structure of Hezbollah. Moreover, Sadr's Fatwa in favor of Syria's Alawi government created a pathway through which Iran could influence Lebanon's Shi'a. This is a path that is maintained today. Therefore, without the vanished Imam, Hezbollah could not have coalesced.

\subsection{Amal, Israel, Iran, and Hezbollah}

Imam Musa al-Sadr disappeared in Libya on August 31, 1978. His loss became a symbol of political struggle to Lebanon's Shi'a population (Ajami 1986, 199). In the wake of his disappearance, Hezbollah seized the Shi'a community that Sadr had begun to unit, using Sadr's Amal as the basis of its development. Hezbollah was able to build off of Amal's foundation as a result of three interconnected factors: an ideological split within Amal, the 1979 Iranian Revolution, and the 1982 Israeli invasion (Norton 1986, Ranstrop 1997, Saad-Ghorayeb 2002).

Following Imam Sadr's disappearance an ideological split occurred within Amal. As mentioned above, Amal, although influenced by Islam, was a secular movement. Following the 1982 Israeli invasion of southern Lebanon an Islamic faction coalesced within Amal, led by the deputy leader of Amal, Husayn al-Musawi, in the Bekaa Valley city of Baalbek - the city in 
which The Movement of the Deprived was founded. This row between the movement's secular moderates and more hardline Islamists developed when Nabih Berri, the post-Sadr the leader of Amal "decided to join the National Salvation Committee, which was formed by President Ilyas Sarkis in mid-June 1982 to deal with Israel's occupation and siege of Beirut" (Ranstrop 1997, 31). For those Amal members influenced by the 1979 Iranian Revolution, who saw Lebanon as a new arena for revolutionary struggle, Berri's decision to work with the state to maintain "the national sovereignty and territorial integrity of Lebanon," in place of establishing a theocratic state modeled on Iran was explicitly un-Islamic (Ranstrop 1997, 31). Husayn al-Musawi was the most explicit critic of the Berri decision. "In July 1982, Musawi charged the movement's leaders with blatant collaboration with the invading Israelis, and apparently with Iranian support, attempted to reorient the movement to what he saw as its proper objective: the replication of Iran's Islamic Revolution in Lebanon” (Norton 1986, 88). The practical consequence was Musawi's creation of Islamic Amal.

Hezbollah then formed as an agglomeration Islamic Amal and several other Shi'a organizations, under the supervision, and with the explicit support of Iran. That is, in July of 1982 Iranian Pasdaran (Revolutionary Guard) forces arrived in the Bekaa to ensure the growth and survival of Islamic Amal, in addition to actively supervising the creation of Hezbollah. In fact, Iran's former ambassador to Syria Ayatollah Ali Akbar Mohtashemi (Najaf educated) "actively supervised the creation of the movement [Hezbollah] by merging the Lebanese alDawa; the Association of Muslim Students; al-Amal al-Islamiyya; and other radical Shi'a movements" (Ranstrop 1997, 33).

In fact, before Hezbollah and its "Open Letter," the founding clerics of the above movements articulated the 'Manifesto of the Nine' that articulated their as yet unnamed 
organization's ideas and goals. The main goals of this new organization were: a recognition that Islam provides the basis for a better life, and that it would be the intellectual, religious, and ideological foundation of the new organization; second, that resistance against Israel was it's raison d'être. Thus, the organization required a "jihad structure." Finally, the manifesto recognized the "'legitimate leadership' of the wli al-faqih, whose 'commands and proscriptions are enforceable.' Nine delegates were selected to represent the different elements within the movement - three from the Bekaa, three from Islamic Amal, and three representing the other factions" (Blanford 2011, 47).

The various Shi'a movements that came together in Hezbollah were influences by Iran and the radical ideology that spurred the Iranian revolution. The leaders of these movements, including Sheik Sobhi Tufayli, Sayyed Abbas Mussawi, and Sheikh Mohammed Yazbek (both Tufayli and Mussawi went on to become the Secretary-General of Hezbollah from 1989-1991 and 1991-1992 respectively), all studied in Najaf, the city in which Ayatollah Ruhollah Khomeini developed the theological underpinnings of his 1979 Revolution (Shapira 1988). “They expressed commitment to Khomeini's leadership and sought to build an organization rooted in Islam that looked beyond Lebanon's parochial purview and was dedicated to the struggle against Israel" (Blanford 2011, 47). It should also be mentioned that for Iran the creation of Hezbollah was a significant accomplishment as it was the first example of the exportation of the Ayatollah Khomeini's Islamic revolution. As Hezbollah endorsed "the doctrine of velayet-e fiqh, the controversial philosophy put forth by the Ayatollah Khomieni that called for the merging of political and religious authority under the most learned cleric" (Byman 2005, 93).

The importance of Najaf-educated clerics cannot be ignored. These clerics, including Mussawi, Tufayli, Yazbek, Hassan Nasrallah, and others, returned to their respective homes in 
the early 1970's, and founded Shi'ite religious educational institutions, hawzat, based on those they had attended in Najaf. Of these hawzat, two "were established in Beirut, one in Baalbek, and two more in southern Lebanon (in Tyre and in the town of Sadikin)" (Shapira 1988, 115). The premise behind these schools was to gather and train disciples of the "activist school" of Shi'a Islam (Shapira 1988). These hawzat became the locations for Hezbollah recruitment in both urban and rural spaces, thereby creating common ideological bonds between urban and rural populations.

Additionally, Najaf-educated clerics founded Lebanese al-Dawa, following the spiritual guidance of Sayyed Mohammad Hussein Fadlallah, a Najaf born and educated Islamic scholar, who is also considered to be the spiritual guide to Hezbollah (Ranstrop 1997; Shapira 1988). Through this organization, activist clerics targeted young urban Shiites in Beirut's southern suburbs who were organized in the Lebanese Association of Muslim Students, which was founded by Shi'a graduates of the Arab University in Beirut (Shapira 1988).

In short, the religious indoctrination of "radical Islamic theory that the future Hizb'allah clerics received at Najaf provided the ideological foundation for the organization and led to the forging of close-knit relationships and personal networks between eminent leaders of the Shi'a community across the Middle East" (Ranstrop 1997, 27).

\section{Education and Hezbollah}

The foregoing discussion explicated how urbanization facilitated to the political mobilization of the Shi'a by Sayyid Musa al Sadr through The Movement of the Deprived, Amal, and ultimately Hezbollah. For an organization to adopt hybrid warfare the population it draws support from must not only be urbanizing, it must also be increasingly well educated and skilled. The type and number of people recruited into an insurgent organization are the dually 
necessary but individually insufficient factors that affect a group's military and organizational capabilities. These two factors facilitates widespread support for an organization in the form of a support cascade, in which growing numbers of people support an insurgent group because their contribution are not likely to be wasted, and because there is safety in numbers.

To begin, from 1975 forward - the year after Amal was founded-Lebanon's gross enrollment rates (GER) in secondary school steadily increases; Lebanon's GER for secondary school increases from 46.9 in 1975 to 89.07 in 2005; in 1997, the net enrollment rate in secondary schools in Lebanon is 66.3 (World Bank 2008, Statistical Appendix). ${ }^{19}$

Table 1. Gross Enrollment Rate in Secondary Education, 1975-2005

\begin{tabular}{cccccccccccc}
\hline & 1975 & 1980 & 1985 & 1990 & 1995 & 2000 & 2001 & 2002 & 2003 & 2004 & 2005 \\
\hline Lebanon & 46.9 & 59.1 & 60.6 & 73.9 & 80.7 & 80.3 & 83.6 & 86.8 & 88.7 & 88.67 & 89.07
\end{tabular}

Source: From UNESCO Institute for Statistics through EdStats (accessed on October 30, 2012)

Source: The World Bank 2008, Statistical Appendix

Table 1 demonstrates the linear increase of secondary enrollments rates in Lebanon over time, including significant increases in secondary school enrollment during the Lebanese civil war and the concurrent Israeli occupation (1982-2000) during which time Hezbollah formed.

Unfortunately, due to a lack of data resulting from the fact that no national census has been conducted in Lebanon since 1932, no thorough data is available on secondary school completion (Harik 1996). Even though no conclusion can be made regarding the net rates of secondary school completion over this time period, it does suggest that an increasing number of individuals are completing at least some portion of secondary schooling. This data then fits with my

\footnotetext{
${ }^{19}$ Gross enrollment rate is "defined as the ratio of total enrollment, regardless of age, to the population of the age group that officially corresponds to the level of education" (World Bank 2008, 204). Net enrollment rate (NER) "is defined as the ratio of the number of children of official school age (as defined by the national education system) who are enrolled in school to the population of the corresponding official school age" (World bank 2008, 204). These data are used here in place of the Barro-Lee data included in the regression analysis in chapter 2 because Lebanon is excluded from that dataset.
} 
hypothesis that as states urbanize their populations become increasingly well educated. Most importantly, when the data from table 1 is plotted against the Lebanese urbanization rate over the same time period (Figure 1), it is evident that the relationship between increasing urbanization and increasing educational attainment holds for Lebanon.

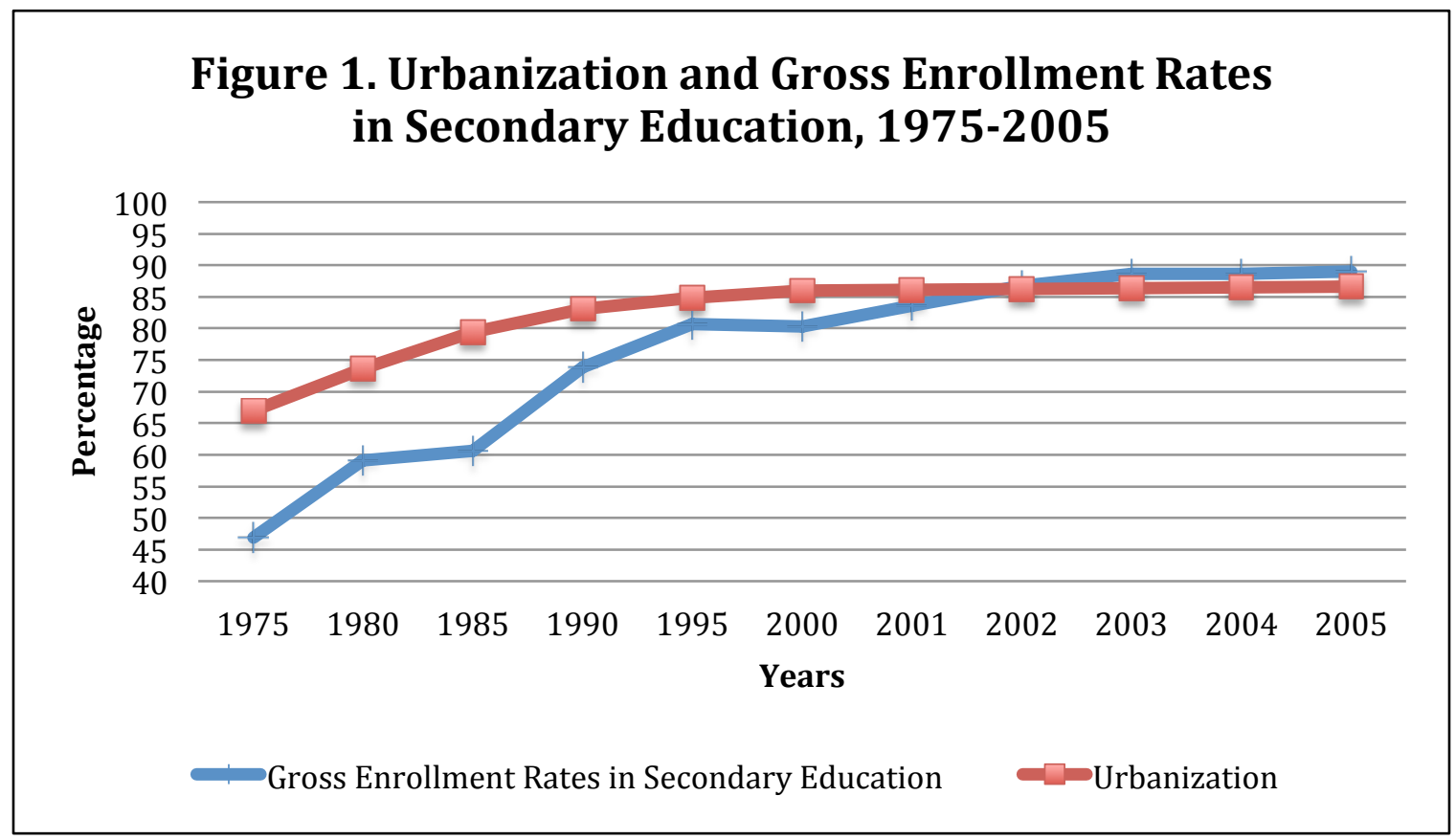

Sourc From UNESCO Institute for Statistics through EdStats (accessed on October 30, 2012)

Source: The World Bank 2008, Statistical Appendix

An interesting finding from both table and figure 1 is that secondary school enrollment rate increased 13.7 percent between 1975 and 1985, the initial period of Shi'a mobilization addressed above. From 1985 to 1995, the period of major Hezbollah expansion, these rates increased by twenty percent. Thus, Hezbollah was able to draw on a much more educated population than Amal. The effects of this education increase on Hezbollah's military strategy, taking into account the time lag associated with educational changes, will be discussed below.

While the above data provides an image of Lebanese education as a whole it is also useful to demonstrate how education works in Hezbollah recruiting more specifically. That is, a more detailed picture of the role of education in Hezbollah's recruitment can be obtained if a 
sample of Hezbollah fighters' education rates is compared to the larger Lebanese population. Table 2, from data accumulated by Kruger and Malečková (2003) and replicated by Kavanagh (2010), does exactly this. The raw data for Table 2 was collected by Eli Hurvitz at Tel Aviv University and provided to Kruger and Malečková (2003). The table includes "biographical information of 129 members of Hezbollah's military wing (Al-Muqawama Al-Islamiya) who died in action from 1982 to 1994 . Two thirds of the Shahids, or martyrs, were killed between 1986 and 1988” (Kruger and Malečková 2003, 130). The biographical information on each fighter was culled from Hezbollah's news weekly, Al-Ahd (Kruger and Malečková, 2003).

This biographical information is compared to Lebanese population data drawn from “individual-level data on a small subset of variables from the Lebanese Population and Housing Survey (PHS), conducted in 1996 by the country’s Administration Centrale de la Statistique” (Krueger and Malečková 2003, 131). This latter survey gathered information of the age, poverty level, and highest education level of 287, 204 individuals (Krueger and Malečková 2003, 131). This survey also reports the highest level of educational attendance (instead of completion) by a respondent. Column three of Table 2 is data for only the Shi'a population of Lebanon (Kavanagh 2010, Appendix).

According to a May 2000 interview with a Hezbollah Chief known only as Maher "None of our fighters join because they want a job. Many of us are educated people - university graduates, teachers, doctors" (Blanford 2011, 109).

Several facts in Table 2 are of particular importance for this work, which comport to the qualitative evidence available. First, and foremost, Hezbollah recruits are 10 percent more likely to attend secondary school than the general Lebanese population, and 14 percent more likely than other members of the Shi'a population. Second, and relatedly, the average poverty rate 
amongst Hezbollah members is five percentage points lower than the overall Lebanese population, and twenty percent lower that the Shi'a population of the state. This suggests that Hezbollah members might actually have better access to education than other Lebanese Shi'a. Interestingly, Hezbollah members also attend university in greater numbers that the rest of the Shi'a population. These statistics provide further evidence for Hezbollah's preference for the well educated and trained.

Table 2:

Demographic Characteristics of Hezbollah Members and Lebanese Individuals of Similar Age

\begin{tabular}{|c|c|c|c|}
\hline & $\begin{array}{l}\text { Percent of } \\
\text { Deceased } \\
\text { Hezbollah } \\
\text { Militants }\end{array}$ & $\begin{array}{l}\text { Percent of } \\
\text { Lebanese } \\
\text { Population }\end{array}$ & $\begin{array}{l}\text { Percent of Shi'a } \\
\text { Population }\end{array}$ \\
\hline Percent of Population & 1 & 100 & 19 \\
\hline Impoverished Background & 28 & 33 & 48 \\
\hline \multicolumn{4}{|l|}{ Education Level } \\
\hline Illiterate & 0 & 6 & 6 \\
\hline Read and Write & 22 & 7 & 11 \\
\hline Primary & 17 & 23 & 27 \\
\hline Preparatory & 14 & 26 & 30 \\
\hline Secondary & 33 & 23 & 19 \\
\hline University & 13 & 14 & 7 \\
\hline Post Graduate & 1 & 1 & 1 \\
\hline \multicolumn{4}{|l|}{ Age } \\
\hline $15-17$ & 2 & 15 & 16 \\
\hline $18-20$ & 41 & 14 & 14 \\
\hline $21-25$ & 42 & 23 & 23 \\
\hline $26-30$ & 10 & 20 & 20 \\
\hline $31-38$ & 5 & 28 & 26 \\
\hline \multicolumn{4}{|l|}{ Region of Residence } \\
\hline Beirut & 42 & 13 & 0.25 \\
\hline Mount Lebanon & 0 & 36 & 0 \\
\hline Bekaa & 26 & 13 & 41 \\
\hline Nabatieh & 2 & 6 & 33 \\
\hline South & 30 & 10 & 26 \\
\hline North & 0 & 22 & 0 \\
\hline
\end{tabular}

Third, Hezbollah members are young. Eighty-three percent of the deceased Hezbollah 
fighters were under the age of 25. Given the trends in increased urbanization and education of the Lebanese population as a whole, these age data can be interpreted as further support for my theoretical claims. That is, this age group is most directly affected by increasingly levels of education; their education might have facilitated political awareness and a willingness to participate in violent collective action. Thus, these young members of Hezbollah, who died in its earliest years of the organization's existence, are the early participants in the cascade of support, those willing to bear the costs (at time $t$ ) of being sanctioned by the opposition. Their deaths as martyrs in a defensive jihad (discussed below) may in fact drive up levels of participation for late joiners (at time $t+1$ ).

Finally, the residence information is critical for my argument. As discussed above, organizations adopting hybrid warfare must have access to a diverse group of fighters, individuals from both rural and urban areas. Table 2 demonstrates that 42 percent of Hezbollah fighters come from Beirut while 56 percent come from the South and the Bekaa Valley. These are variously urbanized areas in which rural and urban populations comingle, for reasons discussed above. It should also be noted that from 1985 on Israel withdrew to an occupation zone south of the Litani River, meaning that the only people subject to direct Israeli aggression were those living in the South (Jabal Amel). Hezbollah, therefore, maintains a diverse group of supporters in a range of communities - urban, rural, and peri-urban. Individuals in these communities have different cost- benefit calculations (a heterogeneous recruitment base), which facilitate widespread support of variously educated and skilled individuals.

\section{Hezbollah and Military Capacity}

The growth and expansion of Hezbollah from its roots in the Beka'a Valley into to a highly capable Shi'a hybrid warfare organization is directly related to the nature of Lebanon's 
Shi'a population, and the organizations that Hezbollah co-opted. The expansion of Hezbollah occurred as a cascade across the rural and urban spaces of Lebanon. From its roots in Islamic Amal in the Bekaa Valley city of Baalbek, The Party of God built up its support base sequentially in the other predominantly Shi'a areas of Lebanon: the southern suburbs of Beirut and then the villages and towns of Jabal Amel (the south of Lebanon).

This cascade of support is the result of several factors. First, the social links between individuals that would become its high-ranking leaders. These ties allowed for the transmission of limited information between communities of people. Consequently, many variously skilled and educated individuals joined the organization in each community, driving up overall support, and creating safety in numbers. The organization's use of technology and media to spread it message, in addition to the flow of information amongst a highly mobile populace, buttressed popular sentiment that contributing to Hezbollah would not be wasted. Finally, the cascade of support for Hezbollah was reinforced by the array of social services the organization provided (Ranstrop 1997; Lichbach 1995; Salim 1978; Flannigan 2008).

\subsection{Mixed Communities and Recruitment in Rural and Urban Spaces}

As discussed above, many of the founding and key members of Hezbollah were Najafeducated theologians. Thus when Sayyed Abbas al-Musawi split from secular Amal (with Iranian assistance) he began working to form a new religious organization within Lebanon. The Najaf cabal that he was a part of had pre-existing relationships that he exploited to build up Hezbollah's capabilities. The extant relationships between Najaf-educated clerics facilitated a cascade of support from both rural and urban individuals. Consequently, Hezbollah was able to recruit educated and skilled individuals as well as the poorly educated and unskilled. This widespread support built up Hezbollah's capabilities over its first 10 years of existence such that 
it was ultimately able to pioneer suicide bombings in its guerrilla warfare campaign, and then move towards a hybrid warfare military strategy. The building of Hezbollah's military and organizations capabilities through widespread support began in the Bekaa valley in 1982, and had spread sequentially to Beirut's southern suburbs and finally to Jabal Amel by 1985 . As Hezbollah spread it attracted a larger proportion of Lebanon's Shia, in absolute terms, as well as a relatively large number of variously educated and skilled recruits.

This cross regional recruitment by Hezbollah was made possible by the social transformations that Lebanon was struggling through during the late 1970's and early 1980's. Due to migration patterns, confessional groups, especially the Shi'a, transcended divisions rural and urban areas, they lived at once in both. "For example, circular migration patterns, in which sons go abroad to make their fortunes but return to their villages for regular visits and often to settle down for life... [mitigated] the insularity of the village" (Norton 1987, 31). In short, children brought urban life back to villages. Talk of Hezbollah's recruitment thus funneled between city and village.

Moreover, the threat of violence from Israel played a key role in connecting rural and urban communities in their need for protection. Urban and rural Shi'a populations often intermingled after 1978 due to displacement associated with ongoing military conflicts. Thus, as a result of the 1978 Israeli invasion Shi'a from the south fled to Beirut's southern suburbs, where Amal, Islamic Amal and later Hezbollah based their organizations. In turn, when Israel besieged Beirut refugees fled south to stay with their rural relatives. These pressures of war served to intermingle discrete populations and spread common themes of resistance to occupation. This continual internal migration of Lebanon's Shi'a therefore created a population that was at once dispersed, yet intimately related. Information about Amal, Islamic Amal, and Hezbollah could 
filter through it quickly (Norton 1987).

Education also linked the city and the countryside. By the 1980 's nearly $100 \%$ of primary school age children were actually attending school, with this figure standing at $50 \%$ for secondary school children (this latter figure was continually increasing even during the civil war as demonstrated above). These figures indicate that rural and urban populations both recognized the essential role that education played in advancing their children's lives (Norton 1987). Therefore both urban and rural populations were drawn to support organizations that supported the advancement of their children's lives; this increased the relative number of educated and skill recruits that Hezbollah could draw on.

\subsubsection{The Bekaa Valley}

As discussed, the first area in which Hezbollah began building support and thus military capability was the Bekaa valley, and its main city, Baalbek. Upon returning from Najaf, Sayyid Abbas al Musawi and Sheikh Sobhi al-Tufayli set up hawzat in Baalbek, as they were considered spiritual leaders. This religious school was initially used to recruit for Imam Sadr's Amal militia. However, following Musawi's creation of Islamic Amal, students were diverted to the new organization. With guidance from a contingent (300-500) of Pasdaran - an advanced force of the Iranian Revolutionary Guard—some of whom were clerics and others who were military trainers, the Lebanese clerics began recruiting and indoctrinating Shi'a residents of the Baalbek into a nascent Hezbollah, “through translating Iran's revolutionary message from Persian into Arabic" (Ranstrop 1997, 35). The immediate observable implication of the religiously inspired organization's prevalence in Baalbek and in the immediate areas of the Bekaa were the elimination of western-style dress, the abolition of liquor sales, and the Pasdaran taught classes on the Koran and Khomeini's theology (Blanford 2011, 45). 
Furthermore, Hezbollah, via Islamic Amal, was able to recruit rapidly and in large numbers in the Bekaa because its was supported by large scale Iranian funding. Iran received tacit acquiescence from Syria for Iranian troop and supply movements in the border area (recall from the above discussion that the Musa al Sadr's fatwa set the relationship up). Money from Iran allowed Hezbollah to establish an "array of social welfare and financial services for the Shi'a community, including religious schools, clinics and hospitals, as well as cash subsidies to... [the poorest] Shi'a families" (Ranstrop 1997, 36). All these services further boosted popular support for the organization, and for Iranian operations in the area. Because the Bekaa Shi'a were on average poor and modestly uneducated, Hezbollah had no trouble attracting unskilled local fighters, as they also paid a relatively high salary as compared to competing militias in the area as well the available agricultural work; new Hezbollah fighters could receive \$150-200 a month, in addition to free education and medical treatment for themselves and their families (Jaber 1997, 52; Ranstrop 1997, 36). By July 1984, the Pasdaran has established six military training centers in the Bekaa for Hezbollah recruits, and was rooted in Baalbek (Jaber 1997, 52; Ranstrop 1997, 36).

\subsubsection{Beirut's Southern Suburbs}

In Beirut, Sheikh Muhammad Ismail al Khaliq used his prominent hawzat as a base of recruitment for Hezbollah. The recruitment drive was assisted by the "expansion of the Iranian Pasdaran from Baalbek into Beirut beginning in April 1983" (Ranstrop 1997, 37). This relationship between Khaliq and Iran was due to the former's studies in Najaf and the fact that he was the "representative of the prominent Ayatollah Montazeri, Khomeini's' successor designate. This status... [accorded] Khaliq a direct link with one of the major power centers in the Iranian hierarchy, which in turn... [enabled] him to wield considerable influence within Hizballah" 
(Shapira 1988, 127).

In addition to Khaliq's work on Hezbollah's behalf, Sheikh Muhammad Hussein Fadlallah was a key, at least, tacit supporter in Beirut. Fadlallah was a central religious figure in Lebanon as the head of the Council of Shi' ite Religious scholars, and his support was therefore vital to legitimacy and potential expansion of a nascent Hezbollah. More, he wielded significant influence within established religious organizations within the city, namely The Association of Muslim Students—-formed by graduates of the Arab University of Beirut — which cooperated closely Lebanon's $A l-D a$ 'wa party. Sheikh Fadlallah's active criticism of the Israeli intervention in Lebanon and his appeals for the establishment of an Islamic Republic, led to his emergence as “the spiritual guide and most senior cleric associated with the Hizb'allah" (Ranstrop 1997, 37). The sheikh actually dissolved Lebanese Al-Da'wa at Iran's request and began to support Islamic Amal and Hezbollah (Shapira 1988; Ranstrop 1997). In his turn towards Hezbollah Seikh Fadlallah brought with him a significant number of new Al- Da'wa recruits from Beirut (Ranstrop 1997).

\subsubsection{Jabal Amel; The South of Lebanon}

Hezbollah's expansion into Jabal Amel was initially slow. Its expansion was hindered by Amal's dominance of the south; into the early-1980's Sayyid Musa al-Sadr's supporters in Amal remained numerous. Amal's dominance however withered when it was perceived as failing to react to the Israeli occupation of the South. This led, by the spring of 1983, to the emergence of more militant organizations in the region, which were led by local clerics with ideological ties to Iran. These local militant organizations ultimately united under the name of: The Association of the Uluma of Jabal Amel. Sheik Rageb Harb (another Najaf clergyman, and the Imam of the southern town of Jibsheet) led the smaller Shi'a cells that made up this association, and who 
executed persistent attacks on the occupying Israeli forces (Shapira 1988). He and his retinue of "young and fire-brand clerics provided the core foundation for the extension of Hizballah in the South and their resistance activity not only undermined the influence of Amal in the area but also seriously challenged Israel's presence, especially through self-martyrdom operations" (Ranstrop 1997, 38).

In short, Hezbollah mobilized the Shi'a of these three key areas by appropriating extant radical organizations. Distinct from all its predecessors, Hezbollah had clearly defined and articulated objectives: (a) ending the Israeli occupation; (b) destroying the state of Israel; (c) liberating occupied Palestine; (d) creating an Islamic Republic. The Party of God used media (their own newspaper al-Ahad, television al-Manar, and radio station The Voice of the Oppressed) to exploit the limited information available in the context of a civil war and a foreign occupation, to popularize their radical message and political objectives. Like Sadr with Amal, Hezbollah employed traditional Shi'a imagery and symbols, especially through Ashura celebrations - which commemorate the martyrdom of Imam Husayn — "to enlist support and promulgate revolutionary activism based on the struggle against tyranny, disinheritance, and social injustice. The exploitation of Shi'ite symbolism was used by the Hizb'allah as a political weapon to embody the condition of the oppressed and disinherited Shi'ite community under the Lebanese confessional system" (Ranstrop 1997, 40).

Hezbollah deploys recruiters in every village and neighborhoods where the party wields influence to look out for likely prospects amongst the local young men and women. The recruiter is looking for pious, disciplined, modest, intelligent, healthy, well-behaved individuals who could fit into Hezbollah's way of life (Blanford 2011, 105).

\subsubsection{Capacity in Militant Operations}

In its earliest incarnation Hezbollah used the weapons available to it, light arms and the pioneering use of suicide bombers, in a guerrilla warfare campaign against foreign military 
forces. At no point did Hezbollah pursue attacks against Lebanon's civilian population; its suicide bombings targeted foreign military installations (Pape 2003). The adoption of this guerrilla strategy must be viewed in the context of its development. Hezbollah began its recruitment campaign in the Bekaa Valley, a fairly rural and largely Shi'a region. The need for popular support in an area with a sparsely populated and modest educated population region meant adopting a strategy that eschewed civilian deaths; thus the quantity and quality of fighters being recruited in Hezbollah at the organization's inception determined the nature of its early military operations. The Party of God's first military operation took place on November 21, 1982, when elements from Musawi's Islamic Amal seized offices, ammunition dumps, and the Sheikh Abdullah army barracks in Baalbek. The Lebanese military forces were "expelled from Baalbek along a main road lines with armed and jeering Shia $[s i c]$ militants. The Sheikh Abdullah barracks became the new Bekaa headquarters for the Revolutionary Guards" (Blanford 2011, 48).

As Hezbollah expanded into Beirut's southern suburbs, southern cities like Tyre, and Jabal Amel (rural southern Lebanon), it was able to recruit larger numbers of variously skilled and educated members. Consequently, its military operations became more technically demanding (it adopted suicide bombing against military targets). Put differently, as Hezbollah expanded its organizational and military capabilities through the sequential recruitment campaign discussed above its military strategy grew in complexity.

It is only after Hezbollah's expansion into cities that it began suicide operations; it's first military operations took place in 1982, while its first suicide bombing occurred on October 23, 1983 wherein its operatives conducted simultaneous suicide attacks against the U.S. marine barracks at the Beirut airport and the French paratrooper headquarters in south Beirut, which 
killed 241 American and 58 French military personnel (Blanford 2011; Ranstrop 1997). This demonstration of military capacity helped draw more recruits to the organization. The organization's growth and the expansion of education in Lebanon therefore facilitated Hezbollah's adoption of guerrilla warfare, then its pioneering of suicide operations, and ultimately its adoption of Hybrid Warfare.

\subsubsection{Expanding Capacity, Sequential Recruitment and Foreign Support}

Hezbollah's sequential expansion from the Bekaa Valley in the north, through the southern suburbs of Beirut, and ultimately into Jabil Amel, helped it build support in Lebanon's mixed Shi'a community. This sequential evolution also led to the influx of sophisticated weaponry from Iran through Syria, thereby allowing the Party of God to evolve its military strategy from guerrilla warfare towards hybrid warfare.

In its earliest years, Hezbollah fought against Amal for support from the Shi'a community, while concomitantly facing off with Israel. The fight between Amal and Hezbollah was fiercest in Beirut's southern suburbs and in Jabal Amel. On February 17, 1988 Hezbollah kidnapped a member of the UN's observer group in Lebanon, Lt. Col. William Higgins. It did this as a direct challenge to Amal's political leadership in south Lebanon. The kidnapping caused fierce fighting between the Party of God and Amal throughout southern Lebanon—including southern Beirut (Ranstrop 1997).

By May of 1988 Hezbollah had gained control of much of southern Beirut and southern Lebanon due to poor leadership in Amal and the defection of Amal members to Hezbollah. As a consequence of Hezbollah's martial gains Hafez al-Assad—Amal's Syrian sponsor-met with a Hezbollah delegation. In this meeting Hezbollah explained its goal of pushing Israel out of Lebanon, and that it had no interest in conflict with Syria (Ranstrop 1997; Blanford 2011). 
In 1990, Iran and Syria worked out the second "Damascus Compromise' which ended the internecine fighting in Jabal Amel. Hezbollah's status as the preeminent Shi'a military force was then formalized in the 1990 Taif agreement, which ended the Lebanese Civil War. In it, with tacit American acquiescence, Syria was established as the preeminent power in Lebanon, as the peace deal formalized Syria's role in maintaining Lebanese security. Through the Taif agreement Syria recognized Hezbollah's military capacity to attrite Israel's will in Lebanon, and its willingness to work with Syria instead of against it (Ranstrop 1997). Consequently, the Taif agreement spared "the Islamic Resistance the fate of wartime militias eligible for termination... Instead, Hezbollah was classified as an officially sanctioned resistance against the Israeli occupation, in accordance with Taif's stipulation that the state must take 'all necessary measure to liberate all Lebanese territory" (Blanford 2011, 95).

Therefore, by 1990, Hezbollah had effectively neutered all other competing Shi'a resistance organizations and had taken control of the south; it gained another external sponsor in Syria; and was legitimized as the official resistance to Israel. In 1992, Hezbollah employed its first heavy weaponry against Israel as it adopted hybrid warfare. This evolution would not have been possible without the organization's sequential expansion within Lebanon's mixed Shi'a community and the obliteration of competing insurgent organizations, both of which demonstrated the Party of God's capacity for sustained militant activity.

\subsection{Positive Inducements for Support}

In order to bolster participation and expand its appeal, Hezbollah has systematically provided social services and material inducements to Lebanon's Shi'a population. This provision of services has been facilitated by the financial and military support Hezbollah has received from Iran since its inception; this support can be traced back to Hezbollah's founding clerics' Najaf 
connections.

“Hezbollah's effort to spread its influence throughout the south was underpinned by an extensive multi-million dollar social welfare program to alleviate the poverty and lack of state utilities in Shia-populated areas" (Blanford 2011, 81). Beginning the Bekaa valley, food aid, clothing, and monthly stipends were given to poor families, in addition to Iran opening the Imam Khomeini Hospital in Baalbek in 1982. In addition, Hezbollah and Iran established the Martyr's foundation, which was created to provide financial support, health care, and free education to the families of dead resistance fighters (Flanigan 2008; Blanford 2011). More, in 1985, Hezbollah opened its construction foundation, Jihad al-Bina (The Holy Struggle for Construction) with the initial goal of rebuilding the war-damaged homes of Lebanon's Shi'a population. This construction foundation also built sewage infrastructure and delivered potable water in the southern slums of Beirut, where the state was conspicuously absent. Over time, Hezbollah has expanded its service provision to all the Shia dominated areas of Lebanon, "building and rehabilitating dozens of schools, hospitals, clinics, mosques, homes and shops. It offers agricultural assistance to farmers, digging wells, and providing finical credit and advice on land reclamation and crop cultivation" (Blanford 2011, 81). After Israeli military incursions, Hezbollah is the organization that assesses the damages and begins reconstruction.

In addition, Hezbollah has created The Islamic Health Unit, which operates hospitals, health centers, infirmaries, dental clinics, and fire departments. These institutions were created to service poor Shi'a at little to no cost. In fact, Hezbollah was so effective at providing these services to its own constituents, that the state gave it the responsibility of operating government hospitals in areas where the state was financially or technically unable to do so (Flannigan 2008, 510). 
Further, due to the violence associated with the Israeli occupation and the concomitant civil war, the Dahiyeh area of south Beirut was cut of entirely from public services after 1988. Hezbollah (with Iran's help) provided these services and built "4,000 liter water reservoirs in each district of the southern suburbs and... [filled] each of them five times a day from continuously circulating tanker trucks. Generators mounted on the trucks also made regular rounds... to provide electricity to pump water from private cisterns" (Harik 2004, 84). The Party of God also built electrical power stations (Harik 2004, 85)

This range of social services, which continue to serve as positive inducements for participation in violent collective action, have been critical to building up Hezbollah's organizational and military capabilities. They have facilitated the growth of the organization from the 150 person initial recruitment class in the Bekaa Valley, to an organization estimated to have as many as 25,000 members when counting its standing reservists (Ranstrop 1997). The "motivations for joining Hezbollah are... multidivisional, blending religious observance, hostility towards Israel, and the Shia commitment to justice and dignity. On a more prosaic level, many young Shia naturally gravitate toward an organization that has helped empower their community and has earned respect for it martial exploits over the years" (Blanford 2011, 103).

\section{Hezbollah's Strategic Doctrine}

The forgoing analysis established the historical development of Hezbollah. Most importantly, it explicated how Hezbollah recruited from a diverse group of supporters that were at once rural and urbanizing as well as increasingly well educated. This diverse group facilitated a cascade of support for the Party of God because people realize that their contributions to Hezbollah would not be wasted, and because Hezbollah provided them with safety in numbers. Finally, as a positive reinforcement mechanism, Hezbollah provided the Shi'a areas of Lebanon 
with social services, this further expanded support for the Shi'a resistance organization. Thus, I now turn to explaining how Hezbollah took this large-scale popular support (organizational capability) and developed its hybrid warfare military strategy.

\subsection{Defensive Jihad}

It is first necessary to understand how radical Islamic ideology and the drive to end the Israeli occupation/destroy the state of Israel combine to influence Hezbollah's military strategy. Hezbollah's religious ideology is predicated upon the logic of resistance. That is, the Party of God has a deep-rooted commitment to wage defensive jihad against occupying military powers. Both "Khumayni and Hizbu'llah regard the protection of the umma [present and future generations] from external danger, or defensive jihad, as a far more pressing concern than other religious rituals such as fasting or praying" (Saad Ghorayeb 2002, 124). Herein lies one of the basic tenets of Hezbollah's military strategy: it considers itself to be by its nature defensive, it is meant to protect the land of the followers of Islam from foreign forces. Jihad is an act that is done for God's cause, and for Hezbollah, this cause is the cause of the people, "the cause of the defense of the land, the cause of the defense of the sacred, of religion... Jihad is therefore an essentially defensive, as opposed to offensive, activity in Hizbu'llah's conception" (Saad Ghorayeb 2002, 122). ${ }^{20}$

Thus, when combating the Israeli occupation, all Hezbollah fighters are considered martyrs for the cause of God, and their deaths, particularly those of high ranking party members like that of Sheikh Raghib Harb, add impetus to resisting the Israeli occupation (Saad Ghorayeb

\footnotetext{
${ }^{20}$ On this point it should be noted that there is no mention of the concept of offensive jihad. Although it can be argued that jihad is in fact offensive, particularly brand of jihad wagged by groups like al-Qaeda. In the case of Hezbollah there is evidence to suggest that for this group jihad is indeed defensive as, at its core, Hezbollah was a reaction to a foreign military presence. As will be shown below, Hezbollah employs a defensive military strategy that is meant to deny an aggressor its goals, instead of orienting its forces for offensive military engagements.
} 
2002, 12). The religious difference between the Lebanese Shi'a and the occupying Israeli forces helped develop the resistance movement's defensive jihad. This resistance allowed for both the demonization of the occupying enemy and popular support for martyrdom and suicide terrorism in the name of national liberation (Pape 2005).

Hezbollah understands itself to be wagging a war of attrition against Israel. Through defensive jihad the party inflicts enough casualties upon the occupying force-punishment- to eventually cause it to withdraw. "According to Hizbu'llah's logic, 'the more body bags that are sent to Israel' the greater the heated debate that will be ignited within Israeli society. In turn, the growing domestic opposition to the continuation of Israel's occupation will pressure the Israeli government to unilaterally withdraw from Lebanon" (Saad Ghorayeb 2002, 118). This logic developed following the invasion, and was the core of the military strategy pursued by the organization in its 34-day 2006 war against Israel.

\subsection{Changing Weapons and Targets: An Evolutionary Strategy}

In the 2006 conflict Hezbollah is estimated to have fielded between 2,000 and 7,000 fighters. Even if a mid-range figure of 4,500 is used this mean that Hezbollah deployed about 6 fighters per square kilometer. This is ten times the density of the Vietcong in 1964, but about the same troop density as the US defense of Saudi Arabia in 1990, which was about 5.5 soldiers per square kilometer. By comparison, the French Maginot line in 1940 was staffed by 75,000 troops over 1260 square kilometers, for a density 10 times that of Hezbollah (Biddle and Friedman 2008).

Hezbollah's relatively high force density in Southern Lebanon in 2006 is incongruous with classical guerrilla warfare, in which fighter are greatly dispersed, which leads to relatively low, but uniform troop densities. It more closely resembles conventional militaries, which 
operate with a greater density of force in order to concentrate at certain points of attack and defense; "[h]ence the greater the relative concentration of combatants, the greater the degree to which the actor's methods approximate the conventional extreme" (Biddle and Friedman 2008, $55)$.

Furthermore, Hezbollah is noted for holding ground for extended periods of time, even in close quarters combat; these facts were particularly evident during the 2006 war in the battles of Bint Jbial and Maroun al-Ras (Biddle and Friedman 2006). Both of the battles occurred over multiple hours/days and involved concentrated groups of Hezbollah fighters. Classical guerrilla military strategy explicitly eschews these types of operations, as the guerrilla does not have the firepower or the skill to deny enemy objectives in this fashion. "Guerrilla are expected to melt away when attacked by superior government forces rather than to stand their ground and accept decisive engagement, and they often prefer booby traps... meant to inflict casualties without denying the opponent access to an area per se" (Biddle and Friedman 2006, 10; Tse-Tung [1966] 2005; Guevara 2006). Thus, Hezbollah cannot be a traditional guerrilla force.

Hezbollah came to global attention in 1983 due to its devastating suicide attacks on American military and political targets in Southern Lebanon. According to Daniel Byman in the “1980s, Hizballah was perhaps the world's most active terrorist organization... In the 1990s, however, the movement reduced its direct involvement in terrorism and focused more on its guerilla struggle against Israel”(Byman 2005, 86). In fact, while Hezbollah is popularly associated with suicide bombings, between 1982 and 2000 (the years of the Israeli occupation), it only conducted 11 suicide attacks, and only 4 were carried out in the 1990's (Blanford 2011, 109). Therefore, Hezbollah should not be thought of as a terrorist organization, because by the early 1990s, terrorism was no longer Hezbollah's operational military strategy. 
In fact, in February of 1992 Hezbollah launched its first heavy weapon: a relatively unsophisticated Russian-made $122 \mathrm{~mm}$ Katyusha Rocket. This rocket is roughly 4.8 inches in diameter, $2.8 \mathrm{~m} / 9.2 \mathrm{ft}$ long, carries a roughly $21 \mathrm{~kg} / 42 \mathrm{lb}$ warhead, requires a stable ground or truck- based launching platform, and has a range of $20 \mathrm{~km} / 12.7 \mathrm{mi}$ (Blanford 2011, 132). Furthermore, some Israeli military analysts argued that as early as 1996 Hezbollah had begun developing a fortified systems of bunkers in the "Security Zone"- this is during the last years of the Israeli occupation —in order to support its rocket and missile capabilities (Kulick 2006; Harik 2006; Exum 2006). Finally, Hezbollah is noted for having successfully launched a land-to-sea C802 anti-ship missile at the INS Hanit during the 2006 campaign, causing significant damage to the ship and killing 4 Israeli sailors (Exum 2006). This is a nearly one-ton, 6.4-meter missile recurring a stable launching platform, an archetypal heavy weapon.

Hezbollah is also the first nonstate actor to successfully employ armed unmanned aerial vehicles in conflict. During the 2006 war Hezbollah used the Iranian made Mirshad 1 or the Ababil 3 Swallow. These are both GPS guided systems with a 450 -kilometer range, and a 50-kg weapons carrying capacity. They also require trained pilots to operate, a position that requires both training and some level of education - in the US for example pilots require a minimum of a bachelors degree (Hoffman 2007, 38; airforce.com).

Thus, Hezbollah demonstrated its capabilities with lower qualities of weaponry, and due to its increasingly well-educated and capable recruits, it was able to acquire a more sophisticated arsenal. Recalling figure 1 above, this increased sophistication in Hezbollah's weaponry coincides with an ongoing and significant increase in the urbanization and education rates of Lebanese citizens. Table 2 demonstrates the increasing levels of education of Hezbollah fighters in particular; these education statistics coincide with the period of Hezbollah's first use of heavy 
weaponry. Thus, it can be argued that increasing levels of education contributed to greater levels of foreign support.

It must also be pointed out that Hezbollah has almost exclusively targeted foreign military personnel. While it has conducted kidnappings, assassinations and bombing of foreign embassies, the vast majority of Hezbollah targets have been Israeli and other national military personnel. In sum, since 1992 (at least), Hezbollah has not been a "terrorist" organization by any definition. It has rarely attacked civilians, and while it is the innovator of modern suicide terrorism, it has conducted only a small faction of these types of operations (Pape 2003). And when it did employ suicide bombers, Hezbollah targeted military forces. Consequently, Hezbollah is a hybrid military organization.

\subsection{Hybrid Warfare}

It was under the guidance of Sheik Hassan Nasrallah (Secretary General 1992-present) that Hezbollah was organized into a decentralized, highly secretive organization, with little formal hierarchy, allowing it to adopt hybrid warfare. The key to this reorganization, as is made clear in Hezbollah's ideology, is that the party is devoted to the effective defense of Southern Lebanon from foreign incursions - to wit Israel. To that end, Nasrallah created three regional commands each with military autonomy, with the leader of each command reporting directly to Nasrallah. "Beirut and the Hezbollah council made policy, but did not try to run the war... [thereby improving] Hezbollah's security... It set up separate largely autonomous units that live among civilians with local reserve forces to provide support, supplies and logistics" (Erlanger and Oppel Jr., 2006). By creating such a loose command structure Nasrallah ensured that Israeli bombardment would not significantly affect the command, control, and intelligence capabilities $\left(\mathrm{C}_{3} \mathrm{I}\right)$ of the organization. With its front-line forces fighting from their home villages, there were 
even fewer command and communication lines to disrupt (Wilson and Cody, 2006).

Under the guidance of Sheik Nasrallah, Hezbollah studied the history of guerilla warfare, and developed a highly accurate understanding of the Israeli military, including a detailed knowledge of the day-to-day operations of Israeli patrols along the border (Blanford 2006). Moreover, the organization came to realize two critical facts about the Israeli military. The first is that the IDF, and the Israeli public writ large, are highly casualty averse. Secondly, Hezbollah understood that the backbone of Israeli military strategy is armor, supported by air power and ground troops. Israeli has historically employed a blitzkrieg military strategy (Ben-Horin and Posen 1981;Harik 2006; Exum 2006; Biddle and Friedman 2008; Blanford 2011). To that end Hezbollah created an elaborate supply system to assist its soldiers in combat with Israeli forces. More specifically, Hezbollah created a system through which its forces can survive Israeli bombardments, and in turn inflict high casualties on Israeli ground forces (Urquhart, 2006). To support this nascent hybrid force, Hezbollah fighters created networks of underground, extremely well equipped, bunkers.

Soldiers have discovered bunkers with air conditioning, electricity generators and sophisticated listening and observation devices working in tandem with computers. These bunkers meant that Hezbollah fighters could shelter from Israeli artillery bombardment and then surprise the advancing Israeli forces. Often the bunkers were so well hidden that the fighters could wait until the soldiers had passed and then attack them from behind (Urquhart 2006; Greenburg 2006).

The most important command bunkers as well as those bunkers used as weapons caches were dug to depths of 40 meter in the rough terrain of Southern Lebanon. According to some estimates, roughly 600 separate weapons and ammunitions bunkers were dug south of the Litani River (Cook and Perry, 2006). "For security reasons, no single commander knew the location of each bunker and each distinct Hezbollah militia unit was assigned access to three bunkers onlya primary munitions bunker and two reserve bunkers, in case the primary bunker was destroyed" (Cook and Perry, 2006). 


\subsection{Defense in Depth as Hybrid Warfare}

As has been discussed, Hezbollah has evolved to protect its homeland from foreign invasion, specifically by Israel. Moreover, according to observers of Hezbollah the organization has "'studied asymmetric warfare, and they have the advantage of fighting on their own landscape, among their people, where they have prepared for just what the Israelis are doingentering behind armor on the ground"” (Erlanger and Oppel Jr. 2006, 4). Put differently, Hezbollah understood that Israel would employ an armor-reliant strategy, blitzkrieg, with the goal of a short and decisive victory. The high level of organization within Hezbollah allowed it to respond Israel's strategic doctrine with an effective counterpunch, hybrid warfare, which is predicated upon an in-depth understanding of defense-in-depth.

According to John Mearsheimer defense in depth is a highly effective strategy for combating blitzkrieg. "The attacker cannot prevent the establishment of secondary defensive positions; there is no possibility of outrunning the defense. The attacker must fight a series of set-piece battles as he attempts to punch through the defender's various positions" $(1983,49-50)$. There are three factors that affect a defender's ability to combat a blitzkrieg. First, the defender must recognize that he is facing a blitzkrieg, understand how it operates, and thus how to combat it. Second, the defender must have the capacity to fight off a blitzkrieg. Finally, the defender must have soldiers that are willing and able to engage attacking armored columns (Mearsheimer 1983, 46).

As has been evidenced above, Hezbollah has recognized the Israeli military doctrine, and over time has developed effective ways to combat it. Being that it has no armor of its own, Hezbollah has developed its own methods of combating armor: "Hezbollah is working with pressure detonators dug into the roads... Israeli tanks have been struck by huge roadside bombs 
planted in expectation that Israeli armor would roll across the border" (Erlanger and Oppel Jr. 2006, 4). Hezbollah has understood that armor, particularly in the mountainous terrain of Southern Lebanon can only pass along certain routes, and as such the organization is able to lay prepared ambushes. "Hezbollah designed its defenses to kill tanks if the IDF tried armored thrusts along traditional movement corridors... Hezbollah made no attempt to construct a Maginot Line; instead, it built weblike defenses that could absorb penetrations and continue to fight, harass and hold" (Peters 2006).

Hezbollah has demonstrated the organizational capacity to effectively fight off the Israeli blitzkrieg. To that end Hezbollah's strategic arsenal has been tailored to effectively fight advanced Israeli armor, and air support. That is, one of Hezbollah's most effective weapons, particularly in the 2006 war, was a guided anti-tank missile. "The use of ATGMs [anti-tank guided missiles] and RPG-29 [anti-tank grenade launchers] not only inhibits the use of armor, but sharply reduces the ability to enter buildings and requires dispersal and shelter" (Cordesman, 2006). This limits the ability of ground forces to penetrate Hezbollah strongholds, as tanks are limited in their effective mobility. "In addition, Israel has restricted its use of helicopters, particularly the Apache gun ships. The Helicopters have been used to hit costal targets, but not in the inland valleys and hills for fear of Hezbollah anti-aircraft weapons" (Urquhart 2006). Hezbollah's capacity to fight the Israeli blitzkrieg was evidenced by the damage it inflicted on Israeli armored forces. At the height of the 2006 conflict Israel had roughly 400 tanks in Southern Lebanon. Of those Hezbollah was able to hit 50 with anti-tank missiles, disabling about half (Katz 2006).

In fact, Hezbollah developed highly specialized anti-tank teams, knowing that the IDF relies heavily on its fleet of Merkava tanks. The Party's anti-tank teams began training on a 
specific anti- tank weapons, such as the AT-13 (heavy), AT-14, Metis-M, AT-3, AT-4 Spigot, and TOW missiles as early as 1997 (Blanford 2011; Exum 2006). In fact, anti-armor teams received advanced training on their weapons systems in Syria and Iran. While training they "improved their accuracy against life-sized mock-ups of Merkava tanks, they were taught to aim for the same point on a tank using two or more missiles in succession. The idea was to blast off the layers of reactive armor, exposing the steel skin to follow up missiles" (Blanford 2011, 198). The typical antitank team in the 2006 war was made up of 4 to 5 fighters: two had received this specialized training, while two or three others teams members, who were less skilled, served as "porters" for the team (Exum 2006, 11).

Hezbollah thus satisfies the final factor for successfully combating blitzkrieg, having soldiers capable and willing to engage with armor. "Iranian Revolutionary Guards have helped teach Hezbollah how to organize itself like an army, with special units for... antitank warfare, explosives, engineering, communications and rocket launching” Erlanger and Oppel Jr. 2006, 1). In other words, Hezbollah fighters trained specifically to defeat invading Israeli forces in Southern Lebanon.

The strategy that Hezbollah employed so successfully would then seem to be hybrid warfare built around defense in depth, which is a series of prepared defensive positions arranged at great depth inside one's own territory. It is designed to wear down the enemy as he fights past each prepared defensive position. "Although every effort is made to stop the attack at the forward positions, the defender assumes that the offense will pierce them, and he therefore distributes his resources somewhat evenly among his various strong points" (Mearsheimer 1983, 49). A former UN political advisor to UNIFIL — the United Nations Interim force in Lebanon made an apposite observation regarding the deployment of Hezbollah forces. He pointed out that 
Hezbollah has "clear tactics, trying to draw Israeli... forces further into Lebanon. 'They can't take the Israeli's in open battle,' he said, 'so they want to draw them in to well-prepared battlefields,'... where there has been fierce fighting” (Erlanger and Oppel Jr. 2006, 4).

It should be noted that this strategy demands a force of significant size to man each defensive position. This strategy is then only effective when it is employed to defend a narrow front (Mearsheimer 1983, 50). In the case of Hezbollah, the organization was in fact defending a relatively small area, and thus was able to successfully employ the strategy, although as mentioned it above, it had a high troop density in the south. Thus, the most efficient use of their forces was to create set areas where its fighters were able to take advantage of the element of surprise and, more importantly, of their intimate knowledge of the terrain. This strategy was devastatingly effective throughout the ground war in 2006, and it was showcased in grim detail at the Battles of Bint Jbail and Aita al Shaab. On both occasions Hezbollah created an ambush point where they had the tactical advantage of cover and familiarity with their surroundings. At Bint Jbial

[d]ozens of Hizbullah gunmen armed with antitank missiles and machine guns and geared up in nightvision goggles and bulletproof vests set a trap for a force of Golani infantrymen... [the] men moved through approximately 15 one-story homes. But as the troops moved through the narrow alleyways a strong Hizbullah force sent a wave of gunfire and missiles at the force killing and wounding several soldiers in the first moments of the fight (Katz and Lazaroff 2006).

Tactical mobility enhances the effectiveness of defense in depth. "Mobility allows the defender to reinforce threatened points as well as retreat, when forced, to secondary positions" $(1983,50)$. In the case of Hezbollah, it was not forced to retreat often but due to its highly mobile forces it was able to reinforce its set ambush positions. At Bint Jbial Israeli force were expecting to engage 30 to 40 Hezbollah fighters, but the evening prior to the Israeli arrival at the village in the predawn hours Wednesday July 26, 2006, Hezbollah was able to reinforce its fighters. "By late Wednesday, Israeli radio, citing military officials, was reporting that there were 200 
Hezbollah fighters in the town" (Smith 2006).

It is necessary to emphasize a point regarding Hezbollah's strategic doctrine. Hezbollah understands the Israeli aversion to casualties, and as mentioned, defense in depth is a strategy explicitly developed to wear down an attacker. This is done in two ways by consistently denying the attacker's military goals and also by inflicting large enough casualties that the costs of combat are higher than the benefits. For Israel relatively small numbers of casualties are seen as significant losses, therefore, a successful Hezbollah strategy is not necessarily one that defeats the Israeli army but one that inflicts a high casualty rate. Hezbollah's strategy was simple, survive the first round or aerial bombardments — in their bunker system — then launch rockets on civilian targets in a punishment campaign for retribution. Survive a second wave of bombing, and thus extend the conflict as long as possible, in direct violation of Israeli doctrine, and wait for the inevitable deployment of ground forces. "It is in this last, and critical, phase that a dedicated, well-trained and well-led force can exact enormous pain on a modern military establishment and defeat it" (Crooke and Perry, 2006).

It is worth pointing out here that Hezbollah was also able, in its punishment campaign against Israeli citizenry during the conflict, to launch some 4100 rockets (Hoffman 2007, 39). In fact, The Party of God maintained a rate of fire of 150-180 rockets a day until July 17 . On July 18 , the organization lunched roughly 350 rockets, but then decreased it rate of fire to about 100 per day until the final day of the war when they launched 250 . This consistent and high rate of fire is a "testament above all to the planning that took place before the war but also to the dedication and skill of the fighters involved" (Exum 2006, 12). This again distinguishes Hezbollah from a terror organization or a traditional guerrilla group neither of whom have the capability to maintain or operate such a large and sophisticated arsenal of arms. Instead 
Hezbollah is the archetypal hybrid warfare organization.

\section{Conclusions}

In sum, Hezbollah has consciously adopted an unconventional variation of the defense in depth military strategy, what I have dubbed as hybrid warfare. The choice of this doctrine was based on several factors. Hezbollah has access to an increasingly urbanized, diversely educated and skilled populace that is supportive of its operations. Since its founding, the Party of God has worked to ensure that it maintains the widespread support of the Shi'a population in Lebanon. To that end it offers the Shi'a significant social services in exchange for their tacit and active support. In so doing Hezbollah created a cascade to support for its military operations. There is safety in numbers when people join Hezbollah, and more importantly, their contributions to the organization have never been perceived as a waste. Consequently, after pioneering the modern suicide bombing, Hezbollah has been able to abandon such operations in favor of more sophisticated hybrid military strategy. This is due to Hezbollah's increasingly educated and skilled supporters; Hezbollah's sophisticated arms, training, and larger weapons stockpiles (from Iran and Syria) are epiphenomena of its fighter's education, as wells its ability to maintain itself in war. Thus, Hezbollah's military development is rooted in both the rising urbanization and education of Lebanon's Shia population. 


\section{Chapter 4: The Communist Party of Nepal-Maoist and Traditional Guerrilla Warfare}

\section{Introduction}

Chapter three established that a hybrid warfare strategy results from a diverse recruitment base. A mixed population (both urban and rural) provides rebels with a variously skilled and educated base of supporters. Heterogeneous populations increase rebels' military capabilities, which in turn facilitate the adoption of hybrid warfare. This chapter, in contrast, examines the consequence of low (but increasing) levels of urbanization - and therefore levels of educationon rebel military strategy. This relationship is explored in the context of the Nepalese civil war between 1996 and 2006.

Recalling the theory I articulate in chapter 1, size and education are the jointly necessary but individually insufficient determinants of rebel capabilities. The Nepalese case demonstrates that in rural environments militant organizations lack capacity: rural communities generally lack educated and skilled individuals, and are small/homogenous populations.

The lack of variously skilled and educated members limits the ways in which rebels can fight, as rural militants often lack any knowledge of how to use modern weaponry, and are incapable of adopting more sophisticated armaments (due to high rates of illiteracy). Moreover, homogenous recruitment limits the appeal of a militant group, which does not facilitate a cascade 
of popular support, keeping rural rebellions relatively small. This small base of willing participants incentivizes forced recruitment to build up organizational capacity. Forced recruitment however is an ineffective method of building capacity, as forced recruits, or "volunteers," may try to escape, and forcible recruitment can alienate the local population (Macours 2010). Finally, due to the isolated nature of rural communities, insurgent leaders often cannot find foreign sponsors to supply significant quantities of light and/or heavy weapons; rural communities often do not have ties to foreign state or nonstate arms networks. These factors further constrain insurgent military and organizational capabilities. These limited capabilities make traditional guerrilla warfare the preferred military strategy of rural militants.

This case will not support my theory of rebel strategic adoption if the Nepalese rebels, even though they are rural and largely uneducated, employ a strategy other than traditional guerrilla warfare. Moreover, if Nepalese Maoists expand their recruitment base into cities, and diversify their membership beyond an identifiable subset of the population, this case will not support my theoretical claims. In order to substantiate my theory the Maoist rebels must (a) solely use light weapons; (b) include few urban and educated members; (c) avoid killing civilians; (d) fight in the countryside alone, and employ hit-and-run attacks against the Nepalese military forces.

\section{The Communist Party of Nepal (Maoist) and Guerrilla Warfare}

On November 21, 2006 the leader of Communist Party of Nepal (Maoist), Prachanda, and the Prime Minister of Nepal (Girija Prasad Koirala) signed the Comprehensive Peace Accord, which formally ended the decade-long Nepalese Civil War (Upreti 2008, 169). ${ }^{21}$ The conflict, which began on 13 February 1996, cost in excess of 13,000 Nepalese lives, led to significant displacement of rural populations, undermined development projects in one of the least

\footnotetext{
${ }^{21}$ Prachanda is the nom de guerre of Pushpa Kamal Dahal. In 2008, Dahal was elected Prime Minister of Nepal.
} 
developed countries in Asia (ahead of only Afghanistan in terms of per capita income), and caused general political instability at the national level (Lawoti 2010; Bohara et al. 2006, 108; Upreti 2008; Thapa and Sijapati 2004).

The Nepalese civil war was a Maoist insurgency. The weaker actor, the Communist Party of Nepal-Maoist (CPN-M), took on the state in a war of attrition to attain its political goal, the establishment of a "new people's democracy." Mao Tse-Tung and Peru's Shinning Path heavily influenced the Nepalese Maoists, consequently, the "new Nepalese people's democracy" was meant to end feudal relations of production, abrogate the special rights and privileges for the Nepalese Monarchy, expand the rights of women, end racial and caste discrimination, and allow for the autonomy of indigenous populations (ICG 2005; Goyal et al. 2005). To accomplish these goals the Maoists followed the guidance of previous communist movements. They initiated a military campaign, which emanated from the poor, rural, and mountainous mid-western region of Nepal; the CPN-M originated in the districts of Rolpa and Rukum, these became two vital districts in the party's "base area." The party used light arms in hit-and-run attacks against Nepali police and military forces. The CPN-M attempted to follow the Maoist dictum of "encircling the cities from the countryside" (Thapa and Sijapati 2004, 169).

The Nepalese case is particularly interesting from the perspective of this work, as the various governments in Nepal from 1950 forward consciously led an urban-centric state development project know as "vakish"-literally, development (Riaz and Basu 2007, 98). The goal of vakish development was to expand the power of the central state throughout Nepal via economic development. However, this development strategy systematically disadvantaged rural communities, which differed from urban areas in caste, ethnic, linguistic, and economic composition. Urban-biased development exacerbated existing inequalities between Kathmandu 
(part of patron-client relationships with large and ethnically similar landholders) and smaller, poorer farmers (Macours 2010; Joshi and Mason 2008; Sharma 2006). The government in Kathmandu, and large-absentee landowners directly connected to the state-via caste and ethnic ties - reaped economic benefits from vakish, at the expense of the rural poor (Lawoti 2003). Rising levels of inequality between Kathmandu, its rural allies, and the rural poor facilitated the development of the Maoist insurgency. It was the rural origins of the insurgency, in a state working to increase levels of urban development, that determined Maoist organizational and military capabilities, and thus the organization's guerrilla warfare military strategy.

This chapter therefore serves a counterfactual purpose to the previous chapter on Hezbollah and hybrid warfare. It demonstrates how rebel organizations in extremely rural states organize. In a mixed population like Lebanon's Shi'a, rebels are both large as well as variously skilled and educated, leading to high levels of military capability. However, nascent rebels in Nepal were solely rural and therefore generally lacked higher education and technical training. As a result, although the CPN-M was able to mobilize 10,000 armed and trained fighters, and a sizable number of other supporters, a combined force of up to 35,000 at the peak of the insurgency, the rebellion lacked military capacity (ICG, 2005). That is, rebel capability is a function of both the number and education of recruits. In Nepal, the Maoists had only one of these (size) dually necessary but individually insufficient factors. ${ }^{22}$ As a result of their limited capacity the Maoists were never able to take and hold territory, or exert complete territorial control; throughout the conflict they relied solely on hit-and-run attacks, even in their base areas,

\footnotetext{
${ }^{22}$ In comparative terms however the Maoist's total size does not suggest high levels of capacity: Hezbollah in 2006 had $0.001 \%$ of the Lebanese population under arms (using a figure of 7000 active fighters out of a population of 4.8 million). Hamas mobilized $0.004 \%$ of the population for violence in 2008 (using a figure of 8,000 fighters in a population of $1,640,000)$ (PCBS 2012). At its height, the CPN-M had only $0.0004 \%$ of the population (10,000 active fighters out of a population of 25 million). In this crude comparison relative size Hezbollah is some 2.5 times larger, as a percentage of the population, than the CPN-M (UN 2011). Therefore, if size is a proxy for rebel capacity, both Hamas and Hezbollah are at least twice as capable as the CPN-M (see Wood 2010 on rebel size and capacity). This may contribute to explaining at least part of the variation in the three organization's military strategies.
} 
and never impacted urban spaces. Due to this lack of demonstrable capacity, the CPN-M only had access to light weapons which it captured from Nepali police and military forces, as the Maoists were unable to find a foreign sponsor (Lawoti 2010, 24).

This case also demonstrates the role that mountainous terrain plays in rebel strategic choice. The CPN-M emanated from the hilly/mountainous areas of the mid and far-western regions of Nepal. This terrain undermined the Nepalese state's ability to exert control, move equipment/troops, communicate with its representatives, and therefore pursue the highly mobile Maoist force; the districts from which the Maoists launched their rebellion lacked traditional roads, instead travel was restricted to "tracks" (Bohara et al. 2006; Ogura 2004). The Maoists exploited topography and limited state mobility in their hit-and-run attacks.

In what follows, I demonstrate that the Communist Party of Nepal (Maoist) is an archetypal example of a rebel organization employing a guerilla warfare strategy in war. The Maoists were lightly armed rebels emanating from the mountainous and rural hinterlands of the Nepalese state. They fought against the relatively strong, but absolutely weak police and military forces of Nepal, and endeavored to kill few civilians_-but abducted noncombatants en masse. This strategy resulted from the rural environment in which the Maoists operated as well as the poor quality and homogenous nature of CPN-M supporters.

\section{Nepal, Centralization-Based Development, and the Communist Party}

The Maoist insurgency in Nepal is rooted in the politics of centralization and urbanization in Nepal. Economic, ethnic, and (Hindu) caste hierarchies are embedded in the political history of Nepal, and have been exacerbated over time due to economic development and political strategies pursued by the state. Seeking to expand the power of Kathmandu over the entirety of the state, Nepal's leaders created a highly centralized polity with little reach and 
influence in rural areas. The process of building up the center's power led to severe underdevelopment in rural areas, where $90 \%$ of the Nepali population has historically lived (Lawoti 2003). This development strategy gave preference to political parties and their cronies over others, and thus advantaged particular geographic locations over others. As a consequence, when Maoists forces began to proliferate in Nepal after 1990 they could appropriate a variety of economic, social, geographic, and political issues to motivate participation in their fight against the state. Inequality in Nepal, exacerbated by urban-biased economic development policies allowed the Maoist rebellion to develop and proliferate.

\subsection{Nepalese State Development: Entrenching Ethnic and Caste Divisions}

Nepal was formed as a sovereign nation in 1768, when Prithvi Narayan Shah, the ruler of a Gorkha principality united the state based on a "Hindu Brahminical notion of caste hierarchy" (Riaz and Basu 2007, 69). Between 1814 and 1816 the Gorkha rulers of Nepal fought and lost a war with the English East India Trading Company. The terms of the 1816 peace treaty (the Treaty of Sagauli) ended this conflict and set Nepal's current geographical boundaries (Nepal is landlocked, and thus economically dependent on India). Most importantly, the new state incorporated many discrete ethnic and linguistic groups under the hierarchical structure of Hinduism - Nepal was founded as an explicitly Hindu state (Thapa and Sijapati 2004, 169).

Gorkha rule was upended due to internal conflict. In the course of this internal conflict, Jang Bahadur Kunwar Rana, a powerful member of the royal court seized power: in 1846 he slaughtered members of the royal family in an effort to gain political power. The king ultimately appointed him prime minister, "Thus, the Rana family became the hereditary prime ministers and de facto head of the state" (Riaz and Basu 2007, 35). The Rana family reigned over Nepal for the subsequent 104 years. During this period the Nepali state privileged high caste Hindu ethnic, 
linguistic, and cultural traditions. To this end, Nepali, the language claimed by the Newar ethnic group (and top Hindu caste), was chosen as the official language of state, despite the fact that it was not until the end of the twentieth century that over $50 \%$ of the population reported it as their mother tongue (Gurung 2003, 13). ${ }^{23}$ Privileging Hindu ethnic, linguistic, and religious traditions helped Nepali political leaders concentrate power amongst a fairly small subset of the population; this subset of the population also controlled the vast majority of arable land.

The caste and ethnic biases of the Gorkha and Rana regimes were formalized in statewide social stratification known as Muluki Ain introduced on January 5, 1854. This served to divide Nepal's society into five separate caste groups. This grouping, while never completely enforced, dictated the power relationships within the state. That is, while the some groups (discussed below) gained power and privilege, others were left without power and lacked any political representation.

The top Hindu castes and ethnic groups in Nepal come from the middle hill regions; these groups include Bahuns, Thakuris, Chetris (CHHEM, the caste hill Hindu elite males), as well as Newars from Kathmandu valley. These four groups, which have historically constituted less than forty percent of the Nepali population, have dominated the politics of Nepal; they have filled a disproportionate number of political and bureaucratic offices, and have much higher literacy rates than other castes and ethnic groups in Nepal (Lawoti 2003; Gurung 2003, 5). As of 1991, Bahuns, Thakuris, and Chetris accounted for roughly 70 percent of all graduates in Nepal (Riaz and Basu 2007, 72). Furthermore, as late as 2001, while these ethnic groups constituted only 37.2 percent of the population, they occupied more than 80 percent of government positions in the executive, parliamentary, and judicial branches (Lawoti, 2007; Riaz and Basu 2007). These caste

\footnotetext{
${ }^{23}$ Castes are "vertically stratified by ritual status while ethnic groups are horizontally distributed in space" (Gurung 2003, 3).
} 
hill Hindu elites have historically controlled the vast majority of arable land in Nepal as well; in $19916 \%$ of the landowners in Nepal controlled over 50\% of the land, and in 1998 this population owned some 33\% (Riaz and Basu 2007).

A byproduct of founding a state that privileged high Hindu castes and particular ethnic groups was a large section of people lacking in political and economic privilege. This latter group was made up of lower Hindu castes, the Dalit (impure and untouchable) population, and indigenous nationalities. ${ }^{24}$ Janjatis (indigenous ethnic groups, literally "nationalities") from the rural western regions of Nepal have been systematically left out of the political process even though they have historically accounted for some 35\% of the population (Gurgung 2003, 5; Eck 2010).

In 1991, Dalits accounted for in excess of 2.2 million people, or 11.9 percent of a total population of 18.4 million. By 2001 this population increased to 2.9 million, accounting for 12.8 percent of the 22.7 million person Nepalese state. Despite its size this section of the population has historically been uneducated, illiterate, and landless (Gurung 2003, 8:33; Riaz and Basu 2007). Moreover, Dalits have been largely excluded from the political process; in the democratic era, post-1990, Dalits have elected only four representatives to the legislative assembly (Riaz and Basu 2007). Successive Neplai regimes (including the democratic regime after 1990) reinforced the lack of privilege for Dalits and ethnic nationalists through their respective political and development agendas; in the post 1990 democratic era the "highly majoritarian and centralized democracy excluded more than two thirds of the... Dalit, [and] indigenous nationalities... from governance" (Lawoti 2010, 20).

Analyses of the Nepalese civil war have found that caste and ethnic disparities (in terms of political representation, economics, and education) best explain the origins of violence in this

\footnotetext{
${ }^{24}$ Dalit is a term imported from India, and is generally defined as those castes that are untouchable.
} 
case. These findings have been buttressed by analyses that find a relationship between expanding levels of economic inequality (between rural poor-Dalits and indigenous ethnicities—and larger state supported land holders) and Maoist recruitment (Murshed and Gates 2005; Macours 2010).

The exclusionary nature of the developing Nepalese state was rooted Rana anxiety regarding the effects of expanding educational access to the rural population. The Ranas worried that a more educated population would ultimately demand greater representation and more public services, thereby undermining Rana control over society. "Ranas regarded education as the exclusive privilege of the ruling elite and opposed any form of public instruction system for the people. Knowledge was regarded as the symbol of social status as well as a toll for dominance over the society" (Riaz and Basu 2007, 39). Part of the Rana problem was that while the Nepalese state was highly centralized in Kathmandu, it was very weak everywhere else. That is, the state had devolved very little power to the district and local levels, and local government institutions had "virtually no responsibility for delivering services" (Lawoti 2003, 50). The delivery of education was therefore beyond the scope of the central state's ability, and providing this service could have undermined the state's power structure.

Consequently, as levels of educational attainment have risen in Nepal major inequalities have remained (and even grown) between the various ethnic, caste, and gender groups. In the 1950's the average literacy rate in Nepal was five percent, with a ten percent literacy rate among males, and less than one percent literacy among females (Riaz and Basu 2007, 40). In 1981, only $24 \%$ of the population was functionally literate; urban males were by far the most educated, with a literacy rate of $62 \%$ compared to $33 \%$ for rural men. By contrast, urban and rural women had much lower literacy rates of 33 and 9 percent respectively. The national literacy rate was only 39 
percent in 1991; Dalit communities had literacy rates between $4.2 \%$ and $11.5 \%$ or less than half the national average. High levels of literacy and education among caste hill Hindu elite males bolstered these national averages (Gurung 2003, 26). By 2004, the total literacy rate had increased to 45.2 percent, but the difference between the sexes remained, with 62.7 percent of men being literate, as compared to only 27.6 percent of women (Riaz and Basu 2007, 105). By 2010 , only 30.7 percent of the population over 15 years old was enrolled in secondary school, and of those, only $7.8 \%$ were completing secondary school (Barro and Lee, Forthcoming).

The first democratic elections in Nepal took place in 1959. The Nepali Congress took 74 of the available 109 seats in parliament. B.P Koirala was appointed Prime Minister of this new government. However, on December 15, 1960 King Mahendra dissolved the democratically elected parliament, arrested B.P. Koirala, as well as other major political leaders, and banned the Nepalese Congress. In place of this democratic system King Mahendra introduced the Panchayat system. This was a system of governance lasted thirty years (until 1990) in which the King ruled directly over Nepal, in a 'guided democracy.' In practice, the Panchayat system "provided for a semblance of national legislature - elected indirectly by the people through three tiers of village, district, and zonal assemblies — but which did not have any real legislative powers... [A new 1962] constitution did provide for a prime minister but he was beholden to the king for his office, and the ultimate source of his authority was the king" (Thapa and Sijapati 2004, 18). This Panchayat system reinforced the Hindu ethno-religious order established by the pervious Rana and Gorkha regimes. In effect, this political order was a large patron-client network, which was founded on a narrow sense of Nepali identity: Hindu devotion to the King who was in turn the custodian of the Hindu state (Riaz and Basu 2007, 47). 
The Panchayat era ended in 1990 with the popular - generally nonviolent - uprising known as the Movement to Restore Democracy, which "compelled the king to allow a multiparty system to replace the no-party Panchayat system" (Joshi 2010, 92). The new multiparty system did little to address enduring ethnic, social, and economic disparities, and thereby facilitated the outbreak of the Maoist insurgency in 1996 (Thapa and Sijapati 2004; Joshi 2010; Riaz and Basu 2007).

After 1990, the central state, led by the newly elected Nepali Congress party focused on increasing the reach of its authority throughout rural Nepal. In effect, the power taken away from the King in 1990 was transferred to political parties and their leaders. The political parties, most notably the Nepali Congress, institutionalized their new power via cronyism: they appointed their own party member to positions of authority within the newly democratic state. However these practices did little to expand the central state's ability to collect taxes, provide security, or maintain law and order (Lawoti 2003). Instead is simply redefined the existing power relationships within the state.

\subsection{Patronage and Clientelism and Inequality}

A factor that reinforced the social, ethnic, caste, and region disparities in Nepal was the pervasive clientelism that survived each new regime. Clientelism in Nepal is predicated upon agricultural production, and took the form of land grants "Birta." During the Rana regime, lands were granted to priests and monasteries in order to curry favor and legitimacy for Rana rule within Hindu Religious institutions, and therefore amongst high caste Hindus (Joshi 2010, 94). Land was also allocated to state officials and relatives of the royal family (Joshi and Mason, 2008). Those "who controlled birta land in a village at any given point in time were the political authority in that village. They controlled peasant access to land in the sense that they determined 
who was allowed to rent birta land, how much each household was allotted, and what the rental terms would be" (Joshi and Mason 2008, 769).

In addition, the post-Rana democratic state institutionalized this rural landed elite. That is, taxes on agriculture have historically been the main source of state revenue in Nepal. Tax collection rights during the Rana era were distributed to village heads in hill regions or other local notables in the Tarai. These village big men were in practice the largest landholders in the area. These individuals reported their collections up to the regional governor, who was himself a family member of a high-ranking official (especially in the case of the post-1990 Nepali Congress) or a member of the dominant caste of a party (as was often the case for the CPNUML) (Lawoti 2003).

The 1951 Tenancy Rights Acquisition Act was passed in order to give people that paid taxes on land they worked, the title to the land. It was an effort to eliminate the largely feudal birta system. However, because local big-men collected and reported the taxes they collected in their own names, they claimed the permanent legal rights to the lands they managed on the state's behalf. This Act therefore created a land-holding elite beholden to the state, and a much larger population of landless rural poor (Joshi 2010, 95).

When the Nepali Congress party took power following the 1991 democratic elections it sought to seize this clientelist network to marshal supporters for their election campaign (Joshi and Mason 2008). At the same time, local power brokers, (large landholding families in villages) turned to the newly dominant Nepali Congress to maintain their power position vis-à-vis the peasantry in rural Nepal (Riaz and Bosu 2007). Large landholders, due to the nature of birta land, could direct peasants working their lands on how to vote in elections or be subject to dispossession. This increased turnout for the Nepali Congress, the party that worked with 
landowners, but undermined the rights of poor farmers and disadvantaged communist party politicians in rural areas (Thapa and Sijapati 2004, 68; Joshi and Mason 2008).

The power of large-landholders over the rural poor, and the Nepali Congresses ability to affect voting patterns in the country, hurt the electoral performance of the various communist parties. Moreover, "the Nepali Congress government jailed and tortured the activists and leaders of the Maoist political party (United People's Front Nepal, UPFN), in their stronghold of Rolpa and Rukum, including the elected official of the district development committees" (Lawoti $2003,54)$. The use of power by the elected central authority, which controlled the police in rural areas, facilitated the growth of the Maoist faction of the Communist Party of Nepal in Rolpa and Rukum.

\subsection{Centralization, Unequal Development, and the Basis for Rural Mobilization}

As has been discussed, a key goal of successive Nepali governments was increasing the power of the central state. This was accomplished was via economic development policies that created large income inequality between the rural poor and Kathmandu as well as its clients. "According to the Maoists, social and economic injustice against the poor, particularly in rural and remote areas, is the reason for their fight against the government" (Sharma 2004, 1238). In addition to privileging urban over rural areas for state services, Nepali economic development further separated the dominant ethnic groups, both urban and rural, from the poorer populations. This was especially evident in the mid and far-western regions of the state. In short, Nepali economic policies, which focused on building up the economy around Kathmandu and dominant castes/ethnic groups, explicitly undermined rural economic growth; low levels of urbanization drove anti-rural policymaking, contributing to high levels of economic inequality. This economic inequality, a direct result of Kathmandu's economic development strategy, created a population 
within Nepal that could be mobilized by the Maoists for violent collective action against the state.

From 1956-1985 Nepal engaged in, as did many other developing countries, import substitution industrialization, with the dual goals of creating more jobs and raising the standard of living and strengthening the power of Kathmandu. To support this strategy a disproportionate amount of state resources were devoted to infrastructural development in the areas in which industry was meant to develop (foreign aid was also allocated to this). Most importantly, Kathmandu was placed at the center of this infrastructural development (Riaz and Basu 2007). From 1986 forward however Nepal, under pressure from the IMF and World Bank, instituted significant economic reforms, but these did little to remedy major economic inequality (Sharma 2005).

Urban-focused development drew state resources away from agricultural investment. Although agriculture was/remains the dominant employer in Nepal, and largest contributor to the economy, it has not received more than $26 \%$ of state expenditures on development since the 1950's; agricultural production contributed as much as $80 \%$ to Nepal's GDP in the late 1960 's, and between 40-50 percent after the turn of the century (Sharma 2006; Deraniyagala 2005). Disproportionate state investment in public industries has undermined traditional Nepalese exports, including rice, timber, hides, and jute, as these goods are "heavily taxed through overvalued exchange rates and direct market interventions. For instance, exporters of rice and oils were required to sell a certain percentage of their output to the Nepal Food Corporation-a public enterprise owned by the Government — at below market prices to provide subsidized food to the urban population" (Sharma 2006, 1242). More, between 1990 and 2002 investment by the 
state in agriculture as an industry was stagnant. As a result, while some $80 \%$ of the population was employed in agricultural production, their products were not being exported.

When controlling for inflation, nominal incomes in Nepal grew by $16 \%$ and $4 \%$ per annum through 1996 for urban and rural populations respectively. However, "when taking the average rate of inflation into consideration, the growth of rural incomes... [was] in fact negative. This not only increased poverty in the rural areas but also increased the rural-urban inequality" (Sharma 2005, 1243). In the districts that became base areas for the Maoist rebellion, Rolpa, Jajarkot, and Salayan (in the mid-western region) the average income was 25, 19, and 17 percent, respectively, of Kathmandu's (Murshed and Gates 2005, 125). Incidences of poverty in Nepal at the onset of the Maoist insurgency (1996) are also telling. Poverty in rural areas was 44\%, while it was only $20 \%$ for urban spaces (Sharma 2005). More importantly, in the rural mid and far western hills/mountain regions, where the Maoists developed, $72 \%$ of the population lived in poverty (Deraniyagala 2005).

It is also important to note here that instances of poverty are significantly lower for the upper castes — which make up the majority of state officials and large landholders; the top ten percent of people in Nepal generate 35\% of Nepal's total income (Sharma 2005). In contrast, over $60 \%$ of Dalits have incomes well below the national poverty line, while incidence of poverty amongst indigenous ethnicities range from $45 \%$ to $59 \%$ (Deraniyagala 2005).

Economic growth figures estimated between 1990 and 2002 are instructive: agricultural production grew by $1.5 \%$ per year between 1990 an 1995, and increased to 3\% per year from 1996-2002. This however was a net decrease from the 1980s when agricultural growth was over $4.5 \%$ per annum. "In sharp contrast, non-agricultural sectors grew at over $8 \%$ per annum in the first half of the 1990s" (Deraniyagala 2005, 58). However, as late as 2004 manufacturing only 
employed three percent of the national workforce, and contributed has maximum of $10 \%$ to GDP (Sharma 2006, 1239). The practical implication is that Nepali economic development led to a long-term decline in real rural incomes (where the majority of the population lived).

Contrastingly, this same development strategy facilitated a significant expansion in manufacturing sectors over the same period, which meant that real urban incomes rose substantially, especially when compared to rural ones (Deraniyagala 2005).

The choice to develop urban industry at the expense of the countryside provided benefits for only a small percentage of the population. At the end of the Rana era (1950) only 2.68 percent of the population lived in urban areas. In 1996, at the outset of the civil war, only $11.4 \%$ of the population lived in urban areas, an increase of 8.72 percent over forty-six years $(0.18 \%$ per annum). By 2010, this figure had increased to $18.62 \%$, a change of 7.22 percent in 14 years, or $0.52 \%$ per year (UN 2010).

State investment in the provision of public service also disproportionately favored urban centers. Rural populations had less access (in terms of distance and time travelled) to primary schools, health centers, banks, markets, paved roads and public transit as compared to urban dwellers (Sharma 2004, 1243).

In sum, the pursuit of urbanization and state centralization, in a state where urbanization was historically low caused anti-rural policy-making, which disadvantaged the vast majority of Nepalese labor. These policies "contributed to a rise in poverty and inequalities (between rural and urban areas, and elite and non-elite groups), which made it easy for the Maoists to mobilize disadvantaged youth from the rural and remote areas in their fight against the political system" (Sharma 2005, 1247). Indeed, Baburam Bhattari (a CPN-M leader) has argued that in order to fix 
inequality the Maoists will seek to revise the urban-centric economic policies of the state, and seek to urbanize the countryside (ICG 2005, 6).

\subsection{Communism in Nepal}

It was in this economic and social environment that the Communist Party of Nepal, and its offshoot, the CPN-Maoist developed. During the Panchayat years, the Communist Party spread clandestinely throughout the state. This was possible because the regime was focused on eliminating overt political challenges from the Nepali Congress party, which held a two-thirds majority in parliament when King Mehendra suspended democracy and instituted the Panchayat regime in 1960.

Throughout the Panchayat years the CPN was beset by factionalism. One subset of communists formed the CPN (Marxist Leninist). The CPN (ML) later merged with the CPNMarxist, "a party with well-known leaders but a weak base, to become the CPN-United Marxist Leninist (CPN-UML) in 1990 and emerged as the major opposition party after the 1991 general election. It formed the first democratically elected communist government (minority) in the world... in 1994 but lasted only for a year" (Lawoti 2010, 5).

CPN-Maoist development is traced to 1974, and the CPN-Fourth Congress (FC), which was led by Nirmal Lama and Mohan Bikram Singh (this strain of communists developed parallel to the CPN-ML/CPN-UML). Following various splits, Lama and the CPN-FC (without Singh) merged with CPN-Mashal led by Pushpa Kamal Dahal (Prachanda, leader of the Maoist insurgency) and another communist faction led by Baburam Bhattari to form the CPN-Unity Center (UC). The CPN-UC founded a political front — the United People's Front Nepal (UPFN) - led by Bhattari to compete in the post-Panchayat 1991 national elections (Thapa and Sijapati 2004; Riaz and Basu 2007; Lawoti 2010; Sinkhada and Oliva 2006). The UPFN won 4\% 
of the national vote ( 9 parliamentary seats) in the 1991 elections, with the Nepali Congress garnering $38 \%$ of the vote and 110 seats, and the CPN-UML taking $28 \%$ of the vote and 69 seats in parliament (Thapa and Sijapati 2004, 36).

Even with this minor electoral success, prior to the 1994 mid-term elections the CPN-UC and the UPFN split, with the faction led by Prachanda and Bhattari boycotting the elections. This was, at least in part, due to the fact that the Election Commission failed to recognize the latters' political front (Lawoti 2010, 6). The Prachanda/Bhattari faction of the CPN-UC then went underground to begin organization and programmatic preparations for a people's war. "After being underground, Maoists began mobilizing and training unemployed youth, particularly from rural and remote areas, who have failed to see the benefits of [urban-centric] development. By the mid-1990's, they trained about 2,000 armed fighter which enabled them to declare a people's war" (Sharma 2005, 1245). In 1995 the Prachanda/Bhattari movement renamed itself the CPNMaoist, and announced its intention to begin an armed insurgency (Sinkhada and Oliva 2006). The Maoists believed that for " "the true liberation of the people all efforts must be concentrated for the development of a people's war that would usher in a new people's democratic form of government', and decided to give up... [their previous] policy of taking part in parliamentary elections" (Thapa and Sijapati 2004, 45).

Therefore on February 4, 1996 Bhattari submitted a list of 40 demands addressing issues of nationalism, democracy, and economics, with an ultimatum of initiating an armed rebellion if the demands were not addressed. The demands ranged from issues of land tenure, to the rights of indigenous nationalities, women and Dalits, to promulgating a new constitution and abolishing royal privileges. In short, the Maoists claimed to be rebelling against the status quo on behalf of “oppressed socio-cultural groups" for issue like ethnic autonomy and privileges for the Dalit 
community (Lawoti 2003, 69). On February 13, 1996, four days before the expiration of the ultimatum the CPN-M simultaneously attacked rural police posts in two mid-western districts and one in the central region, thereby launching its ten-year insurgency (Lawoti 2010,7).

\section{Education and the Communist Party of Nepal (Maoist)}

The foregoing discussion highlighted how urban-centric development strategies and social polices pursued by successive governments/regimes in Nepal created major inequality. This inequality facilitated the mobilization of rural caste and ethnic groups in support of the CPN-M rebellion.

As discussed in chapter one, organizations originating in rural communities generally have limited organizational capabilities due to the nature of their support base. Rural communities are separated from one another by great distances and poor infrastructure, and in the Nepalese case, are rooted in rough and mountainous terrain; Nepalese rural communities are also unrelated to urban populations. These structural factors make large-scale, heterogeneous, participation in violence difficult, as the population of willing participants is homogenous, making a cascade of popular support unlikely. Moreover, due to urban-centric development, the rural population of Nepal, particularly in Maoist base areas, lack the training and technical skills necessary to operate anything but the most basic of armaments. Therefore, I now turn to explaining how a relatively uneducated and unskilled supportive population led the Maoists to adopt a guerrilla warfare strategy.

To begin, in 1990 - the end of the Panchayat era as well as the year in which Prachanda and Bhattari form the CPN-UC and the UPFN—only 3.54 percent of individuals fifteen and over had completed secondary school (only 19.87 percent of this group were enrolled). Enrollment rates in secondary school increased 18.89\% between 1950 (0.86\%) and $1996(19.752 \%)$; over the 
same time period, completion rates increased $3.6 \%$ from $0.3 \%$ (1950) to $3.9 \%$ in 1996 . By the end of the civil war (2006) both enrollment completion rates had actually increased, to $25.32 \%$ and 5.98\% respectively, for those individuals 15 and over (Barro-Lee 2012). Table 1 shows the Nepalese education rates, in terms of enrollment and completion, between 1950 and 2010. Figure 1 illustrates the trends in these data as compared to the rate of urbanization in Nepal.

\begin{tabular}{|ccc|}
\hline Table 1. Enrollment and Completion Rates Nepal: Secondary Education, 1950-2010 \\
\hline & Enrollment & Completion \\
\hline 1950 & 0.86 & 0.30 \\
1955 & 0.88 & 0.31 \\
1960 & 1.06 & 0.33 \\
1965 & 2.11 & 0.47 \\
1970 & 4.08 & 0.84 \\
1975 & 5.26 & 1.04 \\
1980 & 6.90 & 1.17 \\
1985 & 12.89 & 2.12 \\
1990 & 19.87 & 3.54 \\
1995 & 19.40 & 3.76 \\
2000 & 21.16 & 4.47 \\
2005 & 24.44 & 5.65 \\
2010 & 28.82 & 7.29 \\
\hline
\end{tabular}

The data in table and figure 1 demonstrate that, like much of the globe, urbanization and educational attainment have increased in Nepal over time, but both remain extremely low. Thus, in 2010 , less that 30 percent of the population was enrolled in secondary school, with 93 percent of the population not completing secondary education. This may be related to the fact that in $201081 \%$ of the population resided in rural areas, even with a $15 \%$ increase in urbanization after 1975. These figures are buttressed by the facts that in 2010 thirty seven percent of the population received no schooling, and in $201134 \%$ of the population was illiterate (Gurung 2003; Barro- 
Lee 2012). ${ }^{25}$ In rural areas young people are generally required to work in agricultural production — which is necessary for survival—instead of attending primary and secondary school.

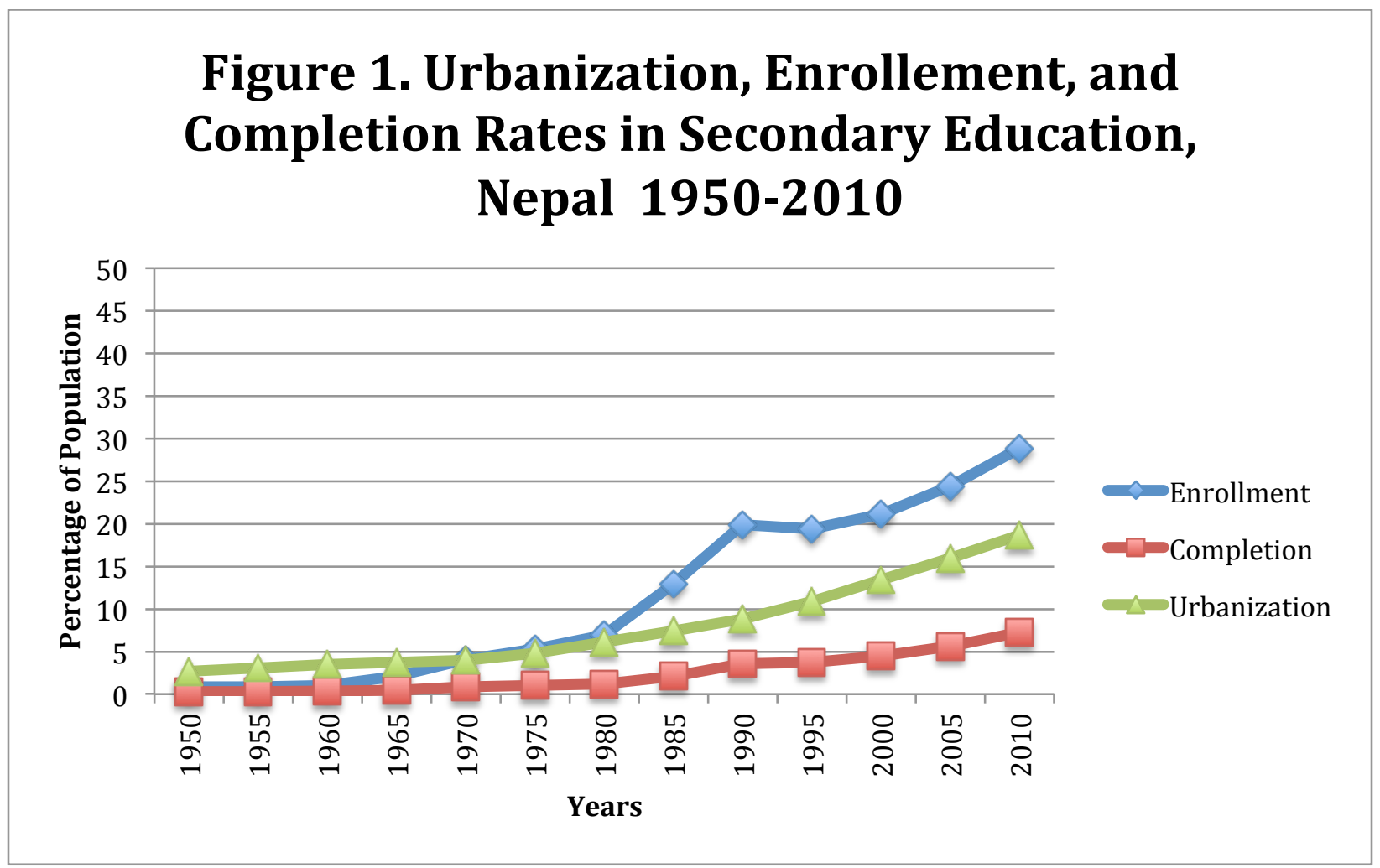

These education and urbanization data support the claims about the increasing levels of development within Nepal in the run up to the insurgency. Although, economic development, educational attainment, and urbanization rates increased through the 1990's when the CPN-M began to organize, there were dramatic differences within the population based on geographic location, gender, caste, and ethnic identity. "Despite general accessibility, education still nonetheless primarily served children of landlords, businessmen, government leaders, or other

\footnotetext{
${ }^{25}$ It should be noted here that these education figures constitute best estimates, and may in fact deviate significantly from other published estimates. GER and NER rates in Nepal are generally "overestimated and unreliable due to the practice of enrolment based government grants to the school" (UNDP 2004, 114). Best estimates come from country level surveys (the 2001 census for example, which is used in this dissertation), and UN estimates. Barro-Lee employs this information.
} 
elite members of the society, for they were the only ones who could easily afford to continue beyond primary school. They also were far more able to afford, and likely to continue, education beyond the high school level" (Savada 1991). Moreover, educational expansion has largely remained urban biased, with the majority of schools, especially the highest quality ones, being found in urban centers; in rural areas that had educational institutions, the quality was poorer relative to urban schools (Savada 1991). A measure of this urban-rural divide is evident in free school textbooks. "While 30\% of the thirty-four hundred thousand primary school-going student in 2002 received free government sponsored text books... in the far-flung rural districts the equivalent figure is only 15 percent" (Raiz and Basu 2007, 106).

Dalits constitute a significant portion of Maoist guerrillas, thus looking at educational information on Dalits is useful here. According to the 2001 Nepalese census, "literacy rates among Dalits (33.8 percent) where much lower that the national average (53.7 percent). Nearly $80 \%$ of Dalits were illiterate in the Terai region, though in the hill regions [their] literacy rate was... higher... (31.51 percent)" (Riaz and Basu 2007, 82). For Dalits, of whom only 5.3 percent where enrolled in secondary school in $2006,41.7 \%$ were girls; female secondary school enrollment amongst Dalits was 5 percent lower that the national average (Acharya 2007, 139).

\subsection{The CPN-Maoist, Janjatis, Dalits, and Women}

The CPN-M, as mentioned above, based its rebellion in the rural mid-western region of Nepal, specifically, in the neighboring districts of Rolpa, Rukum, Salayan, and Pyuthun (de Sales 2003; ICG 2005). These regions were selected for several interrelated reasons. First, these districts are historically amongst the poorest in Nepal; at the outset of the insurgency neither Rolpa nor Rukum had a single hospital or any form of industry, and ninety-five percent of the population make a living in agricultural production (de Sales 2003, 342). More, in the Midwest 
region Dalits account for nearly a quarter of the population (Acharya 2007). Second, the districts are mountainous and heavily forested — over fifty percent of the two districts is forested — which offers cover for guerrilla operations. Also, the communications network in these two districts is primitive further isolating this population, and making state military operations difficult (Ogura 2004).

Third, the majority of the population (70\%) is Chetri (a CHHE) and a minority is Kham Magar. The former inhabit the most fertile lands in Rolpa and Rukum. Moreover, the Chetris in these districts are Nepalese Congress party supporters, meaning they reap disproportionate benefits from clientelist relations with the governing Congress party (de Sales 2003, 342). The latter group is an indigenous ethnic minority (Janjati) that has been excluded from the state, and has suffered as a result of historic land-tenure arrangements.

The Kham Magars populate roughly 30 villages at the higher elevations (each with between 300-400 households and several thousand villagers) in Rukum and Rolpa. Kham Magar communities are deeply tied to their geographical origins. Thus, each of the four Magar clans are known by a geographical designation, which locates it in a particular historic site of residence (de Sales 2003, 345). The Kham Magars supplement their agricultural production with transhumant animal husbandry and the production of hashish (de Sales 2003, 344). This population also has very few outside relationships. "They have hereditary relationships with low service castes (blacksmiths and tailor-musicians) who live at the edge of their villages; no other caste has settled in their territory" (de Sales 2003, 78).

The isolated nature of the Magar community, and their dependence on agriculture has therefore disadvantaged this population, even though their educational attainment is at or above the national average. The literacy rate amongst Magars was 39.3\% in 1991 and $62.5 \%$ in 2001 - 
the Nepalese averages were $39 \%$ and $59.6 \%$ respectively (Gurung 2003). The Magar community therefore highlighted, from the Maoist perspective, the deep social and regional inequalities in Nepal (de Sales 2003). Moreover, the Maoists believed they could use these inequalities for mobilizing the Magar community because many Magars resented the upper and urban castes for their institutionalized advantages (Riaz and Basu 2007).

A letter from a foreigner travelling in Nepal in September 1995, after the formation of the CPN (Maoist) but 5 months before the outbreak of hostilities, summarized the socio-economic situation in future Maoist base areas:

The problem lies in the situation many young Magars are in... Education in the Magar area is bad to nonexistent, the health status in parts is catastrophic, and no interest from the official side in improving anything or even lending an open ear to their problems and needs. Money and big projects are brought to the lower areas [where Bahuns and Chetris, caste hill Hindu elites, reside] but never reach Magars. So they see their only hope on a radical solution which they think the [Maoists] can bring (Thapa and Sijapati 2004, 79).

From the perspective of this work, the Kham Magar population is doubly interesting. This Janjati was both disadvantaged and had an above-average literacy level, and therefore was seemingly a useful source of recruits for the CPN-M. However, while the Maoists endeavored to recruit this population, it resisted. In fact (as will be discussed below), Magars were abducted into Maoists ranks, and many of these "recruits" were not trained as guerrillas, they worked in support roles (Ogura 2004; Macours 2010).

An issue that comes across from any historical analysis of Nepal is the disadvantaged position of women and Dalits. Gender inequality is rampant in Nepal: gross enrollment figures in primary and secondary school are consistently lower for girls than they are for boys. Girls' enrollment rates in secondary school between 2002 and 2005 were between 12 and 14 percent lower than for boys (Acharya 2007). Data on Dalit women further highlights this educational disparity. The "literacy rate among Dalit women is only 7 percent in comparison to $66 \%$ literacy 
rate [2004] among general population Nepal. They also have the lowest life expectancy of any social group in Nepal" (Riaz and Basu 2007, 138).

Membership in the Maoist ranks "directly addresses the structural inequalities, which constrain young people, as Maoism emphasizes the equality of all regardless of age or gender. Positions of leadership are awarded on merit rather than on the basis of age, gender, of clan/caste affiliation" (Pettigrew 2003, 318). In practice therefore, young and poor Dalits can/and did lead groups of fighters on military missions, and this affected the Maoist propaganda campaign (Pettigrew 2003, 318; Ogura 2004).

In examining these data, and the inequalities that they highlight, it should come as no surprise then that Dalits and women made up a significant proportion of active fighters within the Maoist ranks. Women accounted for as much as 30\% of Maoist cadres (including active fighting forces), while Dalits were a majority of Maoist guerrillas according to eyewitness accounts (Ogura 2004). Leaders of Dalit political parties and local organizations "say that dalit [sic] participation is considerable in the insurgency" (Lawoti 2003b, 76). In fact, by 2001, 17 of the 23 “district people's governments" formed by the Maoists were led by Dalits and Janjatis (Lawoti 2003b, 78).

The above data, supported by ethnographic information, all suggest that throughout the insurgency Maoist recruits were young (between the ages of 15 and 25), rural, poor, and generally uneducated/lacking in technical skills (Ogura 2004; Macours 2010). Thus, of the two components of rebel capability as defined in chapter 1 - size and quality of recruits - the Maoists lacked at least one, a supply of educated and technically skilled potential recruits. I now turn to a discussion on Maoist military capabilities. 


\section{The CPN (Maoist) and Military Capacity}

The foregoing has demonstrated that the CPN-M was rooted in rural and mountainous regions of Nepal, and began to build up its organization from a largely uneducated (in many cases illiterate) and largely unskilled population. This population was willing to join the rebellion because they were systematically excluded by state economic and political development after 1950. The rural nature of the CPN-M limited its overall military capabilities, that is, the organization was never able to recruit from a heterogeneous population that was both urban and rural; in addition, the CPN-M never developed an external sponsor. Consequently, the CPN-M, throughout its conflict with the state, employed traditional guerrilla warfare. In other words, due to its limited military and organizational capabilities the Maoist rebels attacked state military forces, largely eschewed civilian victimization, and employed exclusively light weaponry.

The initial groups of Maoist recruits were homogenous; initial rebellion joiners all had similar opportunity costs for participation. In fact, due to the homogenous and rural nature of the initial rebel force, most of the Nepalese public was "quite unaware of even the existence of the CPN (Maoist) and had only a vague knowledge of the UPFN's memorandum enumerating the 40 point list of demands... even after fighting had actually begun, the sketchy information filtering out of remote districts did not lend any urgency to the situation" (Thapa and Sijapati 2004, 85).

Due to the isolated nature of the initial Maoist base areas, it was not until three years after the outbreak of the rebellion, following a bloody counterinsurgency campaign by the state, that the rebellion began to grow significantly. Interestingly, over the course of the insurgency the CPN-M grew to encompass some 35,000 active members-roughly 10, 000 trained guerrillas with some 25,000 untrained militia members (Upreti 2009; Macours 2010). It should be noted here that militia members were "not generally expected to carry out the same guerrilla duties as 
mainstream fighters but can be called upon as reinforcements. They are poorly armed and do not wear uniforms" (ICG 2005, 9). This expansion of CPN-M ranks was due to judicious support building, indiscriminate state killing of civilians, as well as forced recruiting by the Maoists. Most importantly for my theory of rebel strategic adoption, even though the rebels grew into a seemingly large fighting force, they never recruited in urban areas, and thus lacked a significant number of educated fighters.

Low rates of urbanization and significant urban-rural inequality caused by urban-centric development limited the appeal of the CPN-M to urban residents. The problems faced by poor and rural populations were a result of urban development policies pursued by the state. People that benefited from state policy making (urban, educated, and powerful high caste Hindu elite males) were therefore not within the sphere of Maoist influence. Large landholders and high caste Hindus, who had ties in both urban and rural areas, had no interest in the Maoist movement, as they were directly tied to the state via clientelist relationships. This lack of heterogeneous support undermined Maoist recruitment in urban areas, and more importantly, their ability to connect with sources of external support. This demonstrates how a rural and homogenous support base limits the ability of insurgent to build up their organizational and military capabilities.

\subsection{Exclusive and Purposive Rural Recruitment}

As discussed, the CPN (Maoist) initiated its rebellion in the rural and mountainous midwestern region of Nepal, well outside the urban district headquarters, and several hundred miles away from the capital. The Maoist preparations for war began in earnest in 1994 when the Prachanda/Bhattari faction of the CPN-UC went underground for a year of "programmatic and 
organizational preparations for the initiations of the 'people's war (PW)... [and the] formation of the CPN (Maoist)... in 1995" (Sinkhada and Oliva 2006, 22).

In September 1995 the Maoists announced their adoption of 'The Plan for the Historic Initiation of the People's War' in which they laid out the historic political, economic, gender, caste, and ethnic grievances that motivated their choice of armed conflict. The Maoists held a series of public meetings across the country in order to spread their political and ideological message. A key component of the Maoist preparation for war was the Sija Campaign in Rolpa, Rukum, and Jajarkot—named after prominent mountains in the Rolpa and Rukum. "This was a purely political campaign to mobilize party members to propagate the ideology of MarxismLeninism-Maoism. Apart form the party propaganda the cadre also carried out some social work" (Thapa and Sijapati 2004, 47). To this end, during this preparatory stages the rebels focused their propaganda campaign on issues of land tenure, peasant poverty, and urban-biased development (Thapa and Sijapati 2004).

The Maoists conveyed their political program by sending political-cultural teams into villages, and organizing mass meetings. The goal was to educate the rural population about the political goals and overall strategy of the Maoists. The party looked to spread the ideology of Marxism-Leninism-Maoism, and teach the public why it was necessary to employ violence against the state. The CPN-M party secretary for Rukum district emphasized the importance of educating the otherwise politically unaware rural public: "“just before the initiation [of violence], the Party leadership gave many political classes to the masses as the basis for the People's War; and so if they were not politically conscious, we could not be successful in carrying out our program"” (Onesto 2005, 190). 
The Maoists did not affect the Sija campaign in Rolpa and Rukum coincidentally. Guerrilla warfare theory, as laid out by Mao, depends on both topography and demography; protracted guerrilla warfare is favored in regions where populations reside in rough, densely forested, and mountainous terrain. It is easier to hit, run, and hide in this type of terrain, as the enemy's rear is more exposed in rough terrain (Tse-Tung 2000; Upreti 2009). These districts afforded the Maoists this type of terrain.

As has been discussed, underrepresented minorities, landless peasant farmers, and poor agricultural laborers populate the mid-western region of Nepal. Youth in this region also have difficulty accessing work. Moreover, Maoist base areas lack(ed) basic infrastructure, making it difficult for the state to access (Upreti 2009). These factors allowed the Maoists to motivate participation by working to provide the bear minimum of public goods in place of the state. While a cascade of heterogeneous popular support did not occur, over time the Maoists were able to mobilize a large rural fighting force discontent with the urban-bias of Nepalese state development. However, the limited skill and training of the Maoist supporters, and the rough terrain they fought in, limited the organization's military capabilities, leading to the Maoist preference for a guerrilla warfare military strategy.

The cause of mid-western support for the Maoist political and military agenda was simple, these regions received few goods from the state, and large segments of the population in this region were excluded from the state; as discussed above, the Rana, Panchayat and post-1991 democratic regimes of Nepal systematically excluded two thirds of Dalit, indigenous nationalities, and Tarai residents (Madhesi) from governance. As late as 1991, the state had not effectively penetrated into mid and far western rural areas, and therefore did not provide services to a large segment of the population. In the mid-1990's " 11 out of 75 districts did not have public 
hospitals; there was one doctor for nearly 14,000 people in 1993/95; and only 754 health posts

and 117 primary health centers were operating by 1997. Likewise, black-topped roads per 10,000

persons stood at $2 \mathrm{~km}$ and only five out of 1,000 have telephone connections" (Lawoti 2010, 21).

Magars and Kham Magars therefore provided a significant portion of the initial fighting

force, as they reside largely in Pyuthan and the Rukum-Rolpa border area, areas in which the

CPN and then Maoists had a long history of activism;

That guerrilla formations were dominated numerically by Magars stemmed from the ethnic composition of the core areas in which the Maoists had long worked... entire tribal communities would become involved in the insurgency. That tribal links were being exploited was further illustrated by Magar dominance of guerrilla formations as far away from the core Mid-Western areas as Dolakha District the 'Rolpa of the East' (Marks 2003, 16).

The Communist Party of Nepal has also been active in the mid-western region of Nepal since the 1950's. Mohan Bikram Singh, the founder of the CPN-Fourth Congress (the key progenitor of the CPN-M) joined the Communist party of Nepal at end of the Rana era in 1951, and went on to become the CPN district secretary in Pyuthan — a future Maoist base area. Singh actively agitated on behalf of the CPN throughout the Panchayat era in and around Pyuthan. Locals demonstrated their allegiance to the CPN in the post 1990 elections, voting (as a bloc) for UPFN parliamentarians in Rolpa, Rukum, and Pyuthan. No other political party could establish a significant presence in these districts. "It was this solid bloc of left supporters that the Maoists were able to exploit to their advantage when the time came to begin an armed struggle" (Thapa and Sijapati 2004, 67).

Thus, on February 13, 1996 the Maoists, armed only with two World War II-era rifles, overran the office of Small Farmer's Development Programme (run by the Agricultural Development Bank) in Gorkha district. Later the same day the CPN-M forces attacked police posts in Rolpa, Rukum, and in the eastern district of Sindhuli (Thapa and Sijapati 2004). In the first year of the rebellion, the Maoists had an armed force of fewer than 100 people and were so 
poorly armed that they killed only 6 police officers in their attacks, as well as several dozen more “enemies of the people" (ICG 2005; Mehta and Lawoti 2010). According to the Informal Sector Service Center, a Nepalese NGO, the Maoists accounted for only 22 deaths in the first year of the insurgency, and only 32 the following year. The state by contrast killed 59 and 16 people respectively over that time (INSEC 2013). In these first two years of the conflict the Maoists maintained only three units: “"fighting units,' (ladaku dal) 'security units,' (suraksha dal) and “volunteer units,' (swayamsevak dal) and [all] had little equipment" (Mehta and Lawoti 2010, 179).

Between 1996 and 1998 the CPN-M endeavored to expand its influence through Rolpa. To this end the Maoists affected a boycott of local elections in May 1997, and used threats of violence to prevent anyone from standing for election in village development committeesNepal's basic building block, a village and its surrounding area, 3,913 exit-over which they exerted influence (Marks 2003). Eight people were killed during this boycott campaign. More, polls could not be held in 87 village development committees, and consequently "district development committees could not be formed in 15 districts in western Nepal" (Thapa and Sijapati 2005, 89).

The Kathmandu Post reported on May 14, 1998 that the Maoist held some level of control over half of the 51 vdc's in Rolpa district. The Maoists prevented regular elections and terrorized state officials in these districts. The Maoists even worked to fill in for the lack of state services, as people looking for government services would go to the CPN-M with their issues. Maoist 'people's courts' took up legal issues such as land transactions. The extent of Maoist service provision was hampered however by a lack of money and personnel (Thapa and Sijapati 2004). 
It is critical to note here that infrastructural development in Ropla and Rukum districts was so low that the few Maoist cadres that existed could affect control over rural areas "only through their ability to call upon guerrilla manpower for enforcement of the writ" (Marks 2003, 10). This power of the few was exacerbated by the fact that, soon after the rebels began systematically attacking rural police stations the state withdrew the police to the urban district headquarters, effectively removing the state from rural areas. While this facilitated Maoist "control" in base areas it fundamentally undermined the CPN-M's ability to expand the level of popular support (Marks 2003).

\subsubsection{Operation Kilo Sierra Two and Beyond}

"According to the then military commander of the Maoists' central region, Sandip, the real development of the "people's army" only took place after the start of the government's Operation Kilo Sierra 2 of May 1998-April 1999” (ICG 2005, 9). Kilo Sierra 2 was the state’s response to the simmering rural insurgency.

This operation was undertaken for several reasons. First, on the second anniversary of the initiation of the 'people's war (February 13, 1998) the Maoists announced their Control Military Commission led by Prachanda. Secondly, the newly elected Prime Minister Girija Prasad Koirala toured areas of under Maoist influence. Third, the Maoists conducted an attack "on Kalikatar of Tanahu, the home district of Govinda Raj Joshi, the Home Minister" (Thapa and Sijapati 2004, 91).

Operation Kilo Sierra Two was a response to these three factors. This was a "search and kill" operation geared towards preventing the Maoists from gaining any additional strength. It was extreme in its brutality, as made clear by the police chief of the western region: "If they [the Maoists] don't respect the Constitution, we don't have to stick to the Constitution and take them 
to court"” (Thapa and Sijapati 2004, 92).

Over the course of the operation the state killed Maoists, their supporters, and civilians in the areas under attack, namely all areas in which Maoists reportedly operated. Roughly 500 people were killed over the course of Kilo Sierra Two. Importantly for the Maoists, state sponsored violence proved to be a key motivator for participation in the rebellion. In fact, in a national opinion poll, indiscriminate state violence in areas affected by the rebellion was identified the number one motivator for the growth of the CPN-M rebellion, and as the cause of an increase in Maoist activity (Thapa and Sijapati 2004).

As the conflict wore on, teams of Maoists, as well as individual motivators worked through the countryside in an effort to recruit more people; as the violence intensified the recruitment campaigns became increasingly important. Cultural teams of 10 (both men and women) would put on energetic shows recounting Maoist victories, and emphasizing the importance/value of dying as a martyr for the Maoist cause. In these shows the Maoist reenacted battlefield victories and the elimination of 'class enemies.' These shows were used as tangible illustrations of Maoist military capabilities, and to provide a warning to those unwilling to work with, or actively working against, the CPN-Maoist (Eck 2010).

Thus, by late 2000, the Maoists had several thousand trained guerrillas. In one attack on the district headquarters of Dolpa (northwest Nepal) some 1000 fighters engaged in a six hour firefight with police forces killing 14 police and taking 12 prisoner (Thapa and Sijapati 2004). In response the state significantly reduced the presence of its police forces in Maoist areas, due to the increasing pace of the latter's attacks. "For instance, in Rolpa the earlier 39 posts was reduced to just eight, while in Rukum it went down from 23 to eight, and in Jarjarkot, from 15 to six" (Thapa and Sijapati 2004, 106). 
In July of 2001, both the state and the Maoists agreed to the first ceasefire of the conflict. The CPN-M used this lull in violence to further expand its military capabilities. It reorganized its rural forces into a hierarchical military structure, and in September of 2001 announced the formation of the People's Liberation Army. In June 2002 "the central committee plenary formed brigades while in August 2004 the brigades were incorporated into three divisions of three brigades each. Twenty-nine battalions [each battalion with 300-400 fighters], companies, platoons, and squads were under these brigades" (Mehta and Lawoti 2010, 179; Marks 2003). However, the Maoists never acquired heavy weapons, the members of the brigades were armed with small arms, locally made weapons, and those pillaged from the police and Royal Nepalese Army.

While this systematic reorganization was meant to facilitate the adoption of a new strategy, namely direct force on force warfare, the Maoists simply did not have the capacity to execute such a strategic shift. The largest military effort undertaken by the Maoists at the height of the conflict, an attack on the Beni military barracks in Myagoi district, meant to demonstrate the expanding military of the People's Liberation Army's capabilities, had mixed results. The CPN-M's Western Division made up of 4,500 people, with 2,600 armed fighters - all armed with light weapons - its largest military formation to that point, did not take the barracks, and the Maoists lost a number of high-ranking officers. However, the Maoists did occupy the area for 12 hours - only to withdraw afterwards - they destroyed many of the buildings, and captured the police station. The Maoist attack failed to capture the barracks even though the RNA was ill prepared for the attack (although evidence suggested it knew an attack was coming) and did not receive any reinforcements (Ogura 2004). Thus, the Maoists demonstrated a limited military capacity for hit and run attcks. 


\subsubsection{Political Indoctrination, Forced Recruitment, and Military Capability}

In order to expand its force size the Maoists focused on several recruitment strategies:

they recruited from villages in its base areas, they recruited from other regions, and they forcibly recruited school children, teachers, and others (Macours 2010; Ogura 2004; Lawoti 2010). As discussed above, the CPN-M actively recruited throughout the insurgency in its base areas with political-cultural teams and individual participation motivators. After individuals were recruited the Maoist continued their political education. After joining, new members worked at the village level, as political workers, attempting to organize greater local support. It was only after twothree years that new members began training as guerrilla fighters in the People's army, and even then political indoctrination continued (Eck 2010).

This long-lasting political education ensured that rebels were aware of why they fought, and thus increased the likelihood they would be willing to fight when called upon. Additionally, insurgent leaders believed that a common political ideology would allow for cohesion amongst the cadres. Finally, extensive political indoctrination helped with retention rates, as those educated on the common cause would be less likely to abandon it (Eck 2010).

This political indoctrination was effective in large part due to the constituency from which the Maoist recruited. By teaching illiterate recruits the benefits of fighting for an organization devoted to redistributing wealth to the poor, more people were willing to pay the costs of participation. "The CPN-M made it extremely clear that should they come to power, the peasantry would have access to a multitude of political, economic, and social goods currently unavailable to them" (Eck 2010, 44). More, given the range of rural issues in Nepal the Maoists worked to tailor their political goals to appeal to ethnic communities, Dalits, and women. The Maoist knowledge of local grievances with the state, given their historic connections with the 
mid-western region—were vital to their recruitment success (Eck 2010).

Beyond its core areas of operations in the mid-western region (Rolpa, Rukum, Pyuthan, Jajarkot, and Salayan) the Maoists struggled to recruit. The Tarai is a prime example. The Party began significant recruitment operations in the south after the King declared a state of emergency in November 2001 and deployed the Royal Nepalese Army to the conflict area.

The CPN-M attempted to build up a support structure outside of their immediately supportive communities, in a population known as "Madhesi" or those who speak plains languages, which includes over 10 separate languages (Kantha 2010). The CPN established the Madhesi National Liberation Front (MNLF) in 2000 as part of their larger strategy (used in the mid-western region as well) to mobilize popular support based on the politics of exclusion; ethnic groups were systematically disadvantaged by state policies, and Maoists sought to use this to mobilize ethnicities beyond those that supported them.

Following the 2001 declaration of a state of emergency, Maoist recruitment work picked up significantly in the Tarai; the Maoists began fighting the Royal Nepalese Army instead of local police force, and therefore the CPN-M sought more resources and recruits from the Madhesi population (Kantha 2010,161). However, due to their lack of historical relations with this region, and their misunderstanding of local political grievances, the Maoists turned to intimidating the population for support, thereby undermining large-scale popular support; "outside of core areas [the Maoists] held sway only through terror, through their ability to call upon guerrilla formations to act as enforcer" (Marks 2003). Moreover, the Tarai region is flatter than the hilly mid-western region, which facilitated better state military operations, leaving the population of the Tarai caught between Maoist and state violence (Kantha 2010). Consequently, the Maoist influence in the Tarai was limited to areas in which hill tribes were the dominant 
populations. More, over time, due to Maoist intimidation and exploitation, prominent Madhesi Maoists defected from the Party further undermining Maoist support outside of their base populations (Kantha 2010).

The Maoist use of intimidation and terror was not only reserved for groups outside of base areas. "That they do indeed carry out coercive recruitment is not in doubt. Two of their campaigns in particular — 'one house, one guerrilla' and 'shoes'—have been widely publicized" (Shah 2008, 492; ICG 2005, 10). In each case Maoists obligated a member of every house in a village to work for the party as a full time member.

Furthermore, after 2001 the CPN-M took to abducting new "volunteers." In fact between May 2002 and December 2004, 21\% of all reported Maoist actions were mass abductions. The Majority of those abducted were students and teachers. As many as 1500 people were abducted in a single action; in May 2004 alone, some 7787 people were abducted (Macours 2010, 10). While a majority of these people were released and did not join the rebellion, their backgrounds are key. The CPN-M lacked a significant source of educated and trained individuals due to their exclusively rural support base. Therefore, in an effort to build up their capacity, they abducted the young and educated, as well as people able to educated otherwise illiterate recruits. The scale of this abduction-based capacity building was evident by the end of the conflict, when the UN reported, "between 2002 and 2006, the Maoists abducted 10,621 teachers, and 21,998 students" (Valente, 2013, 3). Abductees were generally taken to remote areas and indoctrinated for several days, and then released. This practice has led to human rights groups leveling accusations of forced child soldiering (ICG 2005; Eck 2010).

These abductions were particularly interesting from the perspective of the Kham Magar community. The Maoists, while claiming to struggle for equality on behalf of indigenous 
populations and lower castes, were killing as many (in terms of percent of victims) Janjatis as the Nepali police and military force by 2002 (Lawoti 2003b, 77). Abductions of Kham Magars (given their level of literacy), particularly as violence associated with the insurgency escalated between 2002 and 2004, became a necessary component of maintaining Maoist organizational capabilities (Macours 2010). The abuse of Magars over time fits with "repeated accusations that young people from minority communities have been cynically manipulated by the [Maoist] leadership and used as little more than cannon-fodder" (ICG 2005, 15).

In sum, as the conflict progressed, recruiting became harder for the Maoists, and their capacity reached its zenith, this occurred for several reasons. The CPN-M lacked educated fighters, and access to urban areas, thus limiting the quality of their force. Second, they were maximally exploiting their base areas in terms of resource extraction and recruitment. Third, "the mountainsides of Nepal were being denuded of young people who were fleeing to escape both forced conscription into the Maoist force as well as harassment during ongoing security operations" (Thapa and Sijapati 2004, 135). Fourth, outside of base areas Maoists were forced to employ intimidation and forced recruitment which limits the capability of a military organization, as forced recruits are less willing to fight and die for a rebellion they do not support.

\subsubsection{Failed Urban Expansion,}

An additional attempt by the Maoists to increase their influence and military capabilities was the adoption of the Prachanda Path in 2001. From 1996 to 2001 the Maoists had followed a traditional guerrilla strategy as laid out by Mao. Moving from a guerrilla force and then transitioning to a regularized military organization, through three stages: strategic defense, strategic stalemate, and strategic offense. The ultimate goal was to encircle the urban center from 
the rural periphery (Mehta and Lawoti 2010). However, after five years of war, Prachanda declared the only way to affect political change in the highly centralized Nepalese state was to take the center, Kathmandu. He thus declared a new strategy for both urban and rural operations, Prachandapath (Mehta and Lawoti 2010; Thapa and Sijapati 2004). This urban mobilization campaign failed resoundingly.

The low urbanization rate in Nepal was an important factor in undermining urban support for the CPN-M. Cities in Nepal are small; only $15.1 \%$ of the population lived in urban areas in 2005 (UN 2011). More, urban populations are generally better educated, part of different ethnic groups and castes, and work outside of agriculture (Sharma 2006). Simply put, rural Maoists had few (in any) connections to the relatively small number city dwellers.

Moreover, radical students in the cities, who were ideologically sympathetic to the CPNM political platform, preferred to work within the mainstream parties given the lack of connections they had to rural Maoists (ICG 2005). Thus, as the fighting continued in the rural areas little urban support developed. In fact, the urban population grew exasperated at the Maoists attempt to move into the cities. "Indiscriminate bombing, especially in the capital, certainly instilled a sense of terror, but did nothing to endear the Maoists to the population" (Thapa and Sijapati 2004, 169). More, when the Maoists called for a general strike in Kathmandu the state was able to break it with relative ease, demonstrating the lack of popular commitment (ICG 2005). The Maoists were similarly unable to establish a presence in any district capitals (even in Rolpa and Rukum) as the state concentrated its forces there (Thapa and Sijapati 2004).

Despite... efforts to create urban instability and political division, the Maoist strategy or urban insurrection has not demonstrated the ability to mobilize enough support to make its threat of revolution in the cities appear realistic. It has employed sometimes conflicting tactics - trying to show a presence in the capital through bomb explosions and killing while at the same time holding out the possibility of collaboration with mainstream parties (ICG 2005, 24). 


\subsection{Limited Positive Inducements for Support}

As has been discussed, the CPN (Maoist) lacked any external state support. It garnered support from poor rural populations, diaspora communities, bank robbery and extortion. The Party also sold medicinal herbs from the mid-western region, marijuana and hashish. In 2004 for example, the CPN made an estimated $\$ 600,000$ for the sale of Yarcha Gumba (a medicinal herb) to India (ICG 2005). In 2002 a "former Maoist district commander estimated that 'the Maoists need to spend about Rs. 10 million (almost $\$ 150,000$ ) every month to keep the war going: for the upkeep of their own guerrilla force, logistics, and hardware"” (ICG 2010, 17). In short, local and external financial support was not forthcoming in large sums, but was sufficient to maintain a guerrilla warfare campaign. However, this limited the goods the Maoists could provide to their supporters in base areas, and fundamentally undermined the provision of services outside of base areas (like in urban areas and the Tarai). The best the Maoists could do was to not expropriate goods from the population too harshly (Lawoti 2010).

The Maoists did attempt to build infrastructure and provide legal resolution to disputes in in areas they controlled. In the hilly areas of the state, the Maoists were active in road and bridge building. However, few roads or bridges were ever completed, and vehicles never used them (Laowti 2010). The most successful service provided by the Maoists was the People's Court. The Courts "adjudicated conflicts in villages and punished Maoist opponents. The courts often addressed the immediate needs of the rural people because the [state]...district court system... was far away, slow, costly, and corrupt" (Lawoti 2010, 16).

In sum, however, only in core areas, with longstanding rebel presence, did the Maoists work to create new public services. These new services were largely attempts to make earlier state forms more equitable and responsive (Marks 2003). The rebels simply did not have the 
capability, financial resources, or knowledge base to develop new services in exchange for participation in the rebellion. This is likely why they were hard pressed to develop a following in urban areas, where the state was strongest.

\section{The CPN (Maoist) Strategic Doctrine}

The above discussion has highlighted several important aspects of the Maoist insurgents in Nepal. First, it was an exclusively rural conflict. The CPN-M originated in the mid-western region of Nepal. The militant organization began as a collection of Kham Magar fighters from mid-western region, and drew most of its support from several districts in this region (Rolpa, Rukum, Pyuthan, Salayan, Jajarkot, and Kalikot (ICG 2005).

While the CPN-M grew to a force of some 35, 000 trained and untrained fighters, it never penetrated the Kathmandu Valley, or any of the urban district centers. As a result, it lacked a large number of various educated and skilled fighters, and connections to external sources of funding. The Maoists largely relied on ideological indoctrination of mid-western tribes, who were uneducated and poor to grow its military force. The rural support base that the CPN-M depended on offered little in terms of financial or military support. The Maoists also offered scant services to their supportive population as a positive inducement for support. In short, the Maoists could never affect a large-scale cascade of heterogeneous popular support. Its homogenous support base thereby limited its organizational and military capabilities. The limits of its support base pushed the CPN-M to engage in forced recruitment and the use of child soldiering, which suggests that the organization had reached the apex of its recruiting abilities.

\subsection{Maoist Armaments and Targets}

In its first attack the Maoist forces had but two World War II era rifles, one of which did not work (Marks 2003). As the insurgency grew it managed to obtain a greater number of rifles 
and arms, by pillaging police stocks, and taking the arms of dead police and army forces. More, the Maoists began to make their own muskets, and took a variety of small arms from villagers. Later in the conflict, the rebels purchased arms from the black market in India. These purchases were largely made up of detonators, explosives and bullets, in addition to some AK-47 assault rifles (ICG 2005).

Over time the Maoists developed the acumen for bomb making. Initially they made crude explosives such as homemade pipe bombs, and pressure cooker bombs. Later the CPN-M began deploying self-made electronically detonated landmines.

Their general approach, however, has been to avoid unnecessary escalation in armaments. While they were only fighting with the police, they were happy to rely primarily of weapons looted from police posts. It is since engaging with the RNA that they have sought to increase their stock of semi automatic and automatic weapons and resorted to foreign purchases" (ICG 2005, 19).

The heaviest weapons operated by the Maoists include several $81 \mathrm{~mm}$ mortars, which by the definition laid out in chapter one are considered to be light weapons.

In terms of Maoist targets, the majority of those killed by the CPN were police and military forces. It is estimated that the Maoists accounted for 4970 deaths over the course of the conflict. Of those 2733 were police, military, security, and state officials, or $55 \%$ of the deaths attributed to the Maoists. The majority of deaths occurred after 2001, following the deployment of the Royal Nepalese Army into the conflict (INSEC 2013).

\subsection{Traditional Guerrilla Warfare}

The Maoist insurgency was therefore a classical guerrilla warfare campaign based on encircling the urban areas from the countryside using protracted warfare (ICG 2005). The first series of attacks on February 13, 1996, were not violent in nature, as no one was killed. They were meant to signal that the insurgents intended to attack state forces, and fight against traditional economic relations between center and periphery (the attack on the Agricultural 
Development Bank). This would become the first stage of Maoist development, what is known in Maoist lexicon as strategic defense (Mehta and Lawoti 2010; ICG 2005). It lasted five years and progressed through 6 organizational plans, which culminated in the formation of the People Liberation Army and the attempted formation of a regularized military force (Thapa and Sijapati 2004; ICG 2005).

The Prachandapath was the next evolution of the CPN-M military strategy, in which it looked to initiate an urban component to the rural insurrection, while continuing to build itself up in the rural areas. "The new policy incorporating urban insurrection recognized that in a highly centralized country such as Nepal it would be impossible for rural action alone to put serious pressure of the sate" (ICG 2005, 23). For the Maoist revolution to progress the CPN had to affect a violent struggle where state power was located, Kathmandu. To accomplish this the CPN attempted to employ unions and student groups to carry out strikes and street demonstrations, it worked to polarize political forces on the issue of the insurgency. The Party worked hard to develop an urban student front, which emphasized the inadequacies of the education system, namely fee-paying private schools. However, despite these efforts the Prachandapath could not mobilize a sufficient support base in urban areas to affect violence on any significant and sustained level (Mehta and Lawoti 2010; ICG 2005).

On August 31, 2004, after a series of abortive ceasefires, and after the Maoists claimed they had affected a strategic balance with the state, the latter announced the launch of the strategic offensive. "It followed the selective targeting of the RNA, political leaders and government officials. However, major raids hardly occurred until March 2005, partly because RNA camps were fortified" (Mehta and Lawoti 2010, 182). The CPN-M conducted some halfdozen major raids after March 2005, many only partially successful; the Maoists rarely overran 
the military forces/bases they attacked. Most often, the CPN-M forces destroyed some buildings and withdrew. Although they claimed to have affected a strategic stalemate with the state the Maoists were never able to capture or control urban areas/district headquarters, which the state heavily defended. In point of fact, it can be argued that neither the strategic stalemate nor the strategic offensive ever actually took effect (Mehta and Lawoti 2010).

\section{Conclusion}

In sum, the Nepalese Maoist insurgency is an example traditional guerrilla warfare strategy in action. It was almost an exclusively rural military campaign, in one of the least urbanized and economically developed states in Asia, and thus, the world. The Maoists mobilized rural recruits via local relationships with villagers, ethnic nationalities, and low Hindu caste members who had long established political grievances with a state. As a result, the Maoists were unable to develop a significant support base outside of their initial areas of operation. And although they conducted attacks in 73 out of Nepal's 75 districts, they never took areas that the state wanted to hold, namely urban centers (Ogura 2004). Moreover, they had little/no access to cities or urban and educated recruits.

Consequently, the Maoists exclusively employed light weapons they could seize from the state, make themselves, or buy on the blacks market, to attack state forces in the countryside. The goal of the CPN-M was to attrite the state slowly, to surround the city from the countryside, following Mao's guidance. Terror, to the extent it was used by the Maoists, was a tool for recruitment, given their limited support base.

This chapter therefore has provided further support for the theory of rebel strategic adoption explicated in chapter one. Most importantly, it has highlighted that both the number and quality of rebel recruits are necessary but individually insufficient components for increasing 
rebel capabilities. Given the extremely low urbanization in Nepal, the Maoists could not recruit large numbers of educated individuals, even though their organization grew to encompass roughly 35,000 members. This lack of urban, educated and skilled individuals hurt rebel capabilities, and did not allow for the Maoists to elicit foreign support. Consequently, the rebels employed traditional guerrilla warfare. They took advantage of rough terrain to conduct hit-andrun attacks against state forces. They were never able to gain access to urban areas. This conflict ended in a negotiated settlement in 2006. This settlement was less a result of the Maoist wherewithal in battle, and more due to the costs, for an already weak state, of fighting a ten year insurgency. 


\section{Chapter 5: Hamas The Evolution of Terrorism}

\section{Introduction}

Chapters three and four focused on explaining how urbanization influences a rebel group's preference for hybrid warfare and traditional guerrilla strategies. Here I seek to explain why insurgents adopt terrorism and/or indiscriminate violence.

Recalling from chapter 1, rebels fighting in highly urban areas are likely to be small because they organize at the community level. Communities in urban spaces tend to be small, with members being tightly linked to one another but lacking in social ties to outsiders. Although urban rebel groups tend to be small, they have a disproportionately high number of welleducated members because education is more readily available in cities.

The quantity and quality of recruits are the dually necessary but individually insufficient determinants of an organization's capabilities. Urban groups can recruit high quality members, but only in small numbers, consequently, urban insurgents have truncated military and organizational capabilities. Terrorism is the preferred military strategy for small, well-educated urban insurgents. Terrorism requires high levels of skill, but only small numbers of people to execute. 
In cases where urban terror groups attempt to adopt hybrid warfare, indiscriminate violence is the resultant strategy. A rebel force fighting in an urban area lacks both the manpower and strategic depth to execute a hybrid warfare strategy effectively. Moreover, terrorism in no way prepares fighters for the rigors of holding ground through pitched firefights with oncoming military forces. Therefore, in such cases groups mix elements of hybrid and terrorist strategies: they employ the heavy weapons associate with hybrid warfare against civilian instead of military targets.

Through a detailed case study of Palestinian Hamas (The Islamic Resistance) I demonstrate why organizations fighting in urban environment adopt terrorism and/or indiscriminate violence. I demonstrate that the key to Hamas's strategic choices is its exclusively urban recruitment base. This small but well educated base of supporters, which arises out of significant demographic changes in Palestine after 1948, limits Hamas's organizational and military capabilities. Consequently, Hamas has preferred terrorism as its primary military strategy, and switched to indiscriminate violence as a result of its failed attempt to adopt hybrid warfare. To this end I trace the organization from its roots in the Palestinian/Jordanian Muslim Brotherhood, through the outbreak of the First Intifada (December 8,1987) until Operation Cast Lead (December 27, 2008). Throughout the chapter, I compare Hamas to Hezbollah in order to contrast the impact of varying rates of urbanization and education on each group's military strategy.

\section{Falsification}

My theory can be falsified in two ways. First, if the Israeli occupation of Palestine caused Hamas to launch attacks against Israeli civilians then urbanization can be ruled out as the key 
causal variable. More, if the occupation drove urbanization, then my theory may be biased by an omitted variable.

A relationship between the occupation and violent resistance by Palestinians undoubtedly exists. However, the occupation itself does not explain Hamas's strategic choices. Through twenty years of occupation prior to 1987 there was no indication that any militant group in Palestine, Islamist or secular, would adopt a terrorist strategy, contra extant claims (Pape 2003). In the 1960's Fatah conducted guerrilla operations against Israeli military forces but it rejected the use of suicide bombings until after the outbreak of the al-Aqsa Intifada (Pearlman 2011, Cobban 1984); neither Fatah itself nor its related armed wing the al-Aqsa Martyr's brigade executed a suicide bombing until November 2001 (Clauset et al. 2010). Hamas only adopted violence in its fight against the Occupation, after the outbreak of the First Intifada. Hamas began targeting civilians in 1990, and conducted its first suicide bombing after the signing of the Oslo Accords in 1993 (ICG 2004).

In fact, from 1969-1982 there was very little violence against Israel emanating from Palestine (Benvenisti 1987). The first two years of the Intifada were also fairly peaceful, with Palestinians largely employing non-violent resistance methods (Pearlman 2010). While terrorism did ultimately occur in 1990, the twenty-six year old Occupation offers no insight into why groups adopted particular strategies, or the timing of their adoption.

Additionally, the occupation is not the direct cause of urbanization is Palestine. Urbanization in Palestine began after the foundation of the state of Israel (May 14, 1948), with the flood of refugees into the Palestinian Territories. Furthermore, as will be demonstrated below, the occupation actually slowed urbanization in the territories in the short term. Therefore, the occupation did not cause urbanization in Palestine, nor is there any direct connection between 
the occupation and terrorism; the occupation cannot be considered the direct cause for the formation of Hamas.

Secondly, if religion explains Hamas's strategic choices, then my theory is falsified. Hamas is a Sunni Islamist organization. Some argue that Sunni Islam is antithetical to a hierarchical organization structure necessary for any strategy other than terrorism, with a focus on suicide bombing.

Within Shi'a Islam there "is a hierarchy to the Shi'a clergy and political and religious authority is vested in the most learned who emerge as spiritual leaders. These leaders are transnational" (BBC 2008). In contrast, no such religious hierarchy exists in the Sunni clergy; Sunnis can interpret the Hadith and Sunna, and no individual is required to follow the teachings of a given Islamic scholar (Mishal and Sela 2000). In short, the unstructured Sunni tradition leads to fragmented organizational structures, while the hierarchical nature of the Shi'a religious tradition facilitates the development of more structured insurgent groups

These claims are specious. Hezbollah and the Sri Lankan Tamil Tigers (LTTE) are well known for their suicide operations. Hezbollah (a Shi'a group) maintains a decentralized organizational structure, and is the modern pioneer of the suicide bombing, a tactic it used with deadly efficiency in the middle 1980s to early 1990s (Blanford 2011). Additionally, the Liberation Tiger of Tamil Elam are an avowedly anti-religious Marxist organization, and they have committed more suicide operations that any other insurgent group (Pape 2003). In fact, even within the wider Muslim world, secular resistance organizations accounted for over a third of suicide operations. The Kurddish PKK uses the tactic, as did the Lebanese Communist Party (Paper 2003). Thus, religion cannot explain the choice of terror or suicide operations as a strategy/tactic in unconventional wars. 
In sum, potential counterarguments to my theoretical claims fail. I now turn to laying out my explanation for why rebels adopt of terrorism and indiscriminate violence as military strategies. Below I explain how urbanization in Palestine facilitated Hamas's choice for terrorism and indiscriminate violence.

\section{Resistance after Occupation: The PLO, Hamas and Their Contemporaries}

On December 8, 1987, a car accident occurred in the Gaza Strip in which an Israeli truck struck a vehicle driven by Palestinian workers. Several of the vehicle's occupants died as a result of the collision. This accident triggered riots that spread and evolved into a seven-year period of Palestinian resistance (both violent and not) ultimately known as the intifada_literally "shaking off'(Pearlman 2011).

On December $9^{\text {th }}$ leaders of the Muslim Brotherhood in the Gaza Strip met, at the home of Ahmad Yasin — the founder and future leaders of Hamas - to discuss how to use the December $8^{\text {th }}$ events to provoke larger-scale public protests. Attending the meeting were the future ranking members of Hamas, all of whom were from the Gaza Strip. "On 14 December, the Brotherhood leaders issued a statement calling on the people to stand up to the Israeli occupation. Hamas retrospectively considered this its first serialized leaflet, though the new organization did not identify as such until January 1988 when it issues leaflets under the name 'Hamas"' (Abu-Amr 1993, 10).

Yasin was able to organize and launch Hamas so rapidly because Hamas is a direct offshoot of the Muslim Brotherhood, an organization that has been active in Palestinian cities and refugee camps since 1948. Hamas formed out of existing relationships between militant members of the Muslim Brotherhood in Palestine (Milton-Edwards and Farrell 2010). These 
relationships were predicated upon the urban nature of life in Gaza- the Gaza Stipe is the most densely populated urban space on earth (Helu 2012).

\subsection{Demographics, Competition, and the Origins of Hamas}

The formation of Hamas and the military strategies it has employed are the direct consequences of the demographic realities of the Occupied Territories. The occurrence and expansion of Hamas (as well as its contemporary Islamist organization Palestinian Islamic Jihad) from the Muslim Brotherhood was a reaction to the failure of the secular nationalist PLO to effectively lead the populations of both the West Banks and Gaza in the liberation struggle with Israel (Tamimi 2007; Milton-Edwards and Farrell 2010; Abu-Amr 1993, 1994). Hamas is a local, grass roots organization, which formed in the highly urbanized Gaza Strip as a result of the lack of local services provided by the externally operated PLO.

Relatedly, the military strategies that Hamas has adopted are the result of the urbanization of Gaza and the West Bank. Economic policies pursued by Israel after 1967 unintentionally contributed to the expansion of Palestinian urban areas (Hiltermann 1991). Over time levels of educational attainment increased within the urban population-due to an expansion in the number of secondary and post-secondary institutions - but this did not facilitate a concomitant rise in income levels, political freedom or public service provision (Hatina 2001; Meron 1986; Hiltermann 1991; Angrist 1995; Berrebi 2007). These facts, combined with the social work of, and institutional structures created by the Muslim Brotherhood, shaped a politically aware population that was readily organized for violent collective action after 1987.

\subsubsection{The Rise of Political Islam in Palestinian}

Two factions have competed to represent Palestinian interests in the West Bank and Gaza Strip: secular nationalists and Islamists. Both of these political ideologies filtered into Palestine 
via Egypt. Political Islam in Palestine, embodied by Hamas and Palestinian Islamic Jihad (the two most prominent Palestinian terror organizations), can trace its origins to the Egyptian Islamist organization, the Muslim Brotherhood. In fact, according to Hamas's own history, it is a direct descendent of the Muslim Brotherhood (Mishal and Sela 2000). Therefore, to understand Hamas it is necessary to understand the history of its forbearer; the Muslim Brotherhood's development elucidates Hamas's political program.

It is vital to note that one of the defining differences between Islamists and secular nationalists (until after the signing of the Oslo Peace Accords) was the faction of the Palestinian population they represented. That is, the secular nationalists, led by Fatah and the PLO, were primarily concerned with refugees outside of Israel and Palestine. Conversely, the Muslim Brotherhood and Hamas focused their attention on the issues of Palestinians inside Israel and the Territories. This is largely because Fatah and the PLO were formed outside of Israel and Palestine while the Brotherhood and Hamas are rooted in urban refugee camps of Gaza.

The Muslim Brotherhood opened it first branch in Jerusalem on October 26, 1945. By 1947, there were some twenty-five Muslim Brotherhood branches in the nascent Israeli state with a membership estimated to be between twelve and twenty thousand; Brotherhood leaders in Cairo supervised these branches. The goal of the brotherhood was to slowly Islamitize society through education (Mishal and Sela 2000; Abu-Arm 1993). However, between 1958 and 1967 the Muslim Brotherhood presence in the Territories waned significantly due to the rising prominence of Arab Nationalism. Secular Arab nationalist, represented in Palestine by Fatah (founded in Kuwait, 1959), worked to consolidate national independence (Abu-Amr 1994).

After the 1967 Israeli occupation of Palestine, the Brotherhood began to rebuild itself in order to continue its work on building an "Islamic generation" (Abu-Amr, 1993, 7). In Gaza, the 
key to the Brotherhood's resurgence was the 1973 establishment of the Islamic Center (alMujamma' al-Islami) by Ahmad Yasin. The Center was a voluntary association focused on the development and administration of religious institutions in the Gaza strip, whose ultimate goal was to create an Islamic community. "Its project rested on a large-scale social program to create a network of schools and Qur'anic classes to preach the message of Allah (tabligh wa-da'wa)" (Mishal and Sela 2000). In fact, soon after the Center's founding, all religious organizations and institutions dominated by the Brotherhood, including local mosques, and later, the Islamic University in Gaza, were controlled through al-Mujamma. The Mujamma followed Brotherhood practice of providing charity (zakat) to the poor as the path for penetrating Palestinian social life and expanding popular support for its activities (Mishal and Sela 2000; Abu-Amr 1993).

Through the Islamic Center the Brotherhood established charities that supervised schools, managed kindergartens, blood-banks, medical clinics, women's education centers, and nurseries all of which were tied to mosques. The Muslim Brotherhood/Islamic Center contributed to an incredible expansion of the number of mosques in the territories: between 1967 and 1987 the number of Mosques in the West Bank increased from 400 to 750; in Gaza the number tripled from 200 to 600 . Mosques were seen as the keys to spread the organization's Islamic message. The Brotherhood also constructed neighborhood libraries, sports clubs, gave money to the poor and provided loans to students in Palestinian and Arab universities In addition, religiously controlled land, waaqf, came under Brotherhood control. In Gaza roughly 10 percent of all real estate is waaqf land, therefore many people owe their livelihoods, and the land that they lease, to the Brotherhood (Abu-Amr 1994). All these social services came at a time when the overall percent of urban dwellers inside the Territories was growing at $0.76 \%$ per year (UN 2011). 
The Mujamma was successful in building social institutions because its founder, Ahmed Yasin, worked out of his home in the al-Shati' refugee camp, an area enveloped by Gaza City. Yasin sent teams of Brotherhood members into each neighborhood within the al-Shati camp, and then into other Gazan refugee camps. The "teeming camps in the Gaza strip, which housed the world's highest population density, provided fertile soil for communal activism informed by... religiosity. This striking social reality welcomed the Islamic option as an alternative way [from the PLO] to challenge poverty and life under Israel's military occupation" (Mishal and Sela 2000, 19). The refugee camps were surrounded by rapidly expanding cities; these urban landscapes, which combined the refugee camps and cities, housed groups of young, increasingly educated yet economically and politically disenfranchised/aggrieved individuals, and the Muslim Brotherhood provided an avenue through which these individuals could take action. The PLO simply did not have the capability to serve the rapidly expanding refugee population in Gaza.

The Brotherhood further insinuated itself into the Gazan community through the mediation of conflict between clans involved in feuds. Traditional Palestinian society is built upon kinship relations, with few formal mechanisms of dispute resolution like civil law and courts. Instead, customary laws of mediation and arbitration are used to settle conflicts, with the arbitrator being a position of esteem amongst all Palestinians. As more families and clans clustered in the dense refugee camps and urban areas of Gaza, the Brotherhood took up the role of arbitrator. They gave more equitable representation to the interests of all aggrieved parties in a dispute, instead of favoring the most powerful, and thereby garnered support from an increasingly large segment of the Palestinian population (ICG 2007; Mishal and Sela 2000, 21). Indeed, the Brotherhood and Mujamma attracted many supporters because of these foregoing social programs and services, not because of strictly theological reasons (Milton-Edwards and 
Farrell 2010). The Brotherhood presents "an alternative orientation and strategy that seems to address the needs of the people... [as a result it is] able to break through to the center stage of the Palestinian political community" (Mishal and Sela 2000, 15).

In the mid-to-late 1980's the Brotherhood fought for and wrested control of the Islamic University in Gaza from the secular nationalist PLO — thereby identifying an educated population from which Hamas was able to recruit. The increase in Brotherhood influence at the University (founded in 1978) coincided with declining financial support from the PLO. From 1978 to 1985 the PLO_operating outside the Territories — provided the majority of the University's budget through financial aid from Gulf countries. However various regional conflicts and the PLO's operations in the Lebanese Civil War drew external aid and attention away from funding University operations. This opened the door for other donors to finance the university. Muslim Brotherhood groups, and other Saudi-backed organizations filled the financial void, by funneling money to the university through the Islamic Center. "By the early 1980's representatives of the Islamic Movement in Jordan constituted a majority on the university's board of trustees, and in 1983... Muhammad Saqr, a member of the [Brotherhood]... in Jordan [was appointed]... president" (Mishal and Sela 2000, 24). Moreover, in 1983, Islamic students won $51 \%$ of the votes in the student union elections. This vote share increased to $61 \%$ in 1986 . Thus, by the early 1990 s the majority of the Islamic university's students identified as Islamists (Mishal and Sela 2000).

The rising prominence of the Islamists created internal strife in Palestine. As a consequence, in 1983, Yasin instructed Mujamma members to begin stockpiling arms. Then in 1986, after being released from Israeli prison for his arms collection project, Yasin established a 
Mujamma security apparatus that would collect information on Palestinian collaborators with Israeli intelligence (Mishal and Sela 2000).

As Yasin began to arm and secure the Mujamma, competing radical Islamist resistance organizations began to form. The largest of these Islamic resistant groups was the Palestinian Islamic Jihad. PIJ was an explicitly militant organization from Gaza, which had no interest in social change; Islamic Jihad began its armed struggle against Israel in 1986/87 (Hatina 2001).

\begin{abstract}
Mujamma' leaders felt constrained to submit to the pressure of their young militants and adopt an actively combatant posture, consistent with the Palestinians' public mood and expectations. The young leaders of the Mujamma' consisted of students and professional who had taken part in confrontations with their nationalist counterparts over the control of voluntary and public institutions, in which they acquired the experience in mobilizing, organizing, and leading violent protests. Many of them had also spent time in Israeli prisons, where veteran Palestinian prisoners trained them in clandestine activities. Thus, as the intifada erupted, these young Mujamma' activists were psychologically and organizationally keyed up for armed struggle against Israel (Mishal and Sela 2000, 35).
\end{abstract}

Consequently, by the onset of the Intifada in December 1987, the Mujamma leadership could easily form a separate resistance organization: Hamas. Hamas defined itself as the strong arm of the Brotherhood, and in its charter it dubbed itself a "wing" of the Muslim Brotherhood (Mishal and Sela 2000).

Therefore, by the time the Intifada broke out in 1987, elements of the Gazan population were ready to join an Islamist resistance movement. In fact, many people had already been engaged in some form of resistance, or had been influence by the Islamists through the former's social work in the Gaza Strip. The social services provided by the Muslim Brotherhood to the urban refugee population during the first twenty years of the occupation created a fertile environment for launching an Islamic resistance group. However, this environment also led to internecine conflict, which undermined popular collective action. 


\subsubsection{Palestinian Demographics}

The foregoing has focused on explaining the origins of Hamas. It roots the militant organization in the social structures created by the Muslim Brotherhood in the highly urban Gaza Strip; as discussed above, the majority of Brotherhood activities were focused on the main towns and cities of Gaza and the West Bank, areas that were underserved by the PLO (Sayigh 1997). The nature of urbanization in Palestine must be addressed further, as it is this demographic trend that determines how Hamas has chosen to fight in its ongoing military conflict with Israel.

UN Urbanization data in Table 1 and Graph 1 illustrate the draw of urban spaces in the West Bank. In 1950, two years after the foundation of the state of Israel, only thirty-seven percent of West Bank Palestinians lived in urban areas. By 1967, the urban population (including refugee camps) had grown to $51.06 \%$, a $0.82 \%$ annual increase in the urban population (UN 2011). At the outset of the First Intifada in 1987, the percentage of urban dwellers in the West bank had increased to $66.28 \%$, an annual increase of $0.76 \%$ in the urban population over twenty years of occupation. By $201074.1 \%$ of Palestinians resided in urban areas - this figures stands at 74.82 percent in 2013 (UN 2011). During the 46 year Israeli occupation the urban population of the West Bank has increased by 23.76 percent, or 0.516 percent per annum.

An interesting comparison can be made to Lebanon's urban population, which increased $32.98 \%$ from 54.34 percent in 1967 to 87.34 percent in 2013, an annual rate of change of 0.717 percent (UN 2011). Comparing contemporaneous urbanization in the West Bank and Lebanon provides insight on the impact of urbanization on the strategic development of both Hamas and Hezbollah. That is, looking at Lebanon and West Bank urbanization rates, and then comparing the organizations' resultant military strategies provides analytical leverage on the key independent variable of this analysis (urbanization). 


\begin{tabular}{|l|rrrrrrrrrrr|}
\hline Table 1. & \multicolumn{10}{|c|}{ Percentage of Urban Population 1965-2013. } \\
\hline & 1950 & 1965 & 1970 & 1975 & 1980 & 1985 & 1990 & 1995 & 2000 & 2005 & 2013 \\
\cline { 2 - 11 } Lebanon & 32 & 50.9 & 59.5 & 67 & 73.7 & 79.4 & 83.1 & 84.8 & 86 & 86.6 & 87.3 \\
Palestine & 37.3 & 48.9 & 54.3 & 59.6 & 62.4 & 65.2 & 67.9 & 70.4 & 72 & 73.1 & 74.8 \\
\hline
\end{tabular}

Source: United Nations Urbanization Prospects: The 2011 Revision

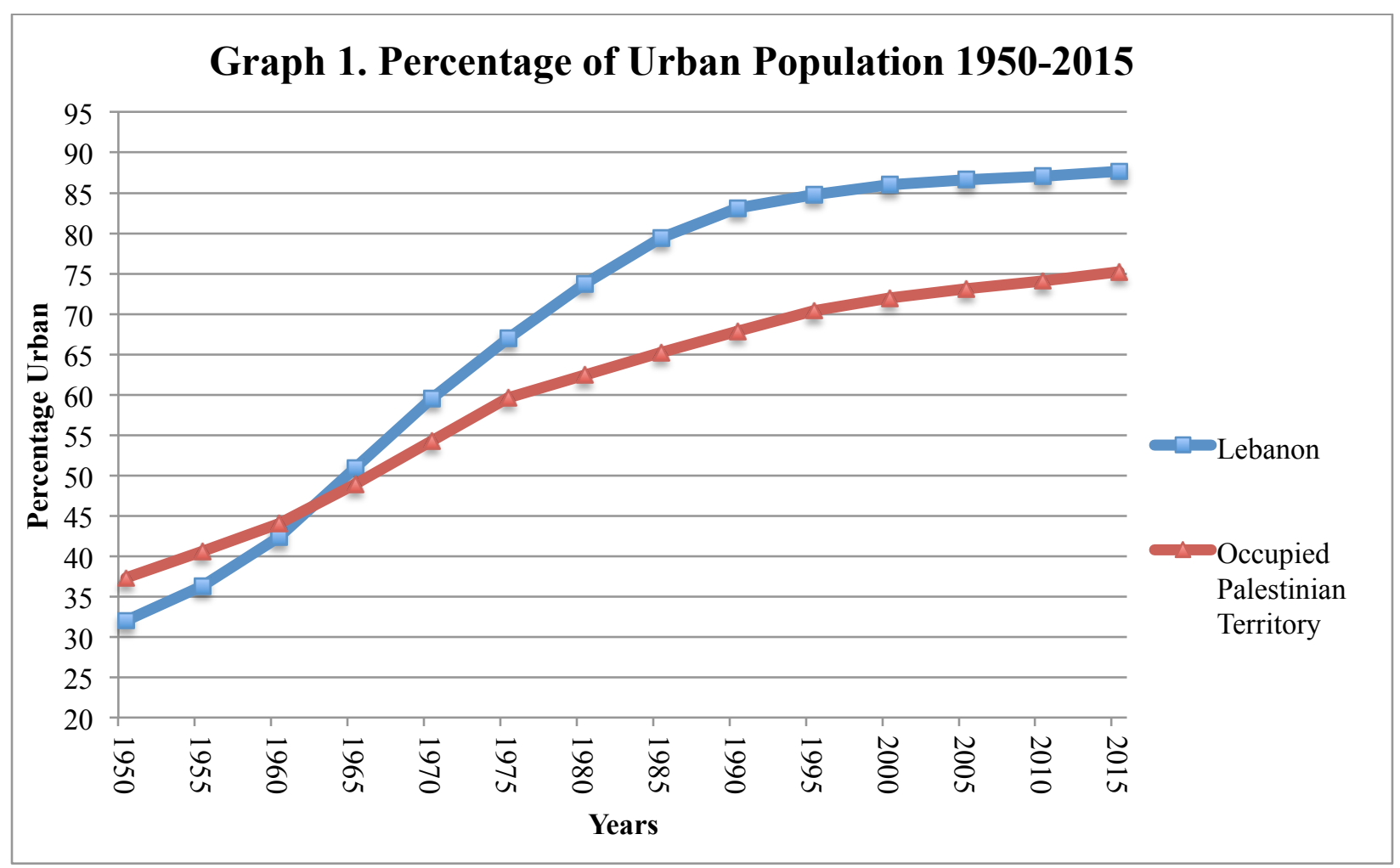

Source: United Nations Urbanization Prospects: The 2011 Revision

Several points must be made on Palestinian versus Lebanese urbanization. Both areas experienced a surge in urban population growth between 1950 and 1965 due to the flow of Palestinian refugees out of Israel. However, the annual urban growth rate in Palestine shrank significantly immediately after of the occupation, and urban growth has continued at a slower pace in the territories than it has in Lebanon (UN 2011).

Slower urbanization Palestine can be attributed to the massive exodus of Palestinians from the West Bank after 1967. Nearly one fifth of the West Bank population, 184,000 people, 
from a prewar population of 848,000 , fled to the East Bank of the Jordan River, leaving only 664,000 inhabitants in the West Bank after the war, according to an Israeli census conducted in September 1967. In fact, the West Bank population continued to decline through 1968, and only returned to its September 1967 levels in 1969; the West Bank population returned to its pre-Six Day War level in the mid-1980s - the majority of this population growth occurred in cities and refugee camps (Gharaibeh 1985).

The population of Gaza similarly decreased after 1967, but returned to its pre-1967 level by 1972 , and expanded by an additional two-fifths by 1982 . This population growth also took place exclusively in cities and refugee camps (Pearlmann, 2012; Gharaibeh 1985). No such population swings occurred in the Lebanese case. Counterintuitively therefore, urbanization in Palestine was actually slowed by the occupation.

Unfortunately neither table 1 nor graph 1 show critical demographic differences between the West Bank and the Gaza Strip (the area in which Hamas originated, and has successfully operated). "The 1967 Israeli census showed that the population of the Strip was highly urbanized; 92 percent lived in settlements, large refugee camps [in or around cities], or in large villages" (Gharaibeh 1985, 30). In contrast, the census reports that in September 1967, a maximum of 48 percent of the West Bank population was urban - living in settlements, camps, or large villages—-which fits with UN estimates for Palestine at that time (Gharaibeh 1985; Pearlmann 2012).

According to the Palestinian Central Bureau of Statistics, the demographic difference between the West Bank and Gaza remain stark. In 2007, 97\% of the Gazan population lived in urban areas (including refugee camps). The least urban governorate in the Gaza Strip, Khan Yunis, was ninety-four percent urban, and the most urban governorate, Deir al Balah, was 99.1\% 
percent urban - these figures do not change significantly by 2013 (PCBS 2013). In contrast, $74.3 \%$ of the West Bank is urban. The least urbanized governorate in the West Bank, Salfeit, is only $36 \%$ urban, whereas the most urban West Bank governorate, Jerusalem, is $88.8 \%$ urban (PCBS 2013). See Graph 2 for a detailed comparison of Gazan and West Bank governorates.

[Graph 2 here]

Thus, Gaza has become almost entirely urban since 1948, as refugee camps and cities have melded, while the West Bank has urbanized at a slower pace, which created discrete populations. When combining the populations of Gaza and the West Bank, 83.97 percent of the Palestinian population lived in urban spaces in 2007 - in the same year the Lebanese urban population stood at $86.8 \%$, a difference of only 2.8 percent. Urbanization levels in Lebanon and Palestine are therefore similar, but the nature of this urbanization has been drastically different.

\subsubsection{Unintended Urbanization}

Urbanization in Palestine is a byproduct of the creation of the state of Israel and Israeli economic policies towards the territories after 1967. Following the 1948 War of Israeli Independence, refugee camps for Palestinians fleeing Israel were set up across the territories; these camps were next to, or inside, existing urban areas, and have been enveloped by growing cities over time. The 'Azza refugee camp is now inside the city of Bethlehem. In the Gaza Strip, both the Khan Yunis and the Deir al-Balah refuge camps are part of those respective cities (Marx 1992).

Within the camps the UNRWA (UN Relief and Works Agency for Palestinian Refugees in the Near East - formed in 1949) provides health care and schooling to the refugee camp 
population, no municipal taxes or rent are paid, and sanitation and water are free. Consequently, from 1950 onwards Palestinians have actually preferred moving into urban refugee camps from more outlying camps/rural areas as urban camps improve the probability of finding work (both in the camps or in Israel). Men in refugee camps "were rapidly absorbed in the labour [sic] market, until their rate of employment was nearly the same as that of the rest of the population" (Marx 1992, 286). Many of these laborers went to work in Israel; by the outbreak of the First Intifada $50 \%$ of the Gazan labor pool, and 40 percent of that in the West Bank, were working in Israel, roughly 120,000 men (Marx 1992).

Israeli economic policies in the territories after 1967 facilitated the expansion of the refugee camp population, thereby unintentionally contributing to Palestinian urbanization (which began in 1948). In the late 1960 's Israel needed a new supply of unskilled, mobile, and unorganized labor, as the pool of Jewish unskilled labor was shirking. To address this issue Israeli leaders, led by minister of defense Moshe Dayan, sought out labor from the Palestinian territories, and endeavored to integrate the meager West Bank and Gazan economies into that of Israel. Dayan believed that by integrating the Palestinian and Israeli economies, Palestinian economic prospects would increase, thereby making recruitment for resistance more difficult (Hiltermann 1994, 18). Moreover, by breaking down economic boundaries, geographic ones would eventually fall as well, leading to one unified state.

Israel placed significant restrictions on Palestinian agriculture, to prevent its competition with Israeli agriculture, which limited its productivity: "Military orders have been issued which make it illegal and therefore punishable to plant new trees or replace old, nonproductive ones. In 1984, a new order was issued by the military making it illegal to plant fruit tree on a commercial scale without permission" (Roy 1987, 66). Moreover, discriminatory agricultural tax policies, as 
well as water use and land reclamation laws have made Palestinian agricultural production cost prohibitive (Roy 1987).

Through military legislation, Israel has facilitated the appropriation of Palestinian land, limited Palestinian agricultural and industrial production, imposed taxes, and withheld social services. In effect, Israel "rendered the economy of the Occupied Territories subservient to its own in an artificial 'common market' arrangement" (Hiltermann 1994). This legislation has drived more Palestinian labor off the land and into urban centered labor. By 1985 Israel had taken control of between 40 and 52 percent of West Bank land for settlement construction (Hiltermann 1994; Benvenisti 1986; Helu 2012); the percentage of seized Palestinian land is now closer to sixty percent (B’tselem 2013, 4). Through settlement construction Israel consumed potentially arable Palestinian lands, thereby further limiting agricultural production, and driving rural labor to cities.

The unintended byproduct of these policies was that Palestinian laborers were drawn from their historic agricultural homes and jobs towards cities/refugee camps in pursuit of industrial employment (Akin 1994). "In 1970, according to official Israeli statistics, 38.7 percent of Palestinians employed in the Occupied Territories were employed in agriculture. In 1986, their numbers had declined to only 25 percent” (Hiltermann 1994, 19). Palestinians increasingly turned to working in urban construction and public service sectors in the Territories and in Israel (Roy 1987; Gharaibeh 1985). In 1970 Palestinians working in Israel made up 12 percent of the total West Bank and Gaza Strip labor force; in 1974 this figure was 32 percent (Hiltermann 1994). By 1982, 30.6 percent of West Bank, and 43.9 percent of Gazan, labor worked in Israel (Gharaibeh 1985). 
Thus, in an effort to incorporate the Palestinian economy into Israel's, and thus increase the pool of available labor, Israel instituted a variety of economic and settlement policies that undermined Palestinian economic production. Israeli policies slowly undermined Palestinian agricultural production in both the West Bank and Gaza, which drove agricultural labor to look for work in cities (Palestinian and Israeli). Urbanization was, in part, the unintended consequence of Israeli economic and settlement policies. More, the opportunities and services available in refugee camps drew people from outlying areas to largely urban refugee camps, a phenomenon that has also increased the urban population of the territories.

\section{Education and Hamas}

The above discussion has highlighted how urbanization in Palestine was an unintentional consequence of the founding of Israel, and how the creation of Hamas was a byproduct of exigencies associated with urbanization.

As discussed in chapter one, the quantity and quality of people recruited into an insurgent organization are the dually necessary but individually insufficient factors that determine a group's military and organizational capabilities. Insurgent groups based in urban populations generally have truncated organizational capabilities because they are rooted specific urban communities/neighborhoods. Urban communities are small and tightly knit, with individuals having few connections to outsiders; exclusively urban communities have no links to rural areas, and in the Gaza Strip, few rural communities exist. These factors make large-scale, heterogeneous participation in violent collective action unlikely, as the population that supports an urban rebel group is homogenous. No cascade of popular support occurs in urban rebellions. Instead, in urban spaces, small rebel groups proliferate, often in competition with other similar organizations. 
Instead of recruiting a large number of variously skilled fighters, urban rebels recruit small numbers of well-educated and technically skilled fighters. Urban insurgents derive military capability from the education and technical skill of their members, not the number of their recruits. The high levels of education and technical skill within urban rebellions facilitate the adoption of the technically demanding but labor un-intensive strategy of terrorism.

I now turn to explaining how a relatively small but well-educated and skilled population facilitated Hamas's adoption of terrorism. A note about educational data must be made here. Education data for Palestinian has not been collected and coded by a single source, nor is the available data uniform. Thus, World Bank gross enrollment figures as well educational attainment data after 1995 are available. However, pre-Oslo figures only measure the total years of schooling for members of the labor force, as surveyed by the Israeli Central Bureau of Statistics. Thus, while I can demonstrate that educational attainment amongst Palestinian is in fact increasing as urbanization increases (a component of my semantic definition of capability), the operational measure of the variable is opaque prior to 1995.

A significant expansion in educational availability and enrollment occurred in the Territories from 1967 onwards, as people funneled towards cities/urban refugee camps due to increasing labor-market integration with Israel. There are several key indicators of this fact. First, beginning in 1975, new universities were opened, of which Birziet University, near Ramallah, was the first. Islamic University in Gaza opened in 1978, and by 1986 twenty separate institutions were granting post-secondary degrees in the territories. "Enrollment in West bank and Gaza Strip universities doubled between 1981 and 1985 (from 6,450 to 13,083 students), and 6,600 university students graduated between 1981 and 1986" (Angrist 1995). 
According to quarterly Israeli labor-force surveys of Palestinian men aged 18 to 64, enumerated between 1981 and 1991, their average years of schooling increased from 7.7 in 1981 to 8.65 in 1991 . The "fraction of the labor force with 13 or more years of schooling rose from 7 percent to 12 percent between 1981 and 1990. The fraction with less than 12 yeas of schooling fell from 81 percent to 67 percent" (Angrist 1995, 1067).

\begin{tabular}{|c|c|c|c|c|c|c|c|c|c|c|c|c|c|c|}
\hline & 1995 & 2000 & 2001 & 2002 & 2003 & 2004 & 2005 & 2006 & 2007 & 2008 & 2009 & 2010 & 2011 & 2012 \\
\hline \multicolumn{15}{|c|}{$\begin{array}{l}\text { Secondary } \\
\text { West Bank }\end{array}$} \\
\hline Male & 13.1 & 15.1 & 16.3 & 17.2 & 17.9 & 17.7 & 17.4 & 17.7 & 18.3 & 18.6 & 18.8 & 19 & 19.2 & 19.6 \\
\hline Female & 10 & 12.5 & 13.7 & 15.2 & 15.6 & 15.9 & 16.2 & 17.3 & 18 & 18.3 & 18.9 & 19.5 & 19.5 & 20.7 \\
\hline \multicolumn{15}{|l|}{ Gaza } \\
\hline Male & 19.5 & 20.6 & 22.5 & 24.2 & 23.9 & 23.7 & 23.4 & 24.3 & 24 & 24.7 & 23.6 & 22.1 & 22.8 & 22.6 \\
\hline Female & 17.8 & 22.1 & 22.9 & 25.2 & 25.4 & 25 & 24.6 & 26.2 & 25.2 & 26.4 & 26.4 & 26.7 & 26.6 & 26.5 \\
\hline \multicolumn{15}{|c|}{$\begin{array}{l}\text { Associates and Above } \\
\text { West Bank }\end{array}$} \\
\hline Male & 11.3 & 12.7 & 13.4 & 13.8 & 13.9 & 13.5 & 13.2 & 13.9 & 14.5 & 14.1 & 15.2 & 14.9 & 15.3 & 15.5 \\
\hline Female & 7 & 8.2 & 8.4 & 8.9 & 9.6 & 10.2 & 10.2 & 11.1 & 11.3 & 12.4 & 13.5 & 14 & 14.8 & 15.6 \\
\hline \multicolumn{15}{|l|}{ Gaza } \\
\hline Male & 13.9 & 13.6 & 13.9 & 13.6 & 13.9 & 14.7 & 15.5 & 16.1 & 15.6 & 16.3 & 17.9 & 17.8 & 19.7 & 20.7 \\
\hline Female & 7.6 & 7.6 & 7.5 & 7.8 & 8.2 & 9.2 & 10.3 & 10 & 11.3 & 12.6 & 14 & 13.3 & 15.8 & 17.8 \\
\hline
\end{tabular}

Source: Palestinian Central Bureau of Statistics (accessed November 12, 2013).

Table 3 presents data disaggregated by region and sex. Between 1995 and 2012, as the West Bank urbanized the percentage of the population completing secondary school increased from 13.1-19.6 for men, and from 10 to 20.7 percent for women. Of particular interest for this work, in the highly urbanized Gaza Strip educational attainment as a percentage of the population is consistently higher than that of the West Bank. Amongst men in 1995 (a year after the end of the First Intifada), $6.5 \%$ more men in Gaza completed secondary school than did their counterparts in the West Bank, a smaller 3\% gap remained in 2012. Interestingly, although the 
West bank is larger and has a greater number of educational institutions, a larger percentage of both men and women in Gaza complete at least 2 years of college. In fact, the gap in postsecondary levels of educational attainment has expanded over time (PCBS 2013).

Table 4 serves as a point of comparison between Palestine and Lebanon. While longitudinal educational data for Palestine is limited, gross enrollment rates in secondary education in Palestine between 2000 and 2005 are available. These data are similar to Lebanon's. As with Lebanon, increases in educational attainment occur concomitantly with increases in urbanization. In 2000 when urbanization and gross enrollment rates stood at $72 \%$ and $83.3 \%$ for the West Bank, the figures were 86 and 80.3 percent, respectfully, for Lebanon. In 2005, West Bank urbanization had increased $1.1 \%$ to $73.1 \%$, gross enrollment rates increased nearly $16 \%$ to 99.27\%. In contrast, urbanization remained unchanged in Lebanon over same period with only a nine percent increase in enrollment. In short, through the data presented above, it can be concluded that, as with Lebanon, urbanization and educational attainment increase simultaneously in Palestine.

\begin{tabular}{|lrrrrrrrrrrr|}
\hline \multicolumn{10}{|l|}{ Table 4. Gross Enrollment Rate in Secondary Education, 1975-2005 } \\
\hline & 1975 & 1980 & 1985 & 1990 & 1995 & 2000 & 2001 & 2002 & 2003 & 2004 & 2005 \\
\hline Lebanon & 46.9 & 59.1 & 60.6 & 73.9 & 80.7 & 80.3 & 83.6 & 86.8 & 88.7 & 88.67 & 89.07 \\
\hline Palestine & - & - & - & - & - & 83.3 & 85.9 & 89.2 & 93.6 & 93.62 & 99.27 \\
\hline
\end{tabular}

Source: UNESCO Institute for Statistics through EdStats (accessed on November 11, 2013) Source: The World Bank 2008, Statistical Appendix

While the above data provides a glimpse of the Palestinian population as a whole, it is vital to focus on the impact of increasing levels of educational attainment on Hamas specifically. Therefore, as with Hezbollah, a more detailed picture of Hamas's recruiting preferences emerges

\footnotetext{
${ }^{26}$ Gross enrollment rate is "defined as the ratio of total enrollment, regardless of age, to the population of the age group that officially corresponds to the level of education" (World Bank 2008, 204). These data are used here in place of the Barro-Lee data included in the regression analysis in chapter 2 because Palestine is excluded from that dataset.
} 
when a sample of Hamas fighters' vital statistics is compared to the larger Palestinian population. Table 5 (below), from data accumulated by Claude Berrebi (2007), provides such a comparison. The data, collected and translated by Berrebi, come from the biographies of 335 Palestinian fighters, 285 of whom were operational terrorists, with the remaining 50 being part of the 417 members of Palestinian Islamic Jihad (PIJ) that were expelled to Lebanon, by Israel on December 17, 1992. In all this data includes 183 Shahids (martyrs) from Hamas, 103 from PIJ, and 50 PIJ leaders. All Shahids included in the data set are male, with one third of the biographies published between 1992-95. These data are contrasted with the 1993 Labor Force Survey in Judaea, Samaria and Gaza. This survey conducted by Israel, includes reliable data that samples from residents from the West Bank and Gaza, but does not include settlers (Berrebi 2007).

According to my theory of rebel strategic adoption, fighters in urban organizations that adopt terrorism should be highly educated and technically skilled, moreover a majority should emanate from urban areas.

Several facts in Table 5 provide valuable supporting evidence from the theory laid out in this work. First and foremost, the membership of Hamas and PIJ (both of which were founded and organized in the Gaza Strip) is significantly more educated than the general Palestinian population. Of the 208 observations in which a fighter's educational information was available, "96 percent (200) have at least a high school education, and 65 percent (135) have some kind of higher education, compared to 51 percent and 15 percent respectively, in the Palestinian population of the same age, sex and religion” (Berrebi 2007, 17). By comparison, $47 \%$ of Hezbollah fighters have at least a high school education. More, only $14 \%$ of Hezbollah fighters have some post-secondary education. 
Second and relatedly, 84 percent of Hamas and PIJ members live at average or above average income levels, as opposed to 68 percent for the Palestinian population at large. This finding suggests that Hamas and PIJ members have better access to education than the rest of the population. Moreover, this suggests that these fighters are not motivated to fight (and die) by a financial incentive.

\begin{tabular}{|c|c|c|c|c|}
\hline Characteristics & Hamas and PIJ & Observations & $\begin{array}{l}\text { Palestinians Age } \\
\text { 15-56 Males and } \\
\text { Muslims }\end{array}$ & Observations \\
\hline Poverty & & 230 & & 19590 \\
\hline Poor & 0.16 & & 0.31 & \\
\hline Average & 0.41 & & 0.48 & \\
\hline Well & 0.33 & & 0.20 & \\
\hline Very Well & 0.10 & & 0.00 & \\
\hline Age & & 246 & & 41762 \\
\hline $15-17$ & 0.04 & & 0.12 & \\
\hline $18-24$ & 0.51 & & 0.28 & \\
\hline $24-34$ & 0.37 & & 0.31 & \\
\hline $35-44$ & 0.06 & & 0.17 & \\
\hline $45-54$ & 0.01 & & 0.09 & \\
\hline $55-56$ & 0.00 & & 0.01 & \\
\hline Education & & 208 & & 40278 \\
\hline Primary & 0.04 & & 0.21 & \\
\hline Intermediate & 0.00 & & 0.28 & \\
\hline Secondary & 0.31 & & 0.35 & \\
\hline Vocational & 0.08 & & 0.01 & \\
\hline Post-Secondary & 0.01 & & 0.06 & \\
\hline Academic Institute & 0.56 & & 0.08 & \\
\hline Region of Residence & & 311 & & 41762 \\
\hline Urban & 0.54 & & 0.34 & \\
\hline Refugee Camp & 0.23 & & 0.54 & \\
\hline Rural & 0.23 & & 0.13 & \\
\hline Source: Berrebi 2007 & & & & \\
\hline
\end{tabular}

Third, 88\% of Hamas and PIJ members are under 35, with over half being under 25 . Given that access to education in Palestine increased significantly after 1967, these age data 
serve as further support of my theoretical claims. That is, members of Hamas and PIJ who were born on or after 1967 were at most 28 years old if they died in martyrdom activities in 1995. It is this age group that would have been most directly affected by increasing levels of educational investment after 1967. Stated explicitly, their willingness to participate in violent resistance was determined by their levels of education. That is, people born after 1967 were the most educated Palestinian generation in history, however by the middle of the 1980's, the economic returns they received from high levels of schooling were actually decreasing, relative to Israelis with equal levels of education (Angrist 1995). Thus, young but well-educated and underemployed individuals formed the first recruiting classes of Hamas. The fighters, who died in the early years of Hamas and PIJ militant activity, set the standard for those who would come later. In urban environments a cascade of popular support is highly unlikely, especially in a factionalized Palestinian society. Only the most committed individuals, those understanding and willing to bear high costs of participation at time $t$ and at time $t+1$, join these organizations.

Finally, the residence information is a critical point of support for my argument. As discussed above, rebels adopting terrorism recruit from urban spaces; they draw on a fairly homogenous subset of the population. Table 5 demonstrates that 54 percent of Hamas and PIJ fighters come from urban areas. This figure is compounded by the additional 23 percent of their membership that comes from refugee camps, which as discussed above, are themselves parts of urban areas. Therefore, $77 \%$ of Hamas and Palestinian Islamic Jihad fighters come from urban areas, and these members comingle with a very small number of rural fighters.

A key point of comparison here is Hezbollah. Drawing from Table 2 in chapter 3, 42 percent of Hezbollah fighters in the dataset came from Beirut, while 56 percent were from the South and the Bekaa Valley, which have both urban and rural space. Thus, Hezbollah, which 
adopted a hybrid warfare military strategy, draws on a very mixed population for support, while Hamas, which employs a terrorism strategy, draws the vast majority of its recruits from urban areas.

Hamas and PIJ therefore maintain a fairly homogenous group of supporters, most of who come from urban areas in Gaza. Individuals in these communities have similar cost-benefit calculations (a homogenous recruitment base), which does not facilitate widespread support, in fact it leads to the proliferation of several competing organizations, all with limited military capabilities. I now turn to a discussion of Hama's capabilities.

\section{Hamas and Military Capacity}

The growth of Hamas from its 1987 foundation into one of the preeminent terrorist organizations in the Middle East is directly related to the demographic characteristics of the Palestinian population. Hamas originated in the tight confines of Gaza's urban areas, and the Islamic Resistance Movement relies almost entirely on support from urban dwellers. This base of support has at once facilitated Hamas's growth and limited its organizational and military capabilities.

Urban and educated people are the explicit target of Muslim Brotherhood and Hamas recruitment, however this population is homogenous; joiners of the Islamic resistance all have similarly high opportunity costs for participation. Thus, early on in the First Intifada Hamas did not call for mass demonstration or outright violence against Israel. It was publicly weak (the PLO dominated the Intifada's evolving leadership in 1987/88 as it has always been the official representative of the Palestinian people), and it had limited popular support (Mishal and Sela 2000). In urban spaces, people are tightly connected to a small number of other people (few out of network ties exist as in mixed communities); individuals are connected to people in their 
immediate vicinity/neighborhood. Hamas, based its recruitment on personal social ties between supporters and potential new recruits, but given the dearth of social ties in urban spaces, Hamas was not able to develop a overwhelming body of supporters, regardless of its capacity to deliver social services. Furthermore, it was forced to compete for support with the PLO and Palestinian Islamic Jihad, further undermining the quantity of its supporters.

\subsection{Urbanization, Education and the Prelude to Violence}

In 1949 urbanization in Palestine began in earnest. After 1967, levels of education in the Occupied Territories also began to increase. These two trends should have led to greater economic and social mobility in Palestine. However, Israeli economic and social polices vis-àvis Palestine stymied its growth; this expanding Palestinian population, which was relatively young in age and increasingly well educated, received few economic and social returns to their changing demographic characteristics. Economic data drawn from the Israeli Labor Force Surveys between 1981 and 1991 demonstrate that educational premiums paid for Palestinian with higher levels of education (13 years and over) actually decreased over this time period, whereas for Israelis with similar education levels they rose. "Palestinian students who observed wage premiums as high as 40 percent when the made enrollment decisions ended up earning less than 20 percent more than high-school graduates when they entered the labor market" (Angrist 1995, 1084).

These poor returns to schooling became points around which Islamist organizations recruited members. Indeed, two vital sources of recruits for Hamas are the Islamic University in Gaza and al-Najah University in the West Bank city of Nablus. The Muslim Brotherhood supported the creation of student associations at both Universities in order to insinuate itself into institutions that were considered bastions of PLO supporters. By 1983 the Brotherhood had taken 
control of the Islamic University, and through it, Hamas and PIJ "recruited, educated and mobilized an entire generation of activists who later emerged as some of the most effective and committed... cadres" (ICG 2004, 5). During the Second Intifada at least 7 Hamas suicide bombers were drawn from the student body of al-Najah University (Levitt, 2006).

\subsubsection{Competitive Recruiting for Jihad: Hamas and Palestinian Islamic Jihad}

Shaykh Ahmad Yasin established Hamas's base of support inside of the Gaza Strip through decades of social work in communities that were otherwise underserved by Israel, the UNRWA, and the PLO (Sayigh 1997). Through the Mujamma (formed in Khan Yunis, Gaza) and its associated charitable works, the Muslim Brotherhood developed and entrenched ties between itself the Palestinian population at large-with a focus on marginalized groups (AbuAmr 1994; ICG 2004). Hamas was spurred to recruit fighters through the social networks established by the Mujamma only after another offshoot of the Muslim Brotherhood, Palestinian Islamic Jihad, began its own resistance organization with support from these networks (Hatina 2001).

The Muslim Brotherhood refrained from participating in violent confrontation with Israel. For the Brotherhood, Palestinian liberation could only accomplished after slowly moving secular society towards Islam through education and communal religious indoctrination—da'wa (Hatina 2001). Over time though his approach caused a rift within the Brotherhood, as more radical members, themselves highly educated yet underemployed, criticized the Society for not initiating a violent struggle (Sayigh 1997, 629). "Religious fervor had a particular appeal in the poor quarters of the Gaza Strip [refugee camps], where a new educated generation was emerging, old enough to have experienced the social distress of the Israeli occupation yet too young to have commitments to a fixed ideology, family or career" (Hatina 2001, 29). Two such disillusioned, 
former Brotherhood members-Fathi al-Shiqaqi, a refugee from Gaza with a degree in math and a doctorate in pharmacy and 'Abd-al'Aziz 'Awda, also a refugee, as well as a preacher and a lecturer at the Islamic University in Gaza-joined forced in 1980 to found Palestinian Islamic Jihad (PIJ). "Jihad criticized the Muslim Brotherhood for choosing the 'path of belief' without jihad, and the PLO for taking the 'path of jihad' without belief' (Sayigh 1997, 627).

Islamic Jihad, like Hamas, recruited through word of mouth, as well as from mosques, universities, and through Brotherhood social activities. For PIJ its sole focus was on militancy against occupation, as armed struggle against Israel is the central tenet of Jihad's strategy. "Contrary to the Muslim Brotherhood's point of view, the Islamic Jihad does not insist on the Islamic transformation of society as a prerequisite to the liberation of Palestine and the establishment of a Palestinian state in it... This can only be achieved through jihad, which cannot be delayed under any pretext” (Abu-Amr 1994, 106). Jihad began its terror campaign in 1982 using a variety of knives and small arms, eventually progressing to larger-scale suicide missions in the 1990's (Alexander 2002; Abu-Amr 1994). By 1987, Jihad was reputed to have between 2000 and 4000 active members (Hatina 2001). Islamic Jihad, while a noted terror group, has always been a third order force, lagging well behind Fatah/PLO/PA and Hamas in terms of popular support. This is largely because it has consistently eschewed the provision of social services and education to attract a mass following. The Jihad founder, Fathi al-Shiqaqi, "believed that a campaign of spectacular terrorist attacks against Israel in the name of revolutionary Islam [alone] would inspire popular revolt" (Levitt 2006, 23). Shiqaqi was incorrect.

Pressure from the formation of Jihad and its militant activities pushed Shaykh Yasin to begin developing a militant wing for the Brotherhood, so as not to loose additional members to PIJ. Thus, in "1982 or 1983 Yasin secretly founded the 'Palestinian mujahidun' as the military 
arm of the Society, but was arrested in 1984 for illegal possession of weapons" (Sayigh 1997, 629). This however did not prevent further organization by Yasin. After his release from prison in 1985 he went on to establish an intelligence organ for the Brotherhood called the Organization of Jihad and Da'wa (Munazzamat al-jihad wal-da'wa) or Majd (glory) for short. Two former student council presidents (Yahya al-Sinuwar and Khalid al-Hindi) from the Islamic University in Gaza, led this body (Mishal and Sela 2000; Sayigh 1997). It was tasked with finding and punishing Palestinian informers for Israel, drug dealers, and others, in addition to revealing “Israeli entrapment techniques to the general population" (Sayigh 1997, 630). In 1991 the Majd was reorganized (as part of a major reorganization within Hamas in response to Israeli crackdowns of the group) and become the Izz al-Din al-Qassam Brigades, the military arm of Hamas led by Salah Shehade - a preacher and faculty member of the Islamic University in Gaza (Mishal and Sela 2000; Sayigh 1997; Levitt 2006).

In effect, the creation of Islamic Jihad propelled Yasin to create a parallel militant structure related to, but independent from, the Muslim Brotherhood, this structure served as the basis for Hamas in Gaza when the Intifada erupted. According to Ismail Abu Shanab, from the Nuseirat refugee camp in Gaza and a Hamas co-founder, “The period 1983-1987 marked the phase of direct preparation for resistance to the occupation, including armed struggle. Sheikh Ahmed Yasin took the lead in this, and did so independently of the Muslim Brotherhood"' (ICG 2004, 6).

\subsubsection{Competitive Recruitment and Limited Capability}

Interestingly though, the sources of Hamas's support did not lend themselves to largescale violent collective action. The population of willing participants in violence was fractured amongst the various Palestinian organizations. The majority of those individuals taking active 
roles in the resistance associated with the First Intifada did so in line with instructions from the PLO through the UNLU (United National Leadership of the Uprising); according to surveys conducted by the Jerusalem Media and Communications Center, at the end of the First Intifada, over 40 percent of survey respondents trusted and supported Fatah/the PLO, while only 20 percent trusted and supported Hamas or PIJ (JMCC 2000). However, Hamas explicitly rejected the leadership of the UNLU/PLO, which created an open competition between the two (ICG 2004). Moreover, those members of the population inclined towards Islamism were divided between Hamas and Jihad, with the more radical, and initially more violent portion of this population streaming to Islamic Jihad due to their focus on militancy. This fracturing of the pool of potential recruits initially limited Hamas's capabilities.

Consequently, Hamas engaged in a diverse set of operations between 1988 and 1993, much like the PLO, in an effort to expand its base of support. Hamas called for both violent and nonviolent actions including: the severing of economic ties with Israel, civil disobedience, and working to promote intra-Palestinian solidarity. In fact, during the first year of the Intifada Hamas explicitly supported unarmed resistance in the leaflets it distributed, calling for strikes and putting on nonviolent demonstrations (Mishal and Sela 2000; Pearlman 2010). These nonviolent resistance activities were explicitly aimed at drawing moderates away from the more popular PLO. Doing “otherwise would have jeopardized its quest for popularity” (Pearlman 2010, 112).

In a contemporaneous effort to draw in more hardline Muslim Brotherhood supporters, Hamas slowly expanded the scope and pace of its violent operations. In 1988 Hamas only claimed responsibility for 10 operations that included shooting at Israeli military forces and civilian transportation in Gaza, as well as the use of roadside charges against Israeli military 
vehicles. This figure tripled in the second year of the Intifada to 32 operations. "The most conspicuous of these operations were the kidnapping and murder of Israeli soldiers inside Israel... Hamas [also] extended its military activity to the West Bank, notably Hebron, and this was followed by actions inside Israel proper, including knife attacks on civilians and the burning of forests" (Mishal and Sela 2000, 57). ${ }^{27}$

In its earliest years of militancy the Islamic Resistance had access to light firearms and hand grenades (no heavy weapons) but lacked organizational and military capacity due to the large number of competing resistance organizations. It therefore explicitly restricted the set of military operations it undertook while it endeavored to expand its base of support.

Contributing to its limited capabilities in the early years of the Intifada was the fact that both Hamas and PIJ recruited by word of mouth through sympathetic mosques, and educational social networks. This recruitment strategy limited the number of people they could reach at the outset of the rebellion; recruitment was very informal (Post et al. 2003). Of fighters interviewed, the majority report knowing their recruiter prior to joining their militant organizations. The social/peer groups from which people originate have a determinate effect of their joining militant organizations in Palestine. "For the Islamist groups, almost 50 per cent cite the Mosque, Moslem Brotherhood, or other religious influence as central [to their recruitment], another 20 per cent cite their experience at the University of other professional school as of primary importance" (Post et al. 2003, 173). As demonstrated in Table 5 above, the majority of shahids from both Hamas and Jihad were urban and educated. This fact is buttressed by an analysis of the 415 Hamas and Islamic Jihad members that were deported by Israel, to Lebanon, in 1992. 86 percent of those deported were between twenty and 35 years old, 32 percent were student, teachers, or

\footnotetext{
${ }^{27}$ For the purposes of this work burning forests falls into the light arms category. That is, it does not require any crew services weapons, nor does it demand any specific military armaments. Moreover, forests are civilian infrastructure. Thus, burning forests are part and parcel of a terror strategy.
} 
professionals, and 53\% came from refugee camps (Hatina 2001). These data support the claim that recruits into these organizations, came from particular communities within Palestine.

These limited recruitment networks fundamentally undermined Islamist organizational capabilities. Word of mouth recruitment though mosques, and universities in urban areas limited the number and type of people that can be recruited in these organizations. In addition, recruits are similar, meaning no large-scale heterogeneous support is forthcoming. Finally, the fragmented nature of the resistance further undermined Hamas's capabilities, as it had to compete with the dominant PLO, as well as Islamic Jihad for support. In sum recruiting through small, personal and urban networks, and the proliferation of competing organizations fundamentally limited Hamas's organizational capacities.

\subsection{Positive Inducements for Support}

Hamas's commitment to providing social services as a positive inducement for support is an inextricable component of its existence. Put more starkly, given the dominance of the PLO within Palestinian politics, Hamas could not have developed, survived and thrived without providing social services in return for support. The provision of social services by Hamas, is largely funded through its own charity network, but also receives funds from external supporters like Iran, Iraq, Kuwait, Jordan, and Syria (Levitt 2006).

As the foregoing has demonstrated support for Hamas is rooted in mosques and educational institutions throughout the urban areas of Palestine, as well as in the group's relief and charity work, their pre-primary and primary education institutions, library building, health care provision, women's organizations and sports leagues (Roy 1999; Levitt 2006). "Islamic institutions reportedly comprise anywhere from $10-40$ percent of all social institutions in the Gaza Strip and West Bank" (Roy 1999). These institutions served some 278, 348 people in 1997, 
with most of these individuals coming from poor/low-income families (ICG 2003). Islamic organizations can provide such a significant proportion of social services because the PLO/PA lacks the capacity to provide for the entire population. Thus, the Palestinian Authority, in 1999 estimated that inside the Gaza Strip, where PA schools are so overwhelmed that students are “educated in shifts, Islamic organizations account for 65 per cent of all educational institutions below secondary level—suggesting the sector would collapse without their continued involvement" (ICG 2003, 8).

Specific examples of Hamas services abound. The Islamic Assembly of Gaza provides nursery services, food and clothing to 5,000 orphans and many poor families. The Al-Salah Islamic Association in Gaza provides money to the families of martyrs killed during the occupation, whether in violent confrontation or not (ICG 2003; Levitt 2006). These organizations supplement the work done by the Mujamma in Kahn Yunis, and various Hamas-affiliated organizations in Universities throughout Palestine. "Although there are no official and precise figures regarding Hamas-affiliated social welfare organizations operating in the West Bank and Gaza Strip... it is believed their number, if branch organizations are excluded, lies somewhere between 70 and 100" (ICG 2003).

Interestingly, Hamas's goal through the provision of these social services is not direct recruitment into its organization. Instead, the Islamic resistance prefers to accumulate popular prestige and political gains from their social services, by keeping these services, professional, and separate from their political activities. If "schools and medial clinics developed a reputation as recruitment centers, and services were provided in exchange for support, the crown jewels of the Islamist movement would be irretrievably debased in exchange for short-term gains of dubious value" (ICG 2003, 21). 
However, these separate social institutions do serve as employment centers for Hamas militants, so that fighters can remain legally employed, while preparing for violence (Levitt 2006). Moreover, available evidence suggests that Islamic charitable organizations do make preferential payments to families of Hamas Shahids. That is, while families suffering losses (members being killed or injured) in combat with Israel receive money from Islamic charities, on average, Hamas fighters receive larger sums than those from non-Hamas groups. These payments are popular amongst the Palestinian population, even amongst those who do not support violent confrontation with Israel; the Palestinian public welfare system does not reach significant proportions of the population, and Islamic charities fill this gap. These payments therefore, indirectly encourage support for Islamist organizations over the secular nationalist PLO (Levitt 2006; ICG 2003).

\subsection{External Support}

External support for Hamas comes from several sources. First, funding comes through Gulf States for the Islamic Resistance's charities. This funding is rooted in the onset of the Israeli Occupation when surrounding states provided money and material assistance to the Muslim Brotherhood. Citizens of Gulf States have also provided significant funding to Islamic charities affiliated with Hamas (ICG 2003).

Secondly, at various points Iran, Iraq, Syria, and even Saudi Arabia have all made substantial financial commitments to Hamas. ${ }^{28}$ Iran is notable for its contributions which in 1995 were estimated to total " $\$ 30$ million and ranged from $\$ 20$ million to $\$ 50$ million annually

\footnotetext{
${ }^{28}$ Saudi Arabia is estimated to have donated at least $\$ 12$ million to Hamas in 2003, aside from any covert donations it makes to the Izz al-Din al-Qassam Brigades. "The Saudi Committee for the Support of the al-Aqsa Intifada, a governmental committee established in September 2000 and headed by Saudi Interior Minister Prince Nayef bin Abdel Aziz, reportedly raised more than $\$ 100$ million in its first two years of operations, much of which went directly to Hamas" (Levitt 2006, 191). This same committee also gave some $\$ 5,000$ to the family of every Palestinian killed during the second Intifada. Saudi funding is thought to have begun in 1994 and was believed to be a punishment for the PLO as a result of its outspoken support of Iraq during the First Gulf War (Levitt 2006).
} 
between 1990 and 2000" (Levitt 2006, 172). Iran's support for Hamas extends beyond financial assistance. Iran's ties to Hezbollah have been vital to the development of Hamas's military strategies. That is, Iran has supplied and trained Hezbollah fighters since 1983. In 1992, after 415 Hamas and Islamic Jihad members were deported by Israel to Lebanon, Hezbollah and Iran shared their military expertise with the deported fighters. Both Hamas and PIJ's expertise in suicide operations can be traced to the training they received from Hezbollah in 1992; the key difference between Hezbollah and its Palestinian counterparts being that the former attack Israeli military targets, while the latter victimize civilians (Alexander 2001; Levitt 2006).

Iran's impact on Hamas's military orientation was on display during the January 2002 Karine A Affair. In this instance, the Israeli Navy seized the MV Karine A, a ship destined for Gaza carrying over fifty tons of Iranian heavy weapons. The weapons were valued at over $\$ 2$ million, and “'have been described as force multiplier systems'... They included $107 \mathrm{~mm}$ and $122 \mathrm{~mm}$ rockets and launchers with rangers of up to twenty kilometers, antitank launchers, and $120 \mathrm{~mm}$ mortars and mortar bombs... While executed by Hezbollah, the entire operation was financed by Iran” (Levitt 2006, 176).

In short, Iran and several Gulf States have played a key role in building up Hamas's capabilities, either through direct funding, charitable support, or training. As Hamas was able to demonstrate its capabilities to sustain a terror campaign against Israel during the First Intifada foreign support increased. Moreover, as Hamas looked to shift towards a hybrid military strategy during and after the Al-Aqsa Intifada the quality of weapons it obtained also increased. Thus, in line with the theory, demonstrating military capability facilitates foreign support. 


\section{Hamas's Strategic Doctrine}

The above discussion has focused on the historical development of Hamas. It has emphasized Hamas's grassroots ties to the urban Gazan population that is increasingly well educated and skilled. Word of mouth recruitment through various social institutions did not however facilitate a cascade of popular support for the Islamic Resistance; this type of narrow recruitment led to a fairly homogenous recruitment, and thus a relatively small organization.

The Palestinian population is divided between the PLO/PA/Fatah, various other secular nationalist groups, Hamas and Palestinian Islamic Jihad. No one organization has been able to marshal enough heterogeneous support to demonstrate that any one individual's contribution would not be wasted, and that therefore, organizational membership provided safety in numbers. While Hamas has provides social services to both its membership and the Palestinian population at large, as a positive inducement for support, its homogenous support base has limited its popular appeal given the variety of competing organizations. After the 2006 Palestinian Legislative elections these facts changed, as Hamas was able to seize sole control of the Gaza Strip. This power grab however has not (yet) resulted in a significant change in the Islamic Resistance's capabilities, and therefore has only a marginal effect on its military strategy. I now turn to explaining how Hamas mobilized its small but educated base of support (organizational capability) for its terrorist and indiscriminate violence military strategies.

\subsection{The Military Evolution of the Islamic Resistance in Palestine}

According to post-Operation Cast Lead strategic assessments, Hamas had a force of $6,000-10,000$ full time fighters, with a total of some 20,000 fighters of various skill and training levels, in the Gaza Strip during the 2008, a seemingly large and capable fighting force, a force some Israeli scholars liken to that of Hezbollah (Cordesman 2009; Schwietzer 2009). Even if a 
mid-range number of 8,000 if used then this means that Hamas deployed roughly 2 fighters per square kilometer in Gaza. This is one third of what Hezbollah had in its 2006 war with Israel (Biddle and Freidman 2008). This relatively low troop density cannot facilitate the hybrid warfare strategy adopted by Hezbollah, which necessitates fighters dispersed in depth, in a spider web-like structure, to take and hold ground for extended periods of time through close quarters combat (Mearsheimer 1983). Moreover, even with this level of troop density, which is 5 times greater that that of the Vietcong in 1964, Hamas focused on the indiscriminate launching of rockets into Israel, and failed to demonstrate any ability to take on Israeli forces in combat (Cordesman 2009). This strategy is therefore not quite the hybrid warfare of Hezbollah, nor does it resemble traditional terrorism (Hamas's strategy during and after the First Intifada). Hamas was forced into a new strategy, is a stop-gap strategy, between hybrid warfare and terrorism: indiscriminate violence.

During the 22-day (December 27, 2008-January 18, 2009) Gaza War Hamas sought to accomplish several goals: first, to indiscriminately launch rockets and heavy mortars at southern Israeli towns in an effort to embarrass Israel — a terrorist goal. Second, to undermine the accomplishment of Israeli military aims. Third, to employ urban areas booby trapped with improvised explosive devises (IEDs), as well as tunnels and hidden shelters as defensive strong points to draw Israeli forces into areas favorable to the significantly smaller and less capable Hamas fighters—-seemingly hybrid warfare goals (ICG 2009b).

Fighters for the most part avoided direct confrontations with the Israeli troops. As one said in the mist of combat, 'just because we are ready to die in the path of God doesn't mean we want to die today.' Instead of deploying hundreds to confront Israel in open areas, the Qassam brigades sent out far fewer combatantsaccording to one estimate ten at a time. They were replaced only when killed. Nor did the Qassam Brigades deploy all their units, focusing instead on rockets, explosives, communication and supply units - about a tenth of the total available, according to a leader. Consequently, only a limited number of fighters were killed (ICG 2009b). 
Hamas's strategy during the Gaza War was an attempt to adopt hybrid warfare a la Hezbollah, a significant departure from the Islamic Resistance's earlier terror strategy. This shift in military strategy did not however work or take hold. That is, Hamas worked to adopt hybrid warfare (the use of heavy weaponry against an opposition's military forces), but didn't have the capacity to hold territory or engage with Israeli military forces; the Israeli Defense Forces segmented the Gaza Strip and isolated Hamas forces inside the center of Gaza City. But, Hamas was able to sustain its rocket barrage against Israel, albeit at a significantly decreased pace by the end of the conflict (Cordesman 2009). Therefore, Hamas, in its attempt to adopt hybrid warfare, actually adopted a middle strategy between terrorism and hybrid warfare: indiscriminate violence - the use of heavy weapons against noncombatants. In order to explain Hamas's adoption of indiscriminate violence it is necessary to examine its origins as a terrorist organization.

\subsection{Choosing Terror: Hamas, Civilian Victimization, and Suicide Operations}

Recall from chapter 1 that terrorism is a military strategy in which light weapons are used indiscriminately on noncombatants in conflict. The goal of this strategy is to induce psychological damage and war-weariness on a population in order to obtain a shift in opposition behavior. Hamas adopted terrorism in the first 18 months of the First Intifada, it employed this strategy until the end of 2001 (15 months into the Second Intifada) when it initiated a strategic shift towards indiscriminate violence (ITIC 2007).

In 1990 Hamas called for violence against Israel on "“all fronts and with every means.' No longer limiting its sporadic attacks to the military and symbols of the occupation, it began to strike at every available target, including civilians both inside and outside of the occupied 
territories. Between November 1990 and February 1991, more than ten Israelis were killed" (ICG 2004, 7).

This turn to indiscriminate attacks on civilians with available light weapons coincided with several key events: a major reorganization of Hamas, the return of 415 deportees from Lebanon, and the Madrid/Oslo peace negotiations. In 1989 Musa Abu Marzuq, moved from his home in Virginia to Amman, Jordan to run the day-to-day operations of Hamas (after Yasin's 1989 arrest). He introduced a hierarchy to Hamas's organization, divided Gaza and the West Bank into five and seven subdistricts, respectively, each with a discrete headquarters (Mishal and Sela 2000). Finally, under Marzuq's leadership the 'Izz al-Din al-Qassam brigades formed as the military arm of Hamas. Sheikh Salah Shehadeh initially led the Brigades; he was selected for this role because he was a well-educated and charismatic Gazan, who was adept at recruiting (Milton-Edwards and Farrell 2010). Thus, Marzuq and the members of Hamas's external leadership built an organizational structure that facilitated the adoption of terrorism: small subunits with educated members able to undertake technically demanding, but labor unintensive military operations.

The terror strategy of 'Izz-al Din al-Qassam Brigades was also affected by the return of 415 PIJ and Hamas members from southern Lebanon. These members were deported by Israel in 1992 and subsequently allowed to return. They brought with them a tactic learned from Hezbollah, suicide bombing. Through the returned deportees Hamas learned how to recruit, train, and build suicide bombers. Indeed, it was the use of suicide bombing in Lebanon that pushed American and French military forces out of the country in 1983, and pushed the IDF south of the Litani River in 1985, into the "security zone." "Thus it was no coincidence that Hamas's first suicide operation [1993] was carried out after the deportees had returned to the occupied 
territories" (Mishal and Sela 2000, 66). Hamas learned from Hezbollah that whilst faced with low organizational capacity, and when operating in an urban space, an effective tool in a growing organization's arsenal is the suicide attack (Blandford 2011; Chapter 3 this work). The key difference between Hezbollah and Hamas being that while the former attacked military personnel the latter targeted civilians. I argue that this critical difference was a result of their respective bases of recruitment (mixed for Hezbollah and urban for Hamas). Due to its relatively small number of urban recruits Hamas lacked the capacity to attack hardened military targets, instead the organization chose to attack softer civilian targets.

Stated explicitly, Hamas's terror strategy reflects the evolution of the organization's capabilities, as well as Hamas's view of militant resistance. The initial Qassam operations in late 1991 led to the murder of some 150 Palestinians; the majority these victims were Palestinians collaborating with the Israeli government, and supporters of the major secular nationalist organizations (Milton-Edwards and Farrell 2010). Between December 1991 and April 1993 the Qassam Brigades began a shift towards targeting Israeli (Bloom 2004). This shift towards civilian victimization was made as a result of lessons learned from Hezbollah and in reaction to the 1991 Madrid peace conference; Hamas rejected the notion that land could be exchanged for peace (ICG 2004). Hamas also saw Madrid and Oslo as the PLO/PA's attempt to marginalize, if not completely eliminate the Islamic Resistance. Indeed, part of the PA's drive to accept Oslo was that it facilitated the dominance of the secular nationalists over the Islamist groups in Palestine (Pearlman 2010). Terror via suicide operations was, from Hamas's perspective, best for both competing with the PLO, and as a way of undermining the peace process (Bloom 2004; Pearlman 2010; Clauset et al. 2010). Thus, from 1989 to 1991 Hamas carried out 11 violent attacks against civilians; between 1992 and 1994 it undertook 46 (Pearlman 2010). 
On April 161993 “the Qassam Brigades claimed responsibility for a blast outside a roadside cafeteria near the Mehola settlement in the West Bank... the bomber had pulled up next to two Egged buses, specifically targeting Israeli civilians" (Levitt 2006, 12). The bomber and the buses were the only casualties in this case, as the bus passengers had already disembarked. Hamas carried out its first "successful" suicide bombing on April 6, 1994 after the signing of the Oslo Accords and in response to Baruch Goldstein's February 1994 attack on the Ibrahimi mosque in Hebron; a car containing some 400 pound of explosives exploded near a bus inside the Israeli town of Afula, forty miles northwest of Jerusalem, eight teenagers were killed (Pressman 2003; Milton-Edwards and Farrell 2010; Hroub 2004; Levitt 2006). "In the weeks, months and years that followed - and until the order from Hamas's political leadership to shift away from...suicide bombing — this became the Qassam Brigade's modus operandi' (MiltonEdwards and Farrell 2010, 123). Hamas adopted terrorism via suicide bombing because suicide operations allowed the Islamic Resistance to strike any target throughout the occupied territories and within Israel proper. Thus, while Hezbollah has used suicide bombers primarily against Israeli military forces, Hamas has chosen to target civilians inside Israeli cities. "As a Hamas training manual explained, 'It is foolish to hunt the tiger when there are plenty of sheep around"' (Gleis and Berti 2012, 159).

In sum, Hamas adopted terrorism as a strategy in 1991, and began employing suicide bombers in 1993. It did so because terror allowed it to choose the location and size of its militant attacks, and it maximized the impact of each attack. The quality of Hamas's urban recruits helped each fighter to choose the timing of their operations in such a way that likelihood of being intercepted was minimized, while the physical and psychological impact of each attack was maximized. Urban and educated fighters that were closely linked to one another and who knew 
where/when to conduct the bombing were key to this process. Terror allowed a relatively small Hamas to increase popular perceptions of its military capacities, while it competed with other groups for recruits. Moreover, terrorism provided a pathway for Hamas to outbid competing organizations for more militant followers (Benmelech and Berrebi 2007). These facts provide evidence to support my claim that terrorism was a strategic choice Hamas made given the constraints (several competing organizations and a limited urban recruitment base) it faced.

\subsection{Increasing Capability and Strategic Evolution}

From its inception through the first full year of the Second Intifada (1987-November 2001) Hamas employed exclusively light weapons, such as small arms, knives, car bombs, and suicide bombers, against Israeli civilian targets. However, this strategy evolved as Hamas increased it capabilities as its base of educated and skilled fighters increased. Evidence gathered from the 151 suicide attacks carried out during the al-Aqsa Intifada (September 2000 - August 2005) demonstrates that Hamas and other militant organizations significantly refined their military capabilities over time. The best-educated and most mature (in terms of age) bombers were being used for the most "productive" (in terms of casualties) attacks in major cities. In contrast, less educated and younger bombers were used for hard to get at military targets: "Palestinian terror organizations match older and more-educated suicide bombers to more important Israeli targets... older and more educated suicide bombers kill more people in their suicide attacks when assigned to important targets... older and more-educated suicide bombers are less likely to fail or to be caught when they attack" (Benmelech and Berrebi 2007, 236).

The spread of educated attackers had two critical effects. First, it facilitated a major increase in the number of attacks. There were more suicide attacks, in the first 14 months of the Second Intifada than in the entirety of the 1990's (33:15). Interestingly though, the number of 
Hamas attacks decreased over time as compared to those conducted by Fatah's al-Aqsa Martyr's Brigades (Benmelech and Berrebi 2007; Moghdam 2003). This suggest that Fatah began to build up its own terrorist capabilities after the onset of the al-Aqsa Intifada in an effort to compete with Hamas and Islamic Jihad militarily; the underlying logic being that demonstrating capacity for terrorism draws more people to an organization thereby increasing popular support—logic followed by Hamas (Bloom 2004).

Secondly, this demonstrable increase in military capability coincided with a fundamental shift in Hamas's strategy. That is, on October 26, 2001 (13 months into the Al-Aqsa Intifada) Hamas launched its first Rocket into southern Israel, a homemade Qassam 1 rocket, which has an effective range of 2 miles (ITIC 2007). Thus, the evolution of Hamas's military capacity, in terms of the quality of its fighters, facilitated its slow transition away from light weapons towards the use of heavy weapons, in an effort to once again emulate Hezbollah. That is, in 2000 Israel withdrew from southern Lebanon, a 'victory' that Hezbollah claimed to be the result of its strategy of resistance, a strategy predicated upon the use of heavy arms against Israeli military forces (Pressman 2003; ITIC 2007; Chapter 3 this work).

From 2001 forward Hamas rapidly escalated its use of heavy weapons, while not abandoning suicide operations. In 2001, the Islamic Resistance launched 249 rockets (4) and mortars (245) into Israel while claiming responsibility for 19 suicide operations, in addition to other violent operations. By 2007, Hamas launched 1423 heavy munitions into Israel, with the majority (783) being more technically demanding rockets, while conducting no suicide operations (Moghdam 2003; ITIC 2007; Israel Ministry 2013). These figures suggest an increasing capability to obtain, maintain, and rapidly fire large and heavy armaments. These 
heavy arms require a trained set of operators, as well as a stationary firing position, as they weigh as much as 110 pounds, and are some 8.5 feet in length (ITIC 2007).

Thus, Hamas's attempted strategic transformation (from terror to hybrid warfare) began in earnest during the Second Intifada. Throughout the Al-Aqsa intifada Iran and Hezbollah provided guidance, funding, training, and technical expertise to Hamas. Early in 2004, Sheikh Ahmed Yasin and his deputy Abdel Aziz Rantisi were assassinated by the Israeli military. These assassinations inadvertently strengthened Hamas's external leadership led by Khalid Mishal and Musa Abu-Marzuq (located in Damascus) vis-à-vis the remnants of the internal leadership, and facilitated the strengthening of ties with Iran. "Consequently, the military wing in the Gaza Strip, directly subordinate to the outside leadership, began to benefit from significant budget and professional guidance from Iran's intelligence service and from Hizbollah" (Aviad 2009, 4).

The practical implication of this monetary and financial support was most clearly demonstrated in the creation of the al-Mourabitoun militia. The militia was meant to form the basis of a regular "people's army" that would help Hamas wrest control of Palestinian from the Palestinian Authority. "These trends, which suited Hamas' [sic] long term strategy, were accelerated when the Knesset approved the disengagement plan on October 26, 2004" (Avid 2009, 4).

There were four major effects of Hamas's move towards Iran and Hezbollah. First, the military wing of Hamas reorganized into six or seven spatially delimited divisions responsible for a particular area within Gaza. Second, with the Israeli withdrawal, recruitment began to increase. Whereas before the Israeli disengagement Hamas was estimated to have as few as a thousand active fighters, the new regional divisions are estimated to include, on average, 1,500 fighters each. Third, the smuggling of more sophisticated armaments was increased. Finally, 
Hamas began mass-producing homemade Qassam rockets in Gaza via a network of production facilities; this mass production increased the quality (in terms of range and impact force) of the rockets. More, Grad missiles, which have a greater range than the Qassam, were smuggled into Gaza in an effort to increase the Organization's capacity to punish Israel. Thus, during the Israeli withdrawal Hamas reoriented towards a hierarchical military organization in an attempt to move away from its terrorist military strategy (Aviad 2009).

Hamas's relationship with Iran and its Lebanese proxy actually expanded after Israel's unilateral disengagement from the Gaza Strip, and as a direct result of Hamas's victory in the 2006 Legislative Council Elections. After the 2006 victory (and in line with the theoretical predications of this work) Iran began upgrading Hamas's rocket arsenal, as the Islamic Resistance had demonstrated the capacity to use heavy weapons; Iran even encouraged Hamas to carry out attacks within Israel. Furthermore Hezbollah, through its Unit 1800, infiltrated operatives and weapons into the Gaza Strip through Egypt—and was caught doing so in 2008, prior to Operation Cast Lead. “The peak year of Hezbollah's assistance to Palestinian... [organizations] was 2006, when there were 85 networks operating with Hezbollah's assistance" (The Meir Amit 2012, 76). In short, Hamas facilitated its attempted shift towards hybrid warfare and away from terror due to the training, technical expertise, and weaponry it received from Iran and Hezbollah (Author Interview, Yaakov Lappin 8.19.13).

While outside assistance and training were key to Hamas attempting to adopt hybrid warfare the importance of its victory in the 2006 Palestinian Legislative Council elections cannot be understated. "This development helped sustain the ongoing growth of the military wing until it became an entity overshadowing the Palestinian Authority's security mechanisms" (Aviad 2009, 6). This allowed Hamas to expand its recruitment base, which increased its military and 
organizational capabilities (in terms of both the quality and quantity of recruits). Thus, by April 2008 Israeli sources estimated that Hamas's Izz al-Din al-Qassam brigades had some 10,000 fighters under arms, in addition to a 5,000 man internal police force (ICIT 2008; Aviad 2009, 6). With this growing military and organizational capacity the Izz a-Din al-Qassam Brigades defeated the PA security services and their largest clan-based support networks in a 2007 conflict, thereby seizing full political control of the Gaza Strip (Aviad 2009). In short, Hamas's rising capacity after 2006 combined with the new arms and training it received from its foreign supporters-Iran and Hezbollah—facilitated the organization's attempt to expand beyond terrorism.

\subsubsection{Hamas and the Drive for Hybrid Warfare}

Between the 2005 Israeli withdrawal and the December 2008 war several hundred "activists left Gaza and underwent advanced training in Iran, Syria, and Lebanon, training that included gathering intelligence, establishing camouflage [in urban areas], constructing sophisticated explosive charges, and operating advanced anti-tank missiles" (Aviad 2009). ${ }^{29}$ Moreover, new recruits within Gaza were trained to use light weapons and homemade antitank missiles. Hezbollah's military activities during its 2006 war with Israel were the model that Hamas sought to replicate. That is, Hezbollah's ability to withstand an Israeli military onslaught for 34 days pushed the external leadership to reorient the operations of Hamas's military wing. "Hizbollah's pattern of action [strategy] became a model for Hamas and a symbol of how to conduct asymmetrical warfare while taking advantage of the conditions on the ground and the enemy's weakness" (Aviad 2009, 8).

\footnotetext{
${ }^{29}$ It is important to note here that anti-tank missiles fit into the category of heavy weaponry, as on average, they require a three-person crew to operate. It is the use of heavy weapons like anti-tank missiles that facilitated Hamas's move away from terror towards indiscriminate violence.
} 
There are several key features of the Islamic Resistance's attempt to adopt hybrid warfare. First, Hamas sought to use the urban spaces of Gaza much like Hezbollah exploited the topography and demographic characteristics of southern Lebanon. Hamas nested rocket and mortar launching platforms throughout civilian areas of Gaza and in underground tunnels throughout the densely populated neighborhoods of Gazan cities (UN 2009).

Second, Hamas sought to blend into the urban population; they removed their uniforms and/or identifying clothing thereby using the populace like shields. The logic of this choice being that this would cause the IDF to kill larger numbers of civilians, which in turn, would limit the duration of Israeli military campaign due to global outcry over civilian causalities. Relatedly, like Hezbollah, Hamas realized that punishing the Israeli civilian population with sustained rocket fire during a conflict frustrates both the Israeli military and civilian populations. Thus, the Islamic Resistance endeavored to "formulate an orderly fire program in conjunction with tight operational discipline, aimed at launching measured but continuous barrages of rockets at Israeli targets, which would continue even if some... launching regions in the north of the Gaza Strip were to be captured, using the crowded urban space of Gaza City and the refugee camps on its outskirts" (Aviad 2009, 8).

Finally, and most importantly, Hamas sought to draw the IDF deep into urban areas to neutralize the military's overwhelming firepower in urban chock points. The Qassam Brigades focused on extracting a large human toll from the IDF as the latter worked its way through preset booby traps, mines, and sniper fire. This was Hamas's attempt to replicate the battlefields that Hezbollah had prepared for invading Israeli forces during the 2006 conflict in southern Lebanon. Therefore, during the land phase of Operation Cast Lead, "Hamas's military wing sought to drag the IDF deep into the urban area, cancelling out some of its advantages, and at the same time 
tried to create tactical surprises that would have changed the cost in human lives and thereby perhaps, also the face of the battle as a whole" (Avid, 2009; UN 2009).

\subsubsection{Indiscriminate Violence as Failed Hybrid Warfare}

During the 22 day Gaza War (Operation Cast Lead), Hamas simply did not have the capability to take on Israeli ground forces or to execute a hybrid warfare strategy, and while many IDF soldiers were wounded only 10 died, 4 of which were due to "friendly fire." Unlike Hezbollah who did execute a hybrid military strategy, by taking and holding territory and accounting for 120 IDF deaths "Hamas forces did not sustain engagements [and] used fire and run tactics... and [avoided] known sites associated with Hamas before the fighting began" (Cordesman 2009, 58; Biddle and Freidman 2008). Hamas fighters generally avoided any direct or long-lasting firefights with Israeli forces.

By the conflict's conclusion, the IDF had secured parts of central and northern Gaza, and had surrounded Gaza City, and carried out military operations into the core of the city, where the majority of Hamas fighters and rockets were located. Estimates of Hamas causalities vary significantly, but between 300 and 1,100 Hamas fighters were killed, with 30-35 killed per day, if the IDF figure of 750 Hamas deaths is used. More, the IDF estimates that nearly 50 top Hamas figures in Gaza were killed during the conflict, with many lower echelon commanders (at the battalion and company level being killed). Many Hamas brigade commanders survived the conflict because they remained in hard and deep buried shelters/tunnels within Gaza that the IDF could not bomb due to the high risk of collateral damage (Cordesman 2009).

Hamas commanders also seem to have felt that their defense tactics... had been far less successful that they anticipated, that their defensive plans did not make effective user [sic] of buildings and terrain in many cases (including the failure to defend part of Tal al-Hawa, that homemade explosives failed more often than expected, and that Hamas forces had unanticipated difficulties in resupply. Other problems were reported to include troubles with Fatah informants that gave key targets to the IDF, a poor $\mathrm{C} 3\left[\mathrm{C}_{3} \mathrm{I}-\mathrm{command}_{\text {, }}\right.$ control, and intelligence] system, and delays in command decision and reaction (Cordesman 2009, 59). 
Several factors therefore undermined Hamas's ability to execute hybrid warfare. First was a lack of the strategic depth. That is, as discussed in chapters 1 and 3, the ability to fall back and wear the attacker down is a necessary feature of Hezbollah's strategy. Sufficient physical space does not exist in the Gaza Strip for Hamas to fall back and slowly attrite Israeli forces (ICG 2009b). Secondly, Hezbollah has controlled most of its areas of operations since 1985 (both urban and rural). Consequently, the Party of God has the capacity to eliminate any competing militant forces in its zones of control (Blanford 2011). Contrastingly, while Hamas has always been powerful in Gaza, and since 2007, has been the de facto government of the Strip, it still competes with other militant groups like Islamic Jihad and the PLO for support (Gleis and Berti 2012). Hamas's capabilities are therefore continually undermined by elements of their competition (such as Fatah informants for Israel); the urban nature of Gaza Strip, where communities are small and tightly knit affects Hamas's ability to build up its capabilities. While Hamas may control Gaza there are still some residents who quietly prefer the PA, and are therefore willing to undermine Hamas's capacity for sustained conflict with Israel.

Therefore, Hamas failed to affect a hybrid warfare strategy in 2008. It did not succeed in fighting off the IDF, nor did it exact a military toll on Israeli military forces. More, Hamas's plan to funnel IDF forces into crowded urban spaces failed. In contrast, the Islamic Resistance did demonstrate its ability to maintain a steady rate of rocket fire into southern Israeli towns. Furthermore, at least half of Hamas's heavy weapons remained operable at the conclusion of the conflict: Hamas indiscriminately fired some 600 rockets during the war (of an estimated stockpile of 3,000), and IDF forces estimate that they destroyed some 1,200 rockets, leaving at least 1,200 inside Gaza (Cordesman, 2009). 
It is the combination of these facets of Hamas's military performance in 2008, as well as the organization's focus on the use of heavy artillery since 2001 that indicate an indiscriminate violence strategy. Hamas has the capacity (in terms of quantity and quality of fighters) to target civilians with either light or heavy arms, as it has developed this ability since its inception. However, the Islamic Resistance lacks the capability to fight against an opposition's military forces using combined arms, a skill it only began to develop in 2004. Moreover, the urban spaces that it operates in do not lend themselves to withdrawing to depth in an effort to attrite Israeli forces as they move; the Gaza Strip slacks any notable strategic depth. These factors suggest a failed attempt to adopt hybrid warfare, which in practice results in indiscriminate violence, or the use of heavy weapons against civilians (a strategy that is not pure terrorism or hybrid warfare, it is a middle point between them).

\section{Conclusions}

In sum, Hamas has evolved over time due to the changing nature of its constituency. As its support base has become more educated, and gained more technical abilities its military strategy has evolved. Thus, this case demonstrates the causal relationship between capacity, in terms of education and the number of available recruits, and strategic choice. Moreover, the key factor that affected these dually necessary but individually insufficient components of organizational capacity was urbanization. Urbanization in Palestine facilitated the expansion of education, and the politicization of the public. However, the truncated nature of social groups in urban areas undermined large-scale popular support for any one insurgent organization, thereby facilitating the proliferation of the Hamas, the PLO, Islamic Jihad and many other rebel organizations. Thus, the fact that Hamas was founded and evolved in an urban environment had 
a direct effect on the number and quality of people it could recruit, and therefore its military strategies.

This case also demonstrates that even when capacity grows in urban spaces, hybrid warfare may not result. The urban nature of Gaza, while initially believed to be an important advantage for Hamas's adoption of hybrid warfare, ultimately did not facilitate a hybrid warfare strategy. Instead, urbanization in Gaza made an indiscriminate violence strategy easier, and therefore seemingly preferable in the 2008 Gaza War. It could be argued that had the Israeli government decided to invade the core of Gaza city Hamas may have demonstrated its successful adoption hybrid warfare strategy. This however seems unlikely given the reticence of Hamas's fighter to engage with advancing IDF forces.

The adoption of indiscriminate violence is likely not itself an end point in Hamas's military and organizational development. Hamas continues accumulate arms, which Israel works to interdict and eradicate (thus the 2012's Operations Returning Echo and Pillar of Defense), and it continues to train its fighters for the next conflict. But, until Hamas demonstrates the capacity for hybrid warfare, its strategy cannot be labeled purely terrorist or guerrilla; it is a quintessential example of indiscriminate violence. 


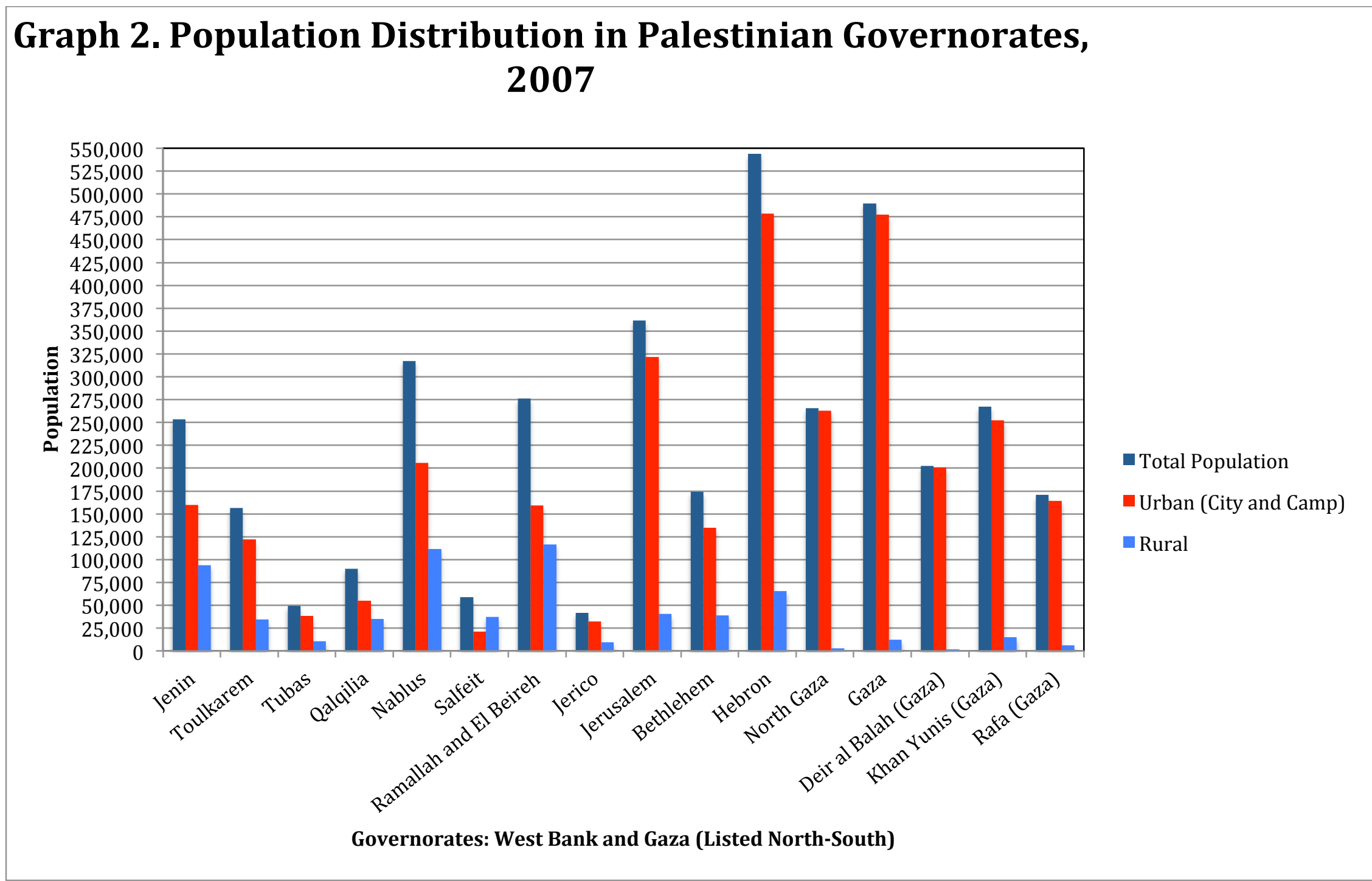




\section{Chapter 6: Conclusion: The Future of Warfare in an Era of Urbanization}

\section{Today in War}

As of this writing the Syrian Civil War is ongoing. The conflict has evolved dramatically. It began in 2011 as a series of peaceful protests. Now, it accounts for the majority of civilian and battle-related deaths of any ongoing conflict (Boxx 2013; Themnér and Wallensteen 2013). For academics and policy makers it is important to understand what caused this evolution. Put differently, why have over 900 separate armed groups totaling some 300,000 fighters developed in Syria, and why have efforts to unite them under the Syrian Supreme Military Council (SMC) been slow to yield results (aljezeera.com 19.07.2013; O’Bagy 2013)? Moreover, why is this conflict so bloody?

From the perspective of this work where the rebellion began and how it has spread is a key, yet generally unconsidered, factor. Protests began in cities, as did the first round of violent government repression (Boxx 2013; ICG 2012). This should come as no surprise given that 56 percent of the Syrian population is urban (UN 2011). Militant groups that have organized to fight against the regime have done so locally, within their neighborhoods, villages or towns. In effect, a number of the organizations in the civil war are small and urban "localized battalions" (O'Bagy 
2013 , 10). Because many of the rebel organizations in Syria are local they lack capability (in terms of size and skill) and are unable to provide positive inducements to gain more popular support; when these groups break from the fighting in attempts to provide electricity and bread to local populations, they generally fail. As a consequence of their failed efforts to "provide services and basic necessities to rebel-held-communities, the local population often turns on the rebels" (O’Bagy 2013, 25). This inability to build up popular support fundamentally undermines local rebels' military capabilities, which limits the ways in which they can fight, and therefore their ability to successfully take and hold critical urban centers.

Efforts to coordinate the Syrian opposition have had limited success thus far. Local organizations are incapable of broadening their base of operations without greater levels of local and international support. As a consequence, larger "franchise rebel groups" have taken the lead in military operations due to their significant foreign support and military proficiency. Increasingly, these larger organizations are Islamist in orientation, like Jabhat al-Nusra (AlNusra Front) and The Islamic States in Iraq and the Levant (ISIL), which may not appeal to local populations, and can undermine intergroup coordination (Nassief 2014). In fact "the bifurcation between localized battalions and franchise brigades has frequently led to infighting and fractures within rebel ranks" (O’Bagy 2013, 10).

The demographic and physical geography of Syria is therefore playing a critical role in how the opposition has organized, and why it is difficult for the disparate groups within the Syrian opposition to coordinate. It is vital to develop theoretical frameworks, which can offer a way to predict how demographic trends and physical geography might interact in the context of future civil wars and insurgencies. Such frameworks will help political scientists and policy 
makers understand how these conflicts might be prevented and/or concluded quickly. This dissertation sought to take up these issues.

\section{My Argument}

I have endeavored to accomplish three tasks in this dissertation: first, to demonstrate that guerrilla warfare is an incomplete descriptor of modern insurgent military strategy. In the era of urbanization, guerrilla warfare is but one of four distinct military strategies that rebel organizations can potentially adopt. Second, and of greater importance, to articulate a theory explaining why rebels chose to the fight the way they do. The core of this second task has been demonstrating that insurgent groups choose certain military strategies as opposed to other based on an evaluation of their capabilities and the constraints they face due to the areas in which they operate/recruit. Finally, I have sought to test the effect of urbanization on insurgent military strategy. The quantitative analysis I conduct in chapter two in combination with the Hezbollah, Hamas, and Nepal case studies have served as the vehicles through which I evaluate my theory.

Rebel military strategy has been conceptualized in this dissertation as the choice of rational risk-averse actors. These rational actors choose their military strategy based on the level of urbanization of the state in which they form; urbanization rates determine where potentially supportive populations reside. In states where the vast majority of the population lives in urban areas, rebel organizations are forced to coalesce in cities, generally mobilizing like-minded individuals from the same neighborhood. This type of neighborhood organization limits the number and diversity of people recruited into a rebel movement. Similarly, in countries where the majority of the population is rural, communities of people are small and tightly connected at the village level, and while rural residents may have the incentive to mobilize for violent 
collective action, they are too unconnected to one another to create large and cohesive insurgent organizations.

Contrastingly, in mixed populations, where communities encompass both urban and rural spaces, insurgents have greater capacity. Militants in mixed populations can recruit a large number of diversely educated and skilled individuals from the city and the country. In such cases, the heterogeneity of the people recruited into a rebel organization makes more people want to join over time.

Therefore, when capacity is high due to diverse recruitment, rebels choose to abandon traditional guerrilla warfare in favor of a more demanding and sophisticated hybrid warfare strategy. In cases where rebels have little capacity due to a small urban recruitment base the preference is for terrorism. As demonstrated in the Hamas case, when capacity grows in cities an attempt may be made to adopt hybrid warfare. However, due to the constraints of urban spaces this attempt may lead an organization to adopt indiscriminate violence. Rural rebels with low capability prefer guerrilla warfare, and are unlikely to be in a position to alter their military strategy.

\section{Theoretical Implications}

From the perspective of advancing scholarship, the theory I elucidate reevaluates the relationship between rebel strategy, demographics, and geography. I show that as human geography changes, so too do the processes of violence in insurgency; examining the relationship between these variables provides a useful framework for understanding the contours of current and future intrastate conflicts. In this way I update the themes in traditional accounts of small and revolutionary war, where the critical factors for rebellion were a supportive population and rough terrain. 
In line with recent research on social networks and the mobilization for violence (Parkinson 2013; Weinstein 2007; Gould 1996) I demonstrate that insurgent groups draw on existing communities/social networks to recruit. This dissertation moves beyond this literature by demonstrating that in the modern world supportive communities are no longer disenfranchised rural inhabitants: support for rebellion also exists in rapidly expanding urban centers, and in periurban areas. As a consequence of their location, supportive communities/social networks vary significantly: rural, urban, and peri-urban communities differ from one another because of the number and type of their members. This dissertation demonstrates that these differences deserve more theoretical consideration because they have observable real-world implications.

Relatedly, this dissertation's focus on social and demographic trends challenges established wisdom on the impact of insurgent motives on the use of violence, while at the same time adding to existing research on rebel capacity (Weinstein 2007; Humphreys and Weinstein 2008; Wood 2010; Horowitz 2010). The size of a community and the nature of its membership jointly determine the capacity of rebels, which in turn affects their preference for violence. This is a significant departure from previous work, which suggests that individual motivations determine organizational capabilities and thus how rebels fight in war. From the perspective of this work individual motivations for participation in violent collective action are generally unknowable, even through ex post interviews. Moreover, while one recruit may be ideologically committed to an organization (s)he may also seek to reap gains from rebellion. It is impossible however to disentangle the two or to estimate which the individual values more, ideas or lootable goods. Thus, a focus on community dynamics for building capacity provides a more generalizable and falsifiable theory. 
Finally, the theory developed in chapter one is a significant contribution to the study of insurgent military strategy. Moving beyond work, which claims that insurgent military strategy is endogenous to the strategy of the opposing state (Arreguín-Toft 2005), I argue that insurgents choose which strategy they adopt based on the constraints they face. In other words, insurgent groups have agency, and therefore chose amongst several "technologies of rebellion" (Kalyvas and Balcells 2010). Moreover, this analysis has established that rebellions evolve from one military strategy/technology of rebellion to another given changing realities of their environment.

\section{Practical and Political Implications}

This argument also has ramifications for American foreign and military policy makers. For American foreign policy makers, the focus should be on expanding economic and business investment into the rapidly urbanizing parts of the globe. This investment might mitigate the willingness of some populations to bear the costs of violent collective action. From a military policy perspective, neither counterinsurgency doctrine nor conventional military theory is sufficient for the modern intrastate wars. As Iraq and Afghanistan have demonstrated, the human terrain and physical geography of a state are the key determinants of how a conflict will unfold. Predicated upon the theory presented in chapter one, a social network approach to modern warfare must be developed further.

\subsection{The Foreign Policy of Urbanization: Preventative Investment}

Insurgent capacity in this analysis is a function of the quality and quantity of rebel recruits. Quality is defined as an individual's level of education and technical skill. As states in the developing world continue to urbanize the number of people completing high school and going on to post-secondary education will also continue to grow. If insurgencies develop in areas with expanding educational attainment and a mixed population, the probability that the rebels 
develop greater levels of organizational and military capabilities increases. Consequently, states may face a greater number of hybrid warfare organizations in the future. Even if rebels are incapable of developing hybrid warfare, the urbanization trend may push an increasing number of groups towards indiscriminate violence. States must seek to prevent the proliferation of these strategies by investing in rapidly urbanizing areas of the world; this can be called preventative investment.

In order to avoid an expansion in the number of militant organization that are capable of adopting (or at least attempting to adopt) hybrid warfare, returns on educational investment must be increased. Individuals join Hamas, in part, because they are not effectively rewarded for their levels of education. Indeed, in the Gaza Strip educated individuals have found it increasingly difficult to find work as the economy has stagnated over time. In short, participation in violent resistance becomes less costly as the likelihood of finding economically and personally rewarding work declines (Angrist 1995).

In employing preventative investment, the United States and its allies should incentivize private investment in the form of foreign direct investment (FDI in manufacturing, service and extractive industries) in the rapidly urbanizing areas of the developing world. ${ }^{30}$ This type of investment will drive down the incentive to join militant resistance organizations. Increasing the range of potential employment opportunities for a new generation of educated and skilled individuals will temper their drive to join nascent insurgent organizations.

As discussed in chapter one, individuals must make a cost-benefit calculation regarding their participation in an insurgency. If they will receive more benefits from working, while avoiding the risk of being sanctioned by the state, most rational individual will not join a

\footnotetext{
${ }^{30} \mathrm{FDI}$ refers to the OECD/IMF definition where foreign firms own $10 \%$ or more of a local enterprise (Hayakawa et al. 2013).
} 
rebellion; employed people are more risk averse. Moreover, if few people join a new rebellion, it will lack the ability to provide positive inducements for later joiners. Small militant organizations lack military and organizational capability. This is especially true if educated individuals refuse to join. Therefore, establishing a preference for employment through preventative investment will drive down aggregate membership in bourgeoning insurgencies, and thus significantly limit rebel capabilities. Smaller and less capable rebellions will be easier to eliminate over the long term, especially when the state can provide better positive inducements for support than an insurgent organization.

\subsection{Military Policy: Social Networks in Modern War}

The American military misadventures in Iraq and Afghanistan have demonstrated that no single doctrinal answer for insurgencies exists. That is, counterinsurgency doctrine as laid out in the Army and Marine Corps Field Manual FM 3-24 may have worked, at least in part, in Iraq, but has been of little use in Afghanistan. The key difference being that the Field Manual does not account for differences in human and physical terrains. In Iraq 68\% of the population was urban in 2000 with some $11 \%$ of the population 15 and over completing a secondary level of education. Contrastingly, only $21 \%$ of the Afghan population lived in cities in 2000 , and only $4 \%$ of males 15 years and older finished high school; only $1 \%$ or women completed primary or secondary school (UN 2011; Barro-Lee 2013). Moreover, while Iraq is generally flat, Afghanistan has significant mountainous terrain. These deep demographic and topographic differences affect very different patterns of organization for violence, and as a result, different types of rebel strategy. Afghanistan has been typified by traditional guerrilla warfare, while in Iraq terrorism is used quite extensively. American military planners therefore should have approached these two conflicts differently. 
For future conflicts, instead of relying on established doctrine, which requires ad hoc modification during a conflict, social network analysis should be applied. That is, one key to the American military's pacification of Iraq's western-most Anbar province was the Sunni Awakening. By helping to stand up large and powerful Sunni tribal networks in Anbar province through cash payments, the American military dropped the aggregate level of violence in Iraq after 2006/07 (Long 2008; Biddle et al. 2012).

The opportunity to work with tribal social networks to pacify Anbar province had been available to US and coalition forces as early as 2004 (Long 2008). However, due to both lack of will and capacity the latter did not work with cooperative tribes, even though they wielded considerable power in Anbar, and thus could affect political outcomes throughout the state (Long 2008; Biddle et al. 2012). At the outset of the Iraqi insurgency a clearer understanding of tribal social network dynamics would have highlighted their utility in deescalating sectarian violence (Long 2008). A lack of attention to human terrain fundamentally undermined the American and coalition war effort for years. A similar ignorance of social network dynamics in Afghanistan has undermined American attempts to suppress that insurgency as well.

\section{Avenues of Future Research}

There are several potential extensions of the argument presented here. First, an in-depth accounting of the different types of social networks will shed greater light on the processes used by rebels to recruit in different areas. Understanding how people are connected to one another, and thus to rebel leaders, will clarify how insurgencies spread before and during a conflict, as well as how these processes are different in urban, rural, and peri-urban areas. In addition, focusing more attention on the organization of local social networks may help policy makers devise ways in which to weaken radicalized social networks at their roots. Much like a weed, 
eliminating the head of a social network is but a short-term accomplishment; ultimately another member will rise to the top.

A real world byproduct of civil wars and insurgencies is a refugee population. Refugees often migrate to neighboring countries in hopes of avoiding the violence and then returning to their homes. Currently there are 2.5 million refugees from Syria located in Lebanon, Jordan, and Turkey (McClelland 13.02.14). Unfortunately, refugee populations often do not or cannot return home in the short term; the average refugee will remain in a "temporary" camp for 12 years. Indeed, three years ago “the largest refugee camp in the world, Kenya's Dadaab, turned 20. It was built for 90,000 refugees. It holds more than 420,000” (McClelland 13.02.14).

More work needs to focus on how these refuge populations affect the contours of violence in civil wars, and how they might impact post-conflict settlements. Refugees are displaced and often unemployed populations that are separate from the state citizenship that surrounds them. As a consequence, refugees often turn to militant organizations for support and protection as demonstrated by Palestinian refugees Lebanon joining the PLO in the 1970s and 80s, as well as by Palestinian refugees in the Gaza Strip joining Hamas since 1987 (Parkinson 2013; chapter 5 this work).

The impact of refugee populations on post conflict settlements is also important. The right of return for Palestinian refugees is an issue that consistently stalls Israeli-Palestinian peace negotiations. Similarly, an estimated 900,000 refugees are fleeing the ongoing civil war in South Sudan, and there is no indication that they will be able to return to their homes if/when violence ends (Kushkush and Kulish 26.03.14). The responsibility for resettling these refugees as well as supporting them during the conflict can undermine potential settlement negotiations. 
Finally, from a definitional perspective insurgencies and civil war are distinct from the ongoing narco-war in Mexico. That is, while the level of violence in Mexico reaches the war threshold (1,000 battle-related fatalities) it is not clear if the drug cartels are making public claims for political authority in Mexico. These claims are a defining characteristic of insurgent organizations (Sambanis 2004; Lyall and Wilson 2009). Interestingly, insurgent groups have been found to interact with drug cartels, and even traffic in narcotics themselves. It seems therefore that some theoretical purchase is to be gained by investigating differences and similarities between drug trafficking organizations and insurgent groups (Levitt 2012).

Insurgencies and civil wars have gained increasing attention from both scholars and policy makers. This is because major interstate conflicts are increasingly rare phenomena, most large-scale violence around the world is now occurring within states. Moreover, there is still much to be learned about the processes associated with violence in these types of conflicts. Both scholars and policy-makers must be attuned to how these types of conflicts will evolve as urbanization increases, and social networks begin to overlap in crowded urban spaces. This dissertation is a first step in thinking about how violence inside states has changed over time, and how it may change in the future. My hope is that this work will inform future analyses. 


\section{References}

Abu-Amr, Ziad. 1993. "Hamas: A Historical and Political Background." Journal of Palestinian Studies 22(4): 5-19.

Abu-Amr, Ziad. 1994. Islamic Fundamentalism in the West and Gaza: Muslim Brotherhood and Islamic Jihad. Bloomington: Indiana University Press.

Acharya, Susan. 2007. Social Inclusion: Gender and Equity in Education Swaps in South Asia: Nepal Case Study. Kathmandu: United Nation's Children Fund.

Alexander, Yonah. 2002. Palestinian Religious Terrorism: Hamas and Islamic Jihad. Ardsley NY: Transnational Publishers, Inc.

Alexander, Yonah. 2003. Palestinian Secular Terrorism: profiles of Fata, Popular Front for the Liberation of Palestine, Popular Front for the Liberation of Palestine-General; Command, and Democratic Front for the Liberation of Palestine. Ardsley NY: Transnational Publishers, Inc.

Alin, Eric G. 1994. "Dynamics of the Palestinian Uprising: An Assessment of Causes, Character, and Consequences." Comparative Politics 26(4): 479-498.

Angrist, Joshua. 1995. "The Economic Returns to Schooling in the West Bank and Gaza Strip." The American Economic Review 85(5): 1065-1087.

Angstom, Jan, and Isabelle Duyvesteyn eds. 2005. Rethinking the Nature of War. New York: Frank Cass.

Archibold, Randal C. and Ginger Thompson. February 22, 2014. "El Chapo, Most-Wanted Drug Lord is Captured." New York Times http://www.nytimes.com/2014/02/23/world/americas/joaquin-guzman-loera-sinaloa-drugcartel-leader-is-captured-in-mexico.html?_r=0. (Accessed March 1, 2014).

Arreguín-Toft, Ivan. 2001. "How the Weak Win Wars: a Theory of Asymmetrical Conflict." International Organization 26(1): 93-128.

Arreguín-Toft, Ivan. 2005. How the Weak Win Wars. New York: Cambridge University Press.

Asal, Victor, and R. Karl Rethemeyer. 2008. "The Nature of the Beast: Organizational Structures and the Lethality of Terrorist Attacks." The Journal of Politics 70(2): 437-449.

Avid, Guy. 2009. "Hamas' Military Wing in the Gaza Strip: Development, Patterns of Activity, and Forecast." Military and Strategic Affairs 1(1): 3-15.

Balcells, Laia. 2010. "Rivalry and Revenge: Violence Against Civilians in Conventional Civil Wars.” International Studies Quarterly 54(2): 291-313. 
Barro, Robert and Jong-Wha Lee. Forthcoming. "A New Data Set of Educational Attainment in the World, 1950-2010.” Journal of Development Economics.

Basma, Atassi and Mohammed Haddad. "Interactive: mapping Syria's Rebellion." AlJazeera. http://www.aljazeera.com/indepth/interactive/2013/07/20137188552345899.html?utm_content $=$ tweets\&utm_campaign $=$ Trial3\&utm_source $=$ SocialFlow\&utm_term $=$ twitter\&utm_medium =ExperimentMasterAccount. (Accessed March 2, 2014).

BBC. 2009. "Sunni and Shi'a."

http://www.bbc.co.uk/religion/religions/islam/subdivisions/sunnishia_1.shtml. (Accessed August 9, 2013).

Beckett, Ian F.W. 2001. Modern Insurgencies and Counterinsurgencies: Guerrillas and Their Opponents since 1750. London: Routledge.

Ben-Horin, Yoav and Barry Posen. 1981. Israel's Strategic Doctrine. Santa Monica: RAND.

Benmelech, Efraim, and Claude Berrebi. 2007. "Human Capital and the Productivity of Suicide Bombers." Journal of Economic Perspectives 21(3): 223-238.

Benvenisti, Meron. 1987. The West Bank Data Project: 1987 Report. Demographic, Economic, Legal, Social, and Political Developments in the West Bank. Jerusalem: Jerusalem Post.

Berman, Eli, and David D. Laitin. 2005. "Hard Targets: Theory and Evidence on Suicide Attacks." National Bureau of Economic Research Working Paper 11740.

Berman, Eli. 2009. Radical, Religious, and Violent: The New Economics of Terrorism. Cambridge: The MIT Press.

Berrebi, Claude. 2007. "Evidence About the Link Between Education, Poverty and Terrorism Among Palestinians.” Peace Economics, Peace Science and Public Policy 13(1): 1-39.

Biddle, Stephen and Jeffery A. Freidman. 2008. The 2006 Lebanon Campaign and the Future of Warfare: Implications for Army and Defense Policy. Carlisle: Strategic Studies Institute.

Blanford, Nicholas. 2006. "Hizbullah's Resilience Built on Years of Homework." Christian Science Monitor. August 11. World Section.

Bloom, Mia. 2004. "Palestinian Suicide Bombing: Public Support, Market Share, and Outbidding." Political Science Quarterly 119(1): 61-88.

Bohara, Alok K., Neil J. Mitchell, and Mani Nepal. 2006. “Opportunity, Democracy, and the Exchange of Political Violence.” Journal of Conflict Resolution 50:1: 108-28.

Boxx, Edward S. Lt. Col. 2013. "Observations on the Air War in Syria." Air \& Space Power Journal 27(2): 147-168. 
Brady, Henry E., and David Collier. 2004. Rethinking Social Inquiry: Diverse Tools, Shared Standards. Marlyland: Rowman \& Littlefield Publishers, INC.

Byman, Daniel. 2005. Deadly Connections: States that Sponsor Terrorism. New York: Cambridge University Press.

Byman, Daniel. 2003. "Should Hezbollah be Next?” Foreign Affairs 82(6): 54-67.

Byman, Daniel, Peter Chalk, Bruce Hoffman, William Rosenau, and David Brannan. 2001. Trends in Outside Support for Insurgent Movements. Santa Monica, CA: RAND.

Caruso, Raul eds. 2011. Ethnic Conflict, Civil War, and Cost of Conflict. United Kingdom: Emerald Group Publishing Limited.

Central Intelligence Agency. 2009. Guide to the Analysis of Insurgency. Washington, DC.

Clauset, Aaron, Lindsay Heger, Maxwell Young and Kristin Skrede Gleditsch. 2010. "The Strategic Calculus of Terrorism: Substitution and Competition in the Israel-Palestine Conflict." Cooperation and Conflict 45(6): 6-33.

Cobban, Helena. 1983. The Palestinian Liberation Organisation: People, Power, and Politics. Cambridge: Cambridge University Press.

Cohen, Barney. 2004. "Urban Growth in Developing Countries: A Review of Current Trends and a Caution Regarding Existing Forecasts." World Development 32(1): 23-51.

Collier, Paul and Anke Hoeffler. 2004. "Greed and Grievance in Civil War." Oxford Economic Papers 56(4): 563-595.

Cordesman, Anthony H. 2006. Preliminary 'Lessons' of the Israeli-Hezbollah War. Washington: Center for Strategic Studies.

Cordesman, Anthony H. 2009. "The 'Gaza War': A Strategic Analysis." Center for Strategic and International Studies. Washington: CSIS.

Crooke, Alastair and Mark Perry. 2006. "How Hezbollah Defeated Israel, Part 1: Winning the Intelligence War." Asia Times Online

http://www.atimes.com/atimes/Middle_East/HJ12Ak01.html. (Accessed December 1, 2013).

Crooke, Alastair and Mark Perry. 2006. "How Hezbollah Defeated Israel, Part 3: The Political War." Asia Times Online http://www.atimes.com/atimes/Middle_East/HJ14Ak01.html. (Accessed December 1, 2013).

Cunningham, David E. 2006. "Veto Players and Civil War Duration." American Journal of Political Science 50(4): 875-892. 
Cunningham, David E., Kristian Skrede Gleditsch, Idean Salehyan. 2009. "It Takes Two: A Dyadic Analysis of Civil War Duration and Outcome." Journal of Conflict Resolution 53(4): 570-597.

Department of the Navy. The Small Wars Manual: Fleet Marine Force Reference Publication 12-25. 1940. http://www.au.af.mil/au/awc/awcgate/swm/index.htm. (Accessed February 21, 2014).

DeRouen, Karl R. Jr. and David Sobek. 2004. "The Dynamics of Civil War Duration and Outcome.” Journal of Peace Research 41(3): 303-320.

Deraniyagala, Sonali. 2005. "The Political Economy of Civil Conflict in Nepal." Oxford Development Studies 33(1):47-62

de Sales, Anne. 2007. "The Kham Magar Country, Nepal: Between Ethnic Claims and Maoism." In Resistance and the State: Nepalese Experience, edited by David N. Gellner. New York: Berghahn Books.

Desch Michael C. eds. 2001. Soldiers and Cities: Military Operations on Urban Terrain Carlisle PA: Strategic Studies Institute.

Diani, Mario and Doug McAdam eds. 2003. Social Movements and Networks: Relational Approaches to Collective Action. New York: Oxford University Press.

Dickenson, Matt. 2013. “The Impact of Leadership Removal on Mexican Drug Trafficking Organizations. Unpublished.

Dixon, Hugo. 2012. “The Revolution Will be Organized." Reuters Magazine June 2012. http://blogs.reuters.com/hugo-dixon/2012/06/29/the-revolution-will-be-organized/. (Accessed July 2, 2012).

Dolnik, Adam and Anjali Bhattacharjee. 2002. "Hamas: Suicide Bombings, Rockets, or WMD?" Terrorism and Political Violence 14(3): 109-28.

Downes, Alexander B. 2008. Targeting Civilians in War. Ithaca: Cornell University Press.

Dunning Thad. 2012. Natural Experiments in the Social Sciences: A Design-Based Approach. Cambridge: Cambridge University Press.

Eck, Christine. 2010. "Recruiting Rebels: Indoctrination and Political Education in Nepal." In The Maoist Insurgency in Nepal: Revolution in the Twenty-First Century, edited by Mahendra Lawoti and Anup K. Pahari, 33-51. New York: Routledge.

Eck, Kristine, and Lisa Hultman. 2007. "One-sided Violence Against Civilians in War: Insights From New Fatality Data.” Journal of Peace Research 44(2): 233-246. 
Erlanger, Steven and Richard A. Oppel Jr. "A Disciplined Hezbollah Surprises Israel with its Training, Tactics and Weapons." New York Times, August 7, 2006, Foreign Desk, Late Edition.

Exum, Andrew. 2006. "Hezbollah at War: A Military Assessment." Policy Focus \# 63. Washington: The Washington Institute for Near East Policy.

Fay, Marianne, and Charlotte Opal. 2003. "Urbanization Without Growth: A Not So Uncommon Phenomenon." World Bank Policy Research Working Paper 2412. Washington DC: The World Bank.

Fearon, James D. and David D. Laitin. 2003. "Ethnicity, Insurgency, and Civil War.” American Political Science Review 97(1): 75-90.

Flanigan, Shawn Teresa. 2008. "Nonprofit Service Provision by Insurgent Organizations: The Cases of Hizballah and the Tamil Tigers." Studies in Conflict and Terrorism 31(6); 499-519.

Frinkel, Steven E., Edward N. Muller, and Karl-Dieter Opp. 1989. "Personal Influence, Collective Rationality, and Mass Political Action." The American Political Science Review 83(3): 885-903.

Gates, Scott. 2002. "Recruitment and Allegiance: The Microfoundations of Rebellion." Journal of Conflict Resolution 46(1): 111-130.

Galula, David. 1964. Counterinsurgency Warfare: Theory and Practice. Connecticut: Praeger Security International.

Gelman, Andrew and Jennifer Hill. 2007. Data Analysis Using Regression and Multilevel/Hierarchical Models. Cambridge: Cambridge University Press.

George, Alexander L., and Andrew Bennett. 2005. Case Studies and Theory Development in Social Sciences. Cambridge, MA: MIT Press.

Gerring, John. 2007. Case Study Research: Principles and Practices. New York: Cambridge University Press.

Gleditch, Nils Petter, Peter Wallensteen, Mikael Eriksson, Margareta Sollenberg \& Håvard Strand. 2002. "Armed Conflict 1946-2001: A New Dataset." Journal of Peace Research 39(5): 615-637.

Gleis, Joshua, L., and Benedetta Berti. 2012. Hezbollah and Hamas: A Comparative Study. Baltimore: Johns Hopkins University Press. 
Gordron, Michael R. and Jodi Rudoren. 2013. "Kerry Achieves Deal to Revive Mideast Talks." New York Times, July 19. http://www.nytimes.com/2013/07/20/world/middleeast/kerryextends-stay-in-mideast-to-push-for-talks.html?pagewanted=all. (Accessed August 5, 2013).

Gould, Roger V. 1993. "Collective Action and Network Structure.” American Sociological Review 58(2): 182-196.

Gould Roger V. 1995. Insurgent Identities: Class, Community, and Protest in Paris from 1848 to the Commune. Chicago: University of Chicago Press.

Goyal, Rajeev, Puja Dhawan, and Smita Narula. 2005. Puja Dhawan, and Smita Narula. 2005. The Missing Piece of the Puzzle: Caste Discrimination and the Conflict in Nepal. Center for Human Rights and Global Justice. New York: NYU Law School.

Greenberg, Hanan. "IDF: Hizbullah Built Mass Bunker Network.” Ynetnews.com, http://www.ynetnews.com/articles/0,7340,L-3278675,00.html. (Accessed December 1, 2012).

Guevara, Che. 1961. Guerrilla Warfare. Lincoln: Bison Books.

Gurung, Harka. 2003. Social Demography Nepal Census 2001. Lalitpur: Himal Books.

Hammes, Col. Thomas X. 2004. The Sling and the Stone: On War in the $21^{\text {st }}$ Century. St. Paul: Zenith Press.

Hatina, Meir. 2001. Islam and Salvation in Palestine: The Islamic Jihad Movement. Tel Aviv: Tal Aviv University.

Hayakawa, Kazunobu, Fukunari Kimura, and Hyun-Hoon Lee. 2013. "How Does Country Risk Matter for Foreign Direct Investment?" The Development Economics 51(1): 60-78.

Hazran, Yusri. 2009. "The Shiite Community in Lebanon: From Marginalization to Ascendancy." Crown Center for Middle East Studies No. 37.

Helu, Musallam F. 2012. "Urban Sprawl in Palestinian Occupied Territories: Causes, Consequences and Future." Environment and Urbanization Asia 3(1): 121-141.

Hiltermann, Joost, R. 1991. Behind the Intifada: Labor and Women's Movements in the Occupied Territories. Princeton: Princeton University Press.

Hoffman, Bruce and Gordon H. McCormick. 2004. "Terrorism, Signaling, and Suicide Attack." Studies in Conflict \& Terrorism 27(4): 243-281.

Hoffman, Frank G. 2007. Conflict in the $21^{\text {st }}$ Century: The Rise of Hybrid Wars Virginia: Potomac Institute for Policy Studies.

Horowitz, Michael C. 2010. "Nonstate Actors and the Diffusion of Innovations: The Case of Suicide Terrorism." International Organization 64(1): 33-64. 
Hroub, Khaled. 2000. Hamas: Political Thought and Practice Washington: Institute for Palestinian Studies.

Hubbard, Ben, Clifford Krauss, and Eric Schmitt. January 28, 2014. "Rebels in Syria Claim Control of Resources." New York Times http://www.nytimes.com/2014/01/29/world/middleeast/rebels-in-syria-claim-control-ofresources.html. (Accessed March 1, 2014).

Hultman, Lisa. 2007. "Battle Losses and rebel Violence: Raising the Costs for Fighting." Terrorism and Political Violence 19(2): 205-222.

Humphreys, Macartan, and Jeremy M. Weinstein. 2008. "Who Fights? The Determinants of Participation in Civil War." American Journal of Political Science 52(2): 436-455.

Intelligence and Terrorism Information Center at the Israel Intelligence Heritage \& Commemoration Center (IICC). 2007. Rocket Threats From Gaza Strip, 2000-2007. http://www.mfa.gov.il/MFA/Terrorism+Obstacle+to+Peace/Terror+Groups/Rocket + threat + fro $\mathrm{m}+$ the + Gaza+Strip+2000-2007.htm. (Accessed March 1, 2011).

Informal Service Security Sector. "Number of Victims Killed by State and Maoist in Connection with the 'People's War."” http://www.insec.org.np/. (Accessed May 12, 2013).

International Crisis Group. 2009a. Ending the War in Gaza. Middle East Report No. 26, 5 January.

International Crisis Group. 2009b. Gaza's Unfinished Business. Middle East Report No. 85, 23 April.

International Crisis Group. 2004. Dealing With Hamas. Middle East Report No. 21, 26 January.

International Crisis Group. 2007. Inside Gaza: The Challenge of Clans and Families, Middle East No. 71, 20 December.

International Crisis Group. 2003. Islamic Social Welfare Activism in The Occupied Palestinian Territories: A Legitimate Target? Middle East No. 13, 2 April.

International Crisis Group. 2005. Nepal's Maoists: Their Aims Structure and Strategy, Asia Report 104(27).

Israel Ministry of Foreign Affairs. http://www.mfa.gov.i1/MFA. (Accessed December 5, 2013).

Jaber, Hala. 1997. Hezbollah: Born With a Vengeance. New York: Columbia University Press.

Jervis, Robert. 1978. "Cooperation Under the Security Dilemma." World Politics. 30(2): 167214. 
Joshi, Madhav. 2010. "Between Clientelistic Dependency and Liberal Market Economy: Rural Support for the Maoist Insurgency in Nepal." In The Maoist Insurgency in Nepal: Revolution in the Twenty-First Century, edited by Mahendra Lawoti and Anup K. Pahari, 92-111. New York: Routledge.

Joshi, Madhav and T. David Mason. 2008. "Between Democracy and Revolution: Peasant Support for Insurgency Versus Democracy in Nepal." Journal of Peace Research 45(6); 76582.

Kalyvas, Stathis. 2005. "Warfare in Civil Wars." In Rethinking the Nature of War, edited by Isabelle Duyvesteyn and Jan Angstrom. New York: Frank Case.

Kalyvas, Stathis, and Laia Balcells. 2010. "International System and Technologies of Rebellion, How the End of the Cold War Shaped Internal Conflict." American Political Science Review 104(3): 415-429.

Kalyvas, Stathis, and Matthew Adam Kocher. 2007. "How 'Free' is Free Riding in Civil Wars? Violence, Insurgency, and the Collective Action Problem." World Politics 59(2): 177-216.

Kantha, Pramod K. 2010. "Maoist-Madhesi Dynamics and Nepal's Peace Process." In The Maoist Insurgency in Nepal: Revolution in the Twenty-First Century, edited by Mahendra Lawoti and Anup K. Pahari, 156-172. New York: Routledge.

Katz, Yaakov and Tovah Lazaroff. "8 Soldiers Killed In Battle of Bint Jbial. Paratrooper Slain in Separate Firefight. At Least 40 Hizbullah Gunmen Killed. Gen. Udi Adam: Sadly There Will be More Days Like This.” The Jerusalem Post, July 27, 2006.

Katz, Yaakov. "Israeli military studies Hezbollah's resilience." USA Today, September 13, 2006, http://www.usatoday.com/news/world/2006-09-13-israel-army_x.htm. (December 1, 2013).

Katzman, Kenneth. 2014. Iraq: Politics, Governance, and Human Rights. Washington D.C.: Congressional Research Service.

Kauffman, Chaim. 1996. "Possible and Impossible Solutions to Ethnic Civil Wars." International Security 20(4): 136-175.

Keefer, Philip and Noramn Loayza eds. 2008. Terrorism, Economic Development, and Political Openness. Cambridge: Cambridge University Press.

Khalaf, Sami. 1987. Lebanon's Predicament. New York: Columbia University Press.

King, Gary, Robert O. Keohane, and Sidney Verba. 1994. Designing Social Inquiry: Scientific Inference in Qualitative Research. Princeton: Princeton University Press.

Krueger, Alan B. 2007. What Makes a Terrorist: Economics and the Roots of Terrorism, Lionel Robbins Lectures Princeton: Princeton University Press. 
Krueger, Alan B., and Jitka Malečková. 2003."Education, Poverty and Terrorism: Is There a causal Connection?" Journal of Economic Perspectives 17(4): 119-144.

Kuran, Timur. 1991. "Now Out of Never-The Elements of Surprise in the east European Revolution of 1989." World Politics 44(1): 7-48.

Kushkush, Isma'il and Nicholas Kulish. February 26, 2014. "Civilian Flee as Violence Worsens in South Sudan. New York Times. http://www.nytimes.com/2014/02/27/world/africa/civiliansflee-as-violence-worsens-in-south-sudan.html. (Accessed March 2, 2014).

Lacina, Bethany, and Nils Petter Gleditch. 2005. "Monitoring Trends in Global Combat: A New Dataset of Battle Deaths." European Journal of Population 21(2): 116-145.

Laqueur, Walter. 1976. Guerrilla: A Historical and Critical Study. Boston: Little, Brown and Company.

Lawoti, Mahendra. 2003. "Centralizing Politics and the Growth of the Maoist Insurgency in Nepal.” Himalaya 23(1):49-58.

Lawoti, Mahendra, ed. 2007. Contentious Politics and Democratization in Nepal. New Delhi: Sage Publications India Pvt Ltd.

Lawoti, Mahendra. 2003b. "Maoists and Minorities: Overlap of Interests of the Case of Exploitation?" Studies in Nepali History and Society 8(1); 67-97.

Lawrence, T.E. 1929. Encyclopedia Britannica $2^{\text {nd }}$ ed. Chicago: Encyclopedia Britannica.

Levit, Ariel. 1990. Offense Defense and Israeli Military Doctrine. Boulder CO: Westview Press Inc.

Levitt, Matthew. 2006. Hamas: Politics, Charity, and Terrorism in the Service of Jihad. Virginia: The Washington Institute for Near East Policy.

Lichbach, Mark Irving. 1995. The Rebel's Dilemma. Ann Arbor: The University of Michigan Press.

Lipset, Seymour Martin. 1964. Political Man: The Social Basis of Politics. Garden City, New York: Anchor Books.

Long, Austin. 2008. “The Anbar Awakening.” Survival 50(2): 67-94.

Lyall, Jason. 2010. "Do Democracies Make Inferior Counterinsurgents? Reassessing Democracy's Impact on War Outcomes and Duration.” International Organization 64(1): 16792. 
Lyall, Jason, and Isaiah Wilson III. 2009. "Rage Against the Machines: Explaining Outcomes in Counterinsurgency Wars." International Organization 63(1): 67-106.

Mack, Andrew. 1975. "Why Big Nations Lose Small Wars: The Politics of Asymmetrical Conflict." World Politics 27(2): 175-200.

Macours, Karen. 2011. "Increasing Inequality and Civil Conflict in Nepal." Oxford Economic Papers 63(1): 1-26.

Majumdar, Sumon, Anandi Mani, and Sharun W. Mukand. 2004. "Politics, Information, and the Urban Bias.” Journal of Development Economics 75(1): 137-165.

Mack, Andrew. 1975. "Why Big Nations Lose Small Wars: The Politics of Asymmetric Conflict." World Politics. 27(2): 175-200.

Ma'oz, Moshe. 1984. Palestinian Leadership of the West Bank: The Changing Role of the Arab Mayors Under Jordan and Israel. Totowa, N.J.: Frank Case \& Co. LTD

Marks, Thomas A. 2003. Insurgency in Nepal. Carlisle: Strategic Studies Institute.

Marshall, Montey, and Keith Jeggers. 2000. Polity IV Project (codebook and data files). http://www.systemicpeace.org/inscr/inscr.htm. (Accessed July 30, 2011).

Marwell, Gerald, Pamela E. Oliver, and Ralph Prahl. 1988. "Social Networks and Collective Action: A Theory of Critical Mass III." American Journal of Sociology 94(3): 502-534.

Marx, Emanuel. 1992. "Palestinian Refugee Camps in the West Bank and the Gaza Strip." Middle Eastern Studies 28(2): 281-294.

Mason, David T. 1996. "Insurgency, Counterinsurgency, and the Rational Peasant," Public Choice 86(1/2): 63-83.

McClelland, Mac. February 13, 2014. "How to Build a Perfect Refugee Camp." The New York Times `http://www.nytimes.com/2014/02/16/magazine/how-to-build-a-perfect-refugeecamp.html.

(Accessed March 1, 2014).

Mearsheimer, John J. 1983. Conventional Deterrence. Ithaca: Cornell University Press.

Mehta, Ashok K. and Mahendra Lawoti. 2010. "Military Dimensions of the 'People's War:' Insurgency and Counter-Insurgency in Nepal." In The Maoist Insurgency in Nepal: Revolution in the Twenty-First Century, edited by Mahendra Lawoti and Anup K. Pahari, 175-194. New York: Routledge.

Menkhaus, Ken. 2004. Somalia: State Collapse and the Threat of Terrorism. Oxford: Oxford University Press for the International Institute for Strategic Studies. 
Meyerle, Jerry, and Carter Malkasian. 2009. "Insurgent Tactics in Southern Afghanistan 20052008.” Washington DC: CAN Strategic Studies.

Milton-Edwards, Beverly and Stephen Farrell. 2010. Hamas: The Islamic resistance Movement. Cambridge: Polity Press.

Mishal, Shaul and Avraham Sela. 2000. The Palestinian Hamas: Visions, Violence, and Coexistence. New York: Columbia University Press.

Moghadam, Assaf. 2003. "Palestinian Suicide Terrorism in the Second Intifada: Motivations and Organizational Aspects." Studies in Conflict \& Terrorism 26: 65-92.

Moss, Robert. 1971. Urban Guerrilla Warfare. London: The International Institute For Strategic Studies.

Murshed, Mansoob S. and Scott Gates. 2005. "Spatial-Horizontal Inequality and the Maoist Insurgency in Nepal.” Review of Development Economics 9(1); 121-134.

Nassief, Isabel. 2014. The Campaign for Homs and Aleppo: The Assad Regime's Strategy in 2013. Middle East Security Report 17. Washington D.C.: Institute for the Study of War.

Neil, Daniel B. 2005. “Cascade Effects in Heterogeneous Populations.” Rationality and Society 17(2): 191-241.

Norton, Augustus Richard. 1987. Amal and the Shi'a: Struggle for the Soul of Lebanon. Austin: Texas University Press.

Norton, Augustus Richard. 2007. Hezbollah: A Short Story. Princeton: Princeton University Press.

O’Bagy, Elizabeth. 2012. "Disorganized Like a Fox: Why It's a Great Thing that the Syrian Opposition is Fragmented.” Foreign Policy. (Accessed July 11, 2012).

O’Bagy, Elizabeth. 2013. The Free Syrian Army. Middle East Report 9. Washington D.C.: Institute for the Study of War.

Oliver, Pamela E., with Gerald Marwell and Ruy Teixeira. 1985. "A Theory of the Critical Mass I: Interdependence, Group Heterogeneity, and the Production of Collective Action." American Journal of Sociology 91(3): 522-556.

Onesto, Li. 2005. Dispatches From the People's War in Nepal. London: Pluto Press.

Palestinian Central Bureau of Statistics. "Annual Statistics. Population Projections by Type of Locality, 2007-2016.” http://www.pcbs.gov.ps/site/lang_en/507/site/803/default.aspx. (Accessed September 3, 2013). 
Pape, Robert A. 1996. Bombing to Win: Air Power and Coercion in War. Ithaca: Cornell University Press.

Pape, Robert A. 2005. Dying to Win: The Strategic Logic of Suicide Terrorism. New York: Random House.

Pape, Robert A. 2003. "The Strategic Logic of Suicide Terrorism." American Political Science Review 97(3): 343-361.

Parkinson, Sara Elizabeth. 2013. "Organizing Rebellion: Rethinking High-Risk Mobilization and Social Networks in War. American Political Science Review 107(3): 418-432.

Pearlmann, Joel. 2012. The 1967 Census of the West Bank and Gaza Strip: A Digitized Version. Annandale-on-Hudson, N.Y.: Levy Economics Institute of Bard College. [Digitized from: Israel Central Bureau of Statistics, Census of Population and Housing, 1967 Conducted in the Areas Administered by the IDF, Vols. 1-5 (1967-70), and Census of Populaiton and Housing: East Jerusalem, Parts 1 and 2 (1968-70). http://www.levyinstitute.org/palestinian-census/].

Pearlman, Wendy. 2011. Violence, Nonviolence, and the Palestinian National Movement. Cambridge: Cambridge University Press.

Peraino, Kevin. “Barak’s View.” Newsweek, (July 18 2006), http://www.msnbc.msn.com/id/13923423/site/newsweek/. (Accessed January 30, 2013).

Perritt, Henry H. 2008. Kosovo Liberation Army: The Inside Story of an Insurgency Chicago: University of Illinois.

Peters, Ralph. "Lessons From Lebanon: The New Model Terrorist Army.” Armed Forces Journal, http://www.armedforcesjournal.com/2006/10/2069044. (Accessed January 30, 2013).

Petersen, Roger D. 2001. Resistance and Rebellion: Lessons from Eastern Europe. Cambridge: Cambridge University Press.

Pettigrew, Judith. 2003. "Guns, Kinship, and Fear: Maoists Among the Tamu-mai (Gurung)." In Resistance and the State: Nepalese Experience, edited by David N. Gellner. New York: Berghahn Books.

Popkin, Samuel L. 1979. The Rational Peasant: The Political Economy of Rural Society in Vietnam. Berkeley: University of California Press.

"Population and Housing Census 2011: Major Highlights," Government of Nepal Central Bureau of Statistics. http://cbs.gov.np/. (Accessed May 1, 2013).

Posen, Berry. 1983. "The Security Dilemma and Ethnic Conflict.” Survival 35(1): 27-47. 
Posen, Berry. 1984. The Sources of Military Doctrine: France, Britain, and Germany Between the World Wars. Ithaca: Cornell University Press.

Posen, Barry R. 2001. "The Struggle Against Terrorism: Grand Strategy, Strategy, and Tactics." International Security 26(3): 39-55.

Post, Jerrold M., Ehud Sprinzak and Laurita M. Denny. 2003. "The Terrorists in Their Own Words: Interviews with 35 Incarcerated Middle Eastern Terrorists." Terrorism and Political Violence 15(1): 171-184.

Pressman, Jeremy. 2003. "The Second Intifada: Background and Causes of the Israeli-Palestinian Conflict.” The Journal of Conflict Studies 23(2): 114-141.

Qassem, Naim. 2005. Hizbullah: The Story from Within. London: SAQI.

Quester, George. 1977. Offense and Defense in the International System. New York: John Wiley $\&$ Sons.

Ranstrop, Magnus. 1997. Hizb'allah in Lebanon: The Politics of the Western Hostage Crisis. New York: St. Martin's Press Inc.

Reiter, Dan and Allan C. Stam. 2002. Democracies at War. Princeton: Princeton University Press.

Reno, William. 2007. "Patronage Politics and the Behavior of Armed Groups." Civil Wars 9(4): $324: 342$.

Reno, William. 2002. "The Politics of Insurgency in Collapsing States." Development and Change 33(5): 837-858.

Riaz, Ali and Subho Basu. 2007. Paradise Lost? State Failure in Nepal United Kingdom: Lexington Books.

Rosen, Nir. 2010. Aftermath: Following the Bloodshed of America's Wars in the Muslim World. New York: Nation Books.

Roy, Arundhati. 2010. "Walking With the Comrades." Outlook India.com. http://www.outlookindia.com/article.aspx?264738-0. (Accessed December 15, 2010).

Roy, Sara. 1987. "The Gaza Strip: A Case of Economic De-Development.” Journal of Palestine Studies 17(1): 56-88.

Roy, Sara. 2000. "The Transformation of Islamic NGOs in Palestine." Middle East Report 214. 
Saab Bilal Y., and Nicholas Blanford. 2011. The Next War: How Another Conflict Between Hizbollah and Israel Could Look and How Both Sides are Preparing for it. Washington D.C.: The Saban Center for Middle East Policy at Brookings 24.

Saad-Ghorayeb, Amal. 2002. Hizbu 'llah: Politics and Religion. London: Pluto Press.

Salim, Nasr. 1978. "Backdrop to Civil War: The Crisis of Lebanese Capitalism." MERIP Reports 73: 3-13.

Sambanis, Nicholas. 2004. "What is Civil War? Conceptual and Empirical Complexities of an Operational Definition." Journal of Conflict Resolution 48(6): 814-858.

Santoro, Laura. 1999. "Islamic Clerics Combat Lawlessness in Somalia." The Christian Science Monitor. http://www.csmonitor.com/1999/0713/p1s2.html. (Accessed July 11, 2012).

Sarkees, Meredith Reid and Frank Wayman. 2010. Resort to War: 1816 - 2007. CQ Press.

Savada, Andrea Matles. ed. 1991. Nepal: A Country Study. Washington: GPO for the Library of Congress. http://countrystudies.us/nepal/34.htm (accessed 13 March 2014).

Sayigh, Yezid. 2001. "Arafat and the Anatomy of a Revolt." Survival 43(3): 47-60.

Sayigh, Yezid. 1997. Armed Struggle and the Search for State: The Palestinian National Movement 1949-1993 Oxford: Oxford University Press Inc.

Schmitt, Carl. 1963. The Theory of the Partisan: A Commentary/Remark on the Concept of the Political. Berlin: Duncker \& Humbolt. English Translation Michigan State University Press. 2004.

Shatz, Adam. "Nasrallah's Game." The Nation, http://www.thenation.com/doc/20060731/nasrallah_game. (Accessed January 30, 2013).

Shah, Saubhagya. 2008. "Revolution and Reaction in the Himilayas: Cultural Resistance and the Maoist 'New Regime' in Western Nepal. American Ethnologist 35(3); 481-99.

Shanahan, Roger. 2005. The Shi'a of Lebanon: Clans, Parties, and Clerics. London: I.B. Tauris \& Company, Limited.

Shapira, Shimon. 1988. “The Origins of Hizballah.” The Jerusalem Quarterly 46: 115-130.

Sharma, Kishor. 2006. "The Political Economy of Civil War in Nepal." World Development 34(7); 1237-1253.

Shellman, Stephen M., Clare Hatfielf and Maggie J. Mills. 2010. "Disaggregating Actors in International Conflict." Journal of Peace Research 47(1): 83-90. 
Siegel, David A. 2009. "Social Networks and Collective Action." American Journal of Political Science 52(1): 122-138.

Simkhada, Shambhu Ram and Fabio Oliva eds. 2006. The Maoist Insurgency in Nepal: A Monograph, Causes, Impact and Avenues of Resolution. Geneva: Graduate Institute of International Studies.

Sislin, John, and Fredric S. Pearson. 2001. Armed and Ethnic Conflict. Maryland: Rowman \& Littlefield Publishers, INC.

Skarbek, David. 2011.“Governance and Prison Gangs.” American Political Science Review 105(4): 702-716.

Smith, Craig S. "For Israeli Unit, Hezbollah Lair is Ambush Site." The New York Times, July 27, 2006, Foreign Desk, Late Edition.

Stam, Allan C. III. 1996. Win Lose, or Draw: Domestic Politics and the Crucible of War. Ann Arbor: University of Michigan Press.

Tamimi, Azzam. 2007. Hamas Unwritten Chapters. London: C. Hurst \& Co. (Publishers) Ltd.

Taw, Jennifer Morrison, and Bruce Hoffman. 1994. The Urbanization of Insurgency. Santa Monica: RAND.

Thapa, Deepak and Bandita Sijpati. 2004. A Kingdom Under Siege: Nepal's Maoist Insurgency, 1996 to 2003. Kathmandu: The Printhouse.

The Meir Amit Intelligence and Terrorism Information Center. 2012. "Hezbollah: Portrait of a Terrorist Organization".

http://www.terrorism-info.org.il/Data/articles/Art_20436/E_158_12_1231723028.pdf. (Accessed February 17, 2014).

Themnér, Lotta and Peter Wallensteen. 2013. "Armed Conflicts, 1946-2012." Journal of Peace Research 50(4): 509-521.

Tilly, Charles. 1990. Coercion, Capital and European States: AD 990-1992. Oxford: Blackwell Publishers Ltd.

Tse-Tung, Mao. 2000. On Guerrilla Warfare. Translated by Samuel B. Griffith II. Champaign: University of Illinois Press.

UNDP. 2004. Nepal Human Development Report 2004: Empowerment and Poverty Reduction. Kathmandu: UNDP.

Uppsala Conflict Data Program Database, (2009) (www.ucdp.uu.se/database). 
Upreti, B.C. 2009. Maoists in Nepal: From Insurgency to Political Mainstream Delhi: Kalpaz Publications.

United Nations. 2011. "World Population Prospects: The 2012 Revision." Department of Economic and Social Affairs, Population Division. http://esa.un.org/unpd/wpp/index.htm. (Accessed January 20, 2014).

United Nations. 2010. World Urbanization Prospects: The 2011 Revision. New York: United Nations.

Urquhart, Conal. "Hezbollah's Sophisticated Weaponry Surprises Israelis." The Toronto Star, August 11, 2006.

U.S. Department of State. 2013. "Country Reports on Terrorism 2012." Accessed August 5, 2013. http://www.state.gov/j/ct/rls/crt/2012/index.htm.

Valente, Christine. 2013. "Education and Civil Conflict in Nepal." World Bank Economic Review 27(1): 1-30.

Valentino, Benjamin A. 2004. Final Solutions: mass Killing and Genocide in the $20^{\text {th }}$ Century. Ithaca: Cornell University Press.

Valentino, Benjamin, Paul Huth, and Dylan Balch-Lindsay. 2004. "Draining the Sea: Mass Killing and Guerrilla Warfare.” International Organization 58(2): 375-407.

Van Evera, Stephen. 1999. Causes of War: Power and the Roots of Conflict. Ithaca: Cornell University Press.

Walter, Barbara F. 2009. Reputation and Civil War: Why Separatist Conflicts are so Violent. Cambridge: Cambridge University Press.

Walton, John. 1984. Reluctant Rebels: Comparative Studies of Revolution and Underdevelopment. New York: Columbia University Press.

Weinstein, Jeremy. 2007. Inside Rebellion: The Politics of Insurgent Violence. Cambridge: Cambridge University Press.

Wilson, Scott and Edward Cody. "Hezbollah Proves a Formidable Foe; Entrenched Guerrilla Force Exposes Limits of Israel's Modern Army.” The Washington Post, July 27, 2006, Washington Post Foreign Service.

Wood, Reed M. 2010. "Rebel Capability and Strategic Violence Against Civilians." Journal of Peace Research 47(5): 601-614. 
World Bank. 2008. The Road Not Traveled: Education Reform in the Middle East and North Africa. Washington D.C.: The International Bank for Reconstruction and Development/ The World Bank 